
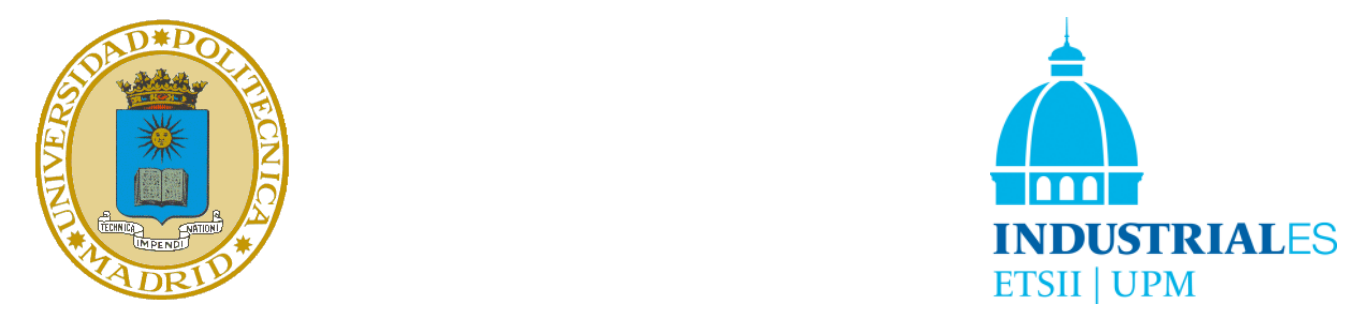

DEPARTAMENTO DE INGENIERÍA MECÁNICA

\author{
ESCUELA TÉCNICA SUPERIOR DE \\ INGENIEROS INDUSTRIALES
}

\author{
TESIS DOCTORAL
}

\title{
INFLUENCIA DE LAS HERRAMIENTAS AMT EN LA COMPETITIVIDAD DE MANUFACTURAS CON USO INTENSIVO DE MANO DE OBRA
}

\author{
Autor \\ D. Jared Roberto Ocampo Martínez \\ Máster en Ingeniería Mecánica \\ Directores \\ D. Antonio Vizan Idoipe \\ Doctor Ingeniero Industrial \\ D. Juan Carlos Hernández Matías \\ Doctor Ingeniero Industrial \\ 2020
}




\section{Agradecimientos}

El haber terminado mi tesis doctoral constituye un verdadero logro profesional que ha venido después de mucho trabajo, sacrificio y la ayuda de muchos. Por ello expreso mis más sinceros agradecimientos:

A mi Padre Celestial, quien me dio la inteligencia, habilidad y esperanza para creer que con su ayuda puedo lograr cualquier cosa que me propongo y que es su voluntad que logre. Sin su guía y mi fe en Él, esto no hubiese sido posible.

A Jessica, mi compañera eterna, quien me ha apoyado durante toda esta larga y ardua travesía, dándome ánimo constante y no dejándome claudicar.

A mis hijos, Roberto, David, Natalia y Ana, quienes sacrificaron tiempo sin mí para verme lograr esta meta y oraron y ayunaron por mi para que mis artículos científicos fueran publicados.

A mis padres, Roberto y Argentina, quienes no dejaron de creer en mí y siempre me infundieron el deseo de concluir con éxito lo que iniciaba.

A D. Juan Carlos Hernández y D. Antonio Vizán Idiope, por no dejar de creer en mí y por su constante dirección, apoyo y ayuda desinteresada a través de todo mi viaje del doctorado.

A José Manuel Bosch y María Antonia Linares, quienes me acogieron en su casa durante mis estadías en Madrid y me apoyaron grandemente en ese tiempo difícil de mi doctorado.

A todos muchísimas gracias. 


\section{Índice}

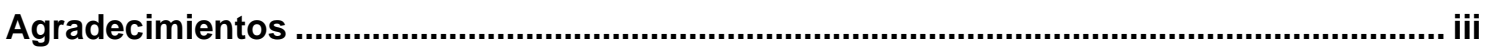

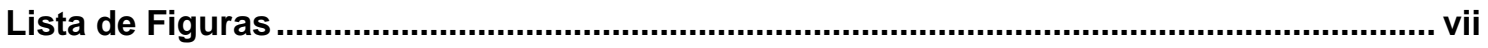

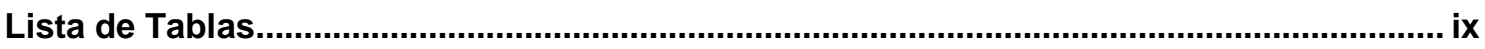

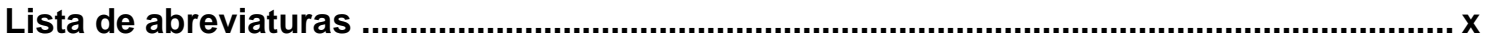

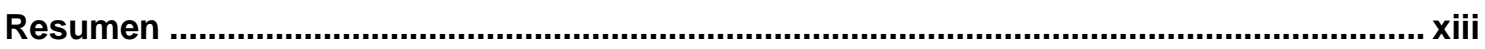

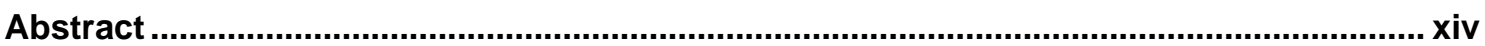

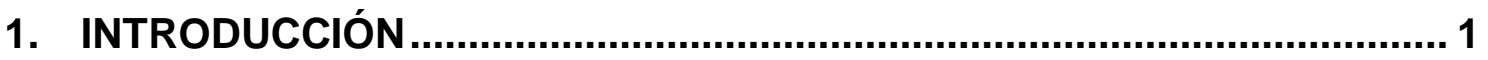

1.1 Ámbito de aplicación y justificación de la tesis ..................................... 1

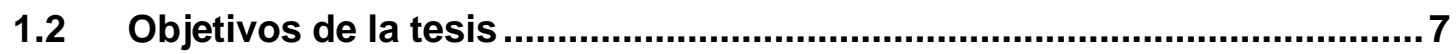

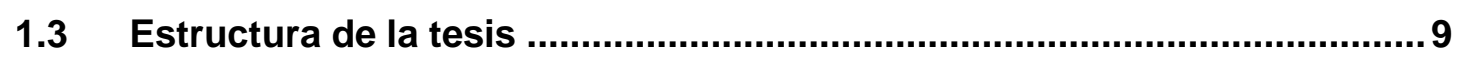

2. ESTADO DEL ARTE ............................................................................ 11

2.1 La industria del ensamblaje con uso intensivo de mano de obra............11

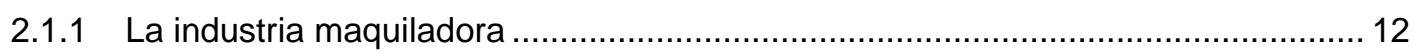

2.1.2 La importancia de la industria maquiladora en el entorno mundial........................ 14

2.2 La medición de la competitividad de fabricación ....................................17

2.2.1 Teorías usadas para medir competitividad ........................................................ 18

2.2.2 Prioridades competitivas y la competitividad de fabricación ..................................20

2.2.3 Modelos de referencia de prioridades competitivas .......................................... 23

2.3 Herramientas AMT para mejorar la competitividad ................................. 29

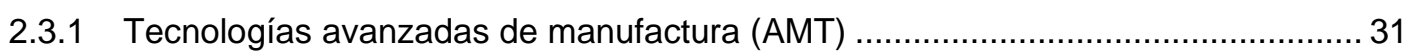

2.3.2 Metodologías de manufactura para la mejora de procesos …................................ 39

2.4 Técnicas y herramientas para el análisis empírico ....................................44

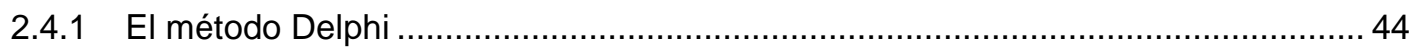

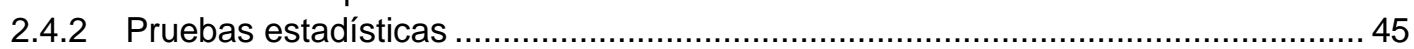

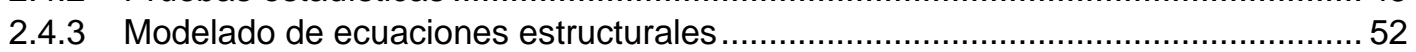

2.5 Identificación de retos de investigación .................................................54

2.6 Definición del caso de estudio ..............................................................56

3. METODOLOGÍA PROPUESTA ......................................................... 59

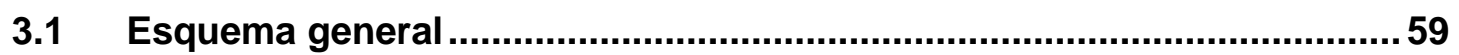

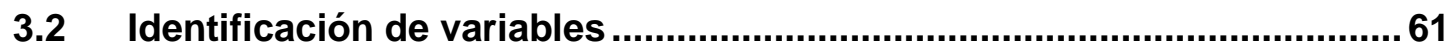

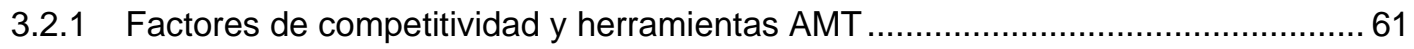

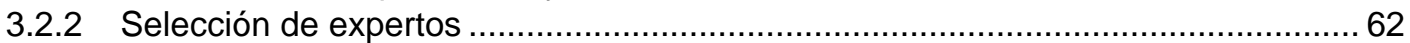

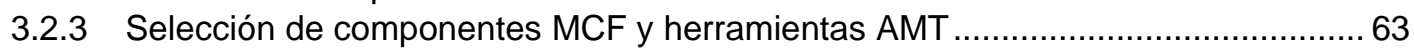

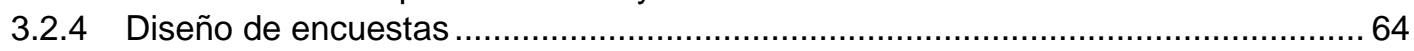




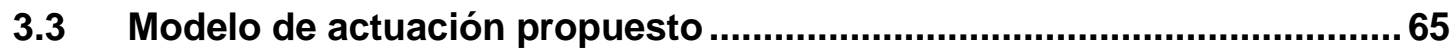

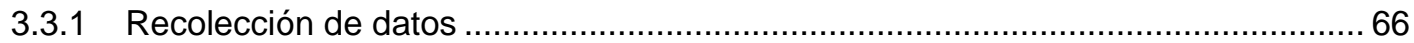

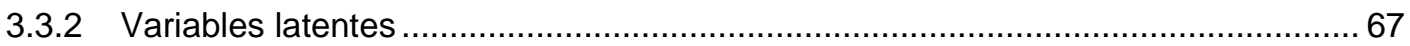

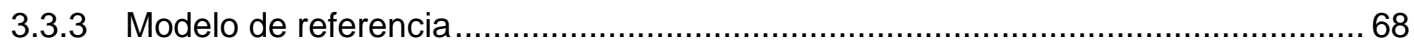

4. DESARROLLO EXPERIMENTAL ..................................................... 71

4.1 Planteamiento general de relaciones y efectos....................................... 71

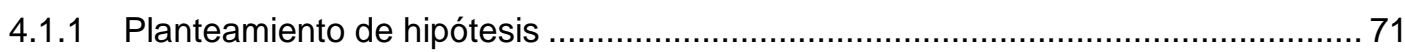

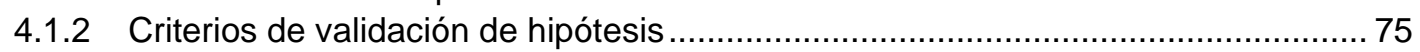

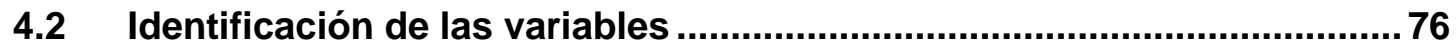

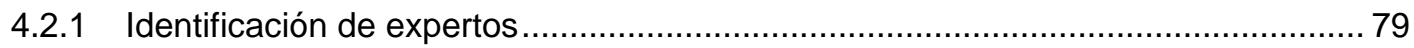

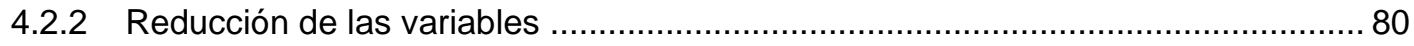

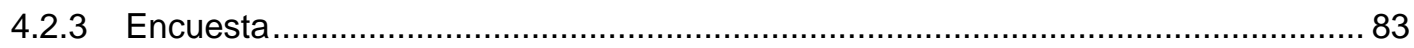

4.3 Definición de modelos de medición ......................................................... 84

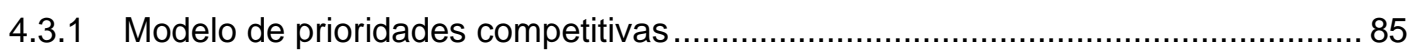

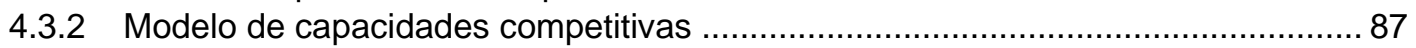

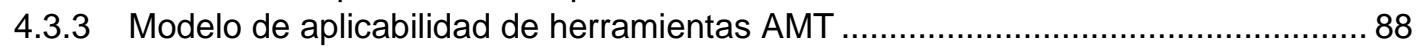

5. ANALISIS DE DATOS........................................................................... 91

5.1 Análisis de las prioridades competitivas ....................................................91

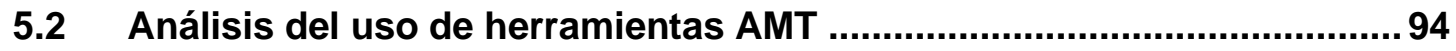

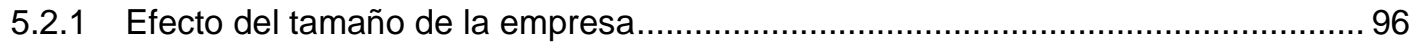

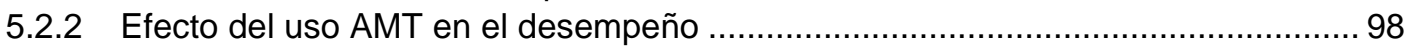

5.3 Modelo final de relaciones de influencia............................................... 100

6. CONCLUSIONES ............................................................................. 107

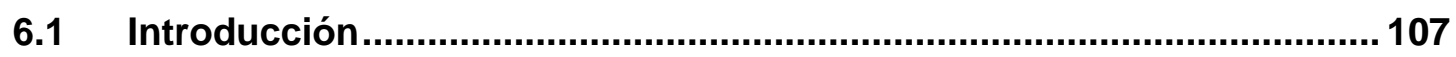

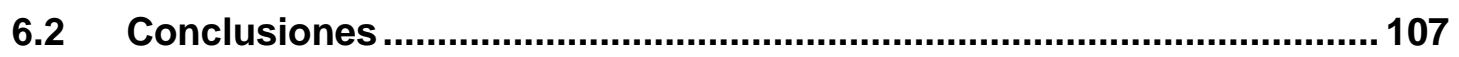

6.3 Resumen de resultados ...................................................................... 110

6.4 Transferencia de resultados .................................................................. 111

6.5 Líneas futuras de investigación ............................................................... 112

7. BIBLIOGRAFÍA ............................................................................... 113

ANEXO. Publicaciones Cientificas JCR ...................................... 


\section{Lista de Figuras}

Figura 1. Modelo del contenido de la estrategia de manufactura ............................... 5

Figura 2. Crecimiento e impacto de la industria maquiladora en México ...................... 13

Figura 3. Fuerzas que gobiernan la competencia de una industria ........................... 17

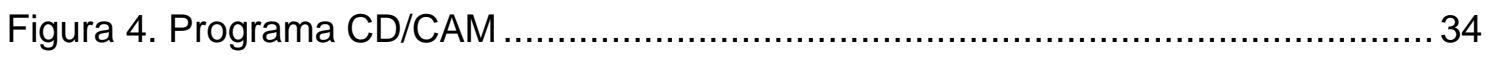

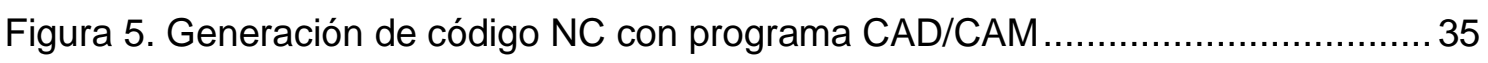

Figura 6. Áreas funcionales principales cubiertas por sistemas ERP ........................ 37

Figura 7. Estructura e interacciones de un sistema MES ....................................... 38

Figura 8. Modelo para la administración de la empresa basada en TQM .................... 40

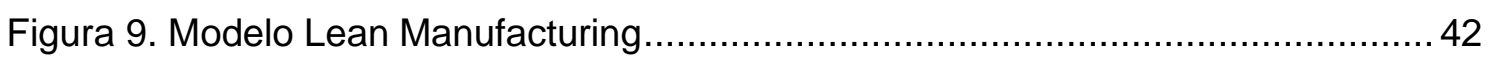

Figura 10. Principios de implementación de Lean .................................................. 43

Figura 11. Diagrama de flujo de un proceso Delphi típico .......................................... 44

Figura 12. Ejemplo de componentes de un diagrama estructural ..............................53

Figura 13. Visión general del diseño de investigación a seguir ..................................60

Figura 14. Ciclo general de la metodología propuesta ..........................................60

Figura 15. Metodología para el análisis de expertos ............................................ 61

Figura 16. Metodología cuantitativa propuesta (modelado, relaciones y efectos)........66

Figura 17. Diagrama estructural de las hipótesis del estudio .................................... 75

Figura 18. Ejemplo de formato en línea de encuesta ........................................... 80

Figura 19. Ejemplo instrumento método Delphi................................................. 81

Figura 20. Muestra de la encuesta diseñada usando la aplicación Qualtrics................ 83

Figura 21. Modelo de medición de la competitividad de fabricación............................ 87

Figura 22. Modelo de referencia de la competitividad de fabricación .......................... 87

Figura 23. Modelo de medición de las herramientas AMT .......................................90

Figura 24. Comparación de los factores de competitividad de fabricación ...................93

Figura 25. Comparación de los componentes de competitividad de fabricación...........94

Figura 26. Uso de herramientas AMT en sector maquilador Honduras ....................... 95

Figura 27. Resultado análisis SEM Herramientas AMT-Competitividad .................... 100

Figura 28. Resultado del análisis de senderos: Diseño e ingeniería ........................ 101

Figura 29. Resultado del análisis de senderos: Administración................................. 102

Figura 30. Resultado del análisis de senderos: Fabricación automatizada ................ 103

Figura 31. Resultado del análisis de senderos: Mejora de procesos......................... 105

Figura 32. Modelo de regresión final ...................................................................... 106 


\section{Lista de Tablas}

Tabla 1. Establecimiento de zonas de procesamiento para exportación ...................... 12

Tabla 2. Análisis de artículos relevantes sector maquilador ...................................... 16

Tabla 3. Prioridades competitivas más importantes ............................................... 21

Tabla 4. Artículos relevantes sobre uso de prioridades competitivas ..........................22

Tabla 5. Prioridades competitivas propuestas en literatura científica ..........................25

Tabla 6. Análisis de artículos relevantes sobre AMT ................................................. 30

Tabla 7. Categorización de las tecnologías avanzadas de manufactura (AMT) ...........32

Tabla 8. Valores frontera para determinar bondad de ajuste de un modelo ................4 47

Tabla 9. Tabla de interpretación de valores de coeficiente Kappa de Fleiss ...............50

Tabla 10. Pruebas paramétricas y no-paramétricas .................................................. 51

Tabla 11. Prioridades competitivas y componentes seleccionados ............................. 77

Tabla 12. Modelo de categorización (taxonomía) de herramientas AMT ..................... 79

Tabla 13. Prioridades competitivas objeto de estudio empírico .................................. 82

Tabla 14. Herramientas AMT objeto de estudio empírico ........................................ 82

Tabla 15. Estadística descriptiva de la muestra que respondió a la encuesta ..............84

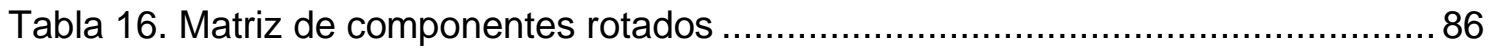

Tabla 17. Parámetros de ajuste del modelo confirmatorio de competitividad ...............86

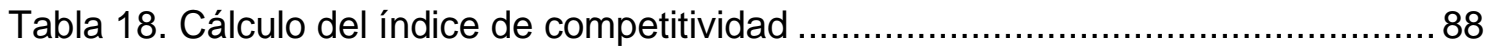

Tabla 19. Matriz de componentes rotados para el modelo de herramientas AMT ....... 89

Tabla 20. Parámetros de ajuste del modelo confirmatorio de herramientas AMT........90

Tabla 21. Análisis del uso de herramientas AMT filtrado por tamaño de la empresa ..97

Tabla 22. Análisis del uso de herramientas AMT 99 


\section{Lista de abreviaturas}

\begin{tabular}{|c|c|}
\hline AGV & Automatic Guided Vehicles \\
\hline AMFE & Análisis Modal de Fallos y Efectos \\
\hline AMT & Advanced Manutacturing Technologies \\
\hline ANOVA & Analysis of Variance \\
\hline ASQ & American Society for Quality \\
\hline ASRS & Automatic Storage and Retrieval Systems \\
\hline AVE & Average Variance Extracted \\
\hline $\mathrm{BCH}$ & Banco Central de Honduras \\
\hline BPR & Business Process Reengineering \\
\hline CACM & Central American Common Market \\
\hline CAD & Computer Aided Design \\
\hline CAE & Computer Aided Engineering \\
\hline CAM & Computer Aided Manufacturing \\
\hline CAPP & Computer Aided Process Planning \\
\hline CEPAL & Comisión Económica para América Latina y el Caribe \\
\hline CFA & Confirmatory Factor Analysis \\
\hline CFD & Computational Fluid Dynamics \\
\hline CFI & Comparative Fit Index \\
\hline CIRP & International Academy of Production Engineering \\
\hline CMB & Common Method Bias \\
\hline CMT & Cut-Make-Trim \\
\hline CNC & Computer Numerical Control \\
\hline CR & Composite Reliability \\
\hline d.f. & Degrees of Freedom \\
\hline DIM & Diseño Integrado de Manufactura \\
\hline DMAIC & Define, Measure, Analyze, Improve and Control \\
\hline DOE & Design of Experiments \\
\hline DR-CAFTA & Dominican Republic-Central America Free Trade Agreement \\
\hline EDI & Electronic Data Interchange \\
\hline EEUU & United States \\
\hline EFA & Exploratory Factor Analysis \\
\hline ERP & Enterprise Resource Planning \\
\hline FA & Factor Analysis \\
\hline FEA & Finite Element Analysis \\
\hline FMS & Flexible Manufacturing Systems \\
\hline GE & General Electric \\
\hline GVC & Global Value Chains \\
\hline HRLP & Human Related Lean Practices \\
\hline$I+D$ & Investigación y Desarrollo \\
\hline
\end{tabular}




\begin{tabular}{|c|c|}
\hline IBM & International Business Machines \\
\hline ICF & Indice de Competitividad de Fabricación \\
\hline IMD & Institute for Management Development \\
\hline JIT & Just In Time \\
\hline KMO & Kaiser-Meyer-Olkin \\
\hline LAN & Local Area Network \\
\hline LSS & Lean Six Sigma \\
\hline MBD & Multi Body Dynamics \\
\hline MES & Manufacturing Execution Systems \\
\hline ML & Maximum Likelihood \\
\hline MRP & Materials Requirement Plan \\
\hline MRPII & Manufacturing Resource Planning \\
\hline MSV & Maximum Shared Variance \\
\hline NAFTA & North American Free Trade Agreement \\
\hline NC & Numeric Control \\
\hline OEM & Original Equipment Manufacturer \\
\hline PAF & Principal Axis Factoring \\
\hline PCA & Principal Component Analysis \\
\hline PIB & Producto Interior Bruto \\
\hline PLC & Programable Logic Controllers \\
\hline PLM & Product Lifecycle Management \\
\hline PYME & Pequeña y Mediana Empresa \\
\hline QFD & Quality Function Deployment \\
\hline RBV & Resource Based View \\
\hline RMSEA & Root Mean Square Error of Approximation \\
\hline SEM & Structural Equation Modeling \\
\hline SME & Small and medium-sized enterprise \\
\hline SMED & Single Minute Exchange Die \\
\hline SPC & Statistical Process Control \\
\hline SPSS & Statistical Package for Social Sciences \\
\hline SRMR & Standardized Root Mean Square Residual \\
\hline TPM & Total Productive Maintenance \\
\hline TPS & Toyota Production System \\
\hline TQM & Total Quality Management \\
\hline U.S. & United States \\
\hline VRIN & Valuable Rare Inimitable Non-Subsitutable \\
\hline VSM & Value Stream Map \\
\hline WAN & Wide Area Network \\
\hline WCM & World Class Manufacturing \\
\hline WEF & World Economic Forum \\
\hline ZIP & Zona Industrial de Procesamiento \\
\hline
\end{tabular}




\section{Resumen}

La globalización ha abierto mercados para que las empresas sean libres de ofrecer sus bienes y servicios o adquirirlos de cualquier proveedor en el mundo. Este paradigma ha fomentado el desarrollo de una industria de ensamblaje intensiva en mano de obra, orientada a la exportación, conocida en América Latina como la Industria Maquiladora, que es uno de los sectores industriales más importantes de América Central y el Caribe.

La competencia planteada por la globalización ha obligado a las maquiladoras a buscar aumentar su competitividad para mantenerse en el mercado. El uso de herramientas de manufactura avanzada (AMT) en sus operaciones de fabricación promete ayudarlos a mejorar su rendimiento y competitividad reduciendo costes, mejorando la calidad, aumentando la variedad de sus productos y optimizando la cadena logística

Esta tesis propone un método para estimar la competitividad de fabricación de las maquiladoras en la industria de la confección y la influencia que los AMT tienen en esa competitividad. El método propuesto utiliza el análisis experto a través del método Delphi, el análisis no paramétrico, de correlación y factorial, así como el modelado de ecuaciones estructurales para estimar la competitividad de fabricación e identificar la influencia que las herramientas AMT tienen sobre dicha competitividad.

Se realizó un estudio de caso empírico utilizando el método propuesto en una muestra de maquiladoras de ropa en Honduras. Los resultados de la prueba empírica muestran un efecto positivo entre el uso de AMT y la competitividad de fabricación, especialmente en el tiempo de entrega, el coste y la protección del medio ambiente. 


\section{Abstract}

Globalization has opened markets so that companies are free to offer their goods and services or to acquired them from any supplier in the world. This paradigm has fostered the development of a labor intensive, export-oriented assembly industry known in Latin America as Maquiladora Industry, which is one of the most important industrial sectors in Central America and the Caribbean.

The competition posed by globalization has forced Maquiladoras to seek to increase their competitiveness in order to stay in the market. The use of advanced manufacturing tools (AMTs) in their manufacturing operations promises to help them improve their performance and competitiveness by reducing costs, improving quality, increasing the variety of their products and optimizing the logistic chain.

This thesis proposes a method for estimating the manufacturing competitiveness of maquiladoras in the apparel industry and the influence that AMTs have on that competitiveness. The proposed method uses expert analysis through the Delphi method, non-parametric, correlation and factor analysis as well as structural equation modelling for estimating manufacturing competitiveness and identifying the influence that AMT has on that competitiveness.

An empirical case study using the proposed method was performed in a sample of apparel maquiladora plants in Honduras. The results of the empirical test show a positive effect between AMTs use and manufacturing competitiveness, especially in the delivery time, cost and environmental protection. 


\section{INTRODUCCIÓN}

\section{1 Ámbito de aplicación y justificación de la tesis}

La globalización de la economía ha abierto los mercados de forma que las empresas tienen libertad de ofrecer bienes y servicios o de adquirirlos de cualquier oferente a nivel mundial. La competencia planteada por dicha globalización ha obligado a las empresas a perseguir aumentar su competitividad mediante la reducción de costes, la mejora de la calidad, el aumento de variedad de sus productos y la optimización de la cadena logística. En un esfuerzo por mejorar sus niveles de competitividad, muchas compañías han buscado abastecerse de lugares en el mundo que ofrezcan la mejor relación valorcoste posible. Su estrategia se ha focalizado en fabricar sus productos en países con mano de obra de bajo coste y vendiendo en mercados en donde obtengan el mejor precio de venta posible (Dornier et al., 1998; Friedman et al., 2006; Sarache et al., 2011). Esta necesidad ha dado lugar a la creación de una industria de ensamblaje con uso intensivo de mano de obra orientada a la exportación, en la cual una corporación multinacional establece fábricas en países con una base industrial menos desarrollada y un índice de desarrollo económico más bajo para producir productos y servicios a precios accesibles, con la calidad requerida y en el plazo establecido los cuales son luego comercializados en naciones desarrolladas (Seguino y Grown, 2006).

Esta estrategia industrial ha generado uno de los sectores industriales más importantes para áreas localizadas en Centroamérica, el Caribe, y en países asiáticos tales como Turquía o India. Este tipo de empresas es conocido en Latinoamérica como "industria de la maquila", y las plantas en donde su actividad productiva se desarrolla como "plantas maquiladoras".

Los gobiernos de México y varios países de Centroamérica y el Caribe han abierto parques industriales especializados llamados zonas de procesamiento de exportación o zonas industriales de procesamiento (ZIP), para poder así atraer este tipo de inversión extranjera. Dentro de estas zonas especiales, las empresas extranjeras pueden 
procesar productos para exportación sin pagar los impuestos normalmente requeridos a los componentes importados necesarios para su producción.

La llegada de esta industria ha impulsado la actividad manufacturera de estos países, generando empleos directos para miles de personas (Alonso, Carrillo, y Contreras, 2002; Interiano, 2004; CEPAL, 2005). Del mismo modo que el acuerdo de libre comercio norteamericano (NAFTA) benefició enormemente a México con el régimen de la maquila, la extensión del tratado a varios países del entorno (DR-CAFTA) y la integración del Mercado Común Centroamericano (CACM) han mejorado las exportaciones en esta área. De hecho, según Vargas-Hernández y Núñez-López (2011), más de la mitad de las exportaciones en Centroamérica provienen de esta industria, con más del $90 \%$ de sus ventas realizadas a los Estados Unidos. De forma particular, la industria maquiladora dedicada a la producción de ropa, que representa el $90 \%$ del total de las exportaciones, genera empleo directo e ingresos a comunidades enteras en donde el sustento de miles de personas depende de su éxito (Interiano, 2004). La importancia de esta industria es tal que, en países como Honduras, el $34 \%$ del producto interior bruto del país procedía de la actividad maquiladora, en la que la industria de confección de prendas de vestir tuvo una participación del $76 \%$ y generó más de 122.000 empleos (BCH, 2014).

Sin embargo, la misma globalización que dio origen a esta industria está produciendo niveles de competencia interna y externa, especialmente con la entrada de Asia y particularmente de China al mercado de producción de ensamblaje. En este sentido, existe una profunda preocupación por las posibles pérdidas que las empresas ensambladoras pueden experimentar con la adopción del esquema denominado "paquete completo" (full packaging). Bajo este esquema, una empresa maquiladora negocia con su cliente un contrato en donde se hace responsable de adquirir todos los insumos, accesorios y maquinarias junto con el cumplimiento de estándares, tiempos de entrega y calidad de los productos finales que entregará. Este esquema permite a la empresa ensambladora tener mejores márgenes de ganancia debido a los ahorros que se pueden obtener al ser más eficiente en los diferentes procesos productivos. Sin embargo, aumenta el riesgo de no cumplir con los requisitos pactados, lo que supondría tener importantes pérdidas de producto y contratos. 
La competencia por parte de los países asiáticos, los desafíos que presenta la adopción del esquema de "paquete completo" y los problemas derivados de la desaceleración de la economía mundial experimentada en los últimos años, presentan serios problemas a la industria maquiladora latinoamericana. En este ambiente competitivo, las empresas deben rediseñar sus estrategias, procesos y procedimientos para ser más competitivas y permanecer en el mercado (Mendoza, 2010; Hadjimarcou et al., 2013). Todos estos riesgos hacen necesario que se lleven a cabo estudios que propongan maneras de mejorar la competitividad de este tipo de empresas, más aun teniendo en cuenta la importancia que este sector industrial tiene en la economía de muchos países en vías de desarrollo.

La mejora de la competitividad a través del incremento del desempeño es una línea de investigación en continua evolución dado que la casuística asociada a la fabricación industrial y a los factores sociales, económicos y tecnológicos de cada sector es muy diferente. Para Chan et al., (2002) y Maranto-Vargas y Gómez-Tagle (2007) existe una relación positiva entre la mejora del desempeño de una empresa y el desarrollo de ciertas capacidades internas, tales como el uso de tecnología y equipos en sus procesos productivos, el uso de estrategias de mejora continua y la administración del cambio y la innovación. López, Marín y Alcalá (2012) explican que la competitividad de las plantas de ensamblaje con uso intensivo de la mano de obra y orientada a la exportación está basada principalmente en su productividad, la cual es un resultado de los procesos de gestión y producción que utiliza y de la calidad de sus productos.

En las últimas décadas, y especialmente a partir del año 2000, se ha hecho evidente que el uso eficiente de tecnologías avanzadas de manufactura (AMT) reduce costes, mejora el desempeño y produce una ventaja competitiva sostenida en las empresas (Koc y Bozdag, 2009). La definición clásica de las tecnologías avanzadas de manufactura (AMT) está relacionada con tecnologías que aplican sistemas mecánicos, eléctricos o electrónicos controlados por ordenadores para el diseño, programación, control y ejecución de procesos de fabricación (Rahardjo y Yahya, 2010). La literatura científica categoriza las AMT de diferentes formas. En la mayoría de los casos la clasificación se ha asociado a la existencia de componentes de hardware, denominándolas tecnologías duras, o componentes de software, denominándolas blandas. Sin embargo, en la última década, se ha empezado a considerar como AMT blandas las técnicas y metodologías introducidas en los años 80 y 90 que están más 
orientadas a la mejora continua de las operaciones, en su mayor parte aquellas relacionadas con las herramientas de la fabricación delgada o lean manufacturing. En este trabajo se usará el término AMT para referirse tanto a las tecnologías como a las metodologías usadas para la mejora de la productividad de las empresas.

Ante la necesidad de mejora de la competitividad del sector de las industrias de ensamblaje con uso intensivo de mano de obra orientada a la exportación surgen varias preguntas. ¿Puede el uso de AMT durante los procesos operativos y la estrategia de fabricación de sus industrias aumentar la competitividad de las empresas? ¿Puede el uso de estas herramientas aumentar el rendimiento de las plantas de fabricación, así como la capacidad de responder más rápido a las necesidades de los clientes o de fabricar productos de mayor calidad y fiabilidad a precios más bajos? Estas preguntas toman mayor importancia si se tiene en cuenta que las tecnologías AMT, por sí mismas, no aseguran que se alcanzarán todos los beneficios prometidos y esperados. De hecho, hay varios estudios empíricos que demuestran que, a pesar de que la mayoría de las empresas alcanzan algunos beneficios por la implantación de AMT en sus procesos de trabajo, son muchas las que no alcanzan todo el potencial que estas tienen (Small y Yasin, 1997).

Algunas razones por las que la implantación de AMT no cumple con las expectativas establecidas son: haberse creado expectativas poco realistas sobre los beneficios reales de la implantación de AMT, no haber aprendido de los errores de aquellos que han adoptado primero dichas herramientas y la pobre ejecución de la implantación de las tecnologías o metodologías de elección. Sin embargo, la principal razón de no existir una correlación positiva directa entre el uso de AMT y la competitividad de manufactura es que muchas empresas que las usan no han fijado claramente el objetivo de reforzar la implantación de una estrategia competitiva en base a metas, objetivos o prioridades de manufactura, entendiendo la influencia que los recursos disponibles y/o las AMT utilizadas tienen en alcanzar dichas prioridades (Díaz-Garrido et al., 2011). Por lo tanto, una empresa que quiere mejorar su competitividad, además de adoptar AMT, necesita definir bien su estrategia de manufactura y asegurarse que está alineada con las prioridades que el mercado demanda.

De acuerdo con Skinner (1969), la estrategia de manufactura es la explotación de ciertas propiedades de la función de manufactura para lograr ventajas competitivas. Como se 
observa en la Figura 1, los dos elementos más importantes de esta estrategia son los objetivos o prioridades competitivas que determinan las áreas de énfasis del sistema de fabricación y las decisiones o recursos que determinan las capacidades que este posee (Größler y Grübner, 2006; Hallgren, 2007). Por lo tanto, cualquier compañía que quiera desarrollar estrategias que la coloquen en una mejor posición con relación a sus competidores necesita conocer que prioridades competitivas y sus correspondientes componentes son más eficientes para afrontar la competencia del mercado. En este sentido, el área de estudio sobre prioridades competitivas ha sido abordada por muchos académicos. Entre las prioridades competitivas identificadas más relevantes se encuentran la calidad, el coste, el tiempo de entrega, la flexibilidad ante el cambio, la innovación, el servicio al cliente y la protección al medio ambiente (Leong, Snyder y Ward, 1990; Carpinetti et al., 2000; Avella, Fernández y Vásquez, 2001).

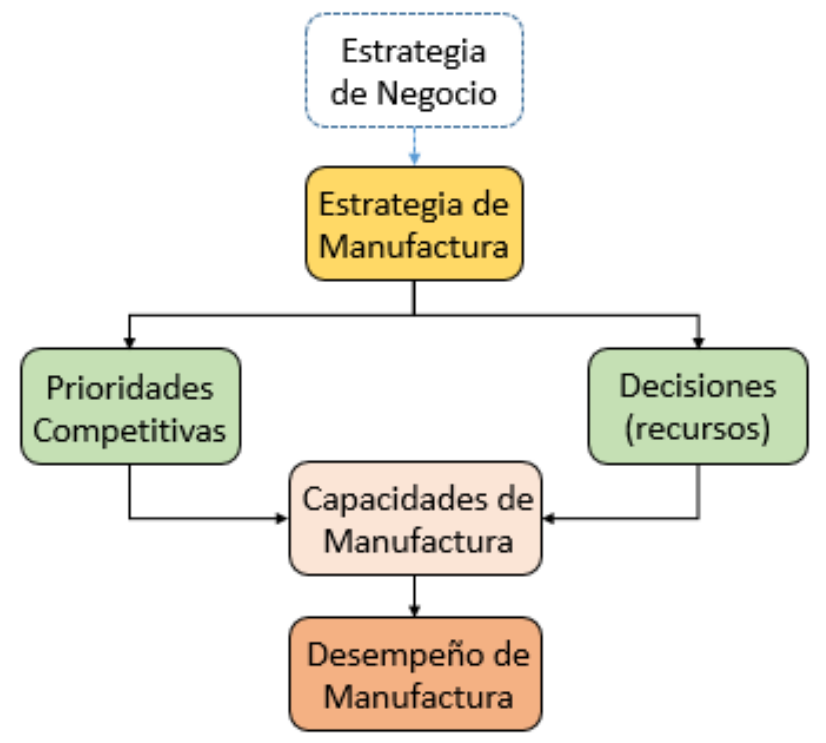

Figura 1. Modelo del contenido de la estrategia de manufactura

Una de las teorías predominantes considera imposible sobresalir en todas estas prioridades de manera simultánea y por eso es necesario realizar un equilibrio entre ellas (Fine y Hax, 1985). Adicionalmente, estas prioridades son por naturaleza multidimensionales porque hay un grupo de componentes o dimensiones que explican cada prioridad o ayudan a medirla. Finalmente, estos componentes varían dependiendo de la industria o de la región en donde se ubican las empresas (Kroes y Ghosh, 2010; Avella et al., 2011; Cai y Yang, 2014). Sin embargo, a pesar de que hay varios estudios hechos sobre las prioridades competitivas de diferentes industrias, no se ha encontrado 
información concreta sobre las prioridades competitivas de la industria de ensamblaje con uso intensivo de mano de obra orientada a la exportación. Adicionalmente, no existe una forma clara de medir la competitividad de fabricación de forma que los gestores puedan usarla para ayudarles a dirigir sus esfuerzos de mejora. Por lo tanto, se observa que existe una necesidad de determinar cuáles son las prioridades competitivas y sus componentes aplicables al sector objeto de estudio, así como proponer formas flexibles de estimar la competitividad de fabricación de este tipo de industrias de manera que estas empresas puedan establecer una estrategia de manufactura que les permita ser más competitivas.

Las decisiones o recursos usados para la mejora de las capacidades de las empresas de fabricación pueden ser de tipo estructural e infraestructural (Rudberg y Olhager, 2003; Hallgren y Olhager, 2006). De acuerdo con Vivares-Vergara et al., (2014), las decisiones estructurales se caracterizan por su impacto a largo plazo, debido a la alta inversión que usualmente requieren, y por afectar de manera significativa a las capacidades del sistema de manufactura. Ejemplos de este tipo de decisiones son las tecnologías de proceso usadas, así como las instalaciones y el tipo de integración de su cadena de suministros. En cambio, las decisiones infraestructurales se enfocan en lograr que los procesos de administración de las diversas áreas de la empresa presten un mejor apoyo a la función de manufactura. Estas decisiones determinan qué tecnologías, metodologías, procesos y recursos deben usarse para alcanzar los objetivos de manufactura establecidos, determinando de esta forma las características operativas del sistema lo cual constituye las capacidades de manufactura del sistema (Tan et al., 2007).

A pesar de que la implantación de AMT debería ayudar a obtener ciertas capacidades de manufactura requeridas para que una empresa sea exitosa y competitiva, no todas son igual de efectivas en cada una de las prioridades de manufactura teóricas. Por esta razón, varios investigadores han tratado de identificar las asociaciones y efectos de las AMT con las diferentes prioridades competitivas, para saber así cuáles generarán mayor beneficio a los objetivos de manufactura que tienen prioridades más altas. A pesar de que hay algunos estudios realizados sobre los efectos de las tecnologías y metodologías avanzadas de manufactura (AMT) en las prioridades competitivas (Boyer et al., 1997; Swink y Nair, 2007; Khanchanapong et al., 2014), estos se han hecho con un grupo reducido de AMT, algunas no aplicables a las empresas ensambladoras de uso intensivo 
de mano de obra orientada a la exportación y en el contexto de países industrializados y con grandes corporaciones (Jonsson, 2000; Diaz et al., 2003). La implantación de las tecnologías AMT en países en vías de desarrollo supone un verdadero desafío que se convierte en el principal proceso de innovación de muchas de sus industrias. Hay que tener en cuenta que los procesos de innovación en países en desarrollo son incrementales y basados en absorción, lo cual es diferente al proceso de cambio que se produce en países desarrollados (Pietrobelli y Rabelloti, 2011; Niebel, 2018). La razón se encuentra en que en estos países el conocimiento y la transferencia de tecnología se basa generalmente en imitación en lugar de un enfoque de transferencia de resultados desde universidades e institutos $1+D$ como sucede en naciones desarrolladas (Putrano et al., 2003; Contreras et al., 2012).

Por lo tanto, existe una necesidad de profundizar en la realización de estudios empíricos sobre los efectos de las AMT en las prioridades competitivas en empresas de ensamblaje con uso intensivo de mano de obra orientada a la exportación localizadas en países en desarrollo que puedan ofrecer una validación externa a los resultados obtenidos en naciones altamente industrializadas y en otros tipos de industrias.

\subsection{Objetivos de la tesis}

La literatura científica muestra que las estrategias empresariales que definen las prioridades competitivas y el nivel de uso de AMT cambian en el tiempo y varían en importancia dependiendo de la región y la industria sobre la cual son estudiadas (Leong et al., 1990; Avella et al., 2001; Yang et al., 2010). En este sentido, hay un interés científico e industrial en estudiar la influencia que el uso de las técnicas AMT tienen en la competitividad de la fabricación de las industrias de países en vías de desarrollo, como es el caso del sector de la industria maquiladora en Centroamérica. Hay que tener en cuenta que, en estos sectores específicos, el estado de desarrollo tecnológico no permite aplicar directamente las estrategias industriales activas de los países más desarrollados. No obstante, los rápidos cambios que se están produciendo en el mundo globalizado pueden desencadenar la necesidad de una rápida revolución que transforme estos sectores. Un ejemplo evidente sería el uso de las nuevas tecnologías habilitadoras asociadas al concepto de industria 4.0, que ahora mismo suponen la principal estrategia en los países desarrollados. 
El presente trabajo doctoral aborda el desarrollo de una metodología para identificar la influencia que el uso de las herramientas AMT tiene en la competitividad de fabricación de las industrias de ensamblaje con uso intensivo de mano de obra orientada a la exportación. Su aplicación debe permitir identificar las prioridades competitivas, así como estimar la competitividad de fabricación de la industria bajo estudio y los efectos que, los diferentes conjuntos de herramientas AMT, tienen en dichas prioridades y en su competitividad. Esta identificación se realizará mediante el uso de una metodología integrada que sincroniza el uso de técnicas cualitativas y cuantitativas como el método Delphi, el análisis de factores y el modelado de ecuaciones estructurales.

En resumen, el objetivo general de esta tesis es medir la influencia que las herramientas AMT tienen en la competitividad de fabricación de industrias ensambladoras con uso intensivo de mano de obra orientada a la exportación mediante una propuesta metodológica integral que sea capaz de modelar, analizar y evaluar todas las variables relacionadas con el problema mediante el uso de herramientas de estadística noparamétrica y modelos de regresión. De una manera más detallada, los objetivos específicos centrados en la industria ensambladora con uso intensivo de mano de obra orientada a la exportación son:

1. Desarrollar un método para encontrar prioridades y capacidades competitivas, estimando la competitividad de fabricación mediante un enfoque de investigación mixto (cualitativo y cuantitativo).

2. Definir un modelo de referencia de la competitividad que solucione la ausencia de estos modelos en la literatura.

3. Identificar las herramientas AMT, tanto tecnologías como metodologías, que son utilizadas en el sector y que pueden influenciar en su competitividad.

4. Desarrollar un método para encontrar la influencia que tienen las herramientas AMT en las capacidades competitivas y en la competitividad de fabricación.

5. Utilizar la metodología desarrollada para estimar la influencia que las herramientas AMT tienen en la competitividad de fabricación de la industria objeto del caso de estudio.

6. Proponer conclusiones y propuestas que permitan incrementar la competitividad de fabricación.

7. Verificar que la metodología desarrollada puede ser aplicada en el estudio de otros factores de producción en entornos industriales distintos al planteado. 


\subsection{Estructura de la tesis}

La tesis que aquí se presenta consta de siete capítulos, siendo la introducción el primero de ellos.

El capítulo 2, "Marco teórico", identifica y estructura las bases conceptuales en las cuales se fundamenta la propuesta doctoral. La revisión afronta el estudio de cuatro grandes temas: la industria de ensamblaje con uso intensivo de mano de obra, la medición de la competitividad de fabricación, las herramientas AMT, y las técnicas y herramientas para análisis empírico de este tipo de datos. La revisión permite identificar los retos de investigación y plantear el caso de estudio.

El capítulo 3, "Metodología propuesta", desarrolla el método propuesto para alcanzar los objetivos de la tesis, basado en la aplicación de técnicas cuantitativas y cualitativas que permitan plantear un modelo de referencia general de relaciones y efectos.

El capítulo 4, "Desarrollo experimental", aborda el proceso de validación empírico de la metodología propuesta a través del desarrollo práctico del caso de estudio que permite obtener los modelos de medición del caso planteado.

El capítulo 5, "Análisis de datos" afronta la explotación avanzada del modelo, analizando los datos obtenidos y relacionándolos con prioridades y capacidades competitivas, uso de herramientas AMT y la conexión entre el uso de estas herramientas con la competitividad de fabricación de las fábricas bajo estudio.

El capítulo 6, expone las conclusiones del estudio y las aportaciones, incluyendo la producción científica realizada y la propuesta de futuras líneas de investigación.

El capítulo 7 presenta la bibliografía utilizada durante la investigación de la tesis doctoral.

Un anexo final recopila las publicaciones científicas en revistas de impacto JCR que ha generado el trabajo doctoral. 


\section{ESTADO DEL ARTE}

La complejidad actual de los sistemas de fabricación implica que todo trabajo que aborde la búsqueda de propuestas que mejoren la competitividad de un sector industrial deba tener un elevado carácter multidisciplinar que incluya metodologías, técnicas, y herramientas de carácter transversal. Con el propósito de estructurar las bases conceptuales que fundamentan la propuesta doctoral, el presente capitulo profundizará en cuatro áreas de interés relacionadas con los objetivos de la tesis:

- La industria del ensamblaje con uso intensivo de mano de obra, revisando el fenómeno de la industria maquiladora en el contexto de la globalización y los países en vías de desarrollo.

- La medición de la competitividad de fabricación, explorando los conceptos de competitividad, estrategia de manufactura, prioridades y capacidades competitivas en el contexto de las empresas de fabricación.

- Las herramientas AMT para mejorar la competitividad, incluyendo un análisis general de las tecnologías y metodologías de manufactura más usadas, su caracterización y la influencia que su uso tiene en el desempeño de las empresas.

- Las técnicas y herramientas para análisis empírico, describiendo las técnicas de recolección de datos y herramientas de análisis estadístico que pueden ser usadas para procesar información, encontrar patrones y llegar a conclusiones de acuerdo con el tipo de datos analizados en este estudio.

La revisión del estado del arte permitirá identificar los retos de investigación que tienen relación directa con los conceptos revisados y el planteamiento general del caso de estudio que se abordará.

\subsection{La industria del ensamblaje con uso intensivo de mano de obra}

La globalización de los mercados ha cambiado la dinámica empresarial del mundo, permitiendo que las empresas puedan ofrecer bienes y servicios o adquirirlos de cualquier oferente en cualquier país. Las corporaciones multinacionales han buscado tomar ventaja de esta apertura para mejorar sus niveles de competitividad estableciendo 
operaciones en aquellos lugares del mundo que ofrezcan mejores condiciones para la fabricación de sus productos. De esta manera al posicionar dichos productos en mercados con altos precios de venta logran una mezcla valor-coste muy beneficiosa (Dornier et al., 1998; Sarache Castro et al., 2011). Entre las expresiones de este modelo se encuentra la industria de ensamblaje orientada a la exportación, en la cual una corporación multinacional establece fábricas industriales internacionales en países en vías de desarrollo para elaborar productos y ofrecer servicios que son luego comercializados en naciones desarrolladas (Seguino y Grown, 2006). Como se puede observar en la Tabla 1, este tipo de industria fue introducida al mundo a inicios de los años 60s en Hong Kong y Puerto Rico, seguido por países tales como Taiwán, Singapur, Filipinas, México y La Republica Dominicana a mediados de los 60s y otros países de Latinoamérica, África y Asia en los 70s y 80s (Wilson, 1991).

Tabla 1. Establecimiento de zonas de procesamiento para exportación

\begin{tabular}{|c|c|c|c|c|c|}
\hline Regiones & $1960-64$ & $1965-69$ & $1970-74$ & $1975-79$ & $1980-85$ \\
\hline Asia & Hong Kong & $\begin{array}{c}\text { Corea del Sur } \\
\text { Taiwán } \\
\text { Singapur } \\
\text { Filipinas } \\
\text { India }\end{array}$ & Malasia & $\begin{array}{c}\text { Indonesia } \\
\text { Sri Lanka }\end{array}$ & $\begin{array}{c}\text { China } \\
\text { Tailandia } \\
\text { Bangladesh } \\
\text { Pakistán }\end{array}$ \\
\hline $\begin{array}{c}\text { Latinoamérica } \\
\text { y El Caribe }\end{array}$ & Puerto Rico & $\begin{array}{c}\text { México } \\
\text { República } \\
\text { Dominicana } \\
\text { Panamá } \\
\text { Brasil }\end{array}$ & $\begin{array}{c}\text { Haitín } \\
\text { El Salvador } \\
\text { Colombia }\end{array}$ & $\begin{array}{c}\text { Jamaica } \\
\text { Honduras } \\
\text { Nicaragua } \\
\text { Chile }\end{array}$ & Costa Rica \\
\hline $\begin{array}{c}\text { África y Oeste } \\
\text { Medio }\end{array}$ & & $\begin{array}{c}\text { Mauritania } \\
\text { Túnez }\end{array}$ & $\begin{array}{c}\text { Egipto } \\
\text { Siria } \\
\text { Liberia }\end{array}$ & Chipre \\
& & & Senegal & \\
\hline
\end{tabular}

\subsubsection{La industria maquiladora}

La industria de ensamblaje orientada a la exportación es conocida en Latinoamérica como "industria de la maquila" y las plantas industriales en donde su actividad productiva se desarrolla como "maquiladoras". La industria maquiladora fue introducida por el gobierno mexicano en un intento de industrializar y aprovechar el efecto frontera con Estados Unidos. Para esto aprobó leyes que permitían a compañías internacionales y domesticas importar temporalmente maquinaria y materiales extranjeros para la producción de artículos de exportación (Brouthers et al., 1999). Estas leyes, que originalmente solo se aplicaban a la frontera, luego se volvieron utilizables en todo el país, con la excepción de ciudades altamente pobladas como Monterey y Ciudad de 
México, logrando así la expansión de esta industria. Producto de ello se crearon "zonas libres" que permitieron que empresarios desarrollaran negocios en estos lugares sin necesidad de someterse a las políticas, restricciones, permisos y tarifas seguidas en otros productos. El concepto económico de este modelo era el de producción compartida, en donde empresas que necesitaban mayor competitividad en productos que requerían trabajo manual intensivo, buscaron países con abundante mano de obra barata, altamente entrenable y productiva con lo que establecer acuerdos globales de producción. El resultado fue una industria que logró reducir el coste total de producción, mejorando la competitividad industrial y que a la vez fue capaz de producir miles de empleos en países en vías de desarrollo (Hadjimarcou et al., 2013). Las constantes devaluaciones de la moneda durante los años 70 s, 80 s y 90 s, junto con su envidiable localización geográfica al lado de Estados Unidos y la abundancia de mano de obra barata calificada hicieron que México se convirtiera en la plataforma ideal de florecimiento de la industria maquiladora en America (Brouthers et al., 1999). Así que una gran parte de la producción de las empresas norteamericanas en ropa, zapatos, juguetes y el ensamblaje de componentes electrónicos para automóviles y electrodomésticos se trasladó a plantas maquiladoras localizadas a través de todo el país. Como se muestra en la Figura 2, el número de plantas de ensamblaje en el país creció aceleradamente, lo que significó un aumento en la contratación de personal y una generación elevada de divisas para el país (Contreras y Munguía, 2007).

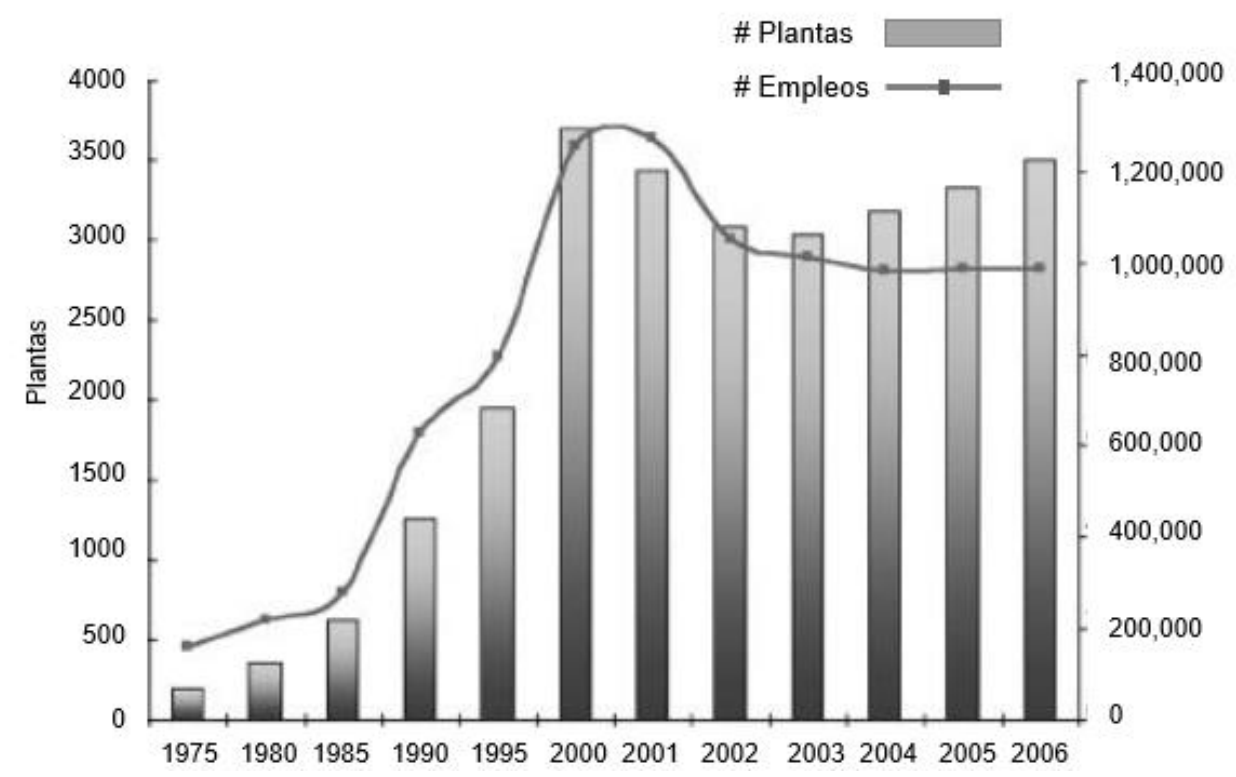

Fuente: Contreras y Munguía, 2007

Figura 2. Crecimiento e impacto de la industria maquiladora en México 
El crecimiento sostenido experimentado por la industria maquiladora en los años 70s y 80s se vio potenciado por la firma del Tratado de Libre Comercio de América del Norte (NAFTA) en 1992, lo que permitió que México se integrara económicamente con sus socios comerciales del norte (Canadá y Estados Unidos). Esta alianza permitió gozar de libre comercio entre los tres países a un coste reducido si se cumplía con una regla de origen establecida consistente en que al menos el $50 \%$ del contenido de los productos debería de ser norteamericano. La firma de este tratado, junto con el aceleramiento de la economía norteamericana durante mediados de los $90 \mathrm{~s}$, logró que las maquiladoras experimentaran un crecimiento sumamente acelerado al punto que, de acuerdo con Sargent y Matthews (2003), el empleo creció en un 110\% y el número de plantas aumentó en un $49 \%$. Sin embargo, el tratado también trajo ciertos problemas para esta industria, ya que obligó a eliminar las disposiciones y tarifas especiales que tenían las maquiladoras. Estas nuevas condiciones, junto con el coste agregado que implicaba mantener el complicado procedimiento burocrático de probar el origen de los productos y la apreciación que sufrió la moneda durante esos años, obligo un aumento en los salarios que incrementaron los costes totales de los productos maquilados en México.

\subsubsection{La importancia de la industria maquiladora en el entorno mundial}

Debido a los problemas en competitividad experimentados por la industria maquiladora mexicana, varias compañías empezaron a subcontratar sus procesos y operaciones a otros países con costes más bajos para buscar recuperar la competitividad perdida (Hadjimarcou et al., 2013) lo que favoreció el crecimiento de este mismo tipo de industria en otros países latinoamericanos. De hecho, así como la industria maquiladora se estableció y creció en México, otros países también desarrollaron una estrategia que buscaba atraer la industria de ensamblaje con mano de obra intensiva de corporaciones extranjeras. Países localizados en Asia tales como Tailandia, Malasia y China, junto con países de Centroamérica y el Caribe se presentaban como alternativas de bajo coste compitiendo con México (Wilson, 1991).

Semejante a lo hecho por México, ciertos países centroamericanos como Honduras crearon zonas industriales de procesamiento (ZIP) para la exportación, para poder atraer así este tipo de inversión extranjera. La llegada de las empresas maquiladoras a estos países en vías de desarrollo significó un impulso muy importante a su actividad manufacturera, generando empleos directos para miles de personas e ingresos para las comunidades beneficiadas (Alonso et al., 2002; Interiano, 2004; CEPAL, 2005). La 
importancia de esta industria para estos países es tal que, en Honduras, durante el 2013, el 34\% del PIB del país provino de la actividad maquilera, con la industria de la confección de prendas de vestir alcanzando un porcentaje del 76\%, generando más de 122,000 empleos (BCH, 2014).

Debido a la importancia que esta industria tiene en la economía de muchos países, son varias las investigaciones que se han realizado desde diferentes perspectivas. La Tabla 2 presenta una pequeña muestra de artículos enfocados en la industria del ensamblaje para exportación encontrados en la revisión de literatura científica. Como puede deducirse de esta muestra, el fenómeno de la industria maquiladora es de interés en el ámbito científico, tanto para revistas de ciencias sociales enfocadas al desarrollo y mejora del estándar de vida (World Development y Business Horizons), como para revistas enfocadas a la administración y mejora de las operaciones (Journal of Operations Management, Journal of International Management, International Journal of Production Economics y Computers in Industry). Al revisar la temática abordada por los artículos identificados en la Tabla 2 se observa que estos pueden dividirse en tres grandes categorías:

- Estudios enfocados en explicar el fenómeno de la industria maquiladora, sus impulsores de crecimiento, los beneficios que provee y su futuro esperado (Sargent y Matthews, 1997; Brouther et al., 1999; Pietrobelli y Rabellotti, 2011; Contreras et al., 2012; Grosse y Fonseca, 2012; Hadjimarcou et al., 2013).

- Estudios que persiguen identificar la relación que existe entre el uso de metodologías de mejora de procesos con el aumento de la eficiencia en esta industria (Lawrence y Hottenstein, 1995; Mefford y Bruun, 1998; Hadjimarcou et al., 2013; García et al., 2014).

- Estudios enfocados en los recursos humanos y la cultura organizacional de estas empresas (Jun et al.,, 2006; Howell et al., 2003; Hadjimarcou et al., 2013; García et al., 2014).

La revisión de literatura pone de manifiesto la importancia que la industria de ensamblaje con uso intensivo de mano de obra tiene en ciertos mercados específicos. 
Tabla 2. Análisis de artículos relevantes sector maquilador

\begin{tabular}{|c|c|c|c|}
\hline Articulo & Autores & Revista & Foco principal del articulo \\
\hline $\begin{array}{l}\text { The relationship between JIT } \\
\text { manufacturing and } \\
\text { performance in Mexican } \\
\text { plants affiliated with U.S. } \\
\text { Companies }\end{array}$ & $\begin{array}{l}\text { Lawrence y } \\
\text { Hottenstein, } \\
1995\end{array}$ & $\begin{array}{l}\text { Journal of } \\
\text { Operations } \\
\text { Management }\end{array}$ & $\begin{array}{l}\text { Determinar si el uso de JIT en plantas maquiladoras } \\
\text { está asociado con mejoras en el desempeño } \\
\text { (incremento en productividad, reducción en tiempo } \\
\text { de producción, mejora en calidad del producto y } \\
\text { mejora en servicio al cliente. }\end{array}$ \\
\hline $\begin{array}{l}\text { Skill Development and } \\
\text { Integrated Manufacturing in } \\
\text { Mexico }\end{array}$ & $\begin{array}{c}\text { Sargent y } \\
\text { Matthews, } 1997\end{array}$ & $\begin{array}{c}\text { World } \\
\text { Development }\end{array}$ & $\begin{array}{l}\text { Explorar como las compañías transnacionales han } \\
\text { ayudado en el desarrollo de habilidades en el uso } \\
\text { de tecnologías avanzadas de manufactura de sus } \\
\text { empleados. }\end{array}$ \\
\hline $\begin{array}{l}\text { Transferring world class } \\
\text { production to developing } \\
\text { countries: A strategic model }\end{array}$ & $\begin{array}{c}\text { Mefford y Bruun, } \\
1998\end{array}$ & $\begin{array}{l}\text { International } \\
\text { Journal of } \\
\text { Production } \\
\text { Economics }\end{array}$ & $\begin{array}{l}\text { Modelo (pasos) para seleccionar la tecnología de } \\
\text { producción a usar en empresas en países en vías } \\
\text { de desarrollo. El modelo guía a empresas a } \\
\text { implementar Lean cuando la implantación se hace } \\
\text { en países del tercer mundo. }\end{array}$ \\
\hline $\begin{array}{l}\text { Maquiladoras: } \\
\text { Entrepreneurial } \\
\text { Experimentation to Global } \\
\text { Competitiveness }\end{array}$ & $\begin{array}{l}\text { Brouthers et al., } \\
1999\end{array}$ & $\begin{array}{l}\text { Business } \\
\text { Horizons }\end{array}$ & $\begin{array}{l}\text { Describir el desarrollo de la industria maquiladora, } \\
\text { con un especial énfasis en los impulsores de su } \\
\text { expansión y previsiones de lo que depara el futuro. }\end{array}$ \\
\hline $\begin{array}{l}\text { Effective leadership in the } \\
\text { Mexican maquiladora: } \\
\text { challenging common } \\
\text { expectations }\end{array}$ & $\begin{array}{l}\text { Howell et al., } \\
2003\end{array}$ & $\begin{array}{l}\text { Journal of } \\
\text { International } \\
\text { Management }\end{array}$ & $\begin{array}{l}\text { Comparación entre las percepciones de los } \\
\text { empleados sobre los efectos de tener un líder } \\
\text { mexicano versus uno norteamericano dentro de una } \\
\text { planta maquiladora en cuanto a satisfacción con el } \\
\text { trabajo y la supervisión. }\end{array}$ \\
\hline $\begin{array}{l}\text { TQM practice in maquiladora: } \\
\text { Antecedents of employee } \\
\text { satisfaction and loyalty }\end{array}$ & Jun et al., 2006 & $\begin{array}{l}\text { Journal of } \\
\text { Operations } \\
\text { Management }\end{array}$ & $\begin{array}{l}\text { Analizar como los efectos de la alta rotación de los } \\
\text { empleados y su falta de compromiso (por causa de } \\
\text { insatisfacción) produce pobres implantaciones de } \\
\text { TQM en la industria maquiladora. Se revisa la } \\
\text { relación entre prácticas de TQM orientadas a los } \\
\text { Recursos Humanos con la satisfacción y lealtad del } \\
\text { empleado. }\end{array}$ \\
\hline $\begin{array}{l}\text { Global Value Chains Meet } \\
\text { Innovation Systems: Are } \\
\text { There Learning Opportunities } \\
\text { for Developing Countries? }\end{array}$ & $\begin{array}{c}\text { Pietrobelli y } \\
\text { Rabellotti, } 2011\end{array}$ & $\begin{array}{c}\text { World } \\
\text { Development }\end{array}$ & $\begin{array}{l}\text { Describir el beneficio experimentado por los países } \\
\text { que cuentan con cadenas globales de valor (GVC) } \\
\text { por causa de la absorción de tecnología y } \\
\text { conocimiento producido el cuál luego de manera } \\
\text { incremental produce innovación. Se explican los } \\
\text { diferentes mecanismos de transferencia (derrame, } \\
\text { imitación, presión por cumplir estándares, etc.) }\end{array}$ \\
\hline $\begin{array}{l}\text { Local Entrepreneurship within } \\
\text { Global Value Chains: A Case } \\
\text { Study in the Mexican } \\
\text { Automotive Industry }\end{array}$ & $\begin{array}{l}\text { Contreras, } \\
\text { Carrillo y Alonso, } \\
2012\end{array}$ & $\begin{array}{c}\text { World } \\
\text { Development }\end{array}$ & $\begin{array}{l}\text { Se explica el camino para producir empresas tipo } \\
\text { spin-off asociados con las maquilas (transferencia } \\
\text { de prácticas administrativas tecnológicas por causa } \\
\text { del Efecto Derrame) }\end{array}$ \\
\hline $\begin{array}{l}\text { Learning Through Imports in } \\
\text { the Internationalization } \\
\text { Process }\end{array}$ & $\begin{array}{c}\text { Grosse y } \\
\text { Fonseca } 2012\end{array}$ & $\begin{array}{c}\text { Journal of } \\
\text { International } \\
\text { Management }\end{array}$ & $\begin{array}{l}\text { Se explica el rol que tienen las importaciones en el } \\
\text { proceso de internacionalización de las empresas } \\
\text { estadounidenses. }\end{array}$ \\
\hline $\begin{array}{l}\text { Maquiladoras in the } 21 \mathrm{st} \\
\text { century: Six strategies for } \\
\text { success }\end{array}$ & $\begin{array}{l}\text { Hadjimarcou et } \\
\text { al., } 2013\end{array}$ & $\begin{array}{l}\text { Business } \\
\text { Horizons }\end{array}$ & $\begin{array}{l}\text { Se identifican factores que las empresas } \\
\text { maquiladoras deben hacer para mantenerse } \\
\text { competitivas ante las amenazas de China y los } \\
\text { problemas económicos en EEUU y adaptarse al } \\
\text { cambio (mejoras en calidad y tiempo de producción, } \\
\text { tomar ventaja de la localización, enfocarse en } \\
\text { manufactura y no en costes, aliarse con mercados } \\
\text { emergentes, etc. }\end{array}$ \\
\hline $\begin{array}{l}\text { A systematic review/survey } \\
\text { for JIT implementation: } \\
\text { Mexican maquiladoras as } \\
\text { case study }\end{array}$ & $\begin{array}{l}\text { García et al., } \\
2014\end{array}$ & $\begin{array}{l}\text { Computers } \\
\text { in Industry }\end{array}$ & $\begin{array}{l}\text { Se exponen los resultados de un análisis mediante } \\
\text { encuestas y modelado de ecuaciones estructurales } \\
\text { sobre los factores críticos de éxito para la } \\
\text { implementación de la metodología "justo a tiempo" } \\
\text { (JIT) en empresas maquiladoras extranjeras } \\
\text { establecidas en México. }\end{array}$ \\
\hline
\end{tabular}




\subsection{La medición de la competitividad de fabricación}

A pesar de que no hay una definición universalmente aceptada del concepto de competitividad, existe un acuerdo común de que un país, sector industrial o empresa es más competitiva si tiene un mejor desempeño que sus contrapartes en áreas específicas de interés. Existen varias teorías sobre cómo entender la competitividad, algunas de ellas muy parecidas entre sí y otras que generan debate continuo en la comunidad científica. Algunos autores han relacionado la competitividad con la capacidad de disminuir los costes laborales y aumentar el PIB (Rao y Lampriere, 1992), o de generar y mantener una ventaja competitiva (Porter, 1998; Lagacé y Bourgault, 2003). Otros han conectado la competitividad con la eficiencia de los procesos utilizados (Dou y Philip, 1998) o los recursos que una empresa tiene a su disposición y utiliza (Barney et al., 2001). De los modelos existentes para entender y analizar la competitividad a nivel de país y de empresa, quizás los más conocidos son los modelos del diamante de competitividad y las cinco fuerzas propuestos por Porter (1998; 2008).

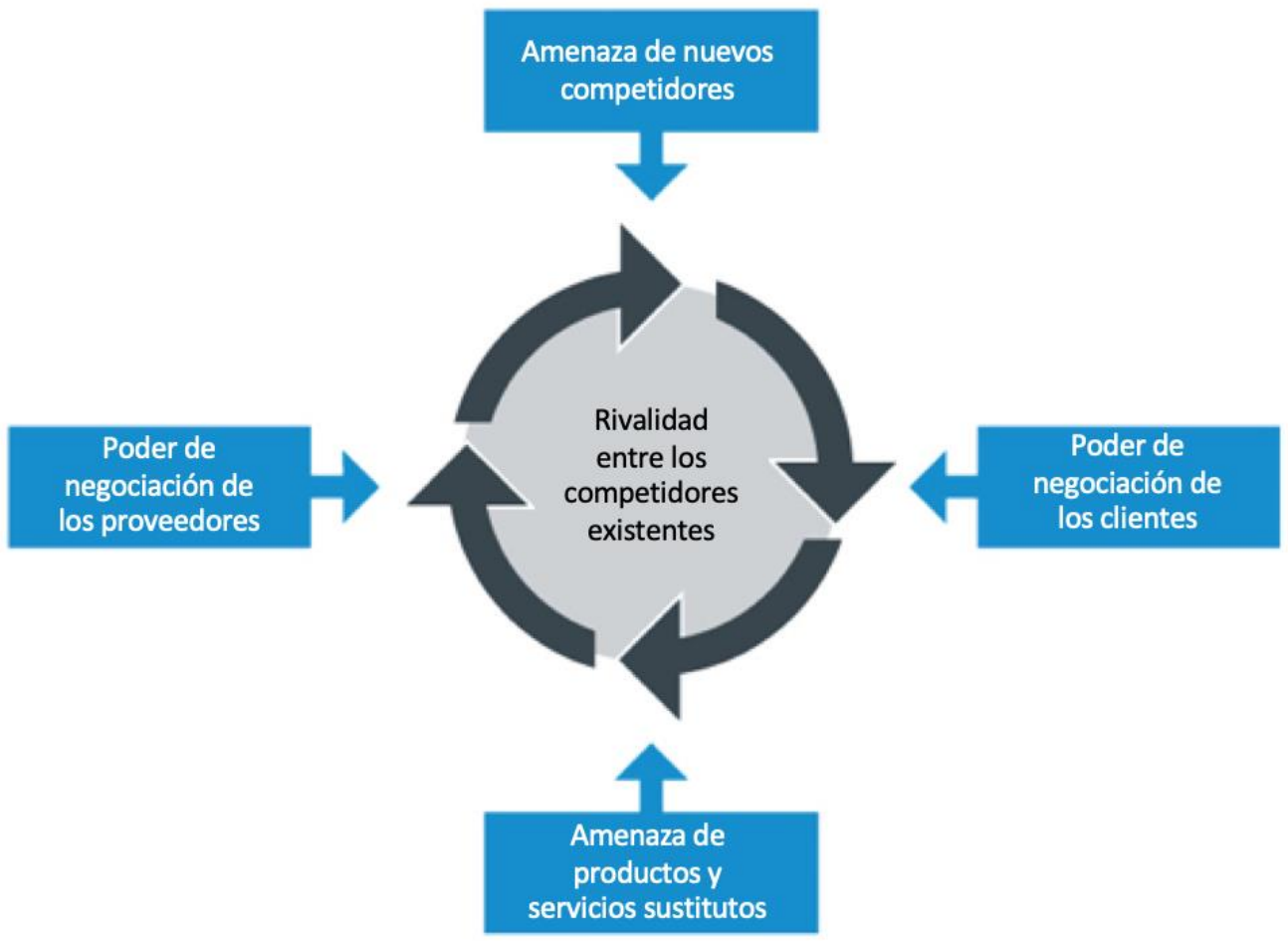

Fuente: www.cgma.org

Figura 3. Fuerzas que gobiernan la competencia de una industria

El modelo del diamante es un modelo económico que busca explicar porque ciertas industrias son exitosas en ciertos lugares específicos. Esta teoría se enfoca en la competitividad de las naciones e identifica seis factores que determinan como la ventaja 
competitiva es creada, dentro de las cuales se encuentran las políticas gubernamentales (impuestos, educación, investigación, etc.), una estructura industrial competitiva y el acceso a industrias de apoyo, materia prima y proveedores (Porter, 1998; Basu, 2015). El modelo de las cinco fuerzas es un modelo estratégico utilizado para entender y analizar la competitividad a nivel de empresa. Según Porter, estas fuerzas afectan el entorno de una empresa y su habilidad para satisfacer las necesidades de los clientes y generar ganancias (Porter, 2008). Usando este modelo es posible evaluar la posición competitiva de una empresa y las causas de su situación actual. Sin embargo, su propósito principal es establecer una estrategia a seguir una vez que se entiende cuáles son las fortalezas y debilidades de la empresa. Como se puede observar en la Figura 3, este modelo invita a una empresa a ver hacia afuera e identificar las amenazas externas para plantear una estrategia que le permita enfrentar estas fuerzas que tiene en contra.

\subsubsection{Teorías usadas para medir competitividad}

La competitividad puede medirse a nivel nacional, regional o sectorial (nivel macroeconómico), así como a nivel de empresa y de producto (nivel microeconómico). Para medir la competitividad a nivel nacional, organizaciones internacionales tales como el Foro Económico Mundial (WEF) y el Instituto de Desarrollo Gerencial (IMD), utilizan cientos de indicadores objetivos y subjetivos. A pesar de la fuerte correlación que existe entre la competitividad de país y la competitividad de las empresas, existen diferencias en la forma en que ambas se miden (Ülengin et al., 2014). De hecho, para medir la competitividad de las empresas la mayoría de los autores utilizan casi exclusivamente indicadores financieros (Lall, 2001). Sin embargo, aunque es más fácil comparar el desempeño de las empresas utilizando indicadores financieros (Lall, 2001; Liargovas y Skandalis, 2010; Magretta, 2012), es bueno recordar que los factores que conducen a una empresa a ser competitiva suelen ser no-financieros (Man et al., 2002). Autores tales como Barney (1991), Teece et al., (1997) y Hanson et al., (2012) defienden que la ventaja competitiva puede adquirirse al poseer recursos, capacidades o rutinas organizacionales que los diferencien de otros.

Existe gran interés en la medición de la competitividad a nivel empresarial porque "son las empresas, y no las naciones, las que compiten en los mercados internacionales" (Porter, 1998). De acuerdo con Ambastha y Momaya (2004) la medicion de la productividad es un buen indicador de la competitividad de una empresa, y variables tales como la flexibilidad, agilidad y velocidad se estan volviendo importantes fuentes de 
competitividad. Sin embargo, a pesar de los muchos estudios en esta tematica, no existe todavía un acuerdo en cuanto a la forma de medir la competitividad de una empresa.

Ambastha y Momaya (2004) demuestran que la competitividad de las empresas es medida desde tres enfoques: basado en desempeño, basado en procesos y basado en recursos. Una de las teorías dominantes en relación con la competitividad de la empresa es la visión basada en los recursos (RBV) y el enfoque de competencias básicas, que propone que la ventaja competitiva de una empresa proviene de una colección de activos o recursos tangibles e intangible que son específicos de la empresa y que no pueden ser fácilmente imitados por sus rivales (Barney, 1991; Flanagan et al., 2007). Sin embargo, es poco probable que los recursos por sí mismos provean una ventaja competitiva, pero cuando un grupo de estos recursos se vuelven una "capacidad", estos pueden realizar tareas o actividades capaces de crear valor y lograr una ventaja competitiva sobre sus rivales empresariales (Hanson et al., 2012). Esta teoría estipula que solo aquellos recursos y capacidades que son valiosos, raros, inimitables, y nosustituibles (VRIN) son capaces de producir ventaja competitiva. Adicionalmente, establece que generalmente este tipo de recursos y capacidades pueden combinarse a través del tiempo de forma armonizada hasta volverse una "competencia central" de la empresa (Barney, 1991).

Sin embargo, en la actualidad la mayoría de las empresas están más centradas en su supervivencia que en obtener ventajas competitivas (Ludwig y Pemberton, 2011). Bajo este paradigma, se propuso que un nuevo tipo de activos denominado "capacidades dinámicas", son los responsables de ayudar a una organización u empresa a adaptarse adecuadamente a los cambios constantes de la economía actual para continuar siendo competitivos y sobrevivir en el mercado (Teece at al., 1997). Yung-Ching y Tsui-Hsu (2006) definen las capacidades dinámicas como "un grupo de procesos específicos e identificables, o un conjunto de recursos que las empresas pueden integrar, reconfigurar, renovar y transferir". Muestras de estas capacidades dinámicas son las rutinas organizativas, los procesos administrativos distintivos de orden superior, el conocimiento organizacional, y los activos tecnológicos, entre otros (Teece y Pisano, 1994; Zollo y Winter, 2002). Esta teoría establece que el desarrollo de estas capacidades dinámicas no conduce necesariamente a una ventaja competitiva sostenible, pero si puede dar una ventaja temporal o paridad competitiva, lo cual ayuda a la supervivencia de la organización (Awwad et al., 2013). 


\subsubsection{Prioridades competitivas y la competitividad de fabricación}

A partir de las teorías expuestas previamente se puede observar que una buena manera de medir la competitividad de fabricación de una empresa es medir sus capacidades de fabricación, es decir el desempeño de esa compañía en sus metas u objetivos de fabricación con respecto a sus competidores. Estas metas, conocidas en la literatura como prioridades competitivas (Avella et al., 2001), son elecciones estratégicas sobre que capacidades son importantes para alcanzar ciertos resultados esperados. Carpinetti et al. (2000) son de la opinión que la competitividad industrial depende principalmente de lo bien que una empresa se desempeña en dimensiones estratégicas tales como la calidad, el coste, el tiempo de entrega, la flexibilidad para cambiar, la innovación y el servicio al cliente. Estas son dimensiones que el sistema de producción de una empresa debe poseer para apoyar las demandas de los mercados en los que la empresa desea competir (Awwad et al., 2013). Por lo tanto, el desempeño de una compañía en sus prioridades competitivas se conoce como las capacidades competitivas de la compañía, que son la conversión de estas prioridades en verdaderas fortalezas para una empresa.

Se ha realizado mucha investigación sobre la relación que existe entre la estrategia de manufactura y su competitividad o rendimiento, y algunos autores han encontrado una relación positiva entre altos niveles de capacidades competitivas y el alcanzar un alto desempeño (Ward et al., 1998; Tracey et al., 1999; Tan et al., 2007; Yang et al., 2010).

La revisión de la literatura muestra que, de entre todas las posibles prioridades y las capacidades asociadas que una empresa puede tener, cuatro emergen como fundamentales: coste u eficiencia, flexibilidad, calidad y tiempo de entrega (Avella et al., 2001; Greasley, 2009). A estas prioridades principales pueden añadirse la innovación (Corbett y Van Wassenhove, 1993; Tan et al., 2007), el servicio al cliente (Davis et al., 2001; Da Silveira y Slack, 2001), protección del medio ambiente (Álvarez et al., 2001; Avella et al., 2011), y la experiencia o conocimientos técnicos (Phusavat y Kanchana, 2007; Nambirajan y Prabhu, 2011).

La Tabla 3 presenta una descripción de cada una de las prioridades competitivas identificadas en la literatura. 
Tabla 3. Prioridades competitivas más importantes

\begin{tabular}{|c|l|}
\hline $\begin{array}{c}\text { Prioridades } \\
\text { Competitivas }\end{array}$ & \multicolumn{1}{c|}{ Descripción } \\
\hline Coste & $\begin{array}{l}\text { Producción y distribución de productos a bajo coste. Está relacionado } \\
\text { con una alta utilización de los recursos, alta productividad y bajos } \\
\text { niveles de coste de producción. }\end{array}$ \\
\hline Flexibilidad & $\begin{array}{l}\text { Habilidad de manejar cambios en el volumen y/o mezcla de producto. } \\
\text { Está relacionado con habilidad de personalizar productos y entregas } \\
\text { de acuerdo con las especificaciones del cliente. }\end{array}$ \\
\hline Calidad & $\begin{array}{l}\text { Manufactura de productos con altos estándares de calidad y } \\
\text { desempeño. Está relacionado con un alto desempeño del producto y } \\
\text { una alta conformidad del producto a las especificaciones de diseño, } \\
\text { seguridad y confiabilidad del producto. }\end{array}$ \\
\hline Entrega & $\begin{array}{l}\text { Entrega de productos confiable (a tiempo) y rápida (tiempo de } \\
\text { entrega corto). Está relacionado con tiempos de producción cortos y } \\
\text { habilidad de entregar el producto final a tiempo. }\end{array}$ \\
\hline Innovación & $\begin{array}{l}\text { Diferenciación de los competidores en función de la innovación de } \\
\text { sus productos y procesos. Está relacionado con características y } \\
\text { funcionalidad innovadora en el producto y la tecnología usada, } \\
\text { ofrecer nuevos productos y uso de tecnología de punta. }\end{array}$ \\
\hline $\begin{array}{c}\text { Servicio al } \\
\text { Cliente }\end{array}$ & $\begin{array}{l}\text { Cubrir las necesidades del cliente. Está relacionado con el servicio } \\
\text { posventa, personalización de productos, soporte técnico del producto } \\
\text { e información para clientes y promesa de confianza. }\end{array}$ \\
\hline $\begin{array}{c}\text { Medio } \\
\text { Ambiente }\end{array}$ & $\begin{array}{l}\text { Minimizar las repercusiones de la actividad productiva en el medio } \\
\text { ambiente. Está relacionado con políticas de protección al medio } \\
\text { ambiente a través de los procesos productivos y del producto en sí. }\end{array}$ \\
\hline $\begin{array}{l}\text { Experiencia } \\
\text { (Know-How) }\end{array}$ & $\begin{array}{l}\text { Administración del conocimiento, creatividad, aprendizaje continuo, } \\
\text { desarrollo de habilidades para resolución de problemas, educación y } \\
\text { entrenamiento, investigación y desarrollo, todo orientado a responder } \\
\text { a ciclos de vida cada vez más cortos. }\end{array}$ \\
\hline
\end{tabular}

El análisis realizado sobre el conjunto de artículos que estudian las prioridades competitivas (Tabla 4), muestra que existe un evidente interés técnico-científico en esta temática, especialmente en revistas de ciencias enfocadas a la administración y mejora de las operaciones tales como International Journal of Production Economics, Journal of Operations Management, CIRP Journal of Manufacturing Science and Technology, Economic Modelling, Journal of Service Science and Management y Management Science.

También se observa que son tres las principales áreas de enfoque de estos artículos:

- El impacto de las prioridades competitivas en el desempeño de las empresas (Miller y Roth, 1994; Kroes y Ghosh, 2010; Díaz-Garrido et al., 2011)

- La relación existente entre estas prioridades con la competitividad (Avella et al., 2001; Sarache Castro et al., 2011; Awwad et al., 2013; Cai y Yang, 2014)

- La identificación de modelos de referencia de prioridades competitivas para diferentes sectores industriales (Rostek, 2012; Vivares-Vergara et al., 2014) 
Tabla 4. Artículos relevantes sobre uso de prioridades competitivas

\begin{tabular}{|c|c|c|c|}
\hline Articulo & Autores & Revista & Foco principal del articulo \\
\hline $\begin{array}{l}\text { A taxonomy of } \\
\text { manufacturing strategies }\end{array}$ & $\begin{array}{c}\text { Miller y Roth, } \\
1994\end{array}$ & $\begin{array}{l}\text { Management } \\
\text { Science }\end{array}$ & $\begin{array}{l}\text { Define el concepto de prioridades } \\
\text { competitivas y presenta una taxonomía de } \\
\text { estrategias de manufactura desarrolladas } \\
\text { usando métodos de análisis de clúster. }\end{array}$ \\
\hline $\begin{array}{l}\text { Analysis of manufacturing } \\
\text { strategy as an exploratory } \\
\text { factor of competitiveness in } \\
\text { the large Spanish industrial } \\
\text { firm }\end{array}$ & $\begin{array}{l}\text { Avella et al., } \\
\quad 2001\end{array}$ & $\begin{array}{l}\text { International } \\
\text { Journal of } \\
\text { Production } \\
\text { Economics }\end{array}$ & $\begin{array}{l}\text { Busca identificar cuál es el énfasis hacia } \\
\text { ciertas prioridades competitivas de } \\
\text { manufactura en la industria española. } \\
\text { Además, revisa si existe una correlación } \\
\text { entre la estrategia de manufactura elegida y } \\
\text { el éxito competitivo o desempeño de negocio. }\end{array}$ \\
\hline $\begin{array}{l}\text { Outsourcing congruence } \\
\text { with competitive priorities: } \\
\text { Impact on supply chain and } \\
\text { firm performance }\end{array}$ & $\begin{array}{l}\text { Kroes y Ghosh, } \\
2010\end{array}$ & $\begin{array}{l}\text { Journal of } \\
\text { Operations } \\
\text { Management }\end{array}$ & $\begin{array}{l}\text { Evalúa el grado de congruencia (ajuste) entre } \\
\text { los conductores para el abastecimiento } \\
\text { externo y sus prioridades competitivas. } \\
\text { Revisa el impacto que tiene esta congruencia } \\
\text { en el desempeño de las empresas. }\end{array}$ \\
\hline $\begin{array}{l}\text { Competitive priorities in } \\
\text { operations: Development of } \\
\text { an indicator of strategic } \\
\text { position }\end{array}$ & $\begin{array}{l}\text { Díaz-Garrido et } \\
\text { al., } 2011\end{array}$ & $\begin{array}{l}\text { CIRP Journal of } \\
\text { Manufacturing } \\
\text { Science and } \\
\text { Technology }\end{array}$ & $\begin{array}{l}\text { Propone un indicador para posicionar las } \\
\text { empresas con respecto a sus prioridades } \\
\text { competitivas y busca identificar relaciones } \\
\text { existentes con el desempeño de la empresa. }\end{array}$ \\
\hline $\begin{array}{l}\text { The reference model of } \\
\text { competitiveness factors for } \\
\text { SME medical sector }\end{array}$ & Rostek, 2012 & $\begin{array}{l}\text { Economic } \\
\text { Modelling }\end{array}$ & $\begin{array}{l}\text { Presenta una metodología para medir la } \\
\text { competitividad en términos de posición } \\
\text { competitiva en el mercado. Se presenta una } \\
\text { herramienta para la toma de decisiones. }\end{array}$ \\
\hline $\begin{array}{l}\text { Prioridades competitivas } \\
\text { para la industria de la } \\
\text { confección. Caso de } \\
\text { estudio }\end{array}$ & $\begin{array}{l}\text { Sarache-Castro } \\
\text { et al., } 2011\end{array}$ & $\begin{array}{l}\text { Cuadernos de } \\
\text { Administración }\end{array}$ & $\begin{array}{l}\text { Presenta un procedimiento multi-criterio para } \\
\text { definir prioridades competitivas desde la } \\
\text { óptica del cliente y construir un indicador de } \\
\text { la posición de una empresa. }\end{array}$ \\
\hline $\begin{array}{l}\text { Competitive priorities and } \\
\text { competitive advantage in } \\
\text { Jordanian manufacturing }\end{array}$ & $\begin{array}{l}\text { Awwad et al., } \\
2013\end{array}$ & $\begin{array}{l}\text { Journal of } \\
\text { Service Science } \\
\text { and } \\
\text { Management }\end{array}$ & $\begin{array}{l}\text { Explora y predice la relación entre las } \\
\text { prioridades competitivas y la ventaja } \\
\text { competitiva de empresas en el sector } \\
\text { industrial Jordano. }\end{array}$ \\
\hline $\begin{array}{l}\text { The content of } \\
\text { manufacturing strategy: A } \\
\text { case study in Colombian } \\
\text { industries }\end{array}$ & $\begin{array}{l}\text { Vivares-Vergara } \\
\text { et al., } 2014\end{array}$ & Dyna & $\begin{array}{l}\text { Se presentan los resultados de un estudio del } \\
\text { contenido de la estrategia de manufactura } \\
\text { (prioridades competitivas, áreas estratégicas } \\
\text { de decisión y enfoques de gestión para la } \\
\text { manufactura) en empresas colombianas. }\end{array}$ \\
\hline $\begin{array}{l}\text { On the relationship } \\
\text { between business } \\
\text { environment and } \\
\text { competitive priorities: The } \\
\text { role of performance } \\
\text { frontiers }\end{array}$ & $\begin{array}{c}\text { Cai y Yang, } \\
2014\end{array}$ & $\begin{array}{l}\text { International } \\
\text { Journal of } \\
\text { Production } \\
\text { Economics }\end{array}$ & $\begin{array}{l}\text { Explora las conexiones existentes entre } \\
\text { fuerzas ambientales de negocio (dinamismo, } \\
\text { coste, disponibilidad de mano de obra y } \\
\text { hostilidad competitiva) y las prioridades } \\
\text { competitivas de una empresa. }\end{array}$ \\
\hline
\end{tabular}

Debido a que las capacidades competitivas de una empresa son generalmente consideradas como una manifestación directa de sus prioridades competitivas o sus estrategias de manufactura (Ward et al., 1998; Cai y Yang, 2014), una de las áreas principales de estudio en esta temática es la influencia que las prioridades competitivas tienen en el rendimiento o competitividad de las compañías. Ciertos investigadores han encontrado que existe una relación positiva entre altos niveles de capacidades competitivas y el logro de un excelente rendimiento (Tracey et al., 1999) lo que hace que el medir el desempeño en las capacidades competitivas parezca una forma adecuada de describir la competitividad de fabricación de una empresa. 
Sin embargo, en algunos de estos estudios no se pudo identificar una relación clara entre esas variables en las empresas bajo estudio (Avella et al., 2001). Una posible explicación para estas discrepancias es el énfasis que algunas empresas dan a ciertas prioridades competitivas específicas. Martín-Peña y Díaz-Garrido (2009) explican que el modelo de "trade-off" (preferencias) consiste en ofrecer un tratamiento preferencial a una de las prioridades competitivas sobre el resto. De acuerdo con este paradigma, esto se hace debido a que es imposible sobresalir en todas las prioridades de manera simultánea y por lo tanto es necesario centrarse en un grupo de ellas que son de mayor importancia para la empresa, haciendo necesario el establecer un balance o "trade-off" que sacrifique equilibradamente el resto de ellas (Fine y Hax, 1985).

\subsubsection{Modelos de referencia de prioridades competitivas}

Para identificar la preferencia que existe entre las diferentes prioridades para un país, región o sector industrial especifico, varios autores han sugerido modelos de referencia que usan un análisis empírico basado en la percepción de directores, vicepresidentes o gerentes de empresa (Kathuria, 2000; Díaz-Garrido et al., 2011; Rostek, 2012; Awward et al., 2013) o de la opinión de expertos (Sarache Castro et al., 2011) sobre el nivel de importancia que tiene cada prioridad. Las respuestas obtenidas son luego ponderadas usando diferentes ecuaciones o algoritmos que permiten encontrar la importancia relativa o peso de cada componente o dimensión y a su vez de cada prioridad. El orden jerárquico o modelo encontrado permite definir cuáles son las tareas que la unidad de manufactura debe de ejecutar bien para alcanzar los requisitos de mercado que le permitirán a la empresa ser competitiva (Porter, 1980; Martínez y Bititci, 2006), o en donde debe de enfocar más recursos (Kathuria, 2000; Boyer y Lewis, 2002). Tener congruencia entre las prioridades competitivas que se persiguen y las decisiones de manufactura que se toman para lograrlo (capacidades de manufactura de la empresa), permitirá a la compañía tener un rendimiento empresarial superior y ser más competitivo.

En general estos modelos se han usado para desarrollar indicadores estratégicos que permitan medir la posición de las empresas con respecto a sus prioridades competitivas. Un ejemplo es el trabajo realizado por Díaz-Garrido et al. (2011) quienes proponen un indicador que permite posicionar a las empresas con respecto a sus prioridades competitivas y analiza la relación de este indicador con otros resultados empresariales. 
En este caso los autores usaron un cuestionario que usaba una escala Likert de 7 puntos con una muestra de 353 empresas de varios sectores industriales en España. El instrumento buscaba identificar la importancia que las empresas le daban a diferentes prioridades competitivas en forma de variables multidimensionales y la fortaleza que tenían en cada una de ellas. Los resultados del cuestionario fueron sometidos a varias pruebas para revisar la validez de cada constructo, es decir la correlación entre las dimensiones de una prioridad, la consistencia interna del instrumento (alfa de Cronbach), y los pesos asignados a cada componente mediante el análisis exploratorio de factores.

Sarache et al. (2011) construyeron un procedimiento multicriterio para definir las prioridades competitivas en la industria de la confección de ropa desde la óptica del cliente y mediante un indicador, determinar el nivel de acercamiento a los deseos de los clientes. En este caso, en lugar de utilizar encuestas se usó el método de expertos con 11 representantes de ventas de empresas transnacionales. La ponderación de factores y componentes en este caso se hizo usando un procedimiento que combinaba la comparación binaria entre factores y componentes usando la escala de Saaty y la ponderación a partir de las matrices obtenidas mediante un conjunto de ecuaciones matemáticas simultáneas. Adicionalmente se realizaron pruebas de inconsistencia, entendida como la calidad de la valoración del experto, y de concordancia, es decir, del nivel de acuerdo entre juicios emitidos.

También es importante resaltar que las prioridades competitivas son multidimensionales por naturaleza, es decir, hay un grupo de componentes o dimensiones que explican cada prioridad o ayudan a medirlas. De acuerdo con la revisión de literatura, estos componentes varían dependiendo de la industria o mercado bajo estudio (Kroes y Ghosh, 2010; Avella et al., 2011; Cai y Yang, 2014). A partir de los estudios hechos por Kroes y Ghosh (2010), Avella et al. (2001), Avella et al. (2011), Díaz-Garrido et al. (2011), Sarache et al. (2011), Cai y Yang (2014), Dangayach y Deshmukn (2006), Swink y Nair (2007), Hallgren (2007) y Khanchanapong et al. (2014), se realizó un análisis para comparar y contrastar los posibles componentes de cada una de las prioridades competitivas que pueden usarse en el "trade-off".

La recopilación unificada de las prioridades competitivas identificadas en la literatura se refleja en la Tabla 5. 
Tabla 5. Prioridades competitivas propuestas en literatura científica

\begin{tabular}{|c|c|c|c|c|c|c|c|c|c|c|}
\hline $\begin{array}{l}\text { Prioridades } \\
\text { Competitivas }\end{array}$ & $\begin{array}{c}\text { Kroes y Ghosh, } \\
2010\end{array}$ & $\begin{array}{c}\text { Avella, et al. } \\
2001\end{array}$ & Avella, 2010 & $\begin{array}{l}\text { Díaz-Garrido, } \\
\text { et al. } 2011\end{array}$ & $\begin{array}{c}\text { Sarache, et al. } \\
2012\end{array}$ & $\begin{array}{c}\text { Cai y Yang, } \\
2014\end{array}$ & $\begin{array}{c}\text { Dangayach y } \\
\text { Deshmukn, } \\
2006 \\
\end{array}$ & $\begin{array}{c}\text { Swink y Nair, } \\
2007\end{array}$ & Hallgren, 2007 & $\begin{array}{c}\text { Khanchana } \\
\text { pong, et al. } \\
2014 \\
\end{array}$ \\
\hline \multirow{6}{*}{ Coste } & $\begin{array}{l}\text { Alta capacidad de } \\
\text { utilización }\end{array}$ & Bajo costo & $\begin{array}{l}\text { Reducción de } \\
\text { costo de } \\
\text { manufactura }\end{array}$ & Bajo costo & Costo & $\begin{array}{l}\text { Reducción de costo } \\
\text { de producción }\end{array}$ & Bajo costo & $\begin{array}{l}\text { Costo inicial de } \\
\text { compra }\end{array}$ & $\begin{array}{l}\text { Costo unitario de } \\
\text { manufactura }\end{array}$ & $\begin{array}{l}\text { Costo de } \\
\text { producción } \\
\text { bajo }\end{array}$ \\
\hline & $\begin{array}{l}\text { Alta productividad } \\
\text { laboral }\end{array}$ & & $\begin{array}{l}\text { Incremento de } \\
\text { productividad } \\
\text { laboral }\end{array}$ & & & $\begin{array}{l}\text { Reducción de costo } \\
\text { al aumentar } \\
\text { productividad }\end{array}$ & & $\begin{array}{l}\text { Costo general de } \\
\text { manufactura }\end{array}$ & $\begin{array}{l}\text { Rotación de } \\
\text { inventarios }\end{array}$ & $\begin{array}{l}\text { Precios } \\
\text { competitivos }\end{array}$ \\
\hline & $\begin{array}{l}\text { Bajo costo de } \\
\text { inventario }\end{array}$ & & $\begin{array}{l}\text { Incremento en } \\
\text { capacidad o } \\
\text { utilización de } \\
\text { equipo }\end{array}$ & & & $\begin{array}{l}\text { Reducción de costo } \\
\text { al mejorar la } \\
\text { utilización de la } \\
\text { capacidad }\end{array}$ & & & $\begin{array}{l}\text { Utilización de la } \\
\text { capacidad }\end{array}$ & \begin{tabular}{|l|} 
Eficiencia de \\
la producción
\end{tabular} \\
\hline & $\begin{array}{l}\text { Baja producción } \\
\text { /costo de } \\
\text { manufactura }\end{array}$ & & $\begin{array}{l}\text { Reducción de } \\
\text { nivel de } \\
\text { inventario }\end{array}$ & & & \begin{tabular}{|l|} 
Reducción de \\
costos mediante \\
reducción de \\
tiempo de ciclos de \\
producción
\end{tabular} & & & Rendimiento & $\begin{array}{l}\text { Rotación de } \\
\text { inventarios }\end{array}$ \\
\hline & & & & & & $\begin{array}{l}\text { Reducción de costo } \\
\text { de inventarios }\end{array}$ & & & $\begin{array}{l}\text { Precio de venta } \\
\text { del producto }\end{array}$ & \\
\hline & & & & & & & & & \begin{tabular}{|l|} 
Precio de \\
mercado
\end{tabular} & \\
\hline \multirow{3}{*}{ Servicio } & & & & Servicio posventa & Asistencia técnica & & & & & \\
\hline & & & & $\begin{array}{l}\text { Necesidades del } \\
\text { cliente }\end{array}$ & & & & & & \\
\hline & & & & Información & & & & & & \\
\hline
\end{tabular}


Capítulo 2. Estado del arte

\begin{tabular}{|c|c|c|c|c|c|c|c|c|c|c|}
\hline & $\begin{array}{l}\text { Alta conformidad } \\
\text { de producto final a } \\
\text { especificaciones de } \\
\text { diseño }\end{array}$ & \begin{tabular}{|l} 
Productos \\
libres de \\
defecto (o \\
bajas tasas de \\
defecto)
\end{tabular} & \begin{tabular}{|l} 
Mejorar la \\
conformidad de \\
especifica-ciones \\
con las \\
especifica-ciones \\
de diseño
\end{tabular} & $\begin{array}{l}\text { Desempeño del } \\
\text { producto }\end{array}$ & Calidad comparada & \begin{tabular}{|l} 
Calidad de \\
desempeño
\end{tabular} & $\begin{array}{l}\text { Conformidad de la } \\
\text { calidad }\end{array}$ & $\begin{array}{l}\text { Características } \\
\text { del producto }\end{array}$ & $\begin{array}{l}\text { Costo de re- } \\
\text { trabajo }\end{array}$ & \begin{tabular}{|l|} 
Durabilidad \\
del producto
\end{tabular} \\
\hline & $\begin{array}{l}\text { Alto rendimiento del } \\
\text { producto }\end{array}$ & \begin{tabular}{|l} 
Calidad \\
percibida por el \\
cliente
\end{tabular} & $\begin{array}{l}\text { Oferta de calidad } \\
\text { consistente y } \\
\text { fiable }\end{array}$ & Conformidad & $\begin{array}{l}\text { Posibilidad de } \\
\text { rechazo }\end{array}$ & \begin{tabular}{|l} 
Durabilidad del \\
producto
\end{tabular} & \begin{tabular}{|l} 
Fiabilidad del \\
producto
\end{tabular} & \begin{tabular}{|l} 
Durabilidad del \\
producto
\end{tabular} & $\begin{array}{l}\text { Porcentaje de } \\
\text { inspección de } \\
\text { calidad superada }\end{array}$ & \begin{tabular}{|l} 
Fiabilidad del \\
producto
\end{tabular} \\
\hline & $\begin{array}{l}\text { Alta fiabilidad de } \\
\text { producto }\end{array}$ & \begin{tabular}{|l|}
$\begin{array}{l}\text { Productos } \\
\text { durables }\end{array}$ \\
\end{tabular} & $\begin{array}{l}\text { Proporcionar } \\
\text { productos de alto } \\
\text { rendimiento }\end{array}$ & \begin{tabular}{|l|} 
Fiabilidad del \\
producto
\end{tabular} & $\begin{array}{l}\text { Fiabilidad de la } \\
\text { entrega }\end{array}$ & $\begin{array}{l}\text { Conformidad de la } \\
\text { calidad }\end{array}$ & \begin{tabular}{|l} 
Desempeño del \\
producto
\end{tabular} & $\begin{array}{l}\text { Conformidad del } \\
\text { producto }\end{array}$ & $\begin{array}{l}\text { Costo del control } \\
\text { de la calidad }\end{array}$ & $\begin{array}{l}\text { Desempeño } \\
\text { del producto }\end{array}$ \\
\hline \multirow[t]{4}{*}{ Calidad } & $\begin{array}{l}\text { Alta seguridad del } \\
\text { producto }\end{array}$ & & $\begin{array}{l}\text { Ofrecer } \\
\text { productos } \\
\text { duraderos y } \\
\text { fiables }\end{array}$ & & & $\begin{array}{l}\text { Reducción de } \\
\text { defectos }\end{array}$ & $\begin{array}{l}\text { Durabilidad del } \\
\text { producto }\end{array}$ & $\begin{array}{l}\text { Fiabilidad del } \\
\text { producto }\end{array}$ & $\begin{array}{l}\text { Conformidad con } \\
\text { las } \\
\text { especificaciones } \\
\text { acordadas }\end{array}$ & \begin{tabular}{|l} 
Calidad global \\
del producto \\
según la \\
percepción del \\
cliente
\end{tabular} \\
\hline & $\begin{array}{l}\text { Pronta resolución } \\
\text { de quejas/dudas de } \\
\text { los clientes }\end{array}$ & & $\begin{array}{l}\text { Fabricación con } \\
\text { tasas constantes } \\
\text { de bajos defectos } \\
\text { (reducción de } \\
\text { tasa de defectos) }\end{array}$ & & & & & $\begin{array}{l}\text { Rendimiento de } \\
\text { la calidad del } \\
\text { producto }\end{array}$ & $\begin{array}{l}\text { Desempeño del } \\
\text { producto }\end{array}$ & $\begin{array}{l}\text { Conformidad a } \\
\text { especifica- } \\
\text { ciones }\end{array}$ \\
\hline & $\begin{array}{l}\text { Facilidad (costo y } \\
\text { tiempo) de reparar } \\
\text { un producto }\end{array}$ & & & & & & & & & \\
\hline & \begin{tabular}{|l|} 
Producto de alta \\
durabilidad (larga \\
vida) \\
\end{tabular} & & & & & & & & & \\
\hline Flexibilidad & $\begin{array}{l}\text { Habilidad de ajustar } \\
\text { capacidad y/o } \\
\text { volumen }\end{array}$ & $\begin{array}{l}\text { Cambios } \\
\text { rápidos en los }\end{array}$ & $\begin{array}{l}\text { Hacer cambios } \\
\text { de diseño } \\
\text { rápidamente }\end{array}$ & $\begin{array}{l}\text { Expansión } \\
\text { (incrementos }\end{array}$ & $\begin{array}{l}\text { Flexibilidad para } \\
\text { cambios } \\
\text { inesperados }\end{array}$ & \begin{tabular}{|l} 
Habilidad de \\
introducir nuevos \\
productos
\end{tabular} & $\begin{array}{l}\text { Cambios en la } \\
\text { mezcla de } \\
\text { productos }\end{array}$ & $\begin{array}{l}\text { nuevos } \\
\text { productos }\end{array}$ & $\begin{array}{l}\text { Tiempo/costo de } \\
\text { preparación (set } \\
\text { up) }\end{array}$ & $\begin{array}{l}\text { Cambio fácil } \\
\text { del volumen } \\
\text { de producción }\end{array}$ \\
\hline
\end{tabular}




\begin{tabular}{|c|c|c|c|c|c|c|c|c|c|c|}
\hline & $\begin{array}{l}\text { efectivamente } \\
\text { dentro de un } \\
\text { periodo corto de } \\
\text { tiempo }\end{array}$ & \begin{tabular}{|l|} 
diseños \\
actuales
\end{tabular} & & $\begin{array}{l}\text { rápidos en } \\
\text { capacidad) }\end{array}$ & & & & $\begin{array}{l}\text { introducidos cada } \\
\text { año }\end{array}$ & & $\begin{array}{l}\text { de un proceso } \\
\text { de } \\
\text { manufactura }\end{array}$ \\
\hline & \begin{tabular}{|l|} 
Capacidad de \\
ajustar las entregas \\
para satisfacer las \\
necesidades del \\
cliente
\end{tabular} & $\begin{array}{l}\text { Rápida } \\
\text { introducción de } \\
\text { nuevos } \\
\text { productos }\end{array}$ & $\begin{array}{l}\text { Introducir nuevos } \\
\text { productos } \\
\text { rápidamente }\end{array}$ & \begin{tabular}{|l} 
Variaciones en \\
volumen de \\
producción \\
(ajustes rápidos \\
en capacidad)
\end{tabular} & \begin{tabular}{|l|} 
Flexibilidad del \\
portafolio de familia \\
de productos
\end{tabular} & $\begin{array}{l}\text { Flexibilidad de } \\
\text { volumen }\end{array}$ & $\begin{array}{l}\text { Personalización del } \\
\text { producto }\end{array}$ & $\begin{array}{l}\text { Tiempo para } \\
\text { introducir nuevos } \\
\text { productos }\end{array}$ & \begin{tabular}{|l} 
Duración del \\
programa fijo de \\
producción
\end{tabular} & $\begin{array}{l}\text { Construir } \\
\text { diferentes } \\
\text { productos en } \\
\text { la misma } \\
\text { planta al } \\
\text { mismo tiempo }\end{array}$ \\
\hline & $\begin{array}{l}\text { Habilidad de } \\
\text { personalizar los } \\
\text { productos para las } \\
\text { necesidades del } \\
\text { cliente } \\
\end{array}$ & $\begin{array}{l}\text { Cambios } \\
\text { rápidos en } \\
\text { volumen }\end{array}$ & $\begin{array}{l}\text { Hacer cambios } \\
\text { rápidos en } \\
\text { volumen }\end{array}$ & $\begin{array}{l}\text { Cambios en } \\
\text { diseño de } \\
\text { producto }\end{array}$ & \begin{tabular}{|l|} 
Flexibilidad en \\
tamaño de la orden
\end{tabular} & $\begin{array}{l}\text { Habilidad de hacer } \\
\text { cambios rápidos de } \\
\text { diseño }\end{array}$ & $\begin{array}{l}\text { Cambios de } \\
\text { volumen }\end{array}$ & \begin{tabular}{|l|} 
Habilidad de \\
responder a \\
cambios en \\
requerimientos \\
de entrega \\
\end{tabular} & $\begin{array}{l}\text { Cantidad de } \\
\text { capacidad de } \\
\text { operación }\end{array}$ & $\begin{array}{l}\text { Cambio rápido } \\
\text { de un } \\
\text { producto al } \\
\text { otro }\end{array}$ \\
\hline & \begin{tabular}{|l|} 
Capacidad para \\
realizar cambios de \\
diseño en el \\
producto una vez \\
iniciada producción
\end{tabular} & $\begin{array}{l}\text { Cambios } \\
\text { rápidos en } \\
\text { mezcla de } \\
\text { producto }\end{array}$ & $\begin{array}{l}\text { Realizar rápidos } \\
\text { cambios de } \\
\text { mezcla de } \\
\text { producto }\end{array}$ & $\begin{array}{l}\text { Amplio rango de } \\
\text { productos }\end{array}$ & $\begin{array}{l}\text { Flexibilidad de } \\
\text { portafolio de telas }\end{array}$ & $\begin{array}{l}\text { Amplia línea de } \\
\text { productos }\end{array}$ & Cambios de diseño & $\begin{array}{l}\text { Posibilidad de } \\
\text { ajustar los } \\
\text { volúmenes de } \\
\text { producción }\end{array}$ & \begin{tabular}{|l|} 
Rango de \\
productos
\end{tabular} & $\begin{array}{l}\text { Cambio fácil } \\
\text { de los } \\
\text { productos a } \\
\text { necesidad } \\
\text { específica del } \\
\text { cliente }\end{array}$ \\
\hline & $\begin{array}{l}\text { Ofrecer un gran } \\
\text { número de } \\
\text { características de } \\
\text { producto u } \\
\text { opciones }\end{array}$ & $\begin{array}{l}\text { Amplia línea de } \\
\text { productos }\end{array}$ & \begin{tabular}{|l} 
Alto grado de \\
variedad de \\
producto (amplia \\
línea de \\
productos)
\end{tabular} & $\begin{array}{l}\text { Amplia variedad } \\
\text { de productos } \\
\text { (productos no- } \\
\text { estándar) }\end{array}$ & & $\begin{array}{l}\text { Posibilidad de } \\
\text { cambiar } \\
\text { rápidamente la } \\
\text { mezcla de } \\
\text { productos }\end{array}$ & & $\begin{array}{l}\text { Posibilidad de } \\
\text { personalizar } \\
\text { productos }\end{array}$ & $\begin{array}{l}\text { Número de } \\
\text { productos } \\
\text { ofrecidos }\end{array}$ & \\
\hline & $\begin{array}{l}\text { Alta flexibilidad de } \\
\text { producción para } \\
\text { permitir la } \\
\text { introducción de } \\
\text { nuevos productos }\end{array}$ & & $\begin{array}{l}\text { Ajustar mezcla de } \\
\text { producto }\end{array}$ & \begin{tabular}{|l|} 
Mezcla de \\
producto
\end{tabular} & & & & $\begin{array}{l}\text { Habilidad de } \\
\text { producir un rango } \\
\text { de productos }\end{array}$ & $\begin{array}{l}\text { Capacidad de } \\
\text { manejar cambios } \\
\text { en volumen y } \\
\text { mezcla }\end{array}$ & \\
\hline & $\begin{array}{l}\text { Producir gran } \\
\text { variedad de } \\
\text { productos }\end{array}$ & & & & & & & & & \\
\hline \multirow{3}{*}{ Tiempo } & $\begin{array}{l}\text { Tiempos cortos de } \\
\text { cambio/preparación }\end{array}$ & $\begin{array}{l}\text { Entregas } \\
\text { rápidas }\end{array}$ & $\begin{array}{l}\text { Proveer entregas } \\
\text { rápidas }\end{array}$ & Entregas rápidas & Tiempo de entrega & $\begin{array}{l}\text { Velocidad de } \\
\text { entrega }\end{array}$ & Entrega confiable & $\begin{array}{l}\text { Velocidad de } \\
\text { entrega (tiempo } \\
\text { transcurrido } \\
\text { corto) } \\
\end{array}$ & $\begin{array}{l}\text { Tiempo de } \\
\text { entrega }\end{array}$ & $\begin{array}{l}\text { Tiempo de } \\
\text { procura- } \\
\text { miento }\end{array}$ \\
\hline & $\begin{array}{l}\text { Tiempo de ciclo de } \\
\text { desarrollo de } \\
\text { producto corto }\end{array}$ & $\begin{array}{l}\text { Entregas a } \\
\text { tiempo o } \\
\text { confiables }\end{array}$ & $\begin{array}{l}\text { Cumplir con las } \\
\text { promesas o } \\
\text { compromisos de } \\
\text { entrega } \\
\end{array}$ & $\begin{array}{l}\text { Entregas a } \\
\text { tiempo }\end{array}$ & $\begin{array}{l}\text { Tiempo de } \\
\text { respuesta a un } \\
\text { cliente que pide } \\
\text { información } \\
\end{array}$ & $\begin{array}{l}\text { Fiabilidad de } \\
\text { entrega }\end{array}$ & $\begin{array}{l}\text { Velocidad de } \\
\text { entrega }\end{array}$ & $\begin{array}{l}\text { Disponibilidad de } \\
\text { entrega (artículos } \\
\text { en stock al } \\
\text { pedirlo) }\end{array}$ & Entregas a tiempo & $\begin{array}{l}\text { Tiempo de } \\
\text { fabricación }\end{array}$ \\
\hline & $\begin{array}{l}\text { Tiempos de ciclo } \\
\text { de producción } \\
\text { cortos }\end{array}$ & & $\begin{array}{l}\text { Reducir tiempo } \\
\text { de manufactura }\end{array}$ & \begin{tabular}{|l|} 
Pedidos y \\
devoluciones
\end{tabular} & $\begin{array}{l}\text { Tiempo de } \\
\text { respuesta a } \\
\text { presupuesto }\end{array}$ & & & $\begin{array}{l}\text { Fiabilidad de la } \\
\text { entrega }\end{array}$ & $\begin{array}{l}\text { Precisión del } \\
\text { estado del } \\
\text { inventario }\end{array}$ & $\begin{array}{l}\text { Velocidad de } \\
\text { entrega }\end{array}$ \\
\hline
\end{tabular}







El análisis bibliográfico expuesto en la tabla 5 identifica a siete como las prioridades competitivas más utilizadas, y cuatro de ellas (coste, calidad, flexibilidad y tiempo de entrega) están presentes en todos los estudios. Este análisis arroja 177 diferentes componentes usados por todos estos investigadores aunque una parte giran alrededor delos mismo concepto pueden considerarse muy parecidos. Debido a que el número de componentes es todavía muy elevado, es necesario investigar cuales son las prioridades competitivas y componentes que son aplicables a una industria específica tal como la de ensamblaje con uso intensivo de mano de obra en el sector geográfico especifico. Para esto es necesario la construcción de un modelo de referencia que permita identificar las prioridades y capacidades competitivas, así como la competitividad de fabricación de esta industria.

\subsection{Herramientas AMT para mejorar la competitividad}

La definición clásica de las tecnologías avanzadas de manufactura (AMT) está relacionada con tecnologías que aplican sistemas mecánicos, eléctricos o electrónicos controlados por ordenadores para el diseño, programación de la producción, control y ejecución de procesos de fabricación (Rahardjo y Yahya, 2010).

Dentro de esta definición general, la literatura científica categoriza las AMT de diferentes formas. Inicialmente, la clasificación se asoció a la existencia de componentes de hardware, denominándolas tecnologías duras, o componentes de software, denominándolas blandas. Ejemplos de las tecnologías duras son los robots, las máquinas de control numérico computarizado (CNC), los vehículos guiados automáticamente (AGV) y los sistemas de almacenaje y recuperación automática de productos (ASRS). Entre las tecnologías blandas se encuentran el diseño asistido por computadora (CAD), la manufactura asistida por computadora (CAM), la planificación de recursos de la empresa (ERP) y la planificación de recursos y materiales (MRP).

Sin embargo, la corriente actual es incluir, como AMT blandas, las técnicas y metodologías de gestión introducidas en los años 80 y 90 orientadas a la mejora continua de las operaciones. Ejemplos de ellas son la administración de la calidad total (TQM), la fabricación esbelta (Lean Manufacturing) o Seis Sigma (Six Sigma), que pueden ser igualmente utilizadas para incrementar la efectividad y el desempeño de las empresas (Boyer et al., 1996; Swink y Nair, 2007; Mohd et al., 2017). 
En los últimos años diversos investigadores han tratado de identificar las AMT que utilizan las empresas para mejorar su desempeño en las dimensiones de la competitividad: coste, calidad, flexibilidad, tiempo de entrega, la innovación, y la protección del medio ambiente.

La tabla 6 muestra un análisis de los artículos más relevantes que afrontan el efecto que la implantación de AMT tiene sobre las capacidades de manufactura y el desempeño de las empresas en diferentes sectores industriales.

Tabla 6. Análisis de artículos relevantes sobre AMT

\begin{tabular}{|c|c|c|c|}
\hline Articulo & Autores & Revista & Foco principal del articulo \\
\hline $\begin{array}{l}\text { Capturing the competitive } \\
\text { advantages of AMT: } \\
\text { Design-manufacturing } \\
\text { integration as a } \\
\text { complementary asset }\end{array}$ & $\begin{array}{c}\text { Swink y Nair, } \\
2007\end{array}$ & $\begin{array}{l}\text { Journal of } \\
\text { Operations } \\
\text { Management }\end{array}$ & $\begin{array}{l}\text { Describe y prueba la teoría de la } \\
\text { complementariedad del Diseño Integrado de } \\
\text { Manufactura (DIM) y las AMT. Examina el rol } \\
\text { de activos complementarios }\end{array}$ \\
\hline $\begin{array}{l}\text { The impact of AMT } \\
\text { practices on firm } \\
\text { performance in } \\
\text { manufacturing SMEs }\end{array}$ & $\begin{array}{c}\text { Koc y Bozdag, } \\
2009\end{array}$ & $\begin{array}{l}\text { Robotics and } \\
\text { Computer- } \\
\text { Integrated } \\
\text { Manufacturing } \\
\end{array}$ & $\begin{array}{l}\text { Informa sobre el uso de AMT en pequeñas y } \\
\text { medianas empresas (PYME). Busca } \\
\text { identificar que AMT adoptar para mejorar los } \\
\text { parámetros de manufactura en la empresa. }\end{array}$ \\
\hline $\begin{array}{l}\text { Cumulative manufacturing } \\
\text { capabilities: An extended } \\
\text { model and new empirical } \\
\text { evidence }\end{array}$ & $\begin{array}{l}\text { Avella et al., } \\
2011\end{array}$ & $\begin{array}{l}\text { International } \\
\text { Journal of } \\
\text { Production } \\
\text { Research }\end{array}$ & $\begin{array}{l}\text { Se revisa el modelo de incompatibilidades } \\
\text { (trade-off) y cono de arena (sand cone). Se } \\
\text { usa el modelado de ecuaciones estructurales } \\
\text { (SEM) para mostrar evidencia empírica de la } \\
\text { existencia de efectos acumulativos en las } \\
\text { capacidades de manufactura al usar AMT. }\end{array}$ \\
\hline $\begin{array}{l}\text { A systematic review/survey } \\
\text { for JIT implementation. } \\
\text { Mexican maquiladoras as } \\
\text { case study }\end{array}$ & $\begin{array}{l}\text { García et al., } \\
2014\end{array}$ & $\begin{array}{l}\text { Computers in } \\
\text { Industry }\end{array}$ & $\begin{array}{l}\text { Se evalúa el impacto que tiene la } \\
\text { implementación adecuada de variables JIT } \\
\text { tales como compromiso organizacional, } \\
\text { canales de comunicación, empoderamiento, } \\
\text { etc. Se usa SEM para identificar las } \\
\text { relaciones y confirmar/rechazar las hipótesis. }\end{array}$ \\
\hline $\begin{array}{l}\text { The unique and } \\
\text { complementary effects of } \\
\text { manufacturing technologies } \\
\text { and lean practices on } \\
\text { manufacturing operational } \\
\text { performance }\end{array}$ & $\begin{array}{l}\text { Khanchanapong } \\
\text { et al., } 2014\end{array}$ & $\begin{array}{l}\text { International } \\
\text { Journal of } \\
\text { Production } \\
\text { Economics }\end{array}$ & $\begin{array}{l}\text { Se revisan los efectos del uso de AMT } \\
\text { (diseño, producción y administración) y } \\
\text { prácticas Lean (flujo, cliente, proceso, } \\
\text { suplidor, recursos humanos) en el } \\
\text { desempeño (coste, calidad, tiempo y } \\
\text { flexibilidad) de las empresas de manufactura } \\
\text { en Tailandia. }\end{array}$ \\
\hline
\end{tabular}

El número de estas investigaciones en entornos específicos de países en vías de desarrollo es muy reducido pues, hasta ahora, la comunidad científica se ha centrado más en identificar y categorizar las diferentes herramientas que constituyen las AMT y en crear modelos para su implantación, asumiendo la posibilidad de generalizar las conclusiones para todos los sectores. En cualquier caso, la comunidad científica ha llegado a un acuerdo generalizado de clasificar los recursos AMT a disposición de las empresas en dos grandes grupos: las tecnologías avanzadas de fabricación y las metodologías de fabricación (Khanchanapong et al., 2014). En este trabajo, el uso del 
término AMT incluirá tanto a las tecnologías avanzadas como a las metodologías usadas para la mejora de la productividad de las empresas. Se entenderá como tecnologías avanzadas de fabricación aquellas soportadas por microprocesadores o programa informáticos que se utilizan para diseñar y producir productos y controlar los procesos de fabricación; las metodologías de fabricación se referirán a las prácticas, los procedimientos, las técnicas y los conocimientos utilizados para gestionar y mejorar dichos productos y procesos. Partiendo de esta clasificación, en los próximos apartados se realiza una descripción general de las AMT más relevantes como punto de partida de la investigación a realizar.

\subsubsection{Tecnologías avanzadas de manufactura (AMT)}

Los avances en la tecnología informática y la electrónica experimentados en las últimas décadas han cambiado las estrategias de fabricación tradicionales, transformándolas desde procesos rígidos de producción en masa a sistemas flexibles y sumamente ágiles. De hecho, de acuerdo con Kotha y Swamidass (2000) y Koc y Bozdag (2009), la flexibilidad se ha convertido en la marca de un conjunto de nuevas tecnologías denominado Tecnologías Avanzadas de Manufactura (AMT) que se orientan a la aplicación de sistemas mecánicos, electrónicos y basados en computadoras para diseñar productos, y operar la producción. Las tecnológicas AMT que más se destacan en la producción científica son las siguientes:

- Diseño Asistido por Computador (CAD)

- Fabricación Asistida por Computador (CAM)

- Ingeniería Asistida por Computador (CAE)

- Control Numérico Computarizado (CNC)

- Planeamiento de Procesos Asistido por Computador (CAPP)

- Automatización mediante Controladores Lógicos Programables (PLC)

- Sistemas de Almacenaje y Recuperación Automática de productos (ASRS)

- Inspección óptica automática (o visión artificial)

- Robots

- Planificación de Requerimientos de Materiales (MRP)

- Planificación de Recursos Empresariales (ERP)

- Sistemas de Ejecución de Fabricación (MES)

- Intercambio Electrónico de Datos (EDI) 
Todas estas herramientas tecnológicas se utilizan en la industria debido a su potencial de dotar al sistema de mayor flexibilidad y reducir los costes al automatizar el diseño, la fabricación, el montaje y manejo de materiales. La Tabla 7 muestra una categorización final de las tecnológicas AMT a partir de la revisión de la literatura científica.

Tabla 7. Categorización de las tecnologías avanzadas de manufactura (AMT)

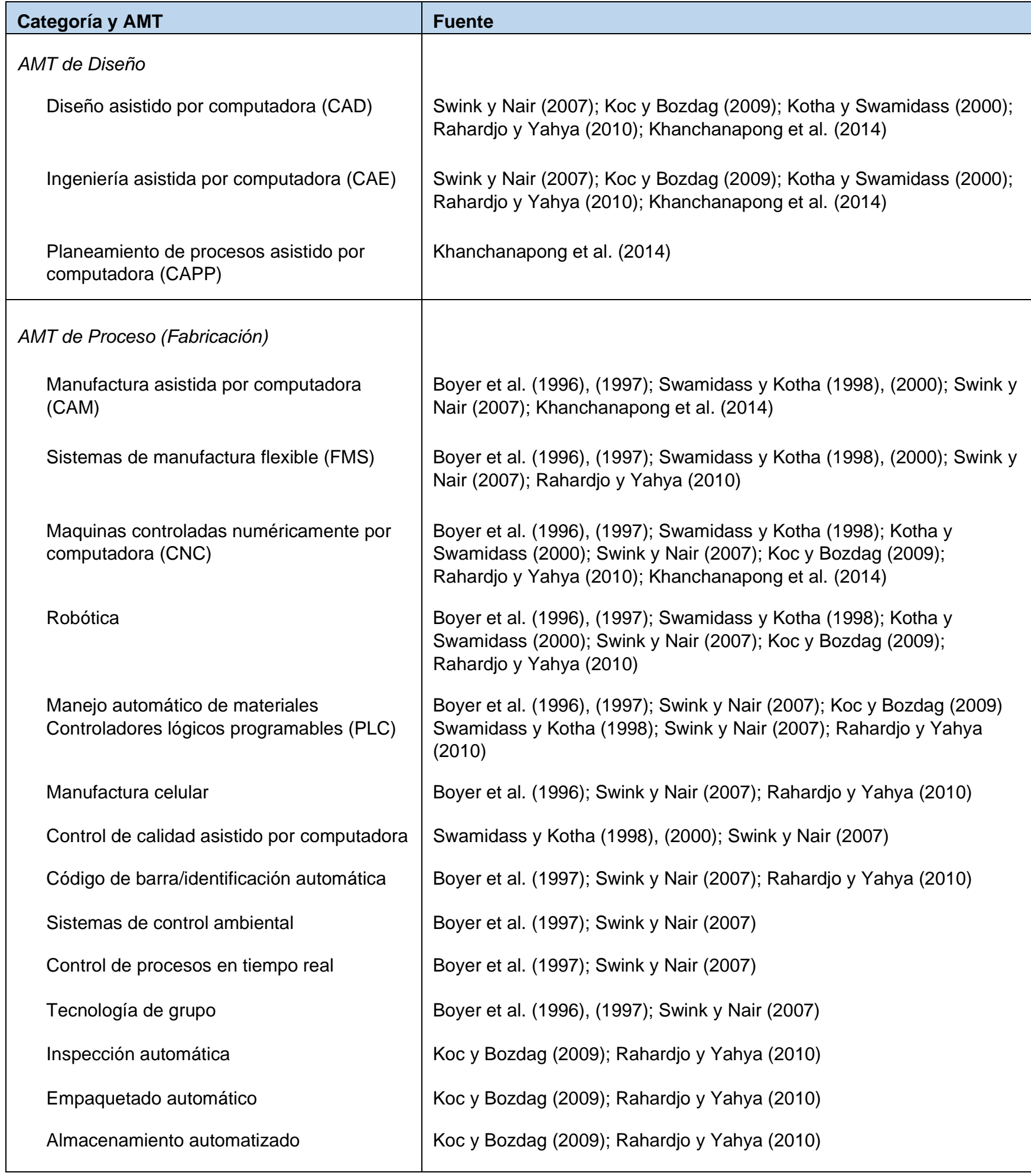


AMT de Planificación (Administración)

Sistemas de Intercambio Electrónico de Datos (EDI)

Justo-a-tiempo (JIT)

Control de Planta

Planificación de Requerimientos de Materiales (MRP)

Planificación de Recursos de Manufactura (MRPII)

Planificación de Recursos de la Empresa (ERP)

Correo electrónico

Automatización de la oficina

Sistemas basados en conocimiento

Sistemas de soporte a la decisión

Contabilidad basada en actividades

Redes locales (LAN) y anchas (WAN)

Control estadístico de procesos (SPC)

Sistemas expertos

Gestión de inventarios por computadora

Gestión del mantenimiento

Gestión de la calidad total (TQM)
Swamidass y Kotha (1998); Kotha y Swamidass (2000); Swink y Nair (2007); Rahardjo y Yahya (2010)

Boyer et al. (1996); Swink y Nair (2007); Rahardjo y Yahya (2010); Khanchanapong et al. (2014)

Boyer et al. (1996); Swamidass y Kotha (1998); Kotha y Swamidass (2000); Swink y Nair (2007)

Boyer et al. (1996), (1997); Kotha y Swamidass (2000); Swink y Nair (2007); Rahardjo y Yahya (2010); Khanchanapong et al. (2014)

Boyer et al. (1996), (1997); Swink y Nair (2007); Kotha y Swamidass (2000); Rahardjo y Yahya (2010); Khanchanapong et al. (2014)

Swink y Nair (2007); Rahardjo y Yahya (2010); Khanchanapong et al. (2014)

Boyer et al. (1997); Swink y Nair (2007)

Boyer et al. (1997); Swink y Nair (2007)

Boyer et al. (1997); Swink y Nair (2007)

Boyer et al. (1997); Swink y Nair (2007)

Boyer et al. (1996), (1997); Swink y Nair (2007)

Koc y Bozdag (2009); Kotha y Swamidass (2000); Rahardjo y Yahya (2010)

Rahardjo y Yahya (2010)

Rahardjo y Yahya (2010)

Rahardjo y Yahya (2010)

Rahardjo y Yahya (2010)

Rahardjo y Yahya (2010); Khanchanapong et al. (2014)

Diferentes investigadores han categorizado las AMT tradicionales de distintas formas, algunos de manera simple, dividiéndolos en tecnologías duras y blandas (Small y Yasin, 1997), mientras otros despliegan clasificaciones más extensas. Kotha y Swamidass (2000) son de la opinión que las AMT se pueden ver como "herramientas que permiten a las empresas aumentar su capacidad de procesamiento de la información" y proponen una clasificación con cuatro categorías basada en las capacidades de procesamiento de información de un sistema: tecnologías de diseño de productos, tecnologías de procesos, tecnologías de logística/planificación y tecnologías de intercambio de información. Otros esquemas adicionales de categorización de AMT que han sido propuestos son: tecnologías directas, indirectas y administrativas (Beaumont et al., 2002), y planificación y control, gestión de recursos de información, diseño y desarrollo de productos, y automatización de fábrica (Sun et al., 2007). Sin embargo, Jonsson (2000), así como Swink y Nair (2007) argumentan que existe un acuerdo general en la literatura con respecto a una taxonomía de tres categorías en función del área de uso: 
tecnologías de diseño, tecnologías de procesamiento (fabricación) y tecnologías de planificación (administrativas).

A título de descripción general de las tecnologías AMT, se realizará una exposición general de las herramientas más relevantes para el entorno de trabajo objeto de estudio.

\subsubsection{Tecnologías avanzadas de diseño e ingeniería}

Llas tecnologías avanzadas de diseño son aplicaciones de software usadas para diseñar productos y preparar la información técnica de cara a la fabricación de los productos. Entre los ejemplos más importantes de estas tecnologías se encuentran:

- Diseño Asistido por Computador (CAD) - Permite crear representaciones graficas en dos o tres dimensiones de objetos físicos. Se utiliza con el propósito de ayudar en el diseño, creación, modificación, análisis y/u optimización de productos, lo que incrementa la productividad, aumenta la calidad y mejora la comunicación.

- Ingeniería Asistida por Computador (CAE) - Asiste en las diferentes tareas del análisis de ingeniería. Se utiliza para la simulación computarizada del desempeño de objetos físicos mediante el uso de algoritmos de análisis de elementos finitos (FEA), dinámica computacional de fluidos (CFD), dinámica multicuerpo (MBD), entre otros (Figura 4).

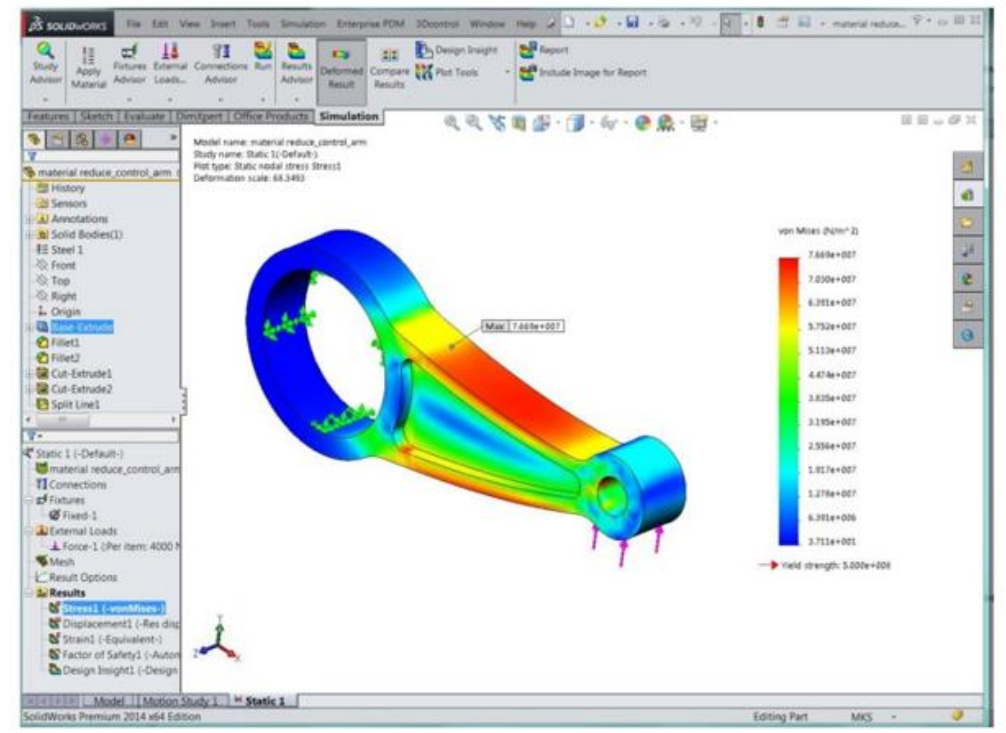

Fuente: www.capinc.com

Figura 4. Programa CD/CAM 
- Planeamiento de Procesos Asistido por Computador (CAPP) - Ayuda en la planificación de los procesos necesarios para fabricar una pieza de forma estructurada y replicable. Se utiliza para producir la secuencia de operaciones de manufactura, velocidades de corte, así como el listado de máquinas y herramientas necesarias para la fabricación de una pieza específica, conectando las aplicaciones CAD con la fabricación.

- Administración del Ciclo de Vida del Producto (PLM) - Gestión completa del ciclo de vida de un producto, desde su concepción, diseño, fabricación hasta su eliminación y/o reciclaje. Se utiliza como un sistema de gestión de la información de los productos, integrando datos, procesos, sistemas y personal en los diferentes niveles de gestión de la empresa.

\subsubsection{Tecnologías avanzadas de procesamiento (fabricación)}

Las tecnologías avanzadas de procesamiento son usadas para producir y fabricar productos, controlando los procesos de manufactura requeridos. Entre los ejemplos más importantes de estas tecnologías se encuentran:

- Fabricación Asistida por Computadora (CAM) - Aplicación informática que permite generar el código de control numérico $\mathrm{CN}$ necesario para fabricar utilizando maquinas CNC. Los programas CAM toman la geometría de una pieza diseñada en CAD y mediante la aplicación de algoritmos generan el código CN necesario. La utilización de la tecnología CAM permite acelerar el proceso de fabricación de piezas y optimizar el uso de los recursos tales como tiempo, materia prima, herramientas de corte, energía, etc (Figura 5).

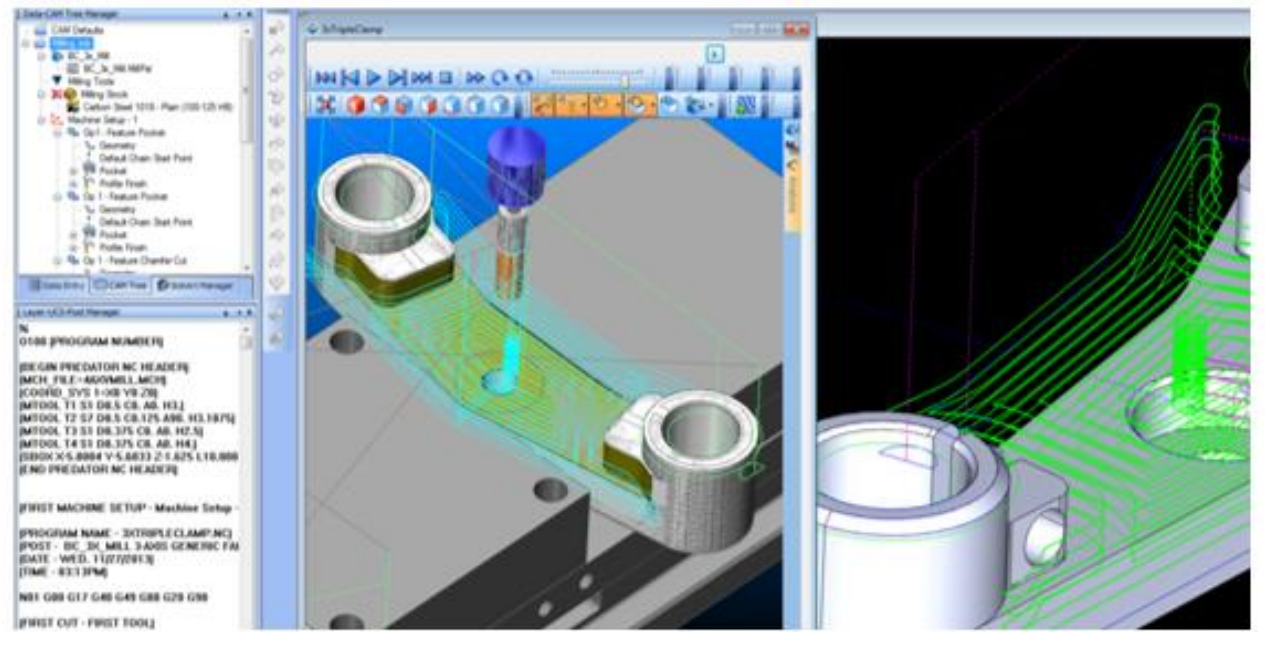

Fuente: www.bobcad.com

Figura 5. Generación de código NC con programa CAD/CAM 
- Control Numérico Computarizado (CNC) - Combinación de software y hardware que permite la automatización completa de los procesos de fabricación realizados en máquinas herramientas $\mathrm{CNC}$. Estas máquinas están dotadas de controles basados en microprocesador y de algoritmos que procesan e interpretan los comandos $\mathrm{CN}$, así como de actuadores que responden a dichos comandos y que utilizan múltiples herramientas para la fabricación de piezas.

- Controlador Lógico Programable (PLC) - Dispositivo industrial basado en microprocesador capaz de leer señales procedentes de diferentes tipos de sensores y controlar distintos tipos de actuadores, con el propósito de automatizar máquinas y procesos de fabricación. La utilización de estos dispositivos permite el control de procesos, mediante el uso de elementos eléctricos, neumáticos e hidráulicos de manera versátil, precisa y económica. En ciertos casos en donde el nivel de complejidad es más elevado, se hace uso de computadoras más poderosas para el control. Los sistemas industriales basados en PLC pueden crecer en gran complejidad cuando se combinan para soportar los sistemas de manutención y control de líneas automatizadas. Uno de estos casos es el desarrollo de los Sistemas de Almacenamiento y Recuperación Automática de Productos (ASRS), en donde se combina hardware y software para almacenar, buscar y recuperar objetos desde ubicaciones de almacenamiento establecidos de forma dinámica. Estos sistemas automáticos son utilizados en aplicaciones que tienen un alto volumen de movimiento de los objetos con almacenamiento controlados en ubicaciones preconfiguradas.

- Robots-Mecanismos poli-articulados controlados automáticamente que pueden ser programados con rutinas de ejecución que les permiten ser utilizados para el manejo de materiales y la automatización de procesos productivos. La utilización de estos dispositivos permite realizar operaciones de manufactura de gran complejidad y peligrosidad de forma rápida, repetitiva, precisa y segura. A pesar de que existen diferentes tipos de configuraciones de robots, la mayoría de ellos pueden ser categorizados como "brazos robóticos" y son usados para operaciones de pintura, ensamblado, empaquetado, soldadura, inspección, etc. Existen robots móviles que se usan para la carga y transporte de materiales tales como los Vehículos Guiados Automáticamente (AGV) que son muy utilizados en industrias de fabricación con niveles altos de automatización. 


\subsubsection{Tecnologías informáticas de planificación (administración)}

Las tecnologías informáticas de planificación son usadas para administrar procesos productivos y de gestión necesarios para el correcto desempeño de la función de manufactura. Entre los ejemplos más importantes de estas tecnologías se encuentran:

- Planificación de Requerimientos de Materiales (MRP) - Gestiona de manera integrada el plan de producción y el inventario que son usados en los procesos de fabricación de una empresa. Este sistema se utiliza para asegurar que los materiales necesarios para la producción y los productos que demandan los clientes son entregados a tiempo, que se manejan los niveles de inventario más bajos posibles y que se programan todas las actividades de fabricación, así como los programas de compra y entrega de manera óptima.

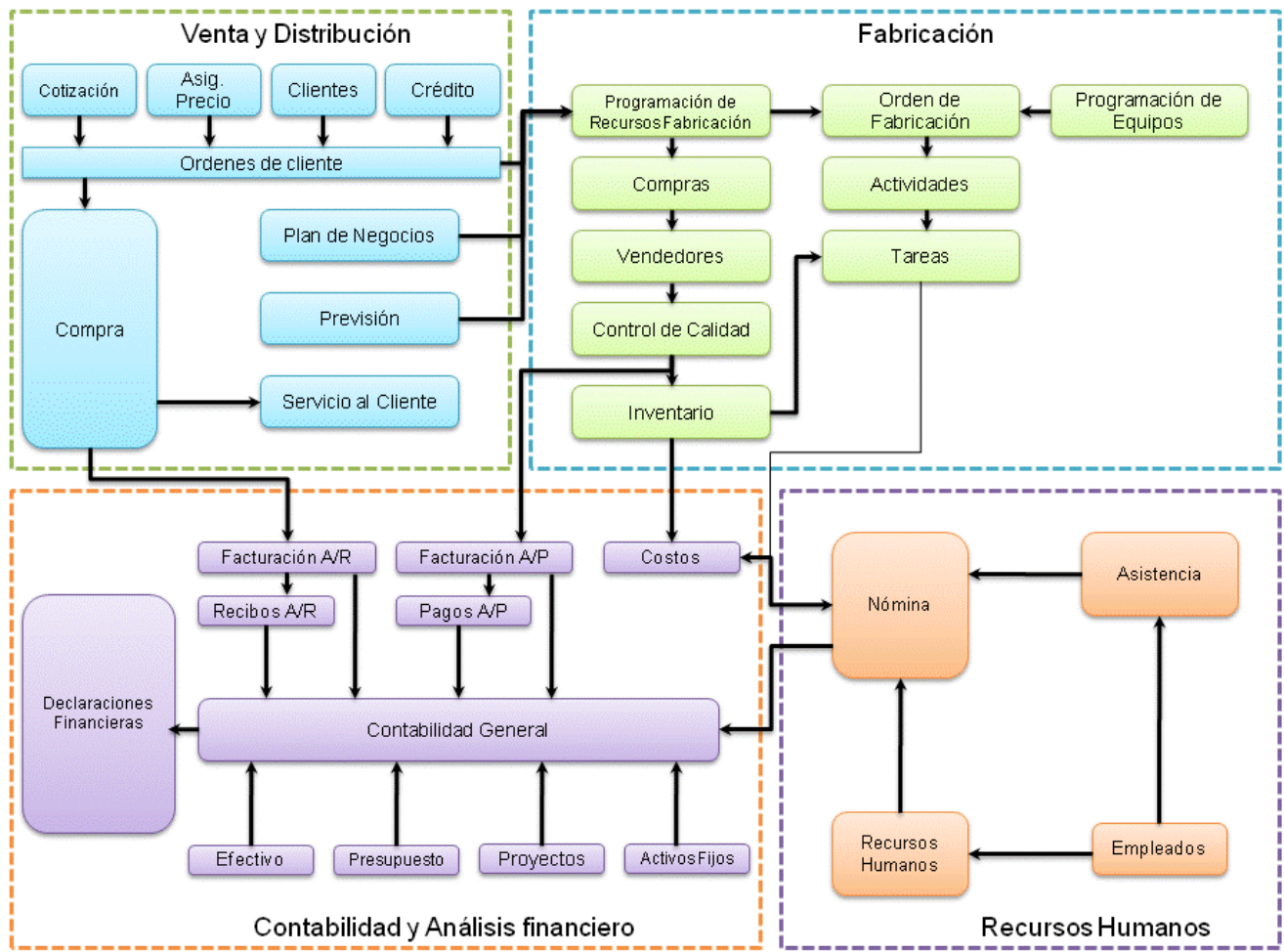

Fuente: Terón (2012)

Figura 6. Áreas funcionales principales cubiertas por sistemas ERP

- Planificación de los Recursos Empresariales (ERP) - Es una colección integrada de módulos de software que va más allá de un MRP, al permitir la administración de los principales procesos de negocio de una empresa. Este sistema es utilizado para recolectar, guardar, administrar e interpretar datos que luego son 
utilizados en procesos de planificación de operaciones de fabricación, compras y ventas, administración de inventarios, contabilidad (costes y pagos), etc. Estas aplicaciones facilitan el flujo de información entre todas las funciones del negocio, y la conexión de la empresa con sus clientes y proveedores (Figura 6).

- Sistemas de Ejecución de Fabricación (MES) - Sistemas informáticos encargados de enlazar el sistema de gestión de la empresa, generalmente un ERP, con los sistemas y controles que están al nivel operacional de la planta. Estos sistemas permiten una realimentación continua de datos logrando así una actualización de la información real de las órdenes ejecutadas y de los recursos empleados para la toma de decisiones operativas de la fábrica (Figura 7).

\begin{tabular}{|c|c|c|c|c|c|}
\hline \multicolumn{2}{|c|}{ Ventas } & \multicolumn{2}{|c|}{$\begin{array}{l}\text { Planificadores Recursos } \\
\text { Empresariales ERP }\end{array}$} & \multicolumn{2}{|c|}{$\begin{array}{c}\text { Gestión cadena suministro } \\
\text { SCM }\end{array}$} \\
\hline $\begin{array}{l}\text { CRM. Gestión } \\
\text { relación Clientes }\end{array}$ & E-Commerce & $\begin{array}{c}\text { Gestión } \\
\text { inventarios }\end{array}$ & MRP & $\begin{array}{c}\text { Gestión } \\
\text { subcontratas }\end{array}$ & $\begin{array}{c}\text { Logistica y } \\
\text { distribución }\end{array}$ \\
\hline $\begin{array}{l}\text { Estado } \\
\text { Recursos }\end{array}$ & $\begin{array}{l}\text { Lanzamiento } \\
\text { Ordenes }\end{array}$ & $\begin{array}{l}\text { Recolección } \\
\text { Datos }\end{array}$ & Gestión Calidad & \multicolumn{2}{|c|}{$\begin{array}{c}\text { Ingeniería de producto y } \\
\text { proceso }\end{array}$} \\
\hline $\begin{array}{l}\text { Trazabilidad } \\
\text { Ordenes }\end{array}$ & \multirow{2}{*}{\multicolumn{2}{|c|}{$\begin{array}{l}\text { M.E.S } \\
\text { Integración de datos } \\
\text { de producción }\end{array}$}} & $\begin{array}{l}\text { Monitorización } \\
\text { Procesos }\end{array}$ & & \\
\hline $\begin{array}{c}\text { Gestión } \\
\text { Mantenimiento }\end{array}$ & & & $\begin{array}{l}\text { Trazabilidad } \\
\text { Producto }\end{array}$ & $\begin{array}{l}\text { Ges } \\
\text { prod }\end{array}$ & $\begin{array}{l}\text { datos } \\
\text { PLM }\end{array}$ \\
\hline $\begin{array}{l}\text { Gestión } \\
\text { Habilidades }\end{array}$ & $\begin{array}{c}\text { Control } \\
\text { Documentación }\end{array}$ & $\begin{array}{l}\text { Secuenciación } \\
\text { Programación }\end{array}$ & $\begin{array}{c}\text { Analisis } \\
\text { Productividad }\end{array}$ & & $\mathrm{AM}$ \\
\hline
\end{tabular}

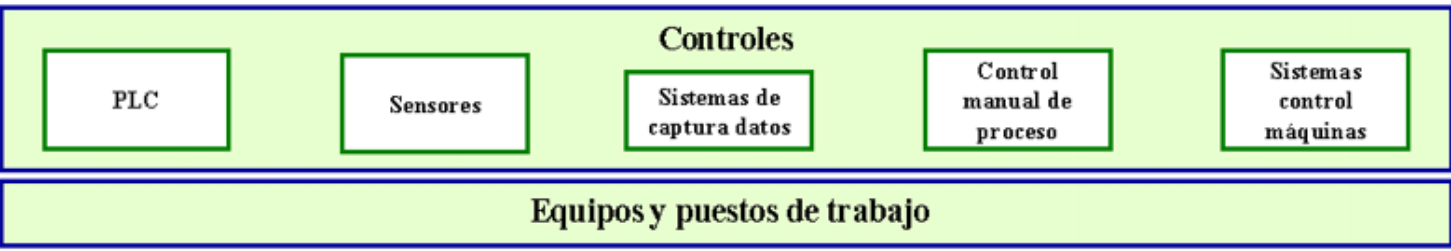

Fuente: Hernández, Pérez, Pérez y Vizán (2005)

Figura 7. Estructura e interacciones de un sistema MES

- Intercambio Electrónico de Datos (EDI) - Estándar de comunicación que permite el intercambio de datos entre los agentes de la cadena logística tales como órdenes de compra, facturas, etc. de forma electrónica entre empresas de manera segura y confiable. No requiere intervención humana en el procesado de la información recibida, ahorrando de esta forma dinero y tiempo a las empresas que lo utilizan. 


\subsubsection{Metodologías de manufactura para la mejora de procesos}

El término Manufactura de Clase Mundial (WCM) se usa para describir un conjunto de prácticas que fueron utilizadas inicialmente por empresas japonesas y alemanas sumamente exitosas para obtener un rendimiento superior (Petrillo et al., 2019). Estas prácticas incluyen habilidades y capacidades de la fuerza laboral y enfoques en mejora incremental (Flynn et al., 1999). Desde entonces muchos autores han utilizado su trabajo como base para identificar mejores prácticas que pueden conducir a un rendimiento superior.

En los últimos años estas mejores prácticas han incluido el uso de metodologías de manufactura centradas en las operaciones de las empresas y enfocadas en la mejora de los procesos. Estas metodologías fueron introducidas en la década de los ochenta y principios de los noventa entre las que se encuentran la Gestión de la Calidad Total (TQM), el "Lean Enterprise System" (sistema de la empresa esbelta), Six Sigma, Lean Six Sigma (LSS), y Reingeniería de Procesos de Negocio (BPR), siendo los tres primeros los métodos más conocidos y utilizados en la industria (Bozdogan, 2014). Estas metodologías se componen de diferentes prácticas que a veces se superponen entre metodologías y que en algunos casos son complementarias entre si (Khanchanapong, et al., 2014). Diferentes estudios han confirmado el impacto que las metodologías tienen en el desempeño de una empresa (Shah et al., 2008; Khanchanapong et al., 2014; Panwar et al., 2018),

\subsubsection{Gestión de la Calidad Total (TQM)}

TQM es una metodología de gestión que fomenta dentro de las organizaciones un clima que busca la mejora continua en la calidad de sus productos y servicios basada en la comprensión de las expectativas del cliente (Padhi, 2015). Su popularidad, que comenzó a principios de los ochenta, se atribuye a la "revolución de la calidad", dirigida por organizaciones estadounidenses que trataban de incorporar las mejores prácticas de las empresas japonesas. Sin embargo, sus orígenes se remontan a la década de 1930 con el desarrollo del control estadístico de procesos (SPC).

Como muestra la Figura 8, el modelo más sencillo de la administración basada en TQM considera 5 elementos principales. El primero de estos elementos es un entendimiento de las necesidades del cliente. El segundo elemento es una continua recolección y 
análisis de datos de todos los procesos de la empresa, lo que permite planificar los procesos de manera integrada para lograr alcanzar los objetivos trazados. Debido a que los clientes solo estarán satisfechos si los productos y servicios recibidos cumplen o sobrepasan sus expectativas, el tercer elemento es el uso de técnicas de administración de procesos que permitan alcanzar procesos estables y eficientes que sean capaces de alcanzar las necesidades del cliente. El cuarto elemento es un proceso continuo de mejora que busca mantener un desempeño incremental superior al esperado. Finalmente, para que el modelo sea exitoso es necesario tener la participación total de todos los miembros de la organización, lo que significa tener un liderazgo comprometido y empleados capaces, entrenados y empoderados (ASQ, 2015).

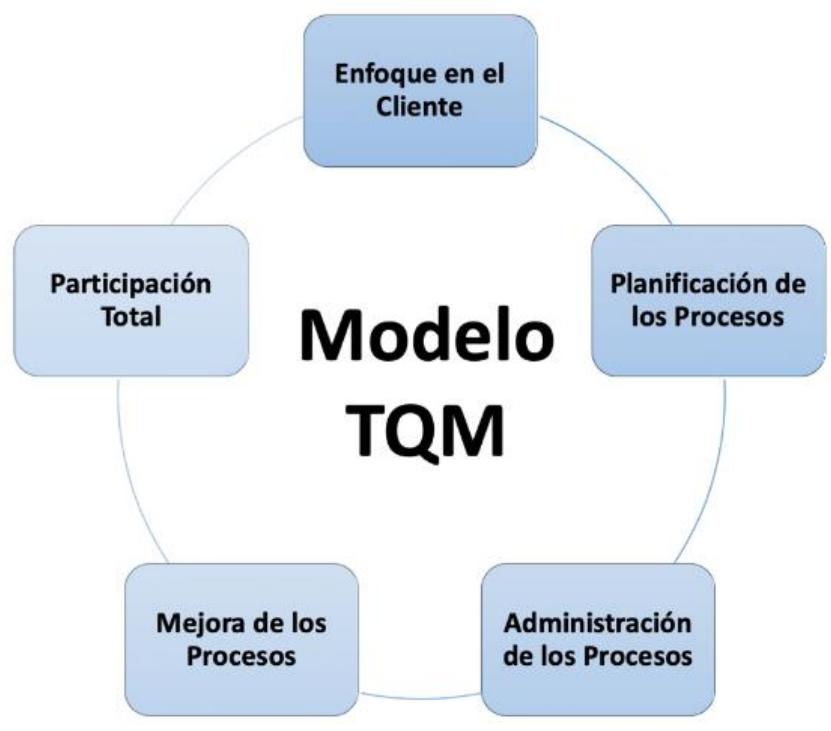

Fuente: www.edrawsoft.com

Figura 8. Modelo para la administración de la empresa basada en TQM

Bozdogan (2014) considera que la columna vertebral del TQM son ciertas prácticas, herramientas y técnicas específicas tales como el SPC, la detección de errores (PokaYoke), los círculos de calidad, el despliegue de la función de la calidad y el diseño robusto.

\subsubsection{Lean Manufacturing}

La fabricación delgada o Lean Manufacturing tiene su origen en el sistema de producción Just in Time (JIT) desarrollado en los años 50 por la empresa automovilística Toyota. Con la extensión del sistema a otros sectores y países se ha ido configurando 
un modelo que se ha convertido en el paradigma de los sistemas de mejora de la productividad asociada a la excelencia industrial.

Este sistema fue diseñado para crear sistemas más eficientes mediante la reducción de desperdicio y de aquellas actividades que no producen valor agregado (García et al., 2014). Los objetivos de la implementación de la manufactura esbelta en una empresa son aumentar la productividad, mejorar la calidad, reducir los tiempos de entrega y reducir costes (Wahab et al., 2013).

Lean se centra en mantener un flujo continuo en su producción al fabricar el artículo correcto, en el momento adecuado y en la cantidad apropiada (JIT), asegurándose que si hay algún defecto éste es identificado y detenido. Los cinco principios Lean incluyen la identificación de lo que es valioso para el cliente, encontrar el mapa de la cadena de valor, crear un flujo continuo que agregue valor al producto/cliente, establecer un sistema que "tira" (pull) del producto de una actividad a la otra y buscar la perfección del producto y de los procesos al identificar las actividades que agregan valor y desechar los desperdicios del sistema (Lean Enterprise Institute, 2017).

Las empresas que realmente tienen un alto grado de compromiso y que han conseguido resultados positivos con LM se caracterizan porque sus directivos apoyan firmemente el liderazgo en calidad, el establecimiento de grupos de mejora, la formación permanente y la delegación de responsabilidad en los trabajadores. La introducción de Lean Manufacturing supone un cambio en el enfoque de la concepción del trabajo por parte de los trabajadores pues otorga más responsabilidad a los niveles inferiores de la organización. Al ser los operarios los que están en permanente contacto con el medio de trabajo son también los primeros en observar cuáles son los problemas por resolver. En esta situación, la adopción de los principios promulgados por el sistema Lean implica una necesidad de reconfigurar completamente las formas de comunicación, colaboración y motivación en el seno de la empresa. Lean Manufacturing propugna la implicación del personal trabajando en grupos multidisciplinares cuyos miembros se comprometan con el cambio, aporten sus conocimientos y aprendan a mejorar de forma continua.

De forma tradicional se ha recurrido al esquema de la "Casa del Sistema de Producción Toyota" para visualizar rápidamente la filosofía que encierra el Lean y las numerosos técnicas y herramientas disponibles para su aplicación. Se explica utilizando una casa 
porque ésta constituye un sistema estructural que es fuerte siempre que los cimientos y las columnas lo sean; una parte en mal estado debilitaría todo el sistema. La Figura 9 representa una adaptación actualizada de este modelo en donde se reflejan las diferentes herramientas jerarquizadas de esta metodología (Hernández y Vizán, 2013).

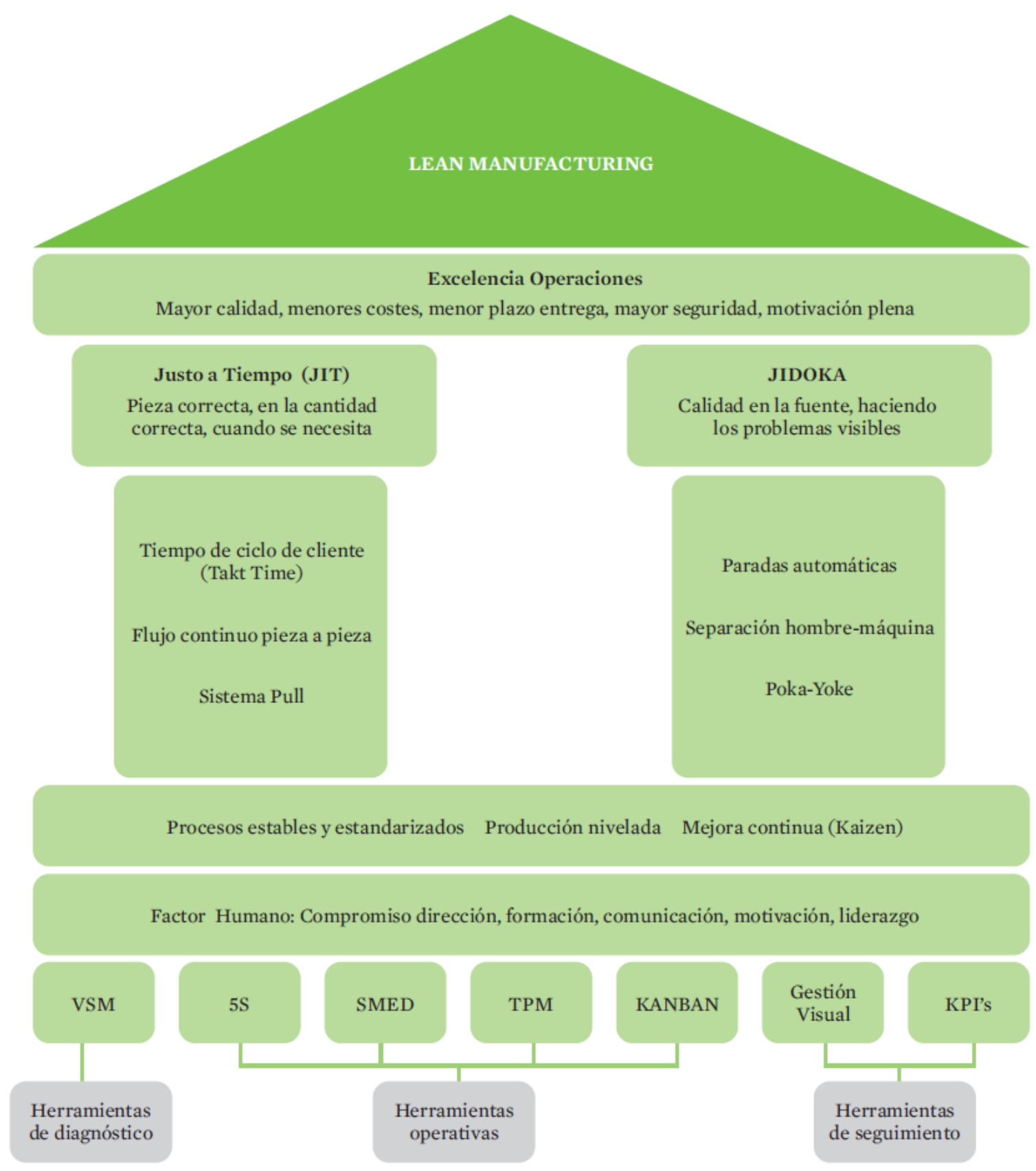

Fuente: Hernández y Vizán, 2013

Figura 9. Modelo Lean Manufacturing 


\subsubsection{Six Sigma}

Seis Sigma es una metodología basada en las ideas de TQM, cuyo principal objetivo es garantizar la mejora continua mediante la reducción de todas las fuentes de variabilidad de proceso o de producto no deseadas. Aplicable en entornos en donde los procesos se puedan medir, analizar y controlar, fue introducido a mediados de la década de los ochenta por Motorola, popularizado por General Electric (GE), y adoptado por varias empresas de todo el mundo. Su herramienta principal es un procedimiento de mejora o ciclo llamado DMAIC que, como muestra la Figura 10, significa definir, medir, analizar, mejorar y controlar (Mast y Lokkerbol, 2012) y que permite dirigir el proceso de mejora en cualquier industria de forma estructurada y lógica (Ocampo y Pavón, 2012). La metodología interconecta herramientas como SPC, gráficos de control, pruebas de significancia estadística como Chi-Cuadrado, t-test y ANOVA, diseño de experimentos (DOE), análisis modal de fallos y efectos (AMFE), despliegue de la función de calidad (QFD), entre otros (Bozdogan, 2014).

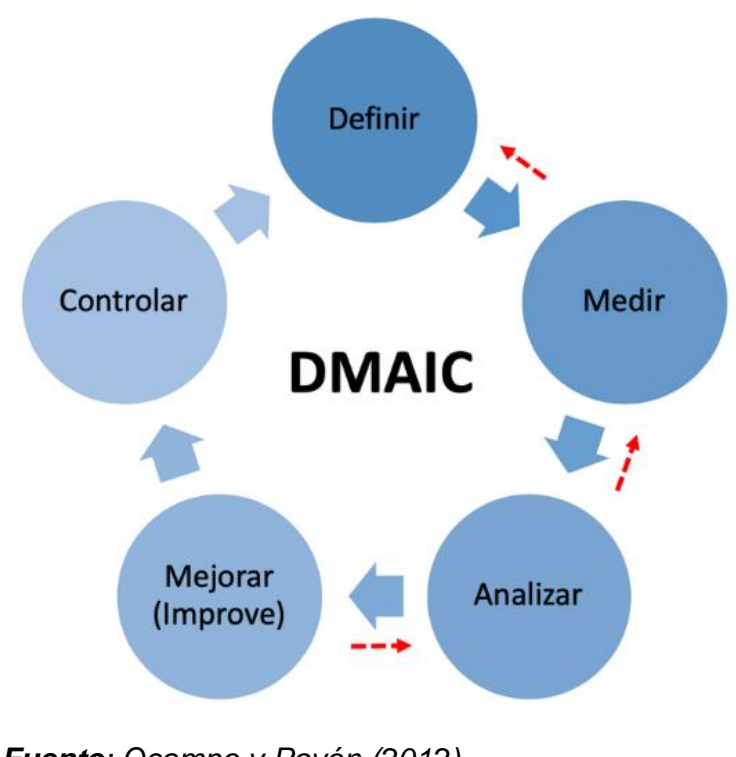

Fuente: Ocampo y Pavón (2012)

Figura 10. Principios de implementación de Lean

Seis Sigma se ha convertido en un conjunto de conceptos de mejora de calidad con un procedimiento bien establecido y un programa de capacitación formal de varios niveles que llegan hasta la certificación cinturón negro (Black Belt) 


\subsection{Técnicas y herramientas para el análisis empírico}

Como se explicó previamente, debido al gran potencial que tienen las tecnologías y metodologías de manufactura de mejorar el rendimiento de fabricación de las empresas, diferentes investigadores han estudiado los efectos de la aplicación de estas herramientas en el rendimiento de las operaciones. Dicho análisis requiere del uso de herramientas para la recolección y el análisis de la información tal como el método Delphi, las pruebas estadísticas de validez de contenido y criterio, el análisis factorial y el modelado de ecuaciones estructurales.

\subsubsection{El método Delphi}

El método Delphi es una técnica de comunicación de grupo ampliamente utilizada y aceptada que se usa con el propósito de alcanzar unidad de opinión entre expertos con respecto a algún tema en específico (Scott, 2000; Hung et al., 2008). El método puede utilizarse para buscar el consenso, el acuerdo o la asociación entre las opiniones de los expertos mediante el uso de diferentes índices estadísticos (Meijering et al., 2013). Esta técnica se basa en la premisa que múltiples personas piensan mejor que una.

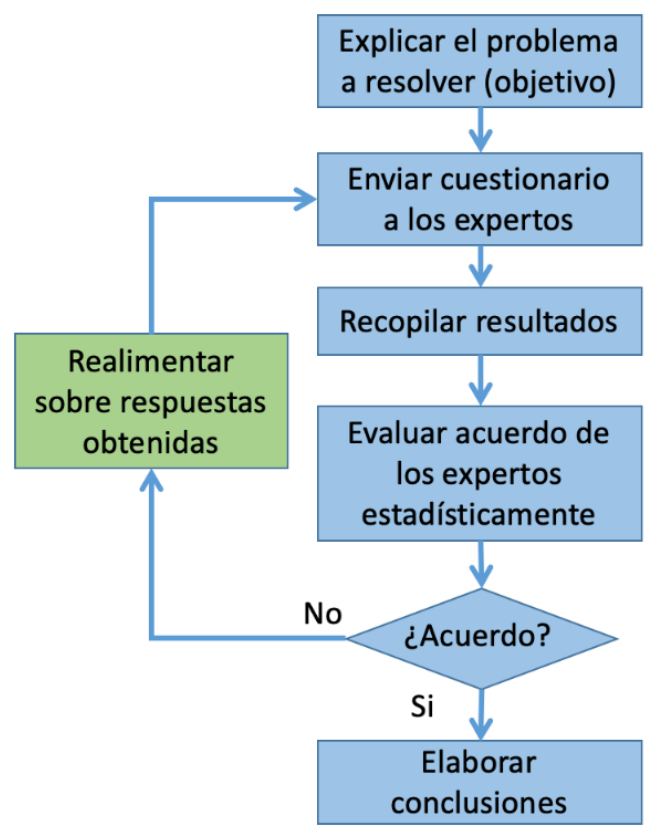

Figura 11. Diagrama de flujo de un proceso Delphi típico

Como se muestra en la Figura 11, el método utiliza cuestionarios o encuestas para presentar a los expertos el tema a discutir y el análisis se hace mediante el uso de 
evaluaciones cuantitativas y comentarios escritos. Debido a que el propósito de la técnica es dirigir al grupo hacia un consenso, es necesario brindar realimentación sobre las respuestas obtenidas para dar la oportunidad a los expertos de reconsiderar sus respuestas originales bajo la luz de las respuestas del resto de sus compañeros.

De acuerdo con Hsu y Sandford (2007) y Skulmoski et al., (2007), algunos de los principios de funcionamiento de esta técnica son:

- El uso de encuestas, en papel o computarizadas, para presentar el tema a discutir y recolectar sus opiniones.

- El anonimato de los expertos utilizados durante el proceso de recolección de información, para evitar sesgo en las opiniones y reducir los efectos de individuos dominantes.

- Varias rondas de encuestas con realimentación controlada de la iteración anterior mediante resúmenes, para buscar reducir el efecto del ruido típico del trabajo en equipo e ir creando consenso entre los expertos.

- El uso de técnicas de análisis estadístico para determinar acuerdo y elaborar las conclusiones finales reduciendo así la presión de grupo sobre cada individuo y asegurando un análisis objetivo e imparcial.

A pesar de que en teoría el proceso puede ser iterado continuamente hasta lograr consenso, generalmente tres iteraciones son suficientes para recolectar los datos necesarios y para alcanzar un acuerdo.

\subsubsection{Pruebas estadísticas}

\section{Alfa de Cronbach}

Cuando se diseña un instrumento para obtener información de una muestra de sujetos, es necesario validar que los ítems que han sido seleccionados son relevantes y representativos del constructo que se está estudiando. Esto se hace para asegurarse que los elementos utilizados en el instrumento (encuesta) realmente miden las dimensiones que se pretenden evaluar. Una de las herramientas más usadas para medir la fiabilidad de la consistencia interna de instrumentos de recolección de datos que usan escalas continuas (no dicotómicas) es el Alfa de Cronbach (Peterson, 1994). Esta prueba estadística mide la correlación esperada entre 2 pruebas que miden el mismo constructo, es decir mide si los ítems del instrumento pertenecen al mismo constructo 0 
miden el mismo constructo. El valor mínimo de aceptación de la fiabilidad de un instrumento para trabajos exploratorios es 0.6 (Nunnally y Bernstein, 1994) y para estudios confirmatorios es de 0.7 (Maldonado Guzmán y Martínez Serna, 2012).

\section{$\underline{\text { Análisis Factorial }}$}

Otra herramienta usada para medir la consistencia de los constructos es el análisis factorial (FA), el cual tiene como propósito principal reducir la cantidad de datos que se usan para explicar la correlación entre variables, identificando un único factor que puede ser usado para representar este grupo de variables (Hallgren, 2007). Esta reducción se hace identificando aquellas combinaciones lógicas de las variables observadas que explican de forma más concreta su comportamiento y variación en términos de un número menor de variables latentes denominadas factores (Johnson y Wichern, 2002). Por lo tanto, el análisis de factores es usado para separar grupos de variables que presentan altas correlaciones dentro de todo el grupo y a la misma vez baja correlación con otros grupos de variables. Las dos aplicaciones más comunes del análisis factorial son el Análisis Exploratorio de Factores (EFA), que se usa para identificar combinaciones lógicas de variables dentro de un conjunto de datos y el Análisis Confirmatorio de Factores (CFA) que permite confirmar que ciertos indicadores definidos a priori son en efecto dimensiones de una variable en particular.

Para lograr diferenciar de forma más clara que elementos se correlacionan mejor entre sí, los datos obtenidos en cada variable son rotados. Existen cinco diferentes métodos para realizar esta rotación; tres siguen una metodología ortogonal (Varimax, Quartimax y Equimax) y dos una oblicua (Direct Oblimin y Promax). De estos cinco tipos, Varimax es la técnica más utilizada, ya que minimiza el número de variables con cargas extremas y permite la rápida identificación de las variables con los factores (Gaskin, 2015). Después de la rotación de los datos se debe buscar extraer los factores presentes. Los tres métodos principales para la extracción de factores son el Análisis de Componentes Principales (PCA), la Factorización de Eje Principal (PAF) y la Máxima Verosimilitud $(\mathrm{ML})$. De estos tres métodos el más utilizado en la literatura es el PCA, probablemente por ser una solución más bondadosa con las variables a la hora de predecir y revelar la estructura interna de los datos. En contraste, el método más estricto es el ML, el cual maximiza la diferencia entre los factores (Rencher, 2005). Una de las ventajas de este método es que provee un estimado del ajuste del modelo generado, además de ser el 
método que utiliza el popular software estadístico IBM SPSS Amos, usado para el Modelado de Ecuaciones Estructurales (SME).

Al final, es posible tener un modelo valido si se descartan aquellos elementos que tienen cargas muy bajas (menores a 0.7 ) y que presentan baja comunalidad. Sin embargo, la mejor forma de saber que los factores se han identificado adecuadamente es realizando un CFA después de haber identificado los elementos y factores usando un EFA. En ambos casos es necesario confirmar que el tamaño de la muestra utilizado es el adecuado, esto se hace mediante la prueba de Kaiser-Meyer-Olkin (KMO), considerando idóneo un conjunto de datos que presente un valor superior a 0.6 (Sharma, 1996). También se debe asegurar que los datos recogidos son apropiados para factorización al observar si la prueba de esfericidad de Bartlett es significativa (Pinjala et al., 2006).

El método de estimación más comúnmente utilizado para el cálculo de CFA es el de máxima verisimilitud (ML). De acuerdo con Hair et al., (2010), la validez discriminante del modelo evaluado usando CFA puede asegurarse al confirmar que tanto la Varianza Máxima Compartida (MSV) como la Media de la Varianza Compartida (ASV) están por debajo de la Media de la Varianza Extraída (AVE). En el caso de la validez convergente, esta se establece revisando que la AVE sea superior a 0.5 . Sin embargo, debido a que la AVE es una medida muy estricta y conservadora, también se puede evaluar asegurando que la Confiabilidad Compuesta (CR) es superior a 0.7 (Malhotra y Dash, 2011). Finalmente, la bondad de ajuste del modelo se puede determinar revisando que ciertas métricas se encuentren en los rangos permitidos tales como $\chi 2 / d$. $f$., el Índice de Ajuste Comparativo ( $\mathrm{CFI}$ ), el Error Cuadrático Medio de Aproximación (RMSEA) y la Raíz Normalizada Cuadrada Media Residual (SRMR) como se muestra en la Tabla 8 (Hair et al., 2010).

Tabla 8. Valores frontera para determinar bondad de ajuste de un modelo

\begin{tabular}{|c|c|}
\hline Medida & Valor frontera \\
\hline$\chi 2 / d . f$. & $<3$ bueno; $<5$ algunas veces aceptable \\
\hline CFI & $>0.95$ grandioso; $>0.90$ tradicional; $>0.80$ algunas veces permisible \\
\hline RMSEA & $<0.05$ bueno; $0.05-0.10$ moderado; $>0.10$ malo \\
\hline SRMR & $<0.09$ \\
\hline
\end{tabular}




\subsubsection{Varianza de método común}

Cuando los datos son obtenidos a través de un diseño de investigación transversal, mediante una encuesta que es contestada por los mismos informantes y durante el mismo periodo de tiempo, la varianza atribuida al método de medición, también conocida como varianza del método común, puede sesgar los estimados de la verdadera relación entre los constructos teóricos de interés (Bagozzi y Yi, 1990; Swink et al., 2005). Por lo tanto, la varianza de método puede inflar o desinflar las relaciones observadas entre los constructos. Una forma de confirmar que no existe sesgo por la presencia de varianza de método común (CMB) es llevar a cabo un EFA con todas las variables estudiadas, pero buscando extraer un solo factor y realizando el análisis sin rotar los factores. Si el factor que emerge del análisis explica más del $50 \%$ de la varianza del modelo, entonces una cantidad sustancial de varianza de método común está presente en el modelo. A este método se le conoce como prueba de factor único de Harman (Kathuria, 2000; Steensma et al., 2005; Kroes y Ghosh, 2010).

\section{Nivel de acuerdo}

Al hacer uso de un análisis de expertos es necesario calcular la concordancia que existe entre las opiniones de estos expertos (Escobar y Cuervo, 2008). La confiabilidad de este juicio es determinada por el grado de acuerdo existente entre ellos, el cual puede variar desde un porcentaje de acuerdo hasta el consenso total (Warrens, 2012). Para determinar el grado de acuerdo, tomando en consideración el acuerdo esperado por el azar, pueden usarse diferentes herramientas estadísticas tales como el cálculo del coeficiente de correlación de Kendall y el coeficiente de Kappa. El coeficiente de correlación de Kendall ( $W$ ) permite calcular el nivel de acuerdo que existe entre un grupo de personas y, de esta forma, medir a través de la unidad de criterio del grupo, que todos ellos tienen el mismo nivel de experiencia o conocimiento (Siegel y Castellan, 1988). Para calcular el coeficiente es necesario pedirles a los expertos que ordenen un grupo de variables o elementos de menor a mayor (ranking), de acuerdo con su grado de importancia relativa. Las respuestas obtenidas son utilizadas con la siguiente ecuación (Zaiontz, 2014):

$$
W=\frac{12 R}{m^{2}\left(k^{2}-k\right)}(1)
$$

En donde 


$$
\begin{gathered}
R=\sum_{i=1}^{k}\left(R_{i}-\bar{R}\right)^{2} \\
R_{i}=\sum_{j=1}^{m} r_{i j}(3) \\
\bar{R}=\frac{1}{k} \sum_{i=1}^{k}\left(\sum_{j=1}^{m} r_{i j}\right)
\end{gathered}
$$

Entendiendo que $r$ es el orden de importancia desde 1 hasta $k$ para un número de variables $k$ por parte de $m$ jueces, en donde el juez $j$ evalúa la variable $i$. Por lo tanto, el coeficiente de concordancia Kendall puede ser calculado usando la siguiente ecuación:

$$
W=\frac{12\left(\sum_{i=1}^{k}\left(\sum_{j=1}^{m} r_{i j}-\frac{1}{k} \sum_{i=1}^{k}\left(\sum_{j=1}^{m} r_{i j}\right)\right)^{2}\right)}{m^{2}\left(k^{2}-k\right)}
$$

Si el valor de $W$ es 1, entonces ha existido unanimidad por parte de los jueces, lo que significa que cada uno de ellos ha asignado el mismo orden a las variables y se puede asumir que el grupo de jueces es experto en el tema en cuestión. Si Wes 0 esto significa que no existe acuerdo entre los jueces y sus respuestas son básicamente aleatorias, lo que presupone que los jueces seleccionados no se consideran expertos en el tema en cuestión. Valores intermedios indican diferentes grados de acuerdo, con un valor de $W$ $>0.8$ considerándose un excelente acuerdo. El coeficiente de Kappa se usa para medir el acuerdo entre dos expertos mediante el uso de una tabla de contingencia cuando se cuenta con datos nominales. En la literatura se documenta el uso de algunas adaptaciones de este coeficiente tales como Kappa de Cohen para ítems cualitativos, Kappa de Cohen con pesos cuando se tienen datos ordinales, o Kappa de Fleiss en el caso de tener más de dos expertos (Sim y Wright, 2005). Por lo tanto, cuando las preguntas para los expertos son dicotómicas, el acuerdo entre los expertos puede ser calculado mediante el coeficiente de Kappa de Fleiss ( $k$ ). La fórmula usada para calcular este índice es la siguiente (Zaiontz, 2014):

$$
k=\frac{p_{a}-p_{s}}{1-p_{s}}(6)
$$

En donde 


$$
\begin{gathered}
p_{a}=\frac{1}{m n(m-1)}\left[\sum_{i=1}^{n} \sum_{j=1}^{k} x_{i j}^{2}-m n\right](7) \\
p_{s}=\sum_{j=1}^{k} q_{j}^{2}(8) \\
q_{j}=\frac{1}{n m} \sum_{i=1}^{n} x_{i j}(9)
\end{gathered}
$$

Entendiendo que $\mathrm{n}$ es el número de variables, $\mathrm{k}$ es el número de categorías de evaluación, $\mathrm{m}$ el número de jueces para cada variable y $x_{i j}=$ el número de jueces que asignan la categoría j a la variable i. Por lo tanto, el coeficiente de Kappa de Fleiss (k) puede ser calculado usando la siguiente ecuación:

$$
k=\frac{\left(\frac{1}{m n(m-1)}\left[\sum_{i=1}^{n} \sum_{j=1}^{k} x_{i j}^{2}-m n\right]\right)-\left(\sum_{j=1}^{k}\left(\frac{1}{n m} \sum_{i=1}^{n} x_{i j}\right)^{2}\right)}{1-\sum_{j=1}^{k}\left(\frac{1}{n m} \sum_{i=1}^{n} x_{i j}\right)^{2}}(10)
$$

A pesar de que no existe una medida de significancia universalmente aceptada para este coeficiente, Landis y Koch (1977) propusieron una escala para interpretar el coeficiente k que ha sido usada por otros investigadores ( $\mathrm{Li}$, Ragu-Nathan, Ragu-Nathan y Subba Rao, 2006) y que se presenta en la Tabla 9. En este trabajo de investigacion se usará esta propuesta como guia siguiendo el ejemplo de Fleiss (1981) quien uso valores arriba de 0.6 para determinar un acuerdo aceptable entre los jueces.

Tabla 9. Tabla de interpretación de valores de coeficiente Kappa de Fleiss

\begin{tabular}{|c|c|}
\hline Coeficiente $\boldsymbol{k}$ & Interpretación \\
\hline$<0$ & Acuerdo pobre \\
\hline $0.01-0.20$ & Acuerdo leve \\
\hline $0.21-0.40$ & Acuerdo justo \\
\hline $0.41-0.60$ & Acuerdo moderado \\
\hline $0.61-0.80$ & Acuerdo sustancial \\
\hline $0.81-1.00$ & Acuerdo casi perfecto \\
\hline
\end{tabular}

\section{Pruebas de hipótesis}

Las pruebas de hipótesis son el uso de la estadística para determinar la probabilidad de que cierta hipótesis planteada sea cierta. Por lo general esta prueba se hace siguiendo cuatro pasos (Weisstein, 2019): 
1. Plantear una hipótesis nula en las que las observaciones son el resultado del azar y una alternativa en las que las observaciones muestran un efecto real.

2. Identificar una prueba estadística (Tabla 10) que pueda ser usada para evaluar la veracidad de la hipótesis nula.

3. Calcular el valor $P$, que es la probabilidad que una prueba estadística sea obtenida asumiendo que la hipótesis nula es cierta. Mientras más pequeño sea el valor $P$, más grande es la evidencia en contra de la hipótesis nula.

4. Comparar el valor $P$ a un valor de significancia $\alpha$ aceptable. Si $p<\alpha$ significa que el efecto observado es estadísticamente significativo por lo que se rechaza la hipótesis nula y la hipótesis alternativa es válida.

Tabla 10. Pruebas paramétricas y no-paramétricas

\begin{tabular}{|c|c|c|}
\hline Tipo de Prueba & Prueba Paramétrica & Equivalente No-Paramétrico \\
\hline \multirow{4}{*}{$\begin{array}{l}\text { Para una } \\
\text { Muestra }\end{array}$} & \multirow{4}{*}{ Medias } & Ji Cuadrado \\
\hline & & Binomial \\
\hline & & Rachas \\
\hline & & Kolmogorov - Smirnov \\
\hline \multirow{4}{*}{$\begin{array}{c}\text { Para dos } \\
\text { Muestras } \\
\text { Independientes }\end{array}$} & \multirow{2}{*}{$\begin{array}{c}\text { Levene para igualdad } \\
\text { de Varianzas }\end{array}$} & U de Mann Whitney \\
\hline & & Reacciones Extremas de Moses \\
\hline & \multirow{2}{*}{$\begin{array}{l}\text { T de igualdad de } \\
\text { Medias }\end{array}$} & Kolmogorov - Smirnov \\
\hline & & Rachas de Wald - Wolfowitz \\
\hline \multirow{2}{*}{$\begin{array}{c}\text { Para varias } \\
\text { Muestras } \\
\text { Independientes }\end{array}$} & \multirow{2}{*}{ Anova de Factor } & Kruskal - Wallis \\
\hline & & de la Mediana \\
\hline \multirow{3}{*}{$\begin{array}{c}\text { Para dos } \\
\text { Muestras } \\
\text { Relacionadas }\end{array}$} & \multirow{3}{*}{ Correlación Pearson } & Wilcoxon \\
\hline & & de los Signos \\
\hline & & Spearman \\
\hline \multirow{3}{*}{$\begin{array}{l}\text { Para varias } \\
\text { Muestras } \\
\text { Relacionadas }\end{array}$} & \multirow{3}{*}{ Anova de Factor } & Friedman \\
\hline & & Coeficiente de Concordancia W de Kendall \\
\hline & & Cochran \\
\hline
\end{tabular}

Cuando los datos que están siendo analizados siguen una distribución normal y se cuenta con una muestra lo suficientemente grande, es conveniente usar pruebas paramétricas para probar las hipótesis. Las pruebas paramétricas producen resultados confiables aun cuando los grupos de datos analizados tienen diferentes cantidades de variabilidad y, debido a su mayor potencia estadística, tienen una mayor probabilidad de detectar los efectos existentes. Sin embargo, cuando no se puede asumir la normalidad de los datos, se cuenta con una muestra pequeña o cuando los datos son de tipo ordinal, 
es mejor hacer uso de las pruebas no-paramétricas (Conover, 2000; Berenson, Levine y Krehbiel, 2006).

\subsubsection{Modelado de ecuaciones estructurales}

El modelado de ecuaciones estructurales (SEM), también conocido como análisis estructural de covarianza, es una técnica estadística multi-variante que utiliza análisis de regresión, análisis factorial y modelado simultaneo de ecuaciones para probar y estimar las relaciones causa-efecto existentes y los supuestos cualitativos sobre causalidad de un grupo de variables (Hallgren, 2007). Estos modelos están teniendo cada vez más difusión entre las empresas debido a su utilidad en descubrir relaciones existentes entre procesos o áreas dentro de dichas empresas. Varios investigadores en administración de operaciones han usado SEM para identificar constructos multidimensionales no observables y analizar sus relaciones estructurales (Shah y Goldstein, 2006; Gröbler y Grübner, 2006).

El conocer estas relaciones y la magnitud de su influencia permite anticipar las consecuencias de acciones de mejora en las diferentes áreas de la empresa (Caballero, 2006).

Como se observa en la Figura 12, en este tipo de modelos las relaciones causales entre variables latentes y las variables manifiestas se expresan mediante diagramas de rutas, en donde las flechas indican la dirección de la influencia que tiene una variable sobre la otra. A estos diagramas se les conoce como diagramas causales o diagramas estructurales. Por lo tanto, los modelos de ecuaciones estructurales están conformados por un modelo estructural que muestra la relación existente entre las variables latentes y por modelos de medición que examinan las relaciones entre las variables latentes y sus mediciones o componentes. A partir de estas relaciones se crean las ecuaciones estructurales que combinan las variables observables (modelo externo) y las latentes (modelo interno). Estas variables latentes son variables que no se miden directamente, sino que son estimadas a partir de la covarianza de distintas variables entre sí. 


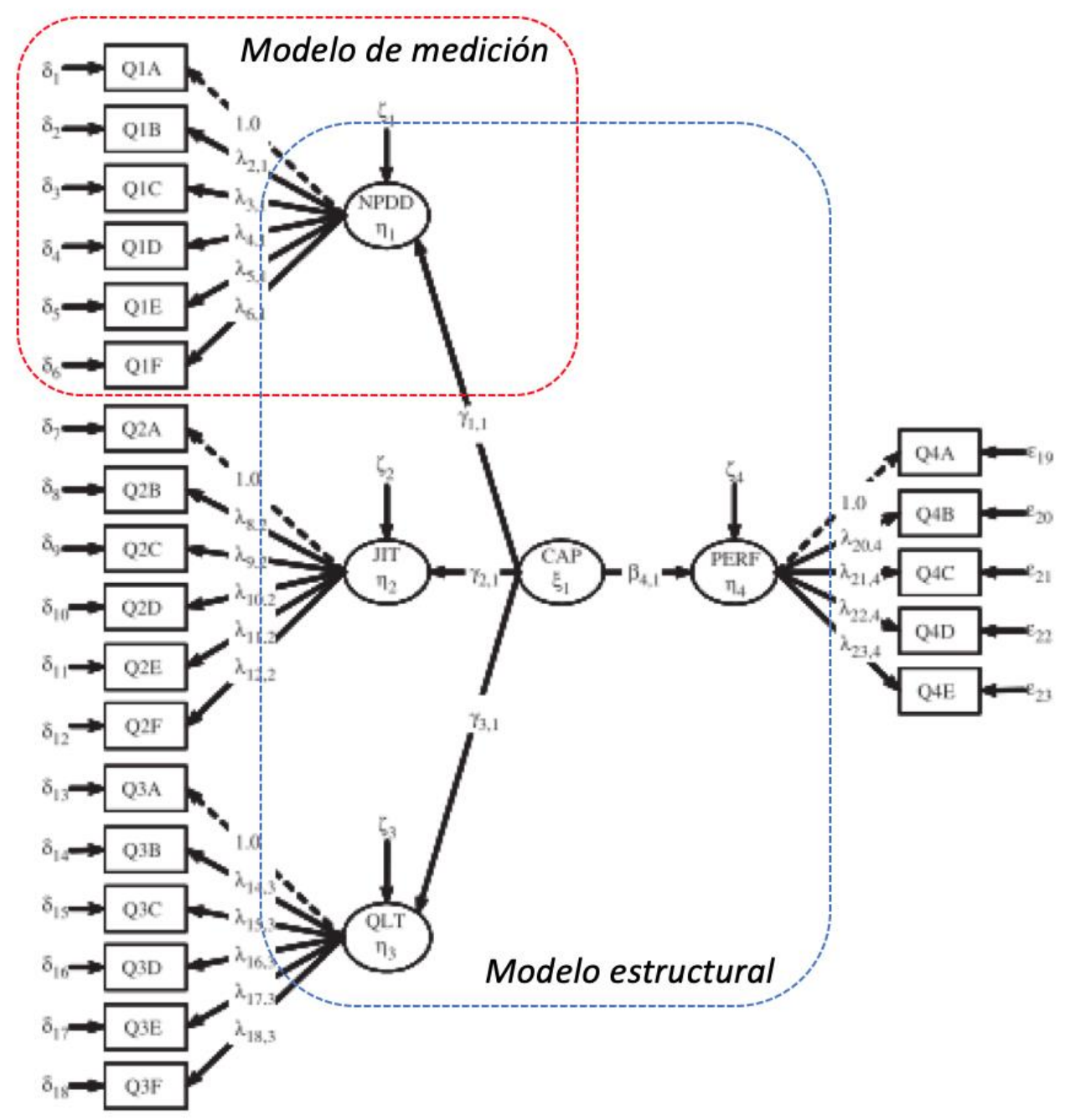

Fuente: Tan, Kannan, y Narasimhan, 2007

Figura 12. Ejemplo de componentes de un diagrama estructural

El propósito de este tipo de herramienta estadística es revisar mediante análisis factorial y regresión lineal el grado de ajuste entre los datos observados y los datos hipotéticos (Casas, 2002).

Al usar SEM es necesario tener en cuenta que uno de los limitantes de este tipo de análisis es que, al igual que con ecuaciones lineales en algebra, un modelo SEM no puede tener un número mayor de variables desconocidas a ser estimadas que la información única provista por los datos que se analizan. Debido a esto, hay que recordar que para obtener estimados estables, modelos grandes requieren muestras grandes. De hecho, de acuerdo con Kline (2005), la regla general establece que el tamaño de muestra mínimo no debería ser inferior a 200 o entre 5 y 20 veces superior al número de parámetros que deben estimarse. En países desarrollados, en donde el 
tamaño de muestra no es un problema debido a la cantidad de empresas disponibles, se pueden hacer estudios SEM completos con todas sus relaciones causales acompañantes.

Sin embargo, para estudios en países en desarrollo con tamaños de muestra pequeños y grandes números de variables existen ciertas técnicas que permiten llevar a cabo análisis SEM que entregan resultados validos con muestras del orden de 50 datos (Hair et al., 2010). Vickery et al., (2003) propusieron el uso de análisis de simulación también conocido como remuestreo Bootstrap.

Li et al., 2006 propusieron la evaluación de modelos alternativos al retirar enlaces entre constructos uno a uno y Jabbour et al., (2012) propusieron el uso de modelos anidados o modelos reducidos (dos por dos) a partir del modelo estructural original completo. De estas tres técnicas, la más adecuada para los objetivos de este trabajo es la propuesta por Jabbour et al. (2012) que reduce el número de parámetros a estimar mediante la construcción de modelos menos complejos ajustados al tamaño de las muestras disponibles al seccionar el modelo estructural más complejo.

Sin embargo, este tipo de análisis SEM no permite encontrar todos los efectos mediados e interacciones que se pueden encontrar con un análisis SEM completo. Sin embargo, con este tipo de estudios si es posible encontrar los efectos directos entre los parámetros bajo estudio.

\subsection{Identificación de retos de investigación}

La revisión crítica del estado del arte realizada en los apartados anteriores permite identificar un conjunto de retos de investigación que dan sentido a los objetivos planteados en esta tesis:

- La revisión de literatura pone de manifiesto la importancia que la industria de ensamblaje con uso intensivo de mano de obra tiene en ciertos mercados específicos. La industria maquiladora textil entra dentro de aquellos sectores que requieren estudios específicos teniendo en cuenta que "es un sector fundamental por la importancia que tiene al producto interior bruto (PIB) y al mercado laboral de los países en desarrollo (Mendoza, 2010). Por lo tanto, se evidencia la existencia de un interés técnico-científico de que se profundice en el estudio y 
desarrollo de acciones que incrementen la competitividad de este sector y sigan contribuyendo a la fortaleza de la estructura industrial de los países afectados.

- El número de componentes asociados a las prioridades competitivas que pueden establecer para una estrategia de mejora de la competitividad es muy elevado. Por ello, se hace necesario investigar cuales son las prioridades competitivas y componentes que son aplicables a una industria específica tal como la de ensamblaje con uso intensivo de mano de obra.

- El número de investigaciones sobre las ventajas de la aplicación de las AMT's en entornos específicos de países en vías de desarrollo es muy reducido pues, hasta ahora, la comunidad científica se ha centrado más en identificar y categorizar las diferentes herramientas que constituyen las AMT y en crear modelos generales para su implantación, asumiendo la posibilidad de generalizar las conclusiones para todos los sectores.

- El número de herramientas avanzadas de manufactura (tecnologías y metodologías) es muy extenso, pero no todas son aplicables o utilizadas por todas las industrias. Por lo tanto, es evidente que son necesarios estudios más enfocados que permita identificar cuales herramientas son más aplicables al sector.

- En la literatura puede observarse que existe debate sobre los beneficios reales que una empresa puede esperar de la implantación de herramientas AMT en sus procesos de diseño, fabricación y control. Aunque los beneficios anunciados son grandes, la evidencia empírica no parece apoyar siempre estas afirmaciones (Swink y Nair, 2007; Bülül, Ömürbek, Paksoy, Bektas, 2013).

- Existe una necesidad de realizar estudios relacionados con el incremento de la productividad a través de herramientas AMT en sectores específicos que se aparten de modelos de aplicación universal que disuaden a los gerentes de empresa de considerar sus resultados como relevantes, aplicables y pertinentes para su industria o sector en particular (Bozdogan, 2014; Ludwig y Pemberton 2011).

- Se hace necesario desarrollar nuevas propuestas metodológicas integrales capaces de modelar, analizar y evaluar todas las variables relacionadas con el problema mediante el uso de herramientas de estadística no-paramétrica y modelos de regresión adaptadas a sectores con características muy específicas como el sector de empresas maquiladoras en el que los tamaños de muestra no son elevados. 


\subsection{Definición del caso de estudio}

En vista que el objetivo de este estudio es poder probar empíricamente si el uso de herramientas AMT en realidad tiene un efecto positivo en la competitividad de fabricación de las industrias que las implantan en sus procesos de diseño, producción y control, se hará uso de la metodología integrada propuesta en un estudio empírico usando plantas maquiladoras de ropa localizadas en Honduras. Esta industria en particular ha sido elegida al ser una buena representación de manufacturas con uso intensivo de mano de obra a nivel mundial, especialmente porque el sector textil tiene la mayor implantación multinacional en países en desarrollo ubicados en Centroamérica y Asia. A pesar de que este caso de estudio será con una muestra localizada en un lugar geográfico específico, Honduras es un buen ejemplo de una pequeña economía emergente de Centroamérica y el carácter multinacional de la mayoría de las empresas encuestadas, tanto en sus estrategias de fabricación como en su gestión, hacen posible que este estudio de caso pueda ser extrapolado a otras fábricas en diferentes países en desarrollo.

Los datos empíricos serán obtenidos mediante una encuesta enviada a gerentes de planta, producción e ingeniería de empresas maquiladoras del sector textil en Honduras. De acuerdo con Banco Central de Honduras $(\mathrm{BCH})$, hay 122 compañías de fabricación textil en Honduras, cada una de ellas con varias plantas de fabricación, la mayoría de ellas localizadas en el norte del país (BCH, 2014).

Los datos obtenidos serán analizados usando herramientas tales como el análisis de expertos, análisis de factores, prueba de hipótesis y modelado de ecuaciones estructurales, cuyo uso fue descrito previamente.

En cualquier caso, se plantea que la metodología a desarrollar tenga la suficiente versatilidad para permitir ser aplicada en entornos industriales distintos y con objetivos diferentes.

Por ello, una vez finalizado el caso de estudio principal, que cumpla los objetivos principales de la tesis doctoral, y como ampliación de la investigación, se pretende aplicar la metodología a otro caso de estudio. En este caso se plantea el análisis de la influencia de las prácticas y herramientas de componente humano en el éxito de los procesos de implantación de metodologías de manufactura para la mejora de procesos, 
más concretamente, la fabricación delgada o lean manufacturing, debido a la importancia del modelo en la industria actual. Este caso surgió al identificar que un porcentaje alto de las implementaciones de las metodologías de gestión fallan o tienen problemas de integración por situaciones relacionadas a las practicas blandas, es decir a factores humanos (Eaton, 2010; Anand y Kodali, 2010; Liker y Rother, 2011; Albliwi et al., 2014). Pearce et al., (2018) defienden que es muy importante considerar el rol que tienen los factores humanos en la implementación de las diferentes metodologías de manufactura y su impacto en la mejora del desempeño y competitividad de las empresas en las que se implementa. 


\section{METODOLOGÍA PROPUESTA}

\subsection{Esquema general}

Los estudios de investigación científica siguen un proceso sistemático y controlado para probar hipótesis sobre supuestas relaciones existentes entre diferentes variables. Estas pruebas usualmente se hacen mediante la observación y el análisis estadístico de datos empíricos sobre los fenómenos que se estudian (Ramírez González, 2015). A pesar de la importancia que tiene definir al inicio de un estudio científico la metodología de investigación que se seguirá para resolver el problema en cuestión, no existe una regla definitiva en cuanto al enfoque de investigación específico que se debe seguir para cada tipo de situación (Bell, 2005). Tanto el enfoque investigativo como el método que se debe utilizar en cada estudio dependen en gran medida de la naturaleza y alcance de la investigación, los datos disponibles y las preguntas y objetivos de la investigación.

Como se expuso en la introducción, el objetivo general de este trabajo es medir la influencia que las tecnologías y metodologías avanzadas de fabricación, denominadas de aquí en adelante "herramientas AMT", tienen en la competitividad de fabricación de las industrias ensambladoras con uso intensivo de mano de obra orientada a la exportación, denominadas de aquí en adelante como "empresas maquiladoras". Se intuye que la competitividad de fabricación será obtenida a partir del desempeño que estas industrias tienen en los factores de competitividad de fabricación, denominados de aquí en adelante "MCF". Para hacerlo, este estudio seguirá inicialmente un diseño exploratorio inductivo y cualitativo que utilizará una revisión de literatura y entrevistas con expertos para determinar la forma de medir la competitividad de fabricación en las industrias de interés y las herramientas AMT a estudiar. Después de esta etapa inicial, la posterior recogida de datos empíricos y el uso de análisis estadístico paramétrico y no-paramétrico transformaran el enfoque a seguir en un estudio deductivo, explicativo y cuantitativo que culminará con un caso de estudio que debe probar y validar la metodología desarrollada. Como se puede apreciar en la Figura 13, este trabajo seguirá un método de investigación mixto capaz de modelar, analizar y evaluar todas las variables relacionadas con el problema, incluyendo prioridades competitivas y medidas de productividad, por lo que este estudio puede categorizarse como investigación aplicada. 


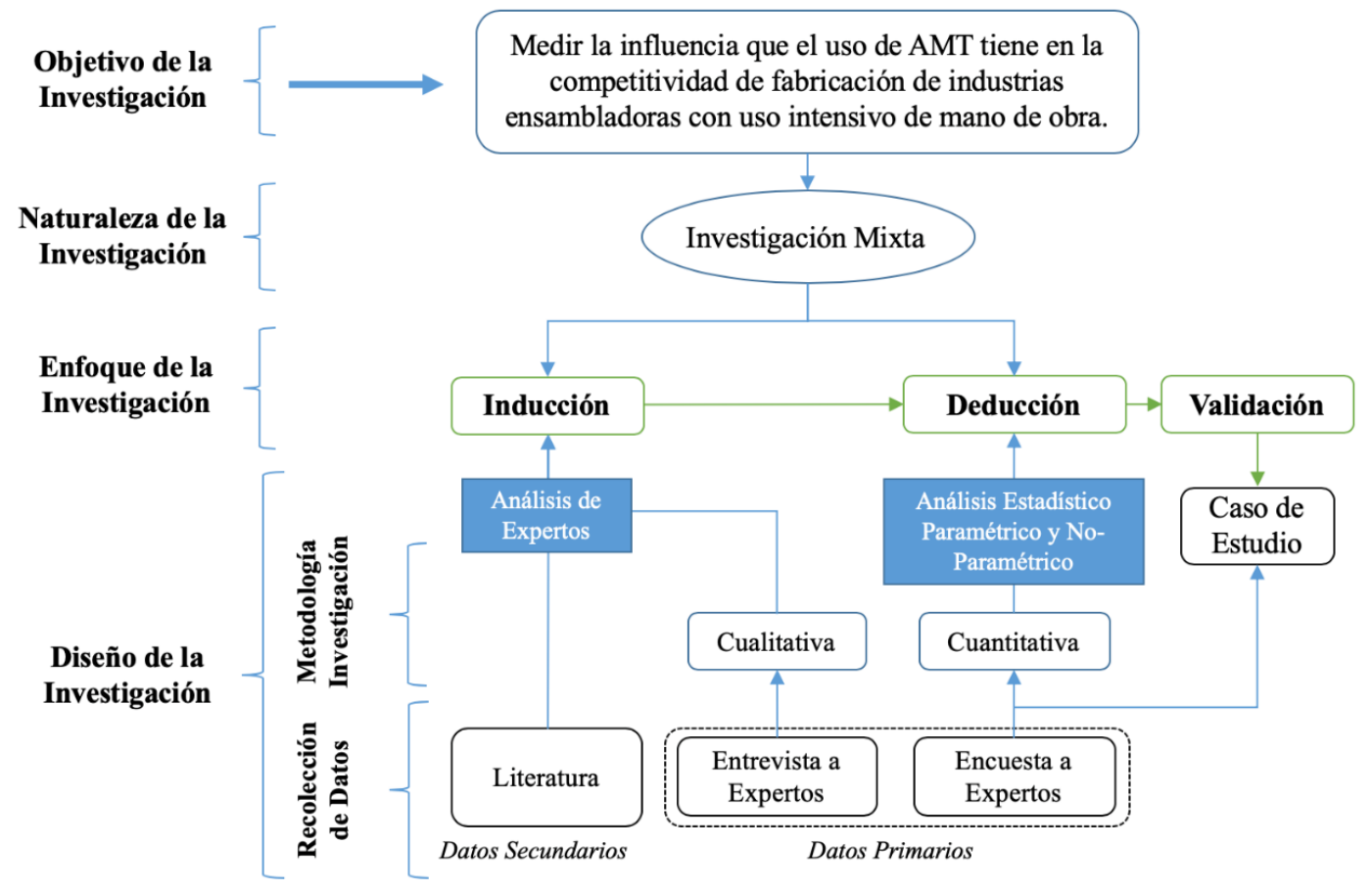

Figura 13. Visión general del diseño de investigación a seguir

A continuación, se describen las fases a seguir en la metodología propuesta que integra técnicas para recolección de datos cualitativos y cuantitativos y el posterior análisis estadístico de los datos empíricos recogidos (Figura 14).

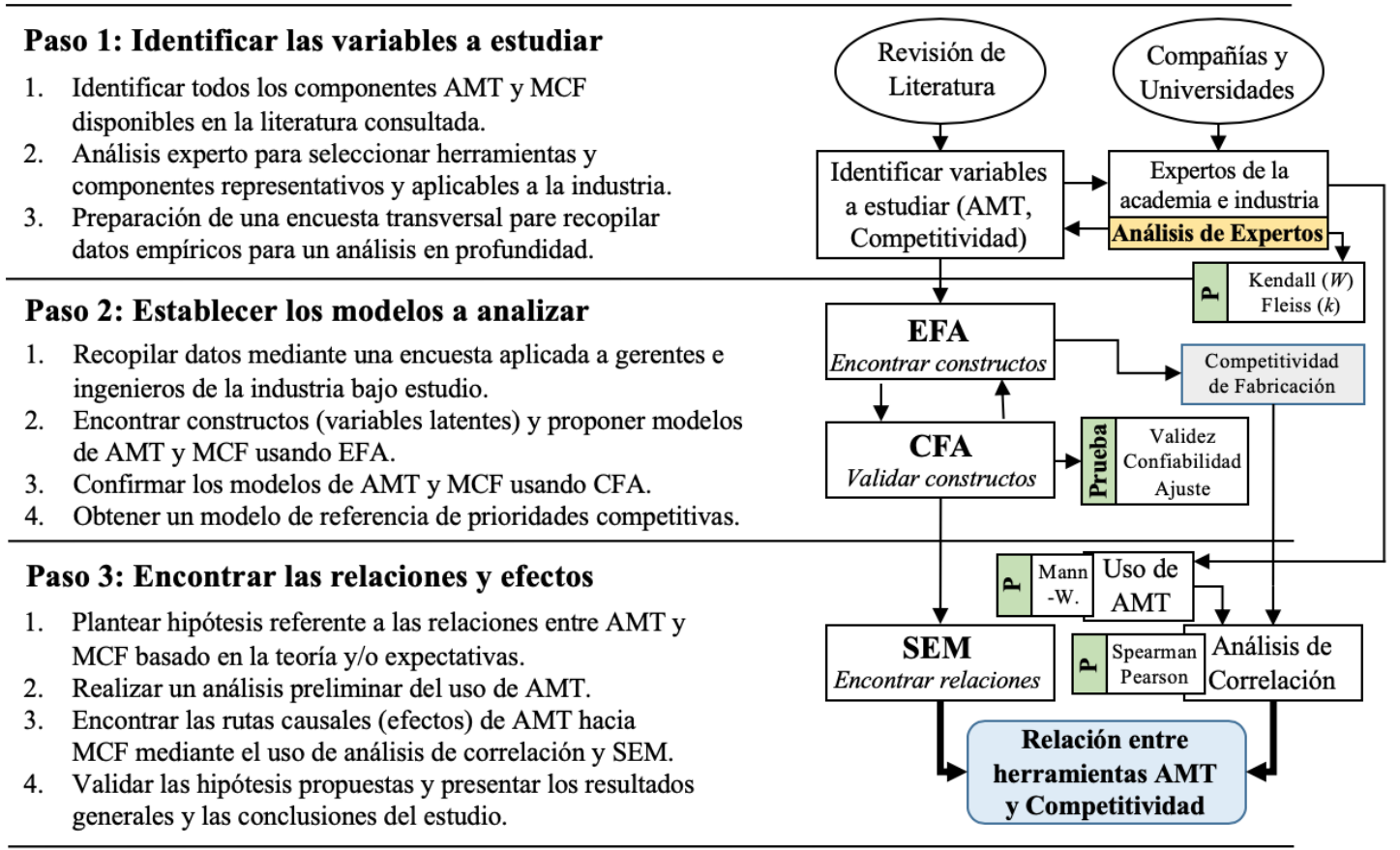

Figura 14. Ciclo general de la metodología propuesta 


\subsection{Identificación de variables}

Como se explicó previamente, el diseño de investigación propuesto es mixto, por lo que la primera parte de la investigación seguirá un enfoque inductivo - cualitativo basado en un análisis de expertos. Este método se usará con el propósito de identificar los factores y componentes del modelo de referencia de las prioridades competitivas de la industria que se pretende analizar en el caso de estudio y determinar que herramientas AMT son aplicables para dicha industria. Por lo tanto, como se visualiza en la Figura 15, la identificación de las variables a estudiar se hará siguiendo 4 pasos principales: (1) identificar los factores de competitividad (componentes MCF) y las herramientas AMT disponibles en la literatura, (2) seleccionar los expertos a usar durante el análisis cualitativo, (3) realizar un análisis mediante el método Delphi para seleccionar componentes MCF y herramientas AMT a usar durante el análisis cuantitativo, y (4) preparar una encuesta transversal para recopilar la información a usar durante la sección cuantitativa del estudio. Estos pasos se explican con más detalle a continuación.

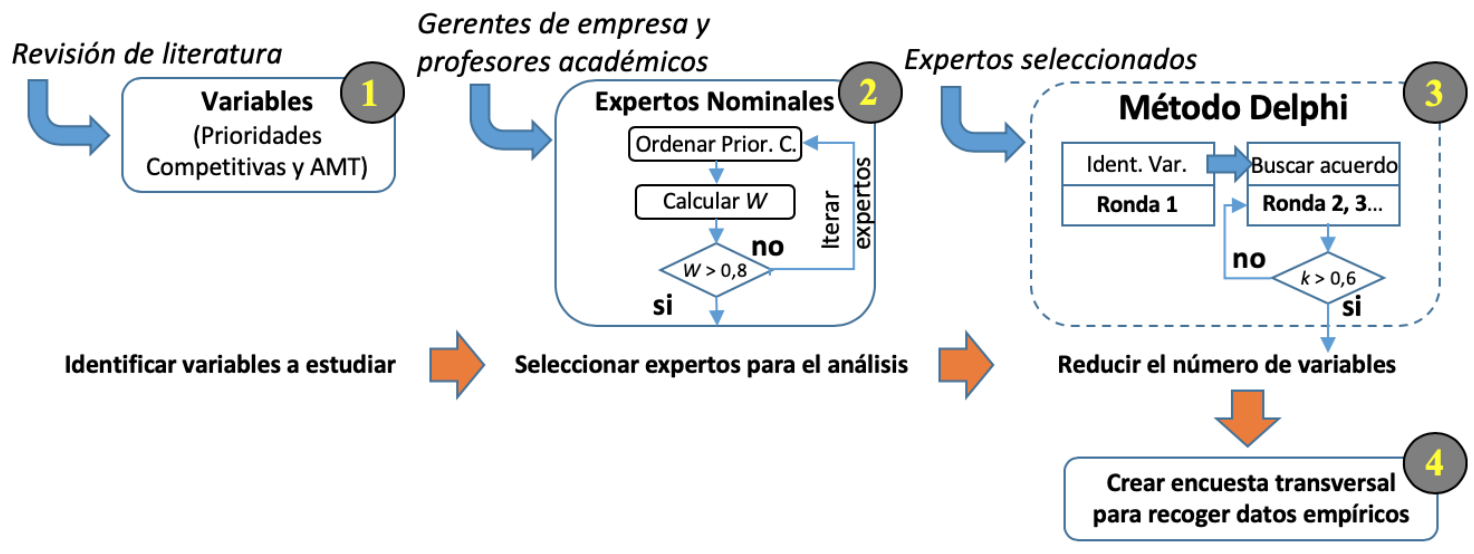

Figura 15. Metodología para el análisis de expertos

\subsubsection{Factores de competitividad y herramientas AMT}

El propósito de este primer paso es lograr identificar las prioridades y componentes (variables) que han sido utilizadas en la literatura para medir competitividad, así como las herramientas AMT que están disponibles para ser usadas en empresas maquiladoras. Este paso requiere de una revisión exhaustiva de la literatura para entender la teoría detrás de los conceptos de competitividad, estrategia de manufactura y herramientas AMT. Adicionalmente es necesario realizar entrevistas preliminares con gerentes de empresas del sector bajo estudio para aclarar los conceptos y las ideas 
obtenidas de la revisión de literatura y poder adaptarlos a la realidad especifica de la industria siendo estudiada. El producto final de este paso es un listado de las prioridades competitivas de la industria bajo estudio junto con un listado de sus posibles componentes (MCF), así como una lista de herramientas AMT aplicables a esta industria los cuales serán utilizados con un grupo de expertos de esta industria.

\subsubsection{Selección de expertos}

Debido a los pequeños tamaños de muestra y la baja tasa de respuesta que típicamente tienen las encuestas en las empresas con uso intensivo de mano de obra (Jun et al., 2006), se determinó que la mejor forma de identificar que variables estudiar es mediante un analisis de expertos usando el metodo Delphi. La razón es que el método Delphi depende del consenso entre los expertos y no de la capacidad estadística, por lo que no es necesario tener un tamaño de muestra grande para tener información confiable (Hung et al., 2008; Okoli y Powlowski, 2004). La selección de componentes MCF y herramientas AMT se inicia con la selección de un grupo de expertos en el tema de empresas maquiladoras que ayuden en el proceso de selección de las variables necesarias para el estudio. Para esto es necesario seleccionar un grupo nominal de expertos con ciertos criterios tales como el que sea un gerente de planta, producción, ingeniería o calidad con, por lo menos, cinco años de experiencia y que trabaje en las empresas más importantes de la industria bajo estudio. A partir de aquí se selecciona el grupo final de expertos con el que se hará en análisis mediante método Delphi.

El paso 2 busca certificar que el grupo seleccionado está compuesto de expertos que tienen un juicio confiable o seleccionar solo aquellos que tienen congruencia de criterio. Para esto se usará como discriminante una prueba basada en el coeficiente de concordancia de Kendall ( $W$. Esto se logra pidiendo a los expertos seleccionados inicialmente que ordenen de acuerdo con su importancia (ranking) el listado de prioridades competitivas encontradas en el paso 1. después, utilizando las respuestas de cada experto y mediante un método iterativo, los expertos cuyas respuestas generan un bajo coeficiente de concordancia de Kendall, porque sus respuestas son diferentes, son retirados hasta encontrar el grupo de expertos que produce el coeficiente de concordancia más alto $(W>0.8)$. El grupo de expertos que genere el coeficiente de concordancia más alto será el grupo de expertos a utilizar en el estudio. Las ecuaciones utilizadas para el cálculo del coeficiente de concordancia de Kendall se habían encuentran explicado en la revisión del estado del arte (2.4.2). 


\subsubsection{Selección de componentes MCF y herramientas AMT}

Una vez seleccionados los expertos con los que se trabajará, se debe reducir el alto número de posibles variables obtenidas en el paso 1 mediante el uso de un análisis a través del método Delphi. Debido a que este método requiere del anonimato de los expertos durante el proceso de recolección de información, para evitar que las opiniones se sesguen, las encuestas deben enviarse a cada experto identificado en el paso 2, asegurando mantener la confidencialidad de estos. El instrumento usado contiene el listado de variables identificadas en el paso 1 (ronda 1), de forma que estos puedan seleccionar cuales de las variables presentadas son importantes para describir la competitividad de las empresas maquiladoras. Esta primera encuesta es de tipo dicotómica, ya que los expertos solo deben seleccionar si consideran que la variable presentada es importante para medir la competitividad de fabricación o no lo es.

Debido a que la metodología Delphi busca lograr consenso o acuerdo entre los expertos sobre un tema en particular, es necesario realizar varias rondas de encuestas con realimentación controlada. Para eso, los expertos reciben un resumen con los resultados obtenidos de la ronda previa y se les envía una nueva encuesta pidiendo que reconsideren su decisión original usando como base la respuesta del resto de los expertos (ronda 2). A cada experto se le envía el listado de variables en las que su acuerdo fue diferente al de la mayoría de los expertos, haciendo mención del número de jueces que opinaron diferente que él. Para cada una de estas variables se le pide seleccionar una de las siguientes tres opciones:

1. El componente si es importante, agregar a mí lista de dimensiones.

2. No agregar a mi lista de dimensiones, ya que a pesar de que el componente es importante ya fue considerado en otra dimensión seleccionada.

3. No agregar a mi lista de dimensiones, ya que el componente no es importante para la industria maquiladora.

Usando la información obtenida de esta segunda encuesta, se utiliza el coeficiente de Kappa de Fleiss $(k)$ para medir el nivel de acuerdo que los expertos tienen referente a cuáles variables son importantes y obtener así un análisis objetivo e imparcial. Las ecuaciones utilizadas para el cálculo del coeficiente de Kappa de Fleiss se encuentran explicadas en la sección 2.4.2. Si el valor del coeficiente $k$ obtenido no es superior a 0.6 se hace otra ronda de realimentación y se vuelve a calcular el coeficiente $k$. Después de 
haber logrado un acuerdo significativo por parte de los expertos, aquellas variables en las que hubo consenso total sobre su no-importancia son retiradas del grupo y se mantienen aquellas variables en las que hubo consenso total sobre su importancia 0 acuerdo parcial en al menos un $70 \%$ de los jueces.

Un proceso semejante al descrito previamente se utiliza para seleccionar aquellas herramientas AMT a utilizar en el estudio. El listado final de prioridades competitivas y sus componentes, así como las herramientas AMT seleccionadas son presentadas al grupo de expertos para informarles del acuerdo final obtenido. El listado de prioridades competitivas y sus componentes junto con las herramientas AMT son las variables que se utilizarán para crear el instrumento (encuesta) que será usado en la parte cuantitativa del estudio.

\subsubsection{Diseño de encuestas}

Después de identificar las variables con las que se realizará el análisis de prioridades competitivas y herramientas AMT es necesario obtener información empírica mediante una encuesta transversal que recoja información sobre dos elementos importantes en las empresas que representan: el nivel de desempeño de las plantas de fabricación, comparadas con sus competidores, en los componentes de las prioridades competitivas siendo estudiadas y el grado de uso que sus plantas dan a las diferentes herramientas AMT típicamente utilizadas para mejorar la competitividad de fabricación. Esta información puede obtenerse a través de una encuesta basada en una escala Likert de cinco puntos de acuerdo con el siguiente esquema:

Prioridades y capacidades competitivas: La siguiente es una lista de estrategias que utilizan las empresas maquiladoras para mejorar su competitividad. Indique el nivel de rendimiento que tiene su planta maquiladora en los siguientes elementos en comparación a otras plantas de la industria maquiladora. Use la siguiente escala Likert: (1) Significativamente más débil que los competidores, (2) Más débil que los competidores, (3) Igual que los competidores, (4) Más alto que los competidores, (5) Significativamente mejor que los competidores.

Herramientas AMT: La siguiente es una lista de herramientas avanzadas de manufactura (tecnologías y metodologías) que suelen utilizar las empresas para mejorar su competitividad. Seleccione la respuesta que mejor indique el grado de uso dado o el beneficio obtenido de estas 
herramientas en su planta: (1) No se utiliza, (2) Se utiliza muy poco, (3) Se utiliza algunas veces, (4) Se utiliza frecuentemente, (5) Se utiliza siempre.

Aunque las escalas Likert generan datos ordinales que usualmente no son aptos para el análisis paramétrico, cuando una serie de preguntas tipo Likert se combinan para describir un constructo, es posible realizar análisis de confiabilidad, de factores y ciertos cálculos de estadística paramétrica. Esta es una práctica utilizada muy frecuentemente en artículos publicados en revistas del área de gestión de operaciones (da Silveira, 2014; Hallgren y Olhager, 2009; Lagacé y Bourgault, 2003; Pinjala et al., 2006; Cho y Lee, 2013).

Al diseño final del instrumento se le debe agregar una sección para recoger información demográfica que permita identificar la empresa, su tamaño, el puesto de trabajo del encuestado y sus años de experiencia. Toda esta información ayudará a interpretar mejor los resultados obtenidos. El instrumento completo puede ser diseñado para ser rellenado y administrado en línea a través del portal www.qualtrics.com, lo que facilita la gestión centralizada de los resultados.

\subsection{Modelo de actuación propuesto}

El instrumento diseñado a partir de las variables encontradas en la sección cualitativa de la metodología propuesta se usa para poder obtener información cuantitativa que permita identificar la influencia que las herramientas AMT tienen en la competitividad de fabricación de la industria maquiladora. El identificar estas influencias requiere de una serie de análisis estadísticos paramétricos y no-paramétricos que validen las hipótesis planteadas. Como se muestra en la Figura 14, la metodología propuesta para la sección cuantitativa del estudio se compone de 3 pasos principales: (1) envío de instrumento y recolección de datos, (2) encontrar los constructos que conforman los modelos a analizar y confirmar los modelos encontrados, y (3) obtener el modelo de referencia de la industria bajo estudio. Estos pasos se explican en los siguientes apartados de acuerdo con la secuencia propuesta en la Figura 16. 


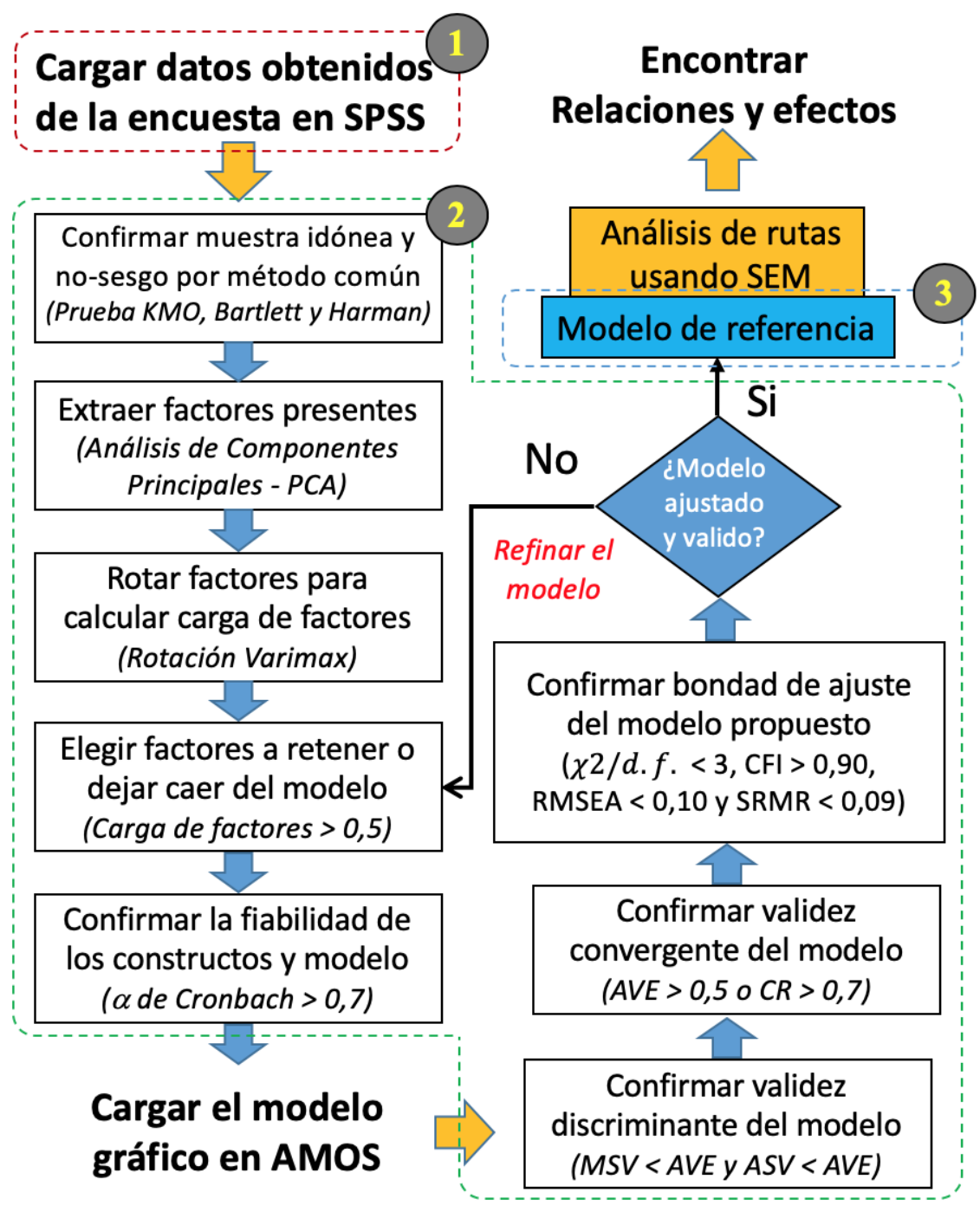

Figura 16. Metodología cuantitativa propuesta (modelado, relaciones y efectos)

\subsubsection{Recolección de datos}

Para llevar a cabo los análisis estadísticos mostrados en la Figura 16, se necesita información empírica obtenida a partir de aplicar la encuesta descrita a una muestra representativa de expertos en empresas maquiladoras (gerentes e ingenieros).

El envío de la encuesta a los expertos de las empresas bajo estudio se hace mediante un correo electrónico con un enlace al portal www.qualtrics.com. Los datos recolectados son exportados desde el portal a Excel para su posterior análisis usando herramientas de procesamiento estadístico. 


\subsubsection{Variables latentes}

En vista que el objetivo final de este estudio es encontrar las relaciones y efectos existentes entre las variables siendo estudiadas, es necesario que estas variables sean agrupadas en factores (variables latentes) para realizar los análisis estadísticos requeridos. Para poder confirmar que la estructura factorial propuesta durante la sección cualitativa del estudio es correcta, es necesario realizar dos tipos de análisis: EFA y CFA. A través de estos análisis es posible plantear modelos de medición que revelen la estructura de las variables latentes (constructos) que están presentes tanto en las prioridades competitivas como en las herramientas AMT para empresas maquiladoras.

Usando el análisis exploratorio de factores se debe revisar cuáles son los grupos de variables, tanto para las prioridades competitivas como para las herramientas AMT, que están fuertemente correlacionadas entre sí y forman factores. Este análisis estadístico sirve para confirmar la unidimensionalidad de cada factor propuesto y la validez de los modelos de medición definidos. El método de factorización y extracción de componentes a utilizar es el análisis PCA a través de una rotación Varimax. La idoneidad de la muestra utilizada debe confirmarse previamente usando la prueba KMO y la prueba de esfericidad de Bartlett. Debido a que todos los datos serán recolectados usando una sola encuesta en-línea también se debe revisar que no existe sesgo por la presencia de CMB mediante una prueba de factor único de Harman. Finalmente, Aquellos elementos con cargas factoriales superiores a 0.6 se mantienen dentro del factor y aquellos con cargas menores son descartados. Todos estos análisis pueden realizarse usando el paquete de software IBM SPSS V.22.

Los modelos conformados por los diferentes factores revelados por el EFA pueden ser validados mediante el uso del análisis confirmatorio de factores, usando el método de estimación ML. Una vez que un modelo propuesto ha sido analizado, es necesario revisar la fiabilidad de los constructos encontrados mediante el cálculo del Alfa de Cronbach. Adicionalmente se debe revisar la validez discriminante del modelo al confirmar que tanto el MSV como el ASV son superiores al AVE, o revisando que el CR es superior a 0.7 tal como se describe en la sección 2.4.2.2. Finalmente, la bondad de ajuste debe determinarse revisando que los coeficientes presentados en la Tabla 8 se mantienen dentro de los límites permitidos. Todos estos análisis se realizan utilizando el paquete de software IBM AMOS V.22. 


\subsubsection{Modelo de referencia}

Una vez que los modelos de medición para las prioridades competitivas y las herramientas AMT han sido definidos y validados, se puede definir el modelo de referencia para la competitividad de fabricación de manufacturas con uso intensivo de mano de obra. Los factores, componentes, cargas factoriales y la varianza explicada obtenida en el modelo de medición de la competitividad de fabricación se pueden utilizar para construir un modelo de referencia usando una variante de la metodología propuesta por Díaz-Garrido et al. (2011). Este modelo ajustará la puntuación obtenida del desempeño comparativo de una empresa en cada capacidad competitiva, usando la importancia que cada componente tiene para el sector o industria bajo estudio. Este ajuste se realiza utilizando las cargas factoriales de cada componente $\left(F_{i}\right)$ y el elemento de ponderación obtenido de la variabilidad explicada por cada factor $\left(P_{i}\right)$ en el EFA. Los factores ajustados $F_{i}$ se calculan multiplicando el desempeño comparativo promedio $(D)$ reportado por la planta cuyo índice de competitividad de fabricación (ICF) se está calculando, con cargas factoriales $(C)$ de cada componente $j$ que conforma cada factor $k$, dividido por la suma de todas las cargas de ese factor específico, utilizando la siguiente ecuación:

$$
F_{i}=\frac{\sum_{i=1}^{j} D_{i} C_{i}}{\sum_{i=1}^{j} C_{i}}(11)
$$

Los pesos $P_{i}$ se pueden calcular dividiendo el porcentaje de varianza de cada factor $\left(V_{i}\right)$ por la suma de todo el porcentaje de varianza explicada por todos los factores. La ecuación para obtener este valor es la siguiente:

$$
P_{i}=\frac{V_{i}}{\sum_{i=1}^{k} V_{i}}(12)
$$

Lo que significa que el índice de competitividad de fabricación puede calcularse usando la siguiente ecuación:

$$
I C F=\sum_{i=1}^{k} P_{i} F_{i}=\sum_{i=1}^{k}\left(\left(\frac{V_{i}}{\sum_{i=1}^{k} V_{i}}\right)\left(\frac{\sum_{i=1}^{j} D_{i} C_{i}}{\sum_{i=1}^{j} C_{i}}\right)\right)
$$


La fórmula descrita producirá un valor que puede oscilar entre 1 y 5 , debido a que esos son los valores mínimos y máximos que pueden asignarse en la escala Likert utilizada. Con el fin de hacer que el índice sea más útil, este se puede estandarizar a valores entre 0 y 100 utilizando la siguiente ecuación:

$$
I C F \text { estandarizado }=\frac{I C F-\min I C F}{\max I C F-\min I C F} \times 100
$$

En donde ICF es el índice de competitividad de fabricación alcanzado, min ICF es el índice mínimo posible o el valor mínimo alcanzado dentro de una muestra comparativa de empresas, y max ICF es el índice máximo posible o el valor máximo alcanzado dentro de una muestra comparativa de empresas del mismo sector industrial. La utilidad de este índice radica en su habilidad para estimar la competitividad de fabricación usando factores diferentes a los tradicionales indicadores financieros y económicos utilizados comúnmente. 


\section{DESARROLLO EXPERIMENTAL}

Este capítulo expone la descripción detallada de los desarrollos experimentales realizados sobre el caso de estudio en plantas de ensamblaje multinacionales dedicadas a la industria textil a partir de la metodología definida en el capítulo anterior.

\subsection{Planteamiento general de relaciones y efectos}

Se plantea presentar y probar hipótesis sobre las relaciones existentes entre las herramientas AMT y los elementos usados para medir la competitividad y verificar así, de forma empírica, si el uso de herramientas AMT en realidad tiene un efecto positivo en la competitividad de fabricación de las empresas maquiladoras. Tal como se expuso en la metodología propuesta se requieren 4 pasos:

1. Plantear hipótesis sobre las relaciones existentes entre las herramientas AMT y los elementos MCF

2. Realizar un análisis preliminar del uso de herramientas AMT en la industria maquiladora.

3. Encontrar las relaciones causales (efectos) de las herramientas AMT en los elementos MCF

4. Validar las hipótesis propuestas.

\subsubsection{Planteamiento de hipótesis}

Las hipótesis iniciales de partida sobre las relaciones entre herramientas AMT y elementos MCF se realizan a partir del examen de las propuestas científicas realizadas en el área de estudio.

Diferentes investigadores han considerado que los niveles de uso de las herramientas AMT y del desempeño de fabricación están influenciados por el tamaño de la planta ya que las empresas más grandes tienen una mejor posición financiera que las PYME, lo que les permite realizar más inversiones y aprovechar la economía de escalas (Small y Yasin, 1997; Swamidass y Kotha, 1998; Jonsson, 2000). 
Sin embargo, algunos estudios recientes muestran que el uso de las herramientas AMT no está necesariamente correlacionado con el tamaño de las plantas (Swink y Nair, 2007; Bülül et al., 2013), sugiriendo que las PYME pueden estar invirtiendo más en la adopción de herramientas AMT para sus operaciones.

Debido a estos resultados contrastantes, este estudio busca profundizar en las evidencias sobre la relación que existe entre el tamaño de las plantas de fabricación y el uso de herramientas AMT en la industria de la confección en Centroamérica. Asumiendo que los hallazgos en las PYME descritas anteriormente se pueden aplicar a las fábricas maquiladoras de ropa, se plantea la siguiente hipótesis:

$H_{1}$ : Las fábricas maquiladoras grandes del sector textil tienen un nivel de uso de herramientas AMT semejante al de las fábricas más pequeñas.

Ha habido mucho debate sobre los beneficios reales que una empresa puede esperar de implementar el uso de herramientas AMT en sus procesos de diseño, fabricación y control. Aunque los beneficios potenciales anunciados de la implementación AMT son excelentes, la evidencia empírica no parece siempre respaldar estas afirmaciones (Swink y Nair, 2007). Este es el caso de los estudios empíricos de Swamidass y Kotha (1998) y Diaz et al. (2003), quienes encontraron que el uso de las herramientas AMT no tuvo un efecto significativo en el desempeño de fabricación de la empresa. Sin embargo, Boyer y Lewis (2002) y Koc y Bozdag (2009) reportaron que el uso de ciertas herramientas AMT tienen un efecto positivo en el desempeño de fabricación. Esta contradicción sugiere que la relación entre estas variables podría depender del tipo de industria y las herramientas que se utilizan.

Adicionalmente, debido a que este tipo de industria requiere mucha mano de obra, se espera que el uso de metodologías de mejora o herramientas tecnológicas incrementará significativamente su competitividad, ya que ayudará a mejorar la eficiencia (Putrano et al., 2003), por lo tanto:

$\mathrm{H}_{2}$ : Las fábricas maquiladoras del sector textil con un mayor nivel de uso de herramientas AMT tienen un mejor desempeño de competitividad de fabricación que aquellos con un menor nivel de uso de herramientas AMT. 
Un análisis de literatura muy completo realizado por Khanchanapong et al. (2014), sugiere que la adopción de herramientas AMT afecta positivamente el coste, la calidad, la flexibilidad y el desempeño del tiempo de entrega. De hecho, de acuerdo con diferentes investigadores, las tecnologías de diseño tales como CAD y CAM ayudan a reducir los costes y a aumentar la productividad al reducir el tiempo de mecanizado (Heim y Peng, 2000; Patterson y West, 2004), así como el desperdicio y el retrabajo (Heim y Peng, 2000). Adicionalmente, estas tecnologías se han relacionado con mejoras en la flexibilidad del diseño y reducción en el tiempo de configuración (Koc y Bozdag, 2002), junto con la obtención de una transición eficiente del diseño de producto a la fabricación (Khanchanapong et al., 2014) lo que aumenta la flexibilidad y el tiempo de entrega, por lo tanto:

$\boldsymbol{H}_{3 \boldsymbol{a}-\boldsymbol{c}}$ : Las herramientas AMT de diseño e ingeniería tienen una relación positiva con mejoras en el coste, la flexibilidad y el tiempo de entrega de las fábricas maquiladoras del sector textil.

La literatura sugiere que las tecnologías informáticas de gestión tales como ERP, MRP y MES tienen un efecto positivo en el rendimiento de los costes (Ward y Zhou, 2006; Khanchanapong et al., 2014) y ayudan en el flujo de materiales proporcionando un mejor control, lo que tiene un efecto positivo en la flexibilidad de las plantas de fabricación. La integración que este tipo de herramientas ofrece a una empresa significa que la información almacenada y entregada es más precisa, mejorando así el rendimiento de la operación de fabricación, lo que reduce los errores y sus costes asociados y mejora el tiempo de entrega (Ward y Zhou, 2006). Además, una mejor coordinación y gestión reduce los errores y el desperdicio, evitando incidentes ambientales (Yang, Hong y Modi, 2011), lo que implica:

$\boldsymbol{H}_{\mathbf{4} \boldsymbol{a}-\boldsymbol{d}}$ : Las herramientas AMT de administración tienen una relación positiva con mejoras en el coste, la protección de medio ambiente, el tiempo de entrega y la flexibilidad de las fábricas maquiladoras del sector textil.

La literatura muestra que las tecnologías duras especificas tales como en CNC y la robótica permiten la fabricación de productos personalizados con gran precisión, velocidad y eficiencia (Boyer y Lewis, 2002; Chang, Lin, Chen y Huang, 2005). El aumento en la precisión y eficiencia de los procesos genera una reducción en los costes. Diversos investigadores también han demostrado que el uso de otras tecnologías 
automatizadas aumenta diferentes tipos de flexibilidad, tales como la flexibilidad de volumen, la flexibilidad de la mezcla de producto, entre otros (Chang et al., 2005; Esan, Khan, Qi y Naylor, 2013). Koc y Bozdag (2009) plantean que la integración y automatización de diferentes unidades de fabricación mediante el uso de tecnologías de fabricación automatizadas, como los PLC y los robots, contribuyen a la reducción de las actividades sin valor agregado y a la mejora de la utilización de la capacidad, lo que significa que:

$\boldsymbol{H}_{\mathbf{5} \boldsymbol{a}-\boldsymbol{d}}$ : Las herramientas AMT de fabricación automatizada tienen una relación positiva con mejoras en el coste, la protección del medio ambiente, el tiempo de entrega y la flexibilidad de las fábricas maquiladoras del sector textil.

Según diferentes investigadores, las prácticas de mejora tales como como TQM, JIT y Lean tienen un impacto positivo en la reducción de costes, la producción eficiente y el desempeño de calidad (Dangayach y Deshmukh, 2001; Swamidass, 2003; Vinodh y Joy, 2012). Por ejemplo, Swink et al. (2005) reportaron que la participación de la fuerza laboral que es requerida por las practicas Lean ayuda a los empleados a mejorar sus habilidades y estos logran realizar sus tareas de manera más eficiente, mejorando la productividad y reduciendo los costes. Del mismo modo, el uso de prácticas de mejora como VSM, 5S y Kaizen han demostrado un impacto directo en la reducción del tiempo de entrega y la mejora de la velocidad y eficiencia del flujo de producción, ya que ayudan a crear diseños de producción eficientes (Ward y Zhou, 2006; Vinodh y Joy, 2012). Del mismo modo, algunas de las practicas JIT, como SMED y Kanban, ayudan a obtener cambios rápidos de equipos y tamaños de lotes pequeños, lo que junto con el uso de trabajadores con múltiples habilidades característicos de estas metodologías de trabajo mejoran la flexibilidad de las plantas de fabricación (Chang et al., 2005). Finalmente, se espera que la adopción de programas de mejora ayude a utilizar procesos de producción amigables con el medio ambiente y proporcione a las empresas una imagen ambiental positiva debido a sus prácticas de eliminación de desperdicio y otras políticas socialmente responsables, por lo tanto:

$\boldsymbol{H}_{\mathbf{5} \boldsymbol{a}-\boldsymbol{d}}$ : Las herramientas AMT de mejora de procesos tienen una relación positiva con mejoras en el coste, la protección del medio ambiente, el tiempo de entrega y la flexibilidad de las fábricas maquiladoras del sector textil. 
La Figura 17 presenta un resumen de las hipótesis a explorar en este estudio, en donde $\mathrm{E}$ (desde 1 hasta $n$ ) representa los elementos que conforman cada subgrupo de herramientas AMT y/o capacidades competitivas de la industria bajo estudio.

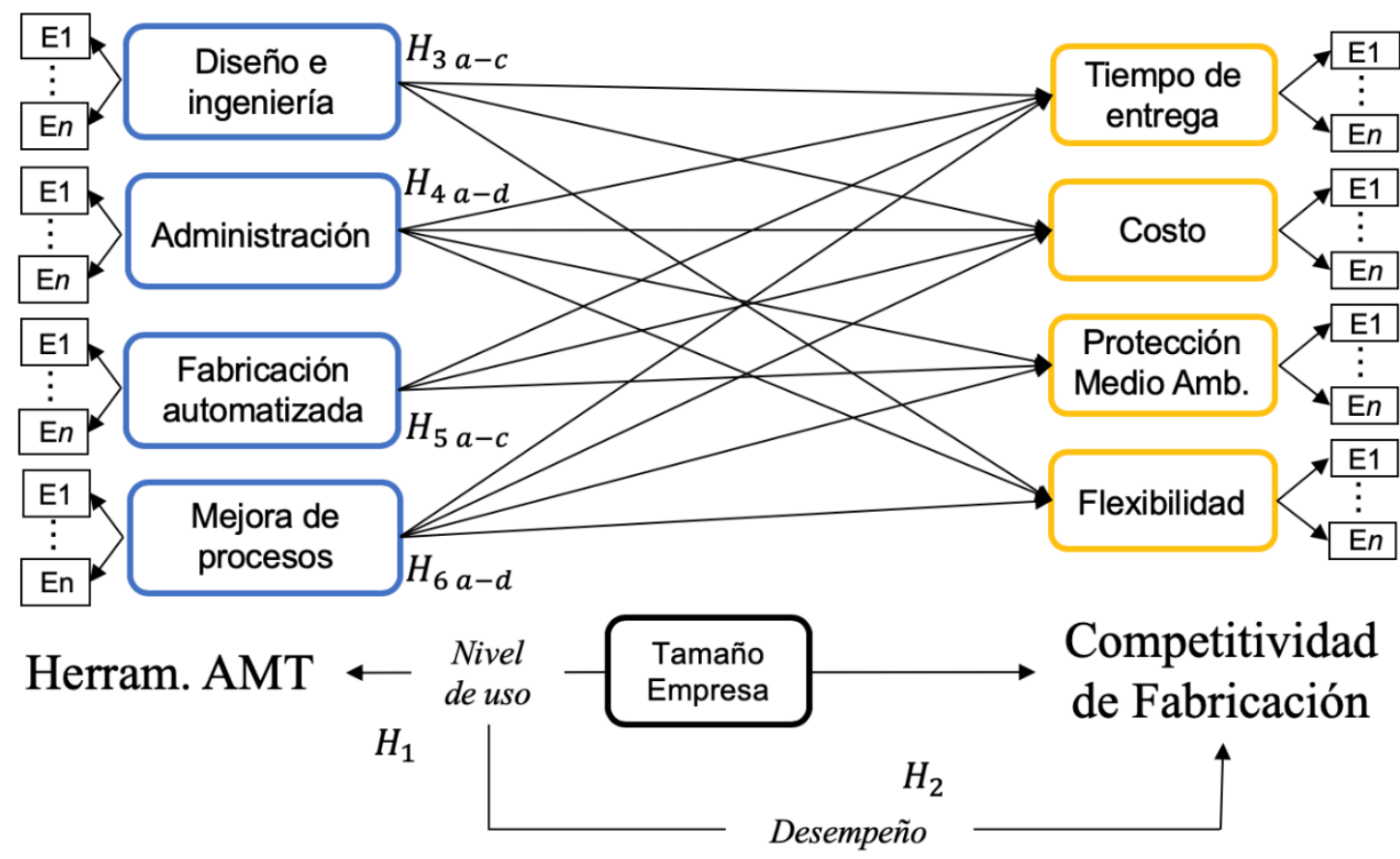

Figura 17. Diagrama estructural de las hipótesis del estudio

\subsubsection{Criterios de validación de hipótesis}

Debido a que $\boldsymbol{H}_{\mathbf{1}}$ busca validar si el nivel de uso de las herramientas AMT es semejante en las maquiladoras del sector textil sin importar su tamaño, la prueba de esta hipótesis requiere separar la muestra de empresas obtenida en dos grupos, usando cantidad de empleados de cada planta como el elemento discriminante. El siguiente paso requerirá que el nivel de uso de las diferentes herramientas AMT sea calculado en cada grupo y luego usando la prueba no-paramétrica Mann-Whitney pueda calcularse si existe o no una diferencia significativa entre ambos grupos. En este caso, si $p<0.05$ significa que si existe una diferencia significativa en el uso de las herramientas AMT y por lo tanto esto significa que el tamaño de las plantas si influye en el uso de herramientas AMT.

Por causa de que $\boldsymbol{H}_{2}$ busca validar que las empresas maquiladoras con niveles más altos de uso de las herramientas AMT tienen un mayor desempeño de competitividad de fabricación, la muestra de empresas será separado en dos grupos usando como discriminante su desempeño de acuerdo con el valor ICF estandarizado obtenido de la 
ecuación 14. Al igual que en la primera hipótesis, el nivel de uso de las diferentes herramientas AMT debe ser calculado en cada grupo para luego usar la prueba noparamétrica Mann-Whitney y así calcular si existe o no una diferencia significativa entre ambos grupos. En este caso, si $p<0.05$ significa que si existe una diferencia significativa en el uso de las herramientas AMT y por lo tanto esto significa que su uso si afecta positivamente el desempeño de fabricación de las plantas maquiladoras.

En el caso de $\boldsymbol{H}_{\mathbf{3}}-\boldsymbol{H}_{\mathbf{6}}$ el propósito es validar el efecto o la relación causal existente entre las herramientas AMT y los elementos usados para medir la competitividad de fabricación. Una buena manera de medir esto es a través de un análisis de regresión múltiple que mida como las variables independientes afectan a las dependientes, capturando así la causalidad existente. Una forma robusta de hacer esto es mediante el análisis de senderos (path analysis) disponible en los estudios SEM. Para ello pueden utilizarse herramientas informáticas como IBM AMOS para calcular, de forma precisa, los coeficientes de regresión estandarizados entre cada variable y medir así el tamaño de los efectos y sus correspondientes valores $P$ que establecen la confiabilidad de los efectos encontrados. La existencia de causalidad, estadísticamente significativa entre las variables analizadas, validará o rechazará las hipótesis planteadas.

De acuerdo con Cohen (1988), efectos con un tamaño de 0.2 se consideran pequeños o "débiles", de 0.5 se consideran "medianos" y de 0.8 grandes o "fuertes". La revisión de los estudios científicos que usan SEM en diferentes industrias y países muestra que los rangos típicos de los efectos encontrados son entre 0.2 y 0.5 (Swink y Nair, 2007; Khanchanapong et al., 2014). Este será el criterio que se usará en el presente desarrollo.

\subsection{Identificación de las variables}

La metodología propuesta plantea, como primer paso, la identificación de las variables a estudiar, tanto en el tema de competitividad como en las herramientas AMT. En el caso de la competitividad, a partir de la revisión bibliográfica y de entrevistas con expertos se identificaron siete prioridades que podrían contribuir a la competitividad de fabricación de las plantas de ensamblaje textil: coste, calidad, flexibilidad, tiempo de entrega, servicio al cliente, innovación y protección ambiental. Usando la identificación hecha en el estado del arte de los componentes propuestos por diferentes académicos para explicar cada prioridad (Tabla 5), fue posible unir todos los componentes semejantes y unificar los 84 componentes que se utilizaran en el estudio (Tabla 11). 


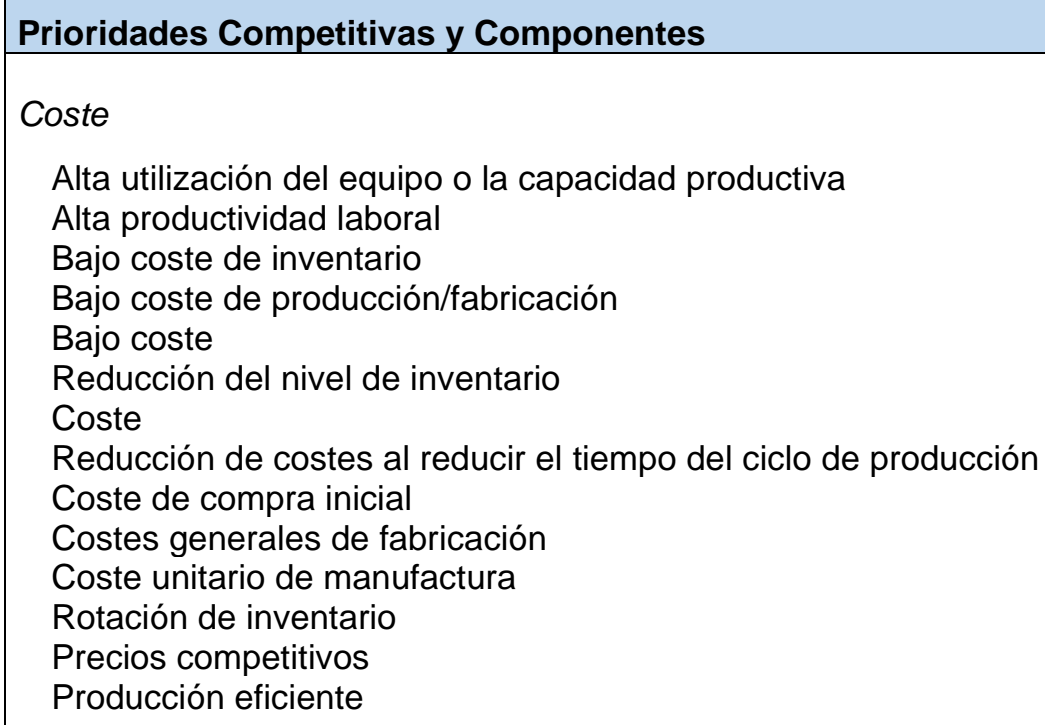

Alta utilización del equipo o la capacidad productiva

Alta productividad laboral

Bajo coste de inventario

Bajo coste de producción/fabricación

Bajo coste

Reducción del nivel de inventario

Coste

Reducción de costes al reducir el tiempo del ciclo de producción

Coste de compra inicial

Costes generales de fabricación

Coste unitario de manufactura

Rotación de inventario

Precios competitivos

Producción eficiente

\section{Calidad}

Alta conformidad del producto final con las especificaciones de diseño

Alto desempeño del producto

Alta confiabilidad del producto

Alta seguridad del producto

Pronta resolución de quejas/preguntas del cliente

Facilidad de reparación (coste y tiempo) del producto

Alta durabilidad del producto (larga vida)

Productos libres de defecto (o bajas tasas de defectos)

Percepción de calidad por parte del cliente

Ofrecer una calidad consistente y fiable

Calidad comparada

Posibilidad de rechazo

Confiabilidad de la entrega

Características del producto

Costes de retrabajo

Porcentaje de inspección de calidad aprobado

Coste del control de calidad

\section{Innovación}

Diferenciación con respecto a la tecnología de productos de los competidores

Características y funcionalidad de producto innovadoras

Ofrecer nuevas innovaciones de producto

Venta de productos en las etapas de iniciación o de crecimiento del ciclo de vida del producto

Uso de tecnologías de producto/proceso de última generación

La tecnología de producto actual representa un gran avance sobre la del producto anterior

Los productos actuales vuelven los productos previos obsoletos

\section{Medio-Ambiente}

Hacer productos respetuosos del medio ambiente

Uso de procesos de producción respetuosos al medio ambiente

Prevenir incidentes ambientales

Proporcionar a la empresa una imagen ambiental positiva 


\section{Flexibilidad}

Habilidad para ajustar la capacidad y/o volumen efectivamente dentro de un corto periodo de tiempo Habilidad para ajustar las entregas para satisfacer las necesidades del cliente

Habilidad de personalizar los productos para satisfacer las especificaciones del cliente

Capacidad de hacer cambios en el diseño del producto una vez iniciada la producción

Ofrecer un gran número de características de producto u opciones

Capacidad de producir una gran variedad de productos

Alta flexibilidad de producción para permitir la introducción eficiente de nuevos productos

Cambios rápidos de los diseños actuales

Rápida introducción de nuevos productos

Cambios rápidos en la mezcla de productos

Alto grado de variedad de productos (amplia línea de productos)

Expansión (aumentos rápidos en la capacidad)

Flexibilidad de la cartera de productos

Flexibilidad en el tamaño del pedido

Flexibilidad en la cartera de telas

Número de nuevos productos introducidos cada año

Tiempo promedio para introducir nuevos productos

Tiempo/coste de preparación (configuración)

Duración del programa de producción fijo

Cambios rápidos de un producto al otro

Tiempo de entrega

Tiempos cortos de cambio/preparación

Corto tiempo del ciclo de desarrollo de producto

Corto tiempo de ciclo de producción

Corto tiempo de entrega de producción

Rápida introducción de nuevos productos

Capacidad para entregar a tiempo

Entregas a tiempo o confiables

Proporcionar entregas rápidas

Órdenes y devoluciones

Tiempo de respuesta a un cliente que solicita información

Tiempo de respuesta a una solicitud de cotización

Disponibilidad de entrega (probabilidad que los artículos estén en inventario cuando se ordenan)

Fiabilidad de la entrega (entregado en la fecha acordada)

Exactitud de la entrega (se entregaron los artículos correctos)

Plazo de entrega

Precisión del estado (status) del inventario

Plazo de ejecución de adquisiciones

Tiempo máximo de fabricación

\section{Servicio}

Servicio postventa

Necesidades del cliente

Información

Asistencia técnica

Un proceso semejante se hizo con las herramientas AMT. Utilizando la revisión de literatura y opinión de expertos se propuso la taxonomía de herramientas AMT que se presenta en la Tabla 12 y que agrupa las herramientas en cuatro categorías: diseño e ingeniería, administración, automatización en la fabricación y mejora de procesos. 
Tabla 12. Modelo de categorización (taxonomía) de herramientas AMT

\begin{tabular}{|c|c|c|c|}
\hline \multicolumn{4}{|c|}{ Herramientas AMT (tecnologías y metodologías) } \\
\hline $\begin{array}{c}\text { Diseño e } \\
\text { ingeniería }\end{array}$ & Administración & $\begin{array}{c}\text { Fabricación } \\
\text { automatizada }\end{array}$ & Mejora de procesos \\
\hline $\begin{array}{l}\text { CAD (Diseño Asistido } \\
\text { por Computadoras) } \\
\text { CAM (Fabricación } \\
\text { Asistida por } \\
\text { Computadoras) } \\
\text { CAE (Ingeniería } \\
\text { Asistida por } \\
\text { Computadoras) } \\
\text { CAPP (Planeación de } \\
\text { Procesos Asistida por } \\
\text { Computadora) } \\
\text { PLM (Administración } \\
\text { del Ciclo de Vida del } \\
\text { Producto) } \\
\text { Ingeniería } \\
\text { Concurrente } \\
\text { AMFE (Análisis } \\
\text { Modal de Fallos y } \\
\text { Efectos) } \\
\text { DOE (Diseño de } \\
\text { Experimentos) }\end{array}$ & $\begin{array}{l}\text { ERP (Planificación de } \\
\text { Recursos de la } \\
\text { Empresa) } \\
\text { - MRP (Planificación de } \\
\text { Recursos y Materiales } \\
\text { - MRP II (Planificación } \\
\text { de Recursos de } \\
\text { Manufactura) } \\
\text { MES (Sistemas de } \\
\text { Ejecución de } \\
\text { Fabricación) } \\
\text { - Mantenimiento } \\
\text { preventivo } \\
\text { - Administración de la } \\
\text { calidad } \\
\text { - Administración de } \\
\text { inventario } \\
\text { - Control y supervisión } \\
\text { - Análisis de } \\
\text { productividad } \\
\text { SCM (Administración } \\
\text { de la Cadena de } \\
\text { Suministros) } \\
\text { CRM (Administración } \\
\text { de las Relaciones con } \\
\text { Clientes) }\end{array}$ & $\begin{array}{l}\text { CNC (Control } \\
\text { Numérico } \\
\text { Computarizado) } \\
\text { PLC } \\
\text { (Controladores } \\
\text { Lógicos } \\
\text { Programables) } \\
\text { FMS (Sistemas } \\
\text { Flexibles de } \\
\text { Fabricación) } \\
\text { AGV (Vehículos } \\
\text { Guiados } \\
\text { Automáticamente) } \\
\text { ASRS (Sistemas } \\
\text { de Almacenaje y } \\
\text { Recuperación } \\
\text { Automática de } \\
\text { productos) } \\
\text { Robots } \\
\text { Inspección de } \\
\text { Calidad Automática } \\
\text { (visión artificial, } \\
\text { sensores, etc.) } \\
\text { Código de barras / } \\
\text { Sistemas RFID }\end{array}$ & $\begin{array}{l}\text { SPC (Control Estadístico de Procesos) } \\
\text { - Graficas de control } \\
\text { - Capacidad de proceso (Cp, Cpk, etc.) } \\
\text { TQM (Administración de la Calidad } \\
\text { Total) } \\
\text { - Diagrama de Ishikawa } \\
\text { - Diagrama de Pareto } \\
\text { - Diagrama de flujo } \\
\text { - Lluvia de ideas } \\
\text { - Grupos foco } \\
\text { - Diagramas de dispersión } \\
\text { - Gráficos de pastel e histogramas } \\
\text { Jidoka (Autonomación errores) } \\
\text { DMAIC } \\
\text { VSM (Mapa de Cadena de Valor) } \\
\text { ANDON (señales de alarma) } \\
\text { TPM (Mantenimiento Productivo Total) } \\
\text { Ingeniería de Métodos } \\
\text { - Método analítico entrenamiento (AMT) } \\
\text { - Método de medición de tiempos (MtM) } \\
\text { JIT } \\
\text { - Eventos Kaizen } \\
\text { - Flujo Celular } \\
\text { - SOP } \\
\text { - Controles visuales } \\
\text { - 5-S } \\
\text { - Kanban (pull system) } \\
\text { - SMED }\end{array}$ \\
\hline
\end{tabular}

\subsubsection{Identificación de expertos}

La metodología diseñada requería que, tanto el listado de componentes de las prioridades competitivas como el de las herramientas AMT, pudieran reducirse a solo aquellas más relevantes y utilizadas. Para esto fue necesario identificar un grupo de expertos con los cuales realizar un estudio Delphi que permitiera hacer esta selección y reducción. Utilizando las siete prioridades competitivas identificadas (Tabla 11) se generó una encuesta usando Google Forms (Figura 18) para que los 12 expertos previamente seleccionados, y que cumplían con las especificaciones definidas en la 
sección 3.2.2, colocaran en orden de importancia para la industria maquiladora textil dichas prioridades. Usando sus respuestas, y a través del proceso iterativo descrito en el algoritmo propuesto en la Figura 15, se calculó $W$ aplicando la ecuación 5 presentada en la sección 2.4.2. Con este método se encontró que un grupo específico de 10 expertos lograron el acuerdo más elevado entre sí $(W=0.81, p<0)$. Por lo tanto, estos 10 expertos fueron seleccionados para realizar el resto del estudio.

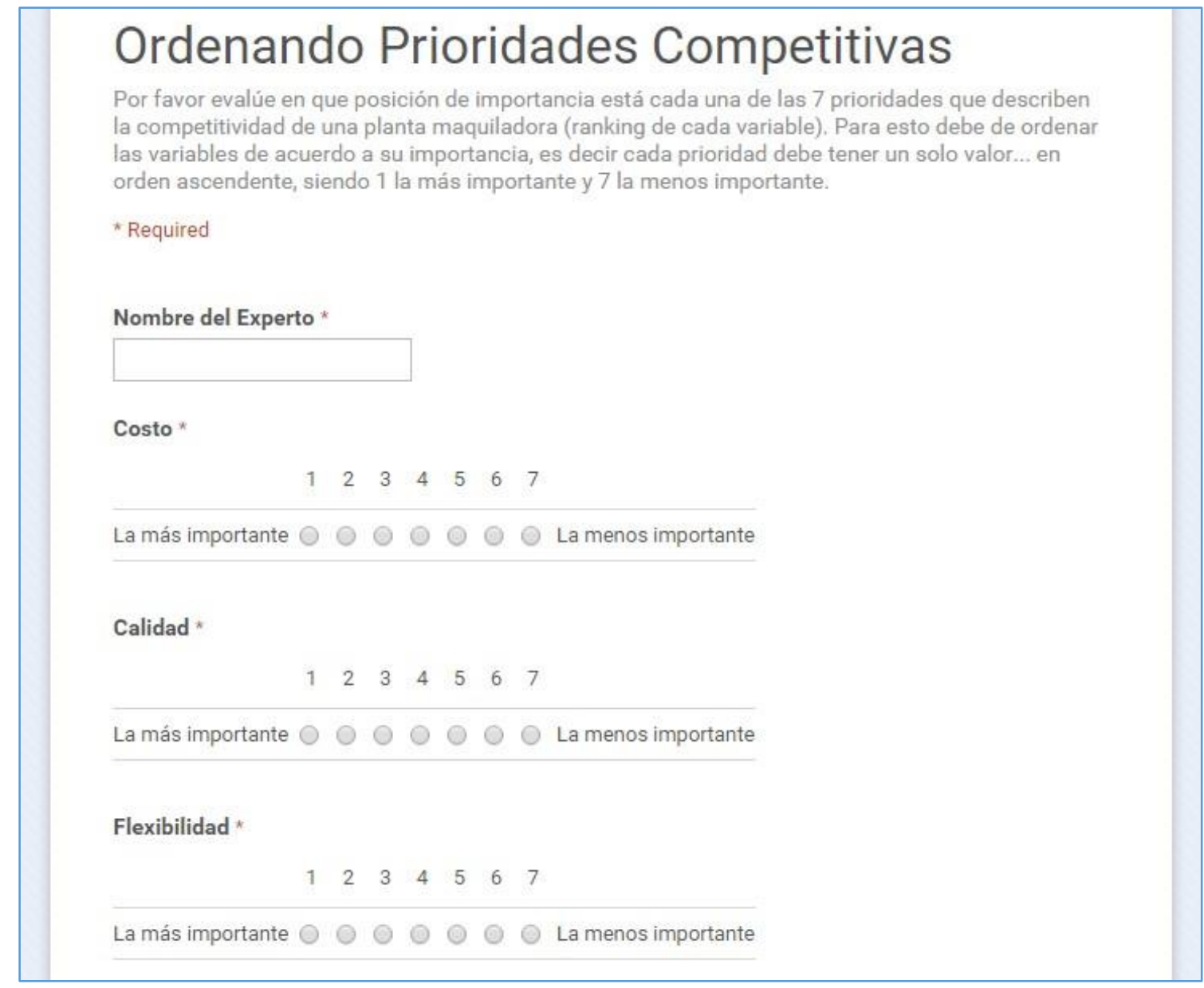

Figura 18. Ejemplo de formato en línea de encuesta

\subsubsection{Reducción de las variables}

La reducción del número de variables a solo aquellas de mayor relevancia y aplicabilidad a la industria maquiladora textil se hizo mediante un estudio Delphi. El instrumento inicial utilizado fue una encuesta que presentaba los 84 componentes obtenidos previamente separados por prioridad competitiva (Tabla 11). El instrumento diseñado en Excel y enviado por correo electrónico solicitó a los expertos seleccionar solo aquellos componentes que, a su criterio, deberían ser utilizados para determinar la prioridad 
competitiva en cuestión. Hubo 24 componentes que ninguno de los expertos seleccionó como importante y fueron retirados de la lista para la segunda ronda de encuestas, a donde si pasaron el resto de los componentes.

\begin{tabular}{|c|c|c|c|}
\hline & Dimensiones en las que coincidieron & Dimensiones que usted no se & eleccionó pero la mayoría de expertos si \\
\hline Variable & Ud. + Resto de Expertos & Expertos & Acción a realizar con esta dimensión \\
\hline \multirow{4}{*}{ Costo } & Reducción del nivel de inventario & $\begin{array}{c}\text { Alta utilización del equipo o de la } \\
\text { capacidad instalada }\end{array}$ & \\
\hline & Reducción del costo al aumentar productividad & Alta productividad de la mano de obra & \multirow{2}{*}{$\begin{array}{l}\text { Si es importante, agregar a mi lista de dimensiones } \\
\text { No agregarla, no es una variable causal o independientes } \\
\text { No agregarla, ya está considerada en otra dimensión selecc } \\
\text { No agregarla, no es aplicable para la industria maquiladora }\end{array}$} \\
\hline & Gastos generales de fabriación & $\begin{array}{l}\text { Reducir costos al aumentar la } \\
\text { utilización }\end{array}$ & \\
\hline & Eficiencia de la producción & & \\
\hline \multirow{5}{*}{ Calidad } & $\begin{array}{l}\text { Productos libres de defecto (o baja tasa de } \\
\text { defectos) }\end{array}$ & $\begin{array}{c}\text { Fabricar con tasas de defectos } \\
\text { consistentemente bajas (reducción de } \\
\text { la tasa de defectos) }\end{array}$ & \\
\hline & Reducción de producto defectuoso & Fiabilidad del producto & \\
\hline & Conformidad a las especificaciones & Costo de re-trabajo & \\
\hline & & Costo del control de calidad & \\
\hline & & $\begin{array}{c}\text { Calidad general percibida por el } \\
\text { cliente }\end{array}$ & \\
\hline \multirow[b]{3}{*}{ Flexibilidad } & Cambios rápidos de volúmen & $\begin{array}{c}\text { Capacidad para ajustar la capacidad y } \\
\text { volúmen efectivamente dentro de un } \\
\text { corto periodo de tiempo }\end{array}$ & \\
\hline & Flexibilidad en la cartera de telas & \begin{tabular}{|c|}
$\begin{array}{c}\text { Rápida introducción de nuevos } \\
\text { productos }\end{array}$ \\
\end{tabular} & \\
\hline & Rápido cambio de un producto al otro & $\begin{array}{l}\text { Habiidad para introducir nuevos } \\
\text { productos }\end{array}$ & \\
\hline
\end{tabular}

Figura 19. Ejemplo instrumento método Delphi

En la segunda ronda, a los expertos se les presentaron los componentes que seleccionaron inicialmente como importantes contrastados con aquellos que sólo sus compañeros identificaron como importantes. La intención de esta ronda era buscar mejorar el acuerdo entre los expertos al pedirles que reconsideraran su respuesta negativa a la luz de la respuesta de sus compañeros (Figura 19). Este fue un proceso iterativo continuo hasta la obtención de un acuerdo sustancial entre los expertos. Se utilizó el algoritmo propuesto en la Figura 15 y la ecuación 10.

Como se explicó en la sección 2.4.2, la herramienta estadística utilizada para determinar el grado de acuerdo entre los expertos en estas rondas fue el coeficiente kappa de Fleiss $(k)$, considerando que un valor $k$ por encima de 0.6 mostraba un acuerdo aceptable entre los expertos. Después de las dos primeras rondas se tuvo claridad sobre cuales componentes se mantendrían y cuales se retirarían, obteniendo un valor $k=0.63$ ( $p<$ $0)$. De este análisis emergieron seis prioridades competitivas, con 24 componentes desagregados entre ellas (Tabla 13). 
Tabla 13. Prioridades competitivas objeto de estudio empírico

\begin{tabular}{|c|c|c|c|c|c|}
\hline \multicolumn{6}{|c|}{ Prioridades Competitivas de Fabricación } \\
\hline Coste & Calidad & Flexibilidad & $\begin{array}{l}\text { Tiempo de } \\
\text { Entrega }\end{array}$ & $\begin{array}{l}\text { Protección } \\
\text { Ambiental }\end{array}$ & Innovación \\
\hline $\begin{array}{l}\text { Alta utilización del } \\
\text { equipo o de la } \\
\text { capacidad } \\
\text { instalada } \\
\text { Alta productividad } \\
\text { de la mano de obra } \\
\text { Bajo coste de } \\
\text { producción / } \\
\text { fabricación } \\
\text { Reducción del nivel } \\
\text { de inventario } \\
\text { Eficiencia de la } \\
\text { producción }\end{array}$ & $\begin{array}{l}\text { Alta conformidad } \\
\text { del producto a } \\
\text { especificaciones } \\
\text { de diseño } \\
\text { Productos libres } \\
\text { de defecto (o } \\
\text { baja tasa de } \\
\text { defectos) } \\
\text { Percepción de } \\
\text { calidad del } \\
\text { cliente } \\
\text { Coste del control } \\
\text { de calidad }\end{array}$ & $\begin{array}{l}\text { Alta flexibilidad } \\
\text { de producción } \\
\text { para permitir la } \\
\text { introducción } \\
\text { eficiente de } \\
\text { nuevos productos } \\
\text { Cambios rápidos } \\
\text { en diseños } \\
\text { actuales } \\
\text { Tiempo de } \\
\text { introducción de } \\
\text { nuevos productos } \\
\text { Coste/tiempo de } \\
\text { preparación }\end{array}$ & $\begin{array}{l}\text { Tiempos cortos } \\
\text { de cambio de } \\
\text { herramienta / } \\
\text { preparación } \\
\text { Tiempo de } \\
\text { producción } \\
\text { cortos } \\
\text { Entregas a } \\
\text { tiempo o } \\
\text { confiables } \\
\text { Precisión del } \\
\text { estatus del } \\
\text { inventario } \\
\text { Tiempo de } \\
\text { fabricación }\end{array}$ & $\begin{array}{l}\text { Uso de procesos } \\
\text { de producción } \\
\text { amigables al } \\
\text { medio ambiente } \\
\text { Prevenir } \\
\text { incidentes } \\
\text { ambientales } \\
\text { Proveer a la } \\
\text { empresa con una } \\
\text { imagen ambiental } \\
\text { positiva }\end{array}$ & $\begin{array}{l}\text { Diferenciación con } \\
\text { la tecnología de } \\
\text { producto de la } \\
\text { competencia } \\
\text { Características y } \\
\text { funcionalidades de } \\
\text { producto } \\
\text { innovadora } \\
\text { Uso de productos / } \\
\text { procesos de última } \\
\text { generación }\end{array}$ \\
\hline
\end{tabular}

En el caso de las herramientas AMT no se siguió un método de selección tan elaborado como el utilizado en para las prioridades competitivas. Usando la taxonomía definida en la Tabla 12 y la opinión de expertos se definieron aquellas herramientas que tenían mayor posibilidad de ser utilizadas en la industria de ensamblaje textil (Tabla 14).

Tabla 14. Herramientas AMT objeto de estudio empírico

\begin{tabular}{|c|c|c|c|c|}
\hline \multicolumn{5}{|c|}{ Categorización de Herramientas AMT } \\
\hline Diseño e ingeniería & Administración & $\begin{array}{l}\text { Fabricación } \\
\text { automatizada }\end{array}$ & Mejora de & procesos \\
\hline $\begin{array}{l}\text { CAD (Diseño Asistido } \\
\text { por Computadora) } \\
\text { CAM (Manufactura } \\
\text { Asistida por } \\
\text { Computadora) } \\
\text { CAE (Ingeniería } \\
\text { Asistida por } \\
\text { Computadora) } \\
\text { Ingeniería } \\
\text { concurrente } \\
\text { PLM (Administración } \\
\text { del Ciclo de Vida del } \\
\text { Producto) } \\
\text { AMFE (Análisis de } \\
\text { Fallos y Efectos) } \\
\text { DOE (Diseño de } \\
\text { Experimentos) }\end{array}$ & $\begin{array}{l}\text { ERP (Planeación } \\
\text { de Recursos } \\
\text { Empresariales) - } \\
\text { MRP, MRPII, etc. } \\
\text { MES (Sistemas de } \\
\text { Ejecución de } \\
\text { Manufactura) - } \\
\text { Administrar } \\
\text { inventarios, } \\
\text { calidad, } \\
\text { productividad, etc. } \\
\text { SCADA (Control y } \\
\text { Supervisión } \\
\text { Remotos) } \\
\text { SCM } \\
\text { (Administración de } \\
\text { la Cadena de } \\
\text { Suministros) } \\
\text { CRM } \\
\text { (Administración de } \\
\text { la Relación con } \\
\text { Clientes) }\end{array}$ & $\begin{array}{l}\text { CNC (Control } \\
\text { Numérico } \\
\text { Computarizado) } \\
\text { PLC } \\
\text { (Automatización } \\
\text { Programable) } \\
\text { Trazabilidad } \\
\text { mediante Código de } \\
\text { Barra y/o RFID } \\
\text { FMS (Sistemas de } \\
\text { Manufactura } \\
\text { Flexible) } \\
\text { AGV (Vehículos } \\
\text { Guiados de forma } \\
\text { Automática) } \\
\text { ASRS (Almacén } \\
\text { Automático) } \\
\text { Robótica } \\
\text { Inspección de } \\
\text { calidad automática } \\
\text { (visión artificial, } \\
\text { sensores, etc.) }\end{array}$ & $\begin{array}{l}\text { SPC (Control } \\
\text { Estadístico de la } \\
\text { Calidad) - Gráficos de } \\
\text { Control, Capacidad del } \\
\text { Proceso } \\
\text { Jidoka (Autonomación } \\
\text { de detección de } \\
\text { errores) } \\
\text { TPM (Mantenimiento } \\
\text { Productivo Total) } \\
\text { VSM (Mapa de la } \\
\text { Cadena de Valor) } \\
\text { Eventos Kaizen (VSM, } \\
\text { 5S, SOP, Fabrica } \\
\text { Visual) } \\
\text { AMT (Método de } \\
\text { Entrenamiento } \\
\text { Analítico) } \\
\text { MTM (Método de } \\
\text { Medición de Tiempos) } \\
5 S\end{array}$ & $\begin{array}{l}\text { TQM (Administración } \\
\text { Total de la Calidad) - } \\
\text { Ishikawa, Pareto, } \\
\text { Diagrama de flujo, } \\
\text { Brainstorming, } \\
\text { Histograma, Grupo } \\
\text { foco, Diagramas de } \\
\text { dispersión, Gráficos } \\
\text { de barra y pastel } \\
\text { DMAIC } \\
\text { Andón (Avisos o } \\
\text { señales de alarma) } \\
\text { Flujo celular } \\
\text { SOP } \\
\text { (Estandarización de } \\
\text { procesos) } \\
\text { Kanban (Sistemas } \\
\text { pull) } \\
\text { SMED (Reducción en } \\
\text { tiempo de setup) }\end{array}$ \\
\hline
\end{tabular}




\subsubsection{Encuesta}

A través del análisis cualitativo realizado se eligieron 24 componentes distribuidos entre 6 prioridades competitivas y 35 herramientas AMT distribuidas en 4 categorías. Con estas variables se procedió a crear un instrumento para recolectar datos empíricos que pudieran utilizarse para realizar el análisis cuantitativo propuesto. El instrumento se diseñó en forma de encuesta con tres secciones y haciendo uso de dos escalas Likert diferentes. Como se estableció en la metodología (sección 3.2.4), la primera escala averiguaba el nivel de rendimiento comparativo de las plantas de fabricación en las prioridades y capacidades competitivas de esa industria. En el caso de las herramientas AMT, se buscó determinar el nivel de uso de cada herramienta AMT por parte de las empresas siendo encuestadas. La encuesta fue diseñada para ser completada en línea usando el portal web www.qualtrics.com (Figura 20).

\section{Por favor indique el grado de desempeño que su empresa/planta maquiladora tiene en los siguientes elementos que ayudan a mejorar el COSTO de las operaciones en la industria maquiladora.}
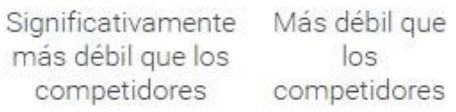
Igual que los competidores

Significativamente mejor que los competidores
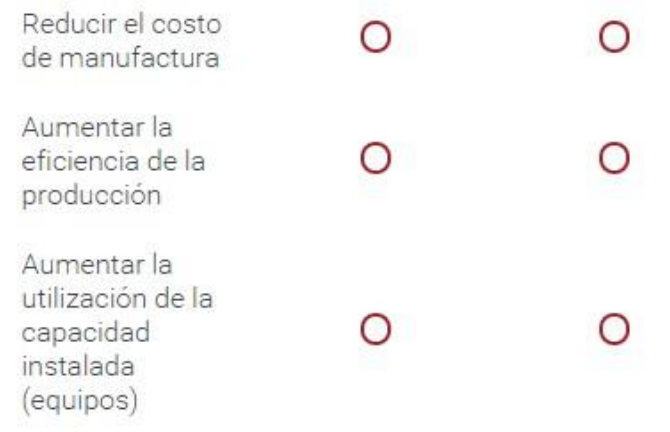

O

O

O
Más alto que competidores

O

0

O

\section{O}

O

O

Figura 20. Muestra de la encuesta diseñada usando la aplicación Qualtrics

De cara a seleccionar las empresas a las que se enviaría la encuesta se utilizaron los datos proporcionados por la Asociación Hondureña de Maquiladores. Honduras cuenta con una población de 68 empresas ensambladoras de textiles (maquiladoras) con más del $80 \%$ de ellas ubicadas en el norte del país. La encuesta creada fue enviada mediante correo electrónico a gerentes de producción, ingeniería y calidad de estas empresas alcanzado una tasa de respuesta del 18\% (12 empresas) con 77 participantes y 57 encuestas utilizables. Ocho de las 12 empresas de la muestra $(66 \%)$ eran fábricas 
multinacionales ubicadas en Honduras con extensa experiencia trabajando en otros países de la región, lo que agrega mucho valor a sus respuestas.

Otras estadísticas descriptivas de la muestra que respondió a la encuesta pueden observarse en la Tabla 15.

Tabla 15. Estadística descriptiva de la muestra que respondió a la encuesta

\begin{tabular}{|l|c|c|}
\hline Descripción (tamaño de la muestra) & Frecuencia & Porcentaje \\
\hline Puesto de trabajo $(\mathrm{n}=57)$ & 10 & $18 \%$ \\
Gerente de planta & 6 & $11 \%$ \\
Gerente de producción & 7 & $12 \%$ \\
Gerente/jefe de ingeniería & 7 & $12 \%$ \\
Gerente/jefe de calidad & 27 & $47 \%$ \\
Otras posiciones de gerencia e ingeniería & & \\
\hline Años de experiencia $(\mathrm{n}=57)$ & 16 & $28 \%$ \\
$<5$ & 13 & $23 \%$ \\
$5 \leq 10$ & 22 & $39 \%$ \\
$10 \leq 20$ & 6 & $10 \%$ \\
$>20$ & & \\
\hline Cantidad de empleados de la planta $(\mathrm{n}=57)$ & 3 & $23 \%$ \\
$<100$ & 13 & $18 \%$ \\
$100 \leq 150$ & 10 & $35 \%$ \\
$500 \leq 1000$ & 20 & $19 \%$ \\
$1000 \leq 3000$ & 11 & \\
$>3000$ & & \\
\hline
\end{tabular}

Para evaluar la fiabilidad y consistencia interna del instrumento diseñado se calculó el valor de alfa de Cronbach para las dos secciones que contenían escalas Likert. El alfa de Cronbach para la sección dedicada a las prioridades y capacidades competitivas fue de 0.88 , con valores alfa para cada constructo superiores al umbral de 0.7 . En el caso de la sección dedicada a las herramientas AMT, el alfa de Cronbach total fue de 0.92 con valores de alfa para cada constructo superiores a 0.8 . Debido a que en todos los casos los valores de alfa de Cronbach se encontraban por encima de los valores mínimos sugeridos, se consideró que se tenía un instrumento fiable y consistente.

\subsection{Definición de modelos de medición}

De acuerdo con la metodología propuesta, el análisis factorial exploratorio (EFA) se utiliza para probar la validez de los constructos propuestos originalmente o para encontrar los cambios que son necesarios realizar. Para asegurar que la muestra obtenida era adecuada para realizar este análisis se realizaron las pruebas KMO y la de esfericidad de Bartlett. El valor $\mathrm{KMO}$, obtenido para la sección del instrumento 
relacionada con la competitividad fue de 0.69 y en el caso de la sección relacionada con las herramientas AMT, fue 0.76. Debido a que ambos valores estaban arriba del valor frontera de 0.6 estos fueron considerados aceptables. En ambos casos, la prueba de esfericidad de Bartlett fue significativa, lo que comprueba que existe suficiente correlación entre las variables como para poder acometer un análisis EFA valido con ambos conjuntos de datos.

Dado que todos los datos fueron recolectados a través de un solo método (encuesta en línea), existía la posibilidad, en la introducción en los datos, de un error de respuesta sistemático. Para probar que no existía sesgo de método común (CMB) en los modelos de competitividad y herramientas AMT, se utilizó la Prueba de Factor Único de Harman. Debido a que el factor único obtenido solo representaba el 37\% (competitividad) y $31 \%$ (herramientas AMT) de la varianza total del modelo, existe un fuerte indicio de que CMB no es un problema en ninguno de los dos modelos.

\subsubsection{Modelo de prioridades competitivas}

Con el fin de probar la unidimensionalidad y validez del modelo de medición propuesto a partir del análisis de expertos (Tabla 12), se realizó un EFA basado en el análisis PCA, usando una rotación Varimax como método de extracción de factores. Los componentes que no tenían comunalidades lo suficientemente altas, cargas factoriales significativas, o que tenían cargas en más de un factor fueron descartados para asegurar la validez convergente y discriminante del modelo. Adicionalmente fue necesario reubicar algunos componentes dentro de otras prioridades competitivas y eliminar aquellas prioridades con solo un componente. La fiabilidad de los nuevos constructos obtenidos en el modelo de medición fue confirmada mediante el cálculo de su alfa de Cronbach.

Como se puede observarse en la Tabla 16, se obtuvo un modelo de medición con solo 13 componentes distribuidos entre cuatro prioridades competitivas (coste, protección ambiental, tiempo de entrega y flexibilidad).

El modelo propuesto presenta valores de alfa de Cronbach para cada constructo superior a 0.77 , cargas factoriales de 0.57 y puede explicar el $72 \%$ del total de la varianza. El análisis fue realizado utilizando el paquete de software IBM SPSS V.22. 
Tabla 16. Matriz de componentes rotados

\begin{tabular}{|c|c|c|c|c|c|c|}
\hline Prioridades Competitivas y Componentes & Mean & SD & Coste & $\begin{array}{l}\text { Prot. } \\
\text { Amb. }\end{array}$ & $\begin{array}{l}\text { Tiempo } \\
\text { Entrega }\end{array}$ & Flexib. \\
\hline \multicolumn{7}{|l|}{ C - Coste $(\alpha$ Cronbach $=0.80)$} \\
\hline $\begin{array}{l}\text { C1 - Aumentar la utilización de la capacidad (equipos) } \\
\text { instalada }\end{array}$ & 4.53 & 0.68 & 0.848 & 0.164 & 0.084 & -0.005 \\
\hline $\mathrm{C} 2$ - Incrementar la productividad laboral & 4.60 & 0.62 & 0.831 & 0.226 & 0.206 & 0.021 \\
\hline C3 - Aumentar la eficiencia de la producción & 4.86 & 0.40 & 0.799 & -0.031 & 0.000 & 0.043 \\
\hline $\begin{array}{l}\text { C4 - Aumentar la conformidad del producto a las } \\
\text { especificaciones }\end{array}$ & 4.58 & 0.57 & 0.573 & 0.017 & 0.478 & 0.094 \\
\hline \multicolumn{7}{|l|}{ PA - Protección ambiental $(\alpha$ Cronbach $=0.82)$} \\
\hline PA1 - Prevenir incidentes ambientales & 4.53 & 0.63 & 0.148 & 0.860 & 0.265 & 0.113 \\
\hline $\begin{array}{l}\text { PA2 - Utilización de procesos de producción } \\
\text { amigables al medio ambiente }\end{array}$ & 4.53 & 0.63 & 0.113 & 0.784 & 0.286 & 0.252 \\
\hline $\begin{array}{l}\text { PA3 - Proporcionar a la empresa una imagen } \\
\text { ambiental positive }\end{array}$ & 4.40 & 0.75 & 0.083 & 0.778 & 0.086 & 0.138 \\
\hline \multicolumn{7}{|l|}{ TE - Tiempo de entrega $(\alpha$ Cronbach $=0.77)$} \\
\hline TE1 - Reducir tiempo de manufactura (inicio a final) & 4.44 & 0.68 & 0.136 & 0.165 & 0.889 & 0.077 \\
\hline TE2 - Reducir tiempo total de producción (lead time) & 4.40 & 0.70 & 0.106 & 0.282 & 0.680 & 0.270 \\
\hline $\begin{array}{l}\text { TE3 - Reducir tiempo/coste de preparación (setup) } \\
\text { y cambio }\end{array}$ & 4.51 & 0.68 & 0.128 & 0.232 & 0.652 & 0.244 \\
\hline \multicolumn{7}{|l|}{ F - Flexibilidad $(\alpha$ Cronbach $=0.81)$} \\
\hline F1 - Reducir tiempo para introducir un nuevo producto & 4.60 & 0.65 & 0.179 & 0.045 & 0.091 & 0.904 \\
\hline F2 - Habilidad para introducir nuevos productos & 4.65 & 0.64 & -0.029 & 0.205 & 0.212 & 0.846 \\
\hline F3 - Cambios rápidos de un tipo de producto al otro & 4.72 & 0.53 & -0.081 & 0.347 & 0.276 & 0.658 \\
\hline \multicolumn{3}{|c|}{ Varianza Total } & 2.503 & 2.365 & 2.244 & 2.212 \\
\hline & \multicolumn{2}{|c|}{$\%$ de Varianza } & 19.250 & 18.190 & 17.259 & 17.013 \\
\hline & \multicolumn{2}{|c|}{$\%$ Acumulado } & 19.250 & 37.440 & 54.699 & 71.712 \\
\hline
\end{tabular}

Método de Extracción: Análisis de Componentes Principales

Método de Rotación: Varimax con Normalización Kaiser

Para confirmar la estructura de factores encontrada mediante el EFA, se hizo un análisis CFA para lo que también se utilizó el paquete de software IBM AMOS V.22 usando el método de estimación ML. Como se observa en la Tabla 17, la validez discriminante del modelo fue estimada comparando MSV, ASV, AVE y CR de acuerdo con los parámetros discutidos en la sección 2.4.2. Adicionalmente, la bondad de ajuste del modelo se determinó revisando que, los valores de Chi-cuadrado / grados de libertad, RMSEA y SRMR, se mantienen dentro de los limites especificados en la Tabla 8.

Tabla 17. Parámetros de ajuste del modelo confirmatorio de competitividad

\begin{tabular}{|c|c|c|c|c|c|c|c|c|}
\hline \multicolumn{9}{|c|}{ Modelo de medición de las prioridades competitivas } \\
\hline & CR & AVE & MSV & ASV & $\mathbf{F}$ & TE & C & PA \\
\hline $\mathbf{F}$ & 0.824 & 0.613 & 0.272 & 0.177 & 0.783 & & & \\
\hline TE & 0.782 & 0.546 & 0.378 & 0.287 & 0.522 & 0.739 & & \\
\hline C & 0.816 & 0.532 & 0.212 & 0.132 & 0.157 & 0.460 & 0.730 & \\
\hline PA & 0.849 & 0.660 & 0.378 & 0.258 & 0.485 & 0.615 & 0.401 & 0.812 \\
\hline \multicolumn{9}{|c|}{$\chi^{2} / d . f=1.469, C F I=0.915, R M S E A=0.092$ y SRMR $=0.0806$} \\
\hline
\end{tabular}


Como se muestra en la Tabla 17, el modelo obtenido puede considerarse valido y con un ajuste aceptable a pesar de tener una muestra relativamente pequeña de datos. Por lo tanto, como se muestra en la Figura 21, el modelo de medición a utilizar para estimar la competitividad está compuesto por 4 factores y 13 componentes distribuidos entre ellos.

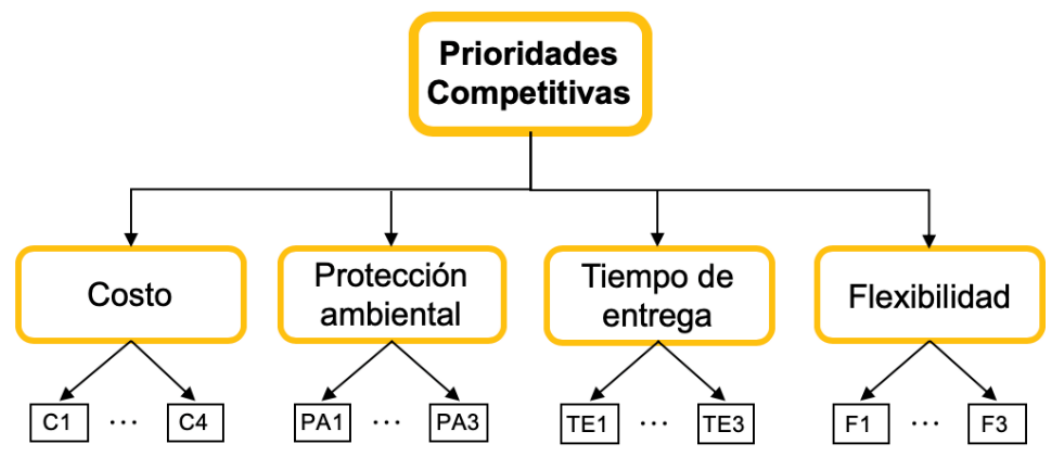

Figura 21. Modelo de medición de la competitividad de fabricación

\subsubsection{Modelo de capacidades competitivas}

Usando el modelo de medicion obtenido así como las cargas factoriales y la varianza explicada descrita en la Tabla 16, es posible definir un modelo de referencia de la competitividad de fabricación de la industria de ensamblaje textil. Para esto es importante recordar que, en este punto, las prioridades competitivas se convierten en decisiones o acciones, es decir en capacidades competitivas. Como se muestra en la Figura 22, este modelo puede ser usado para calcular el ICF usando la ecuacion 13 descrita en la seccion 3.3.3 y las respuestas a las preguntas de la encuesta sobre el desempeño comparativo en las capacidades competitivas descritas en la seccion 3.2.4.

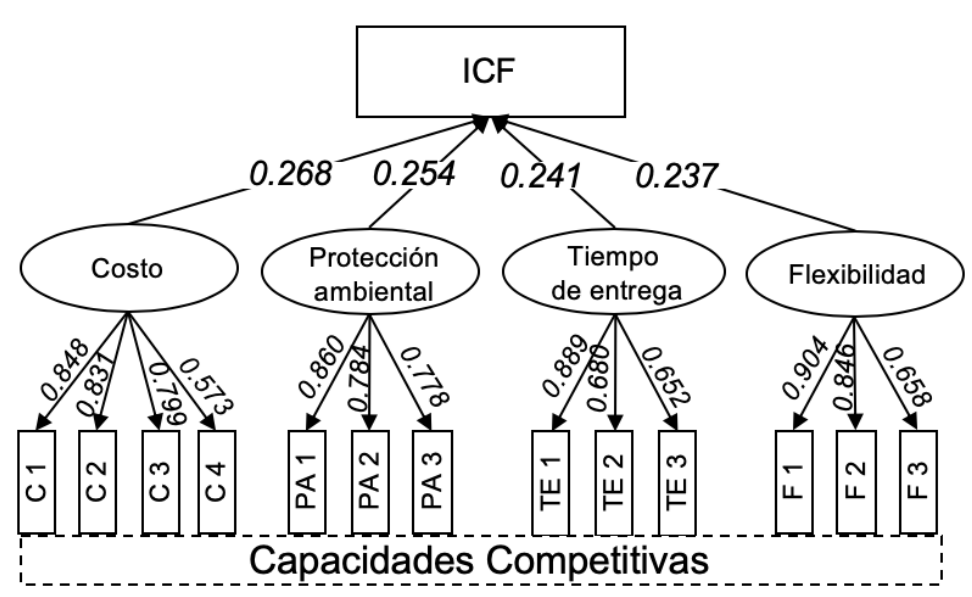

Figura 22. Modelo de referencia de la competitividad de fabricación 
La Tabla 18 demuestra la forma en que el modelo de referencia es usado para calcular el ICF de una empresa líder de fabricacion de prendas de vestir con varias plantas operando en Honduras. Para hacerlo se hace uso del valor promedio del desempeño comparativo $(D)$ en cada componente obtenido de todas las encuestas recibidas de esta empresa, el cual se multiplica por su carga factorial $(C)$ correspondiente, la cual fue obtenida del analisis EFA y que permite así obtener un componente ponderado. El factor ajustado $(F)$ se obtuvo de sumar todos los componentes ponderados de cada factor y dividirlos por la suma de todos las cargas factoriales del mismo factor. El peso $(P)$ de cada factor se obtuvo de dividir el \% de varianza explicada por el factor entre el \% total de varianza explicada por el modelo. EI ICF se obtuvo de la suma de multiplicar los factores ajustados por sus correspondientes pesos.

Tabla 18. Cálculo del índice de competitividad

\begin{tabular}{|c|c|c|c|c|c|c|}
\hline Factores & Comp. & $\begin{array}{c}\text { Desempeño } \\
\text { Comparativo } \\
\text { (D) }\end{array}$ & $\begin{array}{c}\text { Cargas } \\
\text { factoriales } \\
\text { (C) }\end{array}$ & $\begin{array}{c}\text { Factor } \\
\text { Ajustado } \\
(F)\end{array}$ & $\begin{array}{c}\text { Peso } \\
(P)\end{array}$ & ICF \\
\hline Coste & $\begin{array}{l}\text { C1 } \\
\text { C2 } \\
\text { C3 } \\
\text { C4 }\end{array}$ & $\begin{array}{l}3.76 \\
3.80 \\
4.12 \\
3.96\end{array}$ & $\begin{array}{l}0.848 \\
0.831 \\
0.799 \\
0.573\end{array}$ & 3.903 & 0.268 & \multirow{4}{*}{3.93} \\
\hline $\begin{array}{l}\text { Protección } \\
\text { ambiental }\end{array}$ & $\begin{array}{l}\text { PA1 } \\
\text { PA2 } \\
\text { PA3 }\end{array}$ & $\begin{array}{l}4.28 \\
4.16 \\
4.16\end{array}$ & $\begin{array}{l}0.860 \\
0.784 \\
0.778\end{array}$ & 4.203 & 0.254 & \\
\hline $\begin{array}{c}\text { Tiempo de } \\
\text { entrega }\end{array}$ & $\begin{array}{l}\text { TE1 } \\
\text { TE2 } \\
\text { TE3 }\end{array}$ & $\begin{array}{l}3.96 \\
3.76 \\
4.00\end{array}$ & $\begin{array}{l}0.889 \\
0.680 \\
0.652\end{array}$ & 3.911 & 0.241 & \\
\hline Flexibilidad & $\begin{array}{l}\text { F1 } \\
\text { F2 } \\
\text { F3 }\end{array}$ & $\begin{array}{l}3.68 \\
3.64 \\
3.72 \\
\end{array}$ & $\begin{array}{l}0.904 \\
0.846 \\
0.658\end{array}$ & 3.677 & 0.237 & \\
\hline
\end{tabular}

En el caso de esta empresa, su ICF estandarizado se obtiene usando la ecuacion 14 y considerando los valores ICF maximos y minimos posibles como 1 y 5 respectivamente:

$$
\text { ICF estandarizado }=\frac{3.93-1.00}{5.00-1.00} \times 100=73.25 \%
$$

\subsubsection{Modelo de aplicabilidad de herramientas AMT}

De manera similar a lo que se hizo con el modelo de prioridades competitivas de fabricación, la unidimensionalidad y validez del modelo de medición de las herramientas AMT fue probado usando EFA con análisis PCA y rotación Varimax. A través de un proceso iterativo, aquellas herramientas AMT con bajas comunalidades y cargas factoriales no significativas fueron descartadas o movidas a factores en donde 
presentaban mejor carga factorial. Producto del análisis realizado, 15 de las herramientas propuestas originalmente fueron descartadas del modelo final. Sin embargo, como se muestra en la Tabla 19, a pesar de todos estos cambios se logró establecer un modelo de medición que mantenía los cuatro factores propuestos originalmente y que tiene la capacidad de explicar el $64 \%$ de toda la varianza.

Tabla 19. Matriz de componentes rotados para el modelo de herramientas AMT

\begin{tabular}{|c|c|c|c|c|c|c|}
\hline Herramientas Avanzadas de Manufactura (AMT) & Mean & SD & $\begin{array}{l}\text { Mejora } \\
\text { Proceso }\end{array}$ & Admin. & $\begin{array}{l}\text { Autom. } \\
\text { Fabric. }\end{array}$ & $\begin{array}{l}\text { Diseño } \\
\text { Ingen. }\end{array}$ \\
\hline \multicolumn{7}{|l|}{ MP - Mejora de procesos $(\alpha$ Cronbach $=0.887)$} \\
\hline MP1 - Eventos Kaizen & 4.47 & 0.96 & 0.836 & 0.171 & 0.149 & -0.126 \\
\hline MP2 - TPM (Mantenimiento Productivo Total) & 4.33 & 1.21 & 0.825 & 0.212 & 0.130 & -0.012 \\
\hline MP3 - VSM (Mapa de la Cadena del Valor) & 4.24 & 0.94 & 0.814 & 0.070 & 0.111 & 0.072 \\
\hline MP4 - SMED (Reducción en tiempo de Setup) & 4.38 & 1.01 & 0.730 & 0.117 & 0.075 & -0.051 \\
\hline MP5 - Kanban (Sistema Pull) & 4.62 & 0.72 & 0.729 & -0.002 & -0.005 & 0.142 \\
\hline MP6 - 5-S & 4.55 & 0.84 & 0.729 & 0.351 & -0.147 & -0.117 \\
\hline MP7 - TQM (Administración Total de la Calidad) & 4.62 & 0.70 & 0.692 & -0.228 & 0.016 & 0.230 \\
\hline \multicolumn{7}{|l|}{ A - Administración $(\alpha$ Cronbach $=0.844)$} \\
\hline M1 - SCM (Administración de Cadena de Suministros) & 3.55 & 1,48 & -0.043 & 0.754 & 0.102 & 0.287 \\
\hline $\mathrm{M} 2-\mathrm{ANDON}$ & 3.98 & 1.38 & 0.255 & 0.744 & 0.148 & -0.001 \\
\hline M3 - CRM (Administración de la Relación con Clientes) & 3.36 & 1.54 & 0.099 & 0.707 & 0.119 & 0.458 \\
\hline M4 - FMS (Sistemas de Manufactura Flexible) & 2.97 & 1.61 & 0.231 & 0.589 & 0.382 & 0.130 \\
\hline M5 - ERP (Planeación de Recursos Empresariales) & 3.66 & 1.48 & 0.146 & 0.493 & 0.208 & 0.185 \\
\hline M6 - SCADA (Control y Supervisión Remotos) & 2.62 & 1.51 & 0.037 & 0.484 & 0.267 & 0.374 \\
\hline \multicolumn{7}{|l|}{ FA - Fabricación automatizada ( $\alpha$ Cronbach $=0.800$ ) } \\
\hline AM1 - Robótica & 1.47 & $0, .8$ & 0.031 & 0.051 & 0.808 & 0.009 \\
\hline AM2 - PLC (Controladores Lógicos Programables) & 2.59 & $1, .3$ & 0.059 & 0.182 & 0.762 & 0.016 \\
\hline AM3 - ASRS (Almacén Automático) & 1.57 & 1.17 & 0.083 & 0.095 & 0.748 & 0.293 \\
\hline AM4 - Inspección automática (visión artificial, sensores) & 1.98 & 1.42 & 0.038 & 0.310 & 0.686 & 0.255 \\
\hline \multicolumn{7}{|l|}{ DI - Diseño e ingeniería ( $\alpha$ Cronbach $=0.760$ ) } \\
\hline DE1 - AMFE (Análisis de Fallos y Efectos) & 3.38 & 1.37 & -0.013 & 0.155 & 0.112 & 0.817 \\
\hline DE2 - CAD (Diseño Asistido por Computadora) & 3.38 & 1.44 & 0.066 & 0.027 & 0.241 & 0.755 \\
\hline \multirow[t]{4}{*}{ DE3 - Ingeniería Concurrente } & 3.12 & 1.49 & 0.006 & 0.343 & -0.003 & 0.736 \\
\hline & \multicolumn{2}{|c|}{ Varianza Total } & 6.128 & 3.616 & 1.734 & 1.361 \\
\hline & \multicolumn{2}{|c|}{$\%$ de Varianza } & 30.641 & 18.082 & 8.668 & 6.806 \\
\hline & \multicolumn{2}{|c|}{$\%$ Acumulado } & 30.641 & 48.723 & 57.391 & 64.197 \\
\hline
\end{tabular}

Método de Extracción: Análisis de Componentes Principales

Método de Rotación: Varimax con Normalización Kaiser

Usando el paquete de software IBM AMOS V22.0, se realizó un análisis CFA basado en $\mathrm{ML}$ en el modelo. Como muestra la Tabla 20 , el modelo tiene una validez aceptable de acuerdo con los valores MSV, ASV, AVE y CR calculados.

La bondad de ajuste del modelo es igualmente aceptable al revisar que los valores de Chi-cuadrado / grados de libertad, RMSEA y SRMR estaban dentro de los parámetros establecidos (Tabla 8). 
Capítulo 4. Desarrollo experimental

Tabla 20. Parámetros de ajuste del modelo confirmatorio de herramientas AMT

\begin{tabular}{|ccccc|cccc|}
\hline \multicolumn{7}{|c|}{ Modelo de medición de las herramientas AMT } \\
\hline & CR & AVE & MSV & ASV & AF & MP & A & DI \\
\hline AF & 0.808 & 0.515 & 0.383 & 0.217 & 0.718 & & & \\
MP & 0.882 & 0.521 & 0.112 & 0.058 & 0.240 & 0.722 & & \\
A & 0.844 & 0.476 & 0.475 & 0.323 & 0.619 & 0.335 & 0.690 & \\
DI & 0.771 & 0.532 & 0.475 & 0.230 & 0.458 & 0.071 & 0.689 & 0.729 \\
\hline \multicolumn{10}{|c|}{$\chi^{2 / d . f . \neq . \neq 326, C F I=0.897,}$ RMSEA $=0.076$ yRMR $=0.0841$} \\
\hline
\end{tabular}

Por lo tanto, como se muestra en la Figura 23, el modelo de medición a utilizar para las herramientas AMT estará compuesto por 4 factores y 20 componentes.

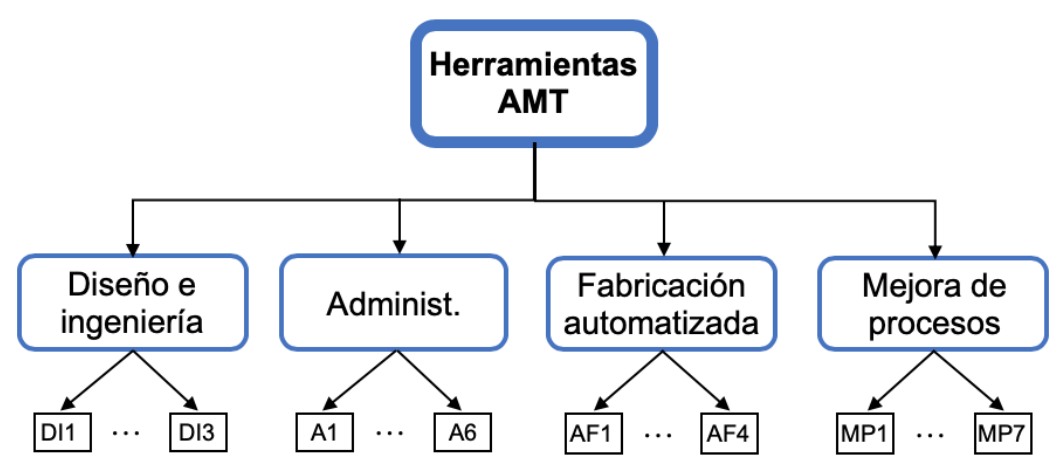

Figura 23. Modelo de medición de las herramientas AMT

Una vez definidos todos los modelos de medición se procedió a realizar las pruebas estadísticas definidas en la propuesta metodológica que se exponen en próximo capítulo. 


\section{ANALISIS DE DATOS}

El análisis de los modelos de medición obtenidos en el desarrollo experimental ha permitido obtener conclusiones referentes al modelo de competitividad de fabricación obtenido y a las hipótesis propuestas. El análisis de las hipótesis se ha dividido entre aquellas que se relacionan con el uso de herramientas AMT en las plantas ensambladoras textiles y aquellas relacionadas a los efectos que este uso tiene en la competitividad de fabricación y sus correspondientes prioridades competitivas.

\subsection{Análisis de las prioridades competitivas}

Uno de los hallazgos más significativos del modelo de referencia obtenido es que la calidad no parece ser una de las prioridades competitivas de la industria ensambladora textil en Honduras. Al tratar de entender por qué parece que los expertos de la industria y la academia entrevistados no consideran la calidad como importante, los conceptos de "calificadores de pedidos" (order qualifiers) y "ganadores de ordenes" (order winners) son los que se manifiestan como causas. Los calificadores de pedidos son aquellos atributos que un cliente considera necesarios para tomar en cuenta a una empresa como un posible proveedor y los ganadores de ordenes son aquellos atributos que causan que los clientes prefieran los productos de una firma sobre su competidor (Hill, 2000).

Por lo tanto, se puede argumentar que los cuatro factores que fueron seleccionados como los más importantes para la estimación de la competitividad de fabricación son los que los expertos consideraron como los atributos que "ganan" los pedidos de los clientes. Aunque la calidad es muy importante para los clientes, se podría argumentar que los expertos la consideran un "calificador" de pedidos, es decir un atributo que sus empresas ya poseen. Es posible que los gerentes de las plantas de ensamblaje textil consideran que ya poseen un nivel de calidad asimilado en sus procesos y productos, por lo que consideran que la calidad es una competencia central ya adquirida de esta industria en particular. Esa podría ser una de las razones por la que la calidad no aparece en el modelo como una de las prioridades competitivas de esta industria.

Otra posible explicación a la paradójica decisión de no considerar a la calidad como un factor importante para la competitividad de fabricación, es que los encuestados si expresaron su opinión sobre la importancia de la calidad, pero a través de componentes 
que están presentes dentro de otros factores. Por ejemplo, "aumentar la conformidad del producto a las especificaciones", que terminó siendo un componente del factor coste (C4), es en realidad un componente de la calidad. Lo mismo sucede con "aumentar la eficiencia de la producción", que también está dentro del factor coste (C3) y que igualmente se puede considerar un componente relacionado con la calidad. El razonamiento de que producir productos de alta calidad reduce los costes, mejora la productividad y reduce los precios es la base de la teoría de la reacción en cadena de Deming (Fuller, 1985), por lo que tiene sentido argumentar que la importancia de este factor está de alguna manera implícita en los otros factores propuestos.

Adicionalmente, es interesante observar la relación que existe entre la calidad, el coste y el tiempo de entrega. Por ejemplo, es lógico pensar que debido a que una planta de ensamblaje textil tiene que entregar la cantidad contratada de prendas con una calidad específica, sus principales preocupaciones son cómo lograrlo en el tiempo acordado y sin necesidad de reprocesar demasiadas piezas con el fin de lograr la calidad adecuada y así no comprometer sus costes (ganancias).

Debido a que los clientes contratan un determinado número de piezas que se entregarán en un plazo determinado y a un precio específico por pieza, el mantener un tiempo de producción y coste bajo es de suma importancia. Entonces, una de las razones por las que el coste y el tiempo de entrega son calificados tan alto en el modelo de competitividad de fabricación podría ser que estos factores son parte de sus ganadores de órdenes. De hecho, uno de los gerentes de producción entrevistados compartió que los dos criterios que determinan si una planta pierde órdenes de producción y/o debe cerrar sus operaciones son el experimentar problemas en sus costes de producción y en sus tiempos de entrega.

Otro dato interesante es la aparición de protección ambiental como prioridad competitiva para la industria ensambladora textil. Una razón por la que esto podría estar ocurriendo es el énfasis que los clientes corporativos dan a la adopción de prácticas de manufactura esbelta y las corrientes actuales Lean Green que se están planteando en la industria textil respecto a la eliminación de residuos asociada al Lean Manufacturing (Carbajal, 2019; Pampanelli, 2014). Otra posibilidad es que, dado que muchos consumidores están tomando decisiones de compra basadas en su deseo de proteger el medio ambiente, las empresas de ensamblaje textil podrían estar tratando de proyectar una imagen de ser socialmente responsables. 
Finalmente, con respecto al último lugar que ocupa la flexibilidad en el modelo de competitividad parece que, en contraste con otros tipos de industrias de ensamblaje que son más dinámicas, la industria textil ha identificado sus principales productos y tiene una producción más enfocada. Esto no quiere decir que esta industria no es capaz de gestionar el cambio, pero parece que sus requisitos de flexibilidad sólo exigen ajustes graduales en la utilización de su capacidad instalada, de la distribución en planta de sus equipos y de la capacitación de su personal. De hecho, de acuerdo con algunos gerentes de planta, algunas compañías incluso tienen plantas flexibles específicas, con máquinas y personal capacitado para manejar cambios drásticos en el estilo de las prendas producidas, con el propósito de no perturbar las plantas de producción normales y poder así alcanzar el coste objetivo y el tiempo de entrega establecido en producciones de alto volumen.

\section{Competitividad de Fabricación}

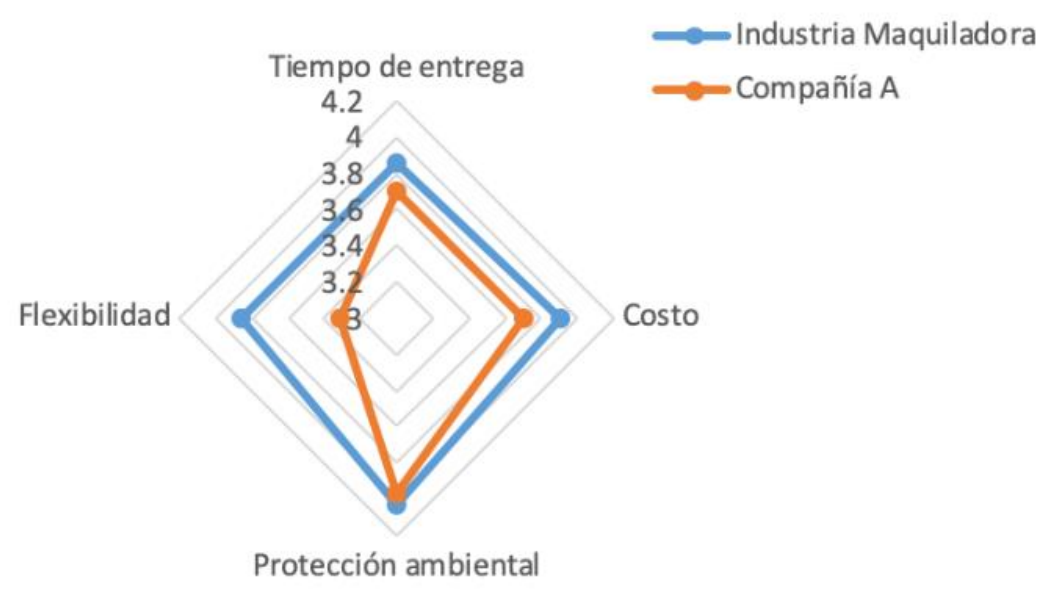

Figura 24. Comparación de los factores de competitividad de fabricación

El modelo de referencia mostrado en la Figura 22 sugiere que la competitividad de fabricación de las plantas de ensamblaje textil puede estimarse utilizando cuatro factores: coste, protección ambiental, tiempo de entrega y flexibilidad. Por lo tanto, es posible comparar la competitividad de fabricación de empresas especificas al usar los valores promedio de las encuestas obtenidas de esa empresa y contranstarlas con los resultados de la industria maquiladora textil como un conjunto. Esta comparación puede hacerse con respecto a cada capacidad competitiva (Figura 24) o a cada uno de sus componentes correspondientes (Figura 25), usando los factores $(F)$ o componentes ajustados $(D \times C)$ respectivamente. 


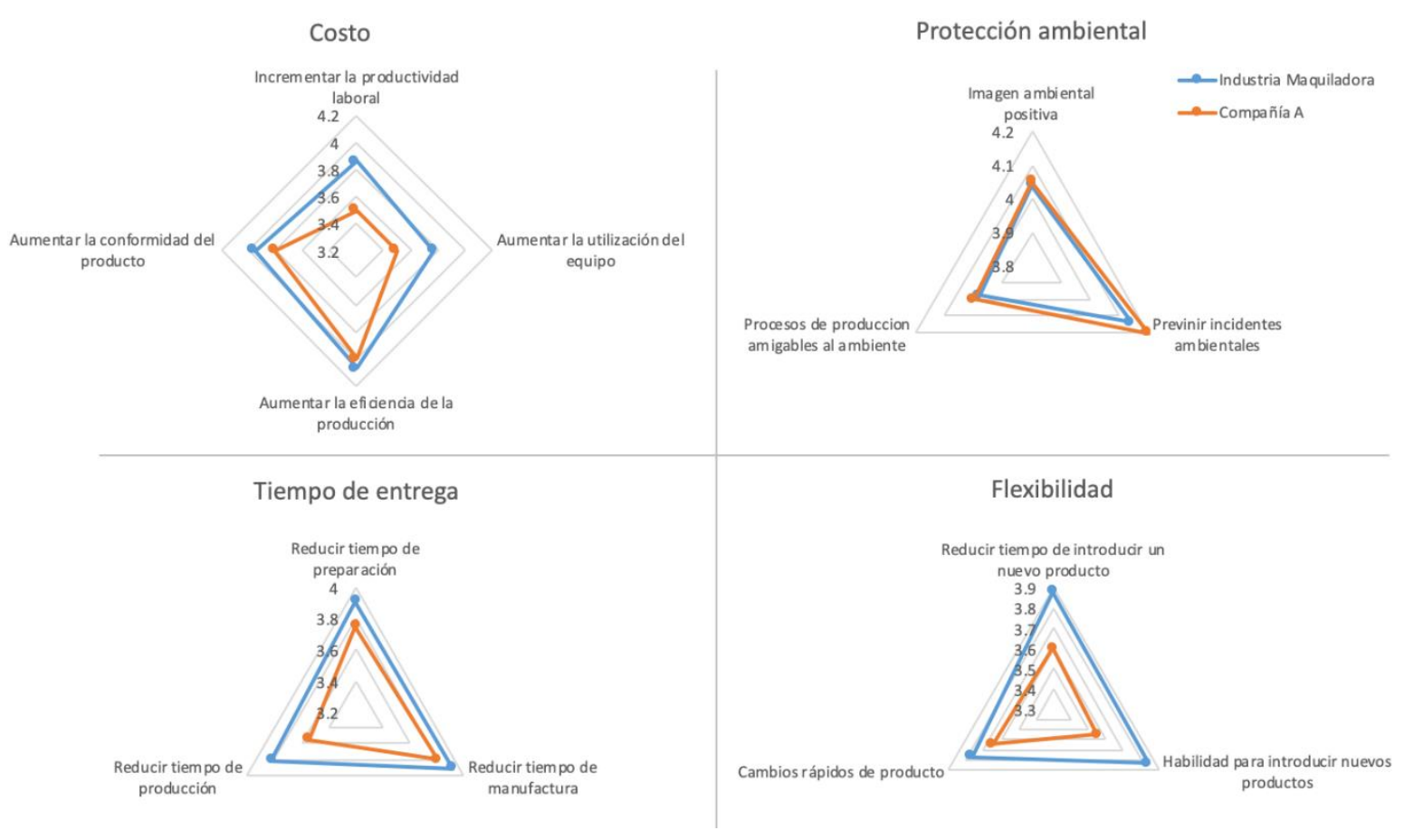

Figura 25. Comparación de los componentes de competitividad de fabricación

Un análisis de este tipo es muy útil ya que permite a una empresa saber cual es su desempeño en comparación a la industria en general y así establecer planes de mejora que les permitan fortalecer los factores y/o componentes de competitividad que requieren atención.

\subsection{Análisis del uso de herramientas AMT}

A pesar que la mayoría de las operaciones en las fábricas de ensamblaje son manuales, en las empresas maquiladoras se busca mejorar la eficiencia y competitividad al adoptar herramientas AMT (metodologias y tecnologias) en sus operaciones (García et al., 2014;. Hadjimarcou et al., 2013). Para poder revisar las hipotesis $\boldsymbol{H}_{\mathbf{1}}$ y $\boldsymbol{H}_{\mathbf{2}}$ se realizó un analisis del uso actual de las herramientas AMT en las plantas maquiladoras textiles en Honduras. La Figura 26 muestra una serie de gráficos radiales de las respuestas promedio obtenidas en la encuesta a la pregunta sobre al grado de uso de las herramientas AMT en las plantas maquiladoras, donde 1 corresponde a "no utilizada", y 5 a "siempre se utiliza". 


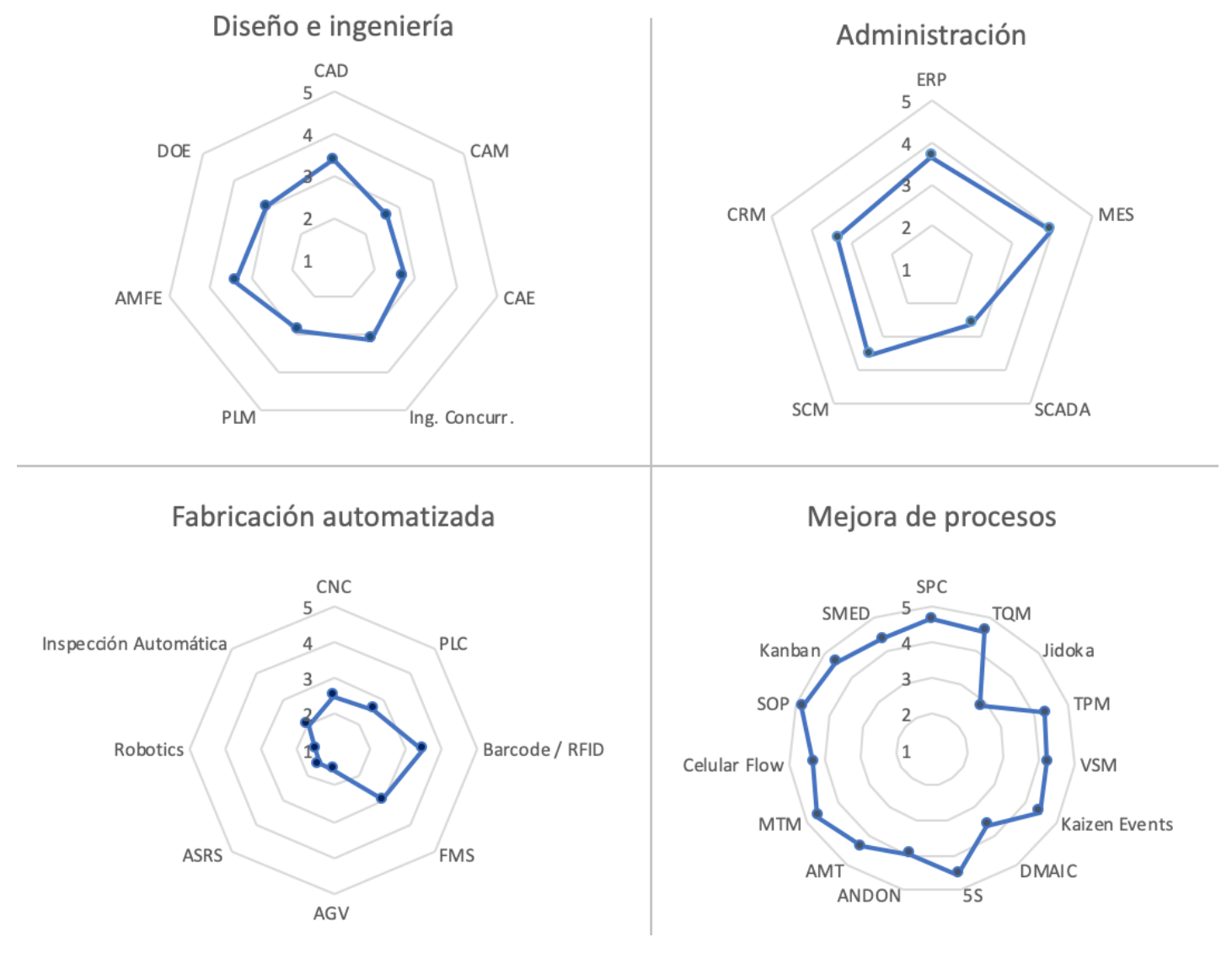

Figura 26. Uso de herramientas AMT en sector maquilador Honduras

Un análisis preliminar de los gráficos radiales en la Figura 26 muestra que, de acuerdo con las respuestas de los gerentes e ingenieros encuestados, en general las herramientas AMT utilizadas más a menudo por las empresas de ensamblaje textil hondureño son las de "Mejora de proceso". De hecho, todas las herramientas de mejora de proceso son bastante usadas con excepción de Jidoka y DMAIC. También se observa que algunas de las herramientas de "Administración", como MES, ERP, CRM y SCM, así como de "Diseño e ingeniería" (CAD y AMFE) son medianamente utilizadas. Las herramientas orientadas a la automatización, tales como los sistemas SCADA o las herramientas CAM y CAE, son de muy poco uso.

Finalmente, se manifiesta que todas las herramientas de "Fabricación automatizada" tienen un uso casi nulo en esta industria, con excepción del uso de lectores de código de barras o tecnología RFID. Estos datos evidencian que las herramientas conocidas en la literatura como "metodologías" y "tecnologías blandas" son las que tienen mayor presencia en esta industria en detrimento de las conocidas como "tecnologías duras". Los resultados obtenidos no son sorprendentes, ya que las fábricas de ensamblaje textil 
utilizan máquinas de coser operadas principalmente por personas y con muy poca automatización para completar la mayoría de sus operaciones. Sin embargo, las entrevistas con diferentes gerentes revelaron que muchos de ellos están evaluando el uso de soluciones para la prueba de errores a través de la automatización parcial de operaciones especificas lo que podría ayudarles a evitar desperdicio y a agregar agilidad a ciertos procedimientos requeridos y que son altamente repetitivos. Uno de los principales obstáculos para el uso de la automatización en las plantas de ensamblaje de prendas de vestir es el alto precio de algunas soluciones estándar para la industria de la confección. El otro obstáculo es la falta de especialistas para ayudarlos a diseñar e implementar soluciones a medida y menos costosas, ya que su fuerza de trabajo de ingeniería está compuesta principalmente por ingenieros sin mucha experiencia en mecatrónica.

Por lo tanto, es evidente que un área de gran oportunidad en esta industria es el uso de tecnologías basadas en hardware que permitan la automatización de ciertos procesos que actualmente se realizan de forma manual. Debido a las restricciones de coste, la adopción de ciertas tecnologías como la robótica, ASRS y AGV parecen difíciles si bien el rápido abaratamiento en los últimos años de estas tecnológicas puede dar un vuelco a la situación. Sin embargo, el uso de PLC brinda la oportunidad de desarrollar soluciones automáticas a un coste relativamente bajo. Debido a que las plantas maquiladoras algunas veces tienen cientos de estaciones de trabajo, el actual desarrollo de plataformas integradas (embedded) de bajo coste tales como Arduino, Raspberry Pi and Beaglebone Black ofrecen oportunidades interesantes para el desarrollo de soluciones de automatización especificas con la versatilidad requerida por esta industria y a precios asequibles.

\subsubsection{Efecto del tamaño de la empresa}

En vista que la primera hipótesis buscaba probar que las plantas de ensamblaje textil grandes usaban las herramientas AMT propuestas con igual intensidad y frecuencia que las plantas de ensamblaje textil pequeñas, se procedió a filtrar los datos por tamaño de las plantas. Usando la pregunta en la encuesta sobre la cantidad de empleados que tenia cada planta, se consideraron como plantas grandes aquellas con 1000 o más empleados y al restante como plantas pequeñas. Con esta información se procedió a crear una tabla que comparaba el uso promedio que se le daba a cada herramienta AMT filtrado por el tamaño de las empresas (Tabla 21). Una inspeccion visual rapida de la 
Tabla 21 muestra que no hay grandes diferencias (mayores de 0.5) en el uso de herramientas AMT que puedan ser atribuibles al tamaño de las plantas. De hecho, las unicas excepciones observables son CAE, DOE, MES y VSM en donde las empresas más grandes muestran claramente un mayor uso de ellas.

Tabla 21. Análisis del uso de herramientas AMT filtrado por tamaño de la empresa

\begin{tabular}{|c|c|c|c|c|c|c|c|c|c|c|}
\hline \multirow{2}{*}{\begin{tabular}{|l|} 
Tamaño de Empresa \\
Herramientas AMT
\end{tabular}} & \multicolumn{2}{|c|}{ Pequeña } & \multicolumn{2}{|c|}{ Grande } & \multirow{2}{*}{\multicolumn{2}{|c|}{$\begin{array}{l}\text { Pequeña Grande } \\
\text { No se utiliza - Se } \\
\text { utiliza muy poco }\end{array}$}} & \multirow{2}{*}{\multicolumn{2}{|c|}{$\begin{array}{c}\text { Pequeña Grande } \\
\text { Se utiliza } \\
\text { algunas veces }\end{array}$}} & \multirow{2}{*}{\multicolumn{2}{|c|}{\begin{tabular}{|c|} 
Pequeña Grande \\
Se utiliza \\
frecuentemente - \\
Se usa siempre \\
\end{tabular}}} \\
\hline & Mean & SD & Mean & SD & & & & & & \\
\hline \multicolumn{11}{|l|}{ Diseño e ingeniería (DI) } \\
\hline CAD & 3,00 & 1,72 & 3,50 & 1,20 & $42 \%$ & $21 \%$ & $4 \%$ & $21 \%$ & $54 \%$ & $58 \%$ \\
\hline CAM & 2,38 & 1,53 & 2,71 & 1,41 & $58 \%$ & $39 \%$ & $13 \%$ & $29 \%$ & $29 \%$ & $32 \%$ \\
\hline CAE & 2,25 & 1,45 & 2,89 & 1,40 & $58 \%$ & $32 \%$ & $17 \%$ & $29 \%$ & $25 \%$ & $39 \%$ \\
\hline Ingeniería Concurrente & 2,92 & 1,41 & 3,07 & 1,49 & $29 \%$ & $39 \%$ & $33 \%$ & $14 \%$ & $38 \%$ & $47 \%$ \\
\hline PLM & 2,83 & 1,63 & 2,64 & 1,45 & $45 \%$ & $46 \%$ & $17 \%$ & $25 \%$ & $38 \%$ & $29 \%$ \\
\hline AMFE & 3,08 & 1,32 & 3,46 & 1,35 & $37 \%$ & $22 \%$ & $21 \%$ & $21 \%$ & $42 \%$ & $57 \%$ \\
\hline DOE & 2,42 & 1,44 & 3,64 & 1,17 & $50 \%$ & $21 \%$ & $29 \%$ & $21 \%$ & $21 \%$ & $58 \%$ \\
\hline \multicolumn{11}{|l|}{ Administración (A) } \\
\hline ERP & 3,54 & 1,50 & 3,64 & 1,47 & $25 \%$ & $25 \%$ & $17 \%$ & $11 \%$ & $58 \%$ & $64 \%$ \\
\hline MES & 3,54 & 1,53 & 4,25 & 1,14 & $25 \%$ & $7 \%$ & $8 \%$ & $11 \%$ & $67 \%$ & $82 \%$ \\
\hline SCADA & 2,50 & 1,50 & 2,54 & 1,45 & $50 \%$ & $50 \%$ & $8 \%$ & $14 \%$ & $42 \%$ & $36 \%$ \\
\hline SCM & 3,29 & 1,52 & 3,61 & 1,47 & $25 \%$ & $25 \%$ & $21 \%$ & $4 \%$ & $54 \%$ & $71 \%$ \\
\hline CRM & 3,04 & 1,57 & 3,43 & 1,53 & $33 \%$ & $25 \%$ & $25 \%$ & $18 \%$ & $42 \%$ & $57 \%$ \\
\hline \multicolumn{11}{|l|}{$\begin{array}{l}\text { Fabricación } \\
\text { automatizada (FA) }\end{array}$} \\
\hline $\mathrm{CNC}$ & 2,58 & 1,59 & 2,21 & 1,40 & $50 \%$ & $68 \%$ & $17 \%$ & $11 \%$ & $33 \%$ & $21 \%$ \\
\hline PLC & 2,50 & 1,29 & 2,5 & 1,43 & $58 \%$ & $64 \%$ & $17 \%$ & $7 \%$ & $25 \%$ & $29 \%$ \\
\hline Código de barra y RFID & 3,38 & 1,64 & 3,39 & 1,52 & $33 \%$ & $29 \%$ & $17 \%$ & $10 \%$ & $50 \%$ & $61 \%$ \\
\hline FMS & 3,08 & 1,64 & 2,68 & 1,56 & $37 \%$ & $47 \%$ & $17 \%$ & $14 \%$ & $46 \%$ & $39 \%$ \\
\hline AGV & 1,63 & 1,13 & 1,39 & 0,79 & $79 \%$ & $89 \%$ & $13 \%$ & $7 \%$ & $8 \%$ & $4 \%$ \\
\hline ASRS & 1,33 & 1,01 & 1,39 & 0,88 & $92 \%$ & $89 \%$ & $0 \%$ & $4 \%$ & $8 \%$ & $7 \%$ \\
\hline Robots & 1,50 & 1,18 & 1,25 & 0,59 & $88 \%$ & $93 \%$ & $4 \%$ & $7 \%$ & $8 \%$ & $0 \%$ \\
\hline Inspección automática & 1,71 & 1,37 & 1,86 & 1,21 & $83 \%$ & $75 \%$ & $4 \%$ & $11 \%$ & $13 \%$ & $14 \%$ \\
\hline \multicolumn{11}{|l|}{ Mejora de procesos (MP) } \\
\hline SPC & 4,50 & 0,78 & 4,68 & 0,94 & $4 \%$ & $7 \%$ & $4 \%$ & $0 \%$ & $92 \%$ & $93 \%$ \\
\hline TQM & 4,46 & 0,78 & 4,68 & 0,67 & $0 \%$ & $4 \%$ & $17 \%$ & $0 \%$ & $83 \%$ & $96 \%$ \\
\hline Jidoka & 2,71 & 1,57 & 2,68 & 1,61 & $50 \%$ & $54 \%$ & $17 \%$ & $11 \%$ & $33 \%$ & $35 \%$ \\
\hline TPM & 4,21 & 1,41 & 4,32 & 1,12 & $21 \%$ & $11 \%$ & $0 \%$ & $7 \%$ & $79 \%$ & $82 \%$ \\
\hline VSM & 3,79 & 1,10 & 4,50 & 0,69 & $13 \%$ & $0 \%$ & $21 \%$ & $11 \%$ & $66 \%$ & $89 \%$ \\
\hline Eventos Kaizen & 4,13 & 1,26 & 4,64 & 0,62 & $13 \%$ & $0 \%$ & $8 \%$ & $7 \%$ & $79 \%$ & $93 \%$ \\
\hline DMAIC & 3,58 & 1,47 & 3,54 & 1,48 & $21 \%$ & $25 \%$ & $21 \%$ & $21 \%$ & $58 \%$ & $54 \%$ \\
\hline $5-S$ & 4,29 & 1,00 & 4,68 & 0,72 & $4 \%$ & $4 \%$ & $13 \%$ & $4 \%$ & $83 \%$ & $93 \%$ \\
\hline ANDON & 4,08 & 1,21 & 3,96 & 1,48 & $13 \%$ & $18 \%$ & $17 \%$ & $0 \%$ & $70 \%$ & $82 \%$ \\
\hline AMT & 4,08 & 1,28 & 4,43 & 1,17 & $13 \%$ & $7 \%$ & $13 \%$ & $11 \%$ & $74 \%$ & $82 \%$ \\
\hline MTM & 4,46 & 0,78 & 4,82 & 0,48 & $0 \%$ & $0 \%$ & $17 \%$ & $4 \%$ & $83 \%$ & $96 \%$ \\
\hline Flujo Celular & 4,25 & 1,15 & 4,36 & 1,13 & $8 \%$ & $7 \%$ & $17 \%$ & $7 \%$ & $75 \%$ & $86 \%$ \\
\hline SOP & 4,67 & 0,70 & 4,86 & 0,52 & $0 \%$ & $0 \%$ & $13 \%$ & $7 \%$ & $87 \%$ & $93 \%$ \\
\hline Kanban & 4,46 & 0,93 & 4,68 & 0,55 & $4 \%$ & $0 \%$ & $4 \%$ & $4 \%$ & $92 \%$ & $96 \%$ \\
\hline SMED & 4,21 & 1,25 & 4,39 & 0,83 & $13 \%$ & $0 \%$ & $4 \%$ & $21 \%$ & $83 \%$ & $79 \%$ \\
\hline
\end{tabular}


Para revisar estadísticamente la hipótesis $\boldsymbol{H}_{\mathbf{1}}$ se procedió a realizar una prueba MannWhitney para muestras independientes (prueba no-paramétrica). Esta prueba arrojo un valor- $p=0.27$, lo que significa que no existe una diferencia significativa en el uso de las herramientas AMT y por lo tanto el tamaño de las plantas en esta industria y/o país no influye en el uso de herramientas AMT.

Este hallazgo es compatible con $\boldsymbol{H}_{\mathbf{1}}$ ya que las fábricas ensambladoras de prendas de vestir grandes no tienen niveles más altos de uso de herramientas AMT que las fábricas pequeñas. Las diferencias encontradas en el uso de DOE y VSM podrían deberse a que las fábricas grandes son las únicas con suficientes recursos humanos para dedicar ingenieros a explotar esas herramientas de análisis y estrategia. En el caso de CAE y MES, la causa de su mayor uso podría atribuirse a que las fábricas grandes son posiblemente las únicas con los recursos económicos para adquirir el software y hardware necesario para el diseño de productos y la administración y monitorización del trabajo en proceso de la planta.

\subsubsection{Efecto del uso AMT en el desempeño}

En vista que la segunda hipótesis buscaba probar que las empresas maquiladoras con niveles más altos de uso de las herramientas AMT tienen un mayor desempeño de competitividad de fabricación, la muestra de empresas fue separada en dos grupos usando como discriminante su desempeño de acuerdo con el valor ICF estandarizado definido en la seccion 3.3.2. Para esto fue necesario usar los datos obtenidos de la encuesta en conjunto con la ecuación 14 tal como se muestra en la seccion 4.2.2 y se creo una tabla (Tabla 22) en donde se dividieron las empresas en dos grupos, plantas con bajo desempeño $(\leq 70 \%)$ y alto desempeño $(>70 \%)$.

Como se observa en la Tabla 22, 11 de las 35 herramientas AMT evaluadas muestran una diferencia significativa en su nivel de uso. De hecho, las compañias con mejor desempeño de acuerdo al ICF muestran un uso consistentemente más alto de las herramientas AMT que aquellas con menor desempeño, lo que hace pensar que tener un uso mayor de las herramientas AMT aumenta la competitividad de fabricación de las empresas. Para validar estadísticamente este hallazgo se procedió a realizar una prueba no-paramétrica de Mann-Whitney para muestras independientes entre ambos grupos. Esta prueba arrojó un valor- $p=0.04$, lo que significa que si existe una diferencia significativa en el uso de las herramientas AMT. Esto indica que el desempeño de 
fabricación de las plantas maquiladoras puede estar afectado positivamente por el mayor uso de las herramientas AMT, lo que apoya $\boldsymbol{H}_{2}$, por lo que se concluye que las compañías que desean aumentar su competitividad deberían considerar adoptar el uso de herramientas AMT en sus operaciones de fabricación.

Tabla 22. Análisis del uso de herramientas AMT

\begin{tabular}{|c|c|c|c|c|c|c|c|c|c|c|}
\hline \multirow{2}{*}{$\begin{array}{c}\text { Desempeño de la Empresa } \\
\text { Herramientas AMT }\end{array}$} & \multicolumn{2}{|c|}{ Bajo } & \multicolumn{2}{|c|}{ Alto } & \multirow{2}{*}{\multicolumn{2}{|c|}{$\begin{array}{l}\text { Bajo Alto } \\
\text { No se utiliza - Se } \\
\text { utiliza muy poco }\end{array}$}} & \multirow{2}{*}{\multicolumn{2}{|c|}{$\begin{array}{c}\text { Bajo } \quad \text { Alto } \\
\text { Se utiliza } \\
\text { algunas veces }\end{array}$}} & \multirow{2}{*}{\multicolumn{2}{|c|}{$\begin{array}{c}\text { Bajo Alto } \\
\text { Se utiliza } \\
\text { frecuentemente - } \\
\text { Se usa siempre }\end{array}$}} \\
\hline & Mean & SD & Mean & SD & & & & & & \\
\hline \multicolumn{11}{|l|}{ Diseño e ingeniería (DI) } \\
\hline CAD & 3,19 & 1,52 & 3,35 & 1,44 & $31 \%$ & $31 \%$ & $11 \%$ & $15 \%$ & $58 \%$ & $54 \%$ \\
\hline CAM & 2,23 & 1,39 & 2,88 & 1,48 & $58 \%$ & $38 \%$ & $15 \%$ & $27 \%$ & $27 \%$ & $35 \%$ \\
\hline CAE & 2,38 & 1,39 & 2,81 & 1,50 & $50 \%$ & $38 \%$ & $15 \%$ & $31 \%$ & $35 \%$ & $31 \%$ \\
\hline Ingeniería Concurrente & 2,54 & 1,27 & 3,46 & 1,48 & $46 \%$ & $23 \%$ & $27 \%$ & $19 \%$ & $27 \%$ & $58 \%$ \\
\hline PLM & 2,23 & 1,34 & 3,23 & 1,56 & $62 \%$ & $31 \%$ & $19 \%$ & $23 \%$ & $19 \%$ & $46 \%$ \\
\hline AMFE & 2,81 & 1,2 & 3,77 & 1,31 & $42 \%$ & $15 \%$ & $27 \%$ & $16 \%$ & $31 \%$ & $69 \%$ \\
\hline DOE & 2,54 & 1,21 & 3,42 & 1,45 & $42 \%$ & $27 \%$ & $31 \%$ & $19 \%$ & $27 \%$ & $54 \%$ \\
\hline \multicolumn{11}{|l|}{ Administración (A) } \\
\hline ERP & 3,23 & 1,53 & 3,96 & 1,34 & $35 \%$ & $15 \%$ & $19 \%$ & $8 \%$ & $46 \%$ & $77 \%$ \\
\hline MES & 3,81 & 1,44 & 4,04 & 1,31 & $19 \%$ & $12 \%$ & $8 \%$ & $12 \%$ & $73 \%$ & $77 \%$ \\
\hline SCADA & 1,96 & 1,37 & 3,08 & 1,35 & $69 \%$ & $31 \%$ & $8 \%$ & $15 \%$ & $23 \%$ & $54 \%$ \\
\hline SCM & 3,38 & 1,53 & 3,54 & 1,48 & $27 \%$ & $23 \%$ & $12 \%$ & $12 \%$ & $62 \%$ & $65 \%$ \\
\hline CRM & 2,92 & 1,57 & 3,58 & 1,47 & $39 \%$ & $19 \%$ & $23 \%$ & $19 \%$ & $38 \%$ & $62 \%$ \\
\hline \multicolumn{11}{|l|}{$\begin{array}{l}\text { Fabricación automatizada } \\
\text { (AF) }\end{array}$} \\
\hline $\mathrm{CNC}$ & 2,04 & 1,37 & 2,73 & 1,54 & $69 \%$ & $50 \%$ & $12 \%$ & $15 \%$ & $19 \%$ & $35 \%$ \\
\hline PLC & 2,42 & 1,42 & 2,58 & 1,30 & $62 \%$ & $61 \%$ & $12 \%$ & $12 \%$ & $26 \%$ & $27 \%$ \\
\hline Código de barra y RFID & 3,58 & 1,42 & 3,19 & 1,70 & $23 \%$ & $39 \%$ & $12 \%$ & $15 \%$ & $65 \%$ & $46 \%$ \\
\hline FMS & 2,50 & 1,48 & 3,20 & 1,66 & $50 \%$ & $35 \%$ & $15 \%$ & $15 \%$ & $35 \%$ & $50 \%$ \\
\hline AGV & 1,35 & 0,75 & 1,65 & 1,13 & $92 \%$ & $77 \%$ & $4 \%$ & $15 \%$ & $4 \%$ & $8 \%$ \\
\hline ASRS & 1,27 & 0,72 & 1,46 & 1,10 & $92 \%$ & $88 \%$ & $4 \%$ & $0 \%$ & $4 \%$ & $12 \%$ \\
\hline Robots & 1,38 & 0,94 & 1,35 & 0,89 & $88 \%$ & $92 \%$ & $8 \%$ & $4 \%$ & $4 \%$ & $4 \%$ \\
\hline Inspección automática & 1,73 & 1,19 & 1,85 & 1,38 & $76 \%$ & $81 \%$ & $12 \%$ & $4 \%$ & $12 \%$ & $15 \%$ \\
\hline \multicolumn{11}{|l|}{ Mejora de procesos (MP) } \\
\hline SPC & 4,69 & 0,68 & 4,50 & 1,03 & $4 \%$ & $8 \%$ & $0 \%$ & $4 \%$ & $96 \%$ & $88 \%$ \\
\hline TQM & 4,49 & 0,71 & 4,65 & 0,75 & $0 \%$ & $4 \%$ & $12 \%$ & $4 \%$ & $88 \%$ & $92 \%$ \\
\hline Jidoka & 2,38 & 1,68 & 3,00 & 1,40 & $65 \%$ & $38 \%$ & $0 \%$ & $27 \%$ & $35 \%$ & $35 \%$ \\
\hline TPM & 3,81 & 1,58 & 4,73 & 0,53 & $31 \%$ & $0 \%$ & $4 \%$ & $4 \%$ & $65 \%$ & $96 \%$ \\
\hline VSM & 3,92 & 1,13 & 4,42 & 0,70 & $12 \%$ & $0 \%$ & $19 \%$ & $12 \%$ & $69 \%$ & $88 \%$ \\
\hline Eventos Kaizen & 4,12 & 1,14 & 4,69 & 0,74 & $8 \%$ & $4 \%$ & $12 \%$ & $4 \%$ & $80 \%$ & $92 \%$ \\
\hline DMAIC & 3,10 & 1,54 & 3,81 & 1,36 & $27 \%$ & $19 \%$ & $23 \%$ & $19 \%$ & $50 \%$ & $62 \%$ \\
\hline $5-S$ & 4,23 & 1,07 & 4,77 & 0,51 & $7 \%$ & $0 \%$ & $12 \%$ & $4 \%$ & $81 \%$ & $96 \%$ \\
\hline ANDON & 3,62 & 1,58 & 4,42 & 0,95 & $27 \%$ & $4 \%$ & $8 \%$ & $8 \%$ & $65 \%$ & $88 \%$ \\
\hline AMT & 4,15 & 1,29 & 4,38 & 1,17 & $12 \%$ & $8 \%$ & $15 \%$ & $8 \%$ & $73 \%$ & $84 \%$ \\
\hline MTM & 4,58 & 0,76 & 4,73 & 0,53 & $0 \%$ & $0 \%$ & $15 \%$ & $4 \%$ & $85 \%$ & $96 \%$ \\
\hline Flujo Celular & 4,15 & 1,12 & 4,46 & 1,14 & $8 \%$ & $8 \%$ & $19 \%$ & $4 \%$ & $73 \%$ & $88 \%$ \\
\hline SOP & 4,65 & 0,75 & 4,88 & 0,43 & $0 \%$ & $0 \%$ & $15 \%$ & $4 \%$ & $85 \%$ & $96 \%$ \\
\hline Kanban & 4,35 & 0,94 & 4,81 & 0,40 & $4 \%$ & $0 \%$ & $8 \%$ & $0 \%$ & $88 \%$ & $100 \%$ \\
\hline SMED & 3,85 & 1,26 & 4,77 & 0,43 & $12 \%$ & $0 \%$ & $27 \%$ & $0 \%$ & $61 \%$ & $100 \%$ \\
\hline
\end{tabular}




\subsection{Modelo final de relaciones de influencia}

Como se explicó previamente, el propósito de usar modelos de ecuaciones estructurales es el de revisar la relación existente entre los constructos de las herramientas AMT y las capacidades competitivas a través de las hipótesis $\boldsymbol{H}_{\mathbf{3}}$ hasta $\boldsymbol{H}_{\mathbf{6}}$. Sin embargo, tomando en cuenta que las prioridades competitivas tienen 13 variables y las herramientas AMT 20 variables, si se buscara estimar todas las relaciones existentes a través de un solo modelo SEM (Figura 27) se requeriría de una muestra de al menos 165 datos (Kline, 2005). Debido a que solo se contaba con una muestra de 57 datos disponibles, no fue posible analizar el modelo completo planteado en el software AMOS V22.

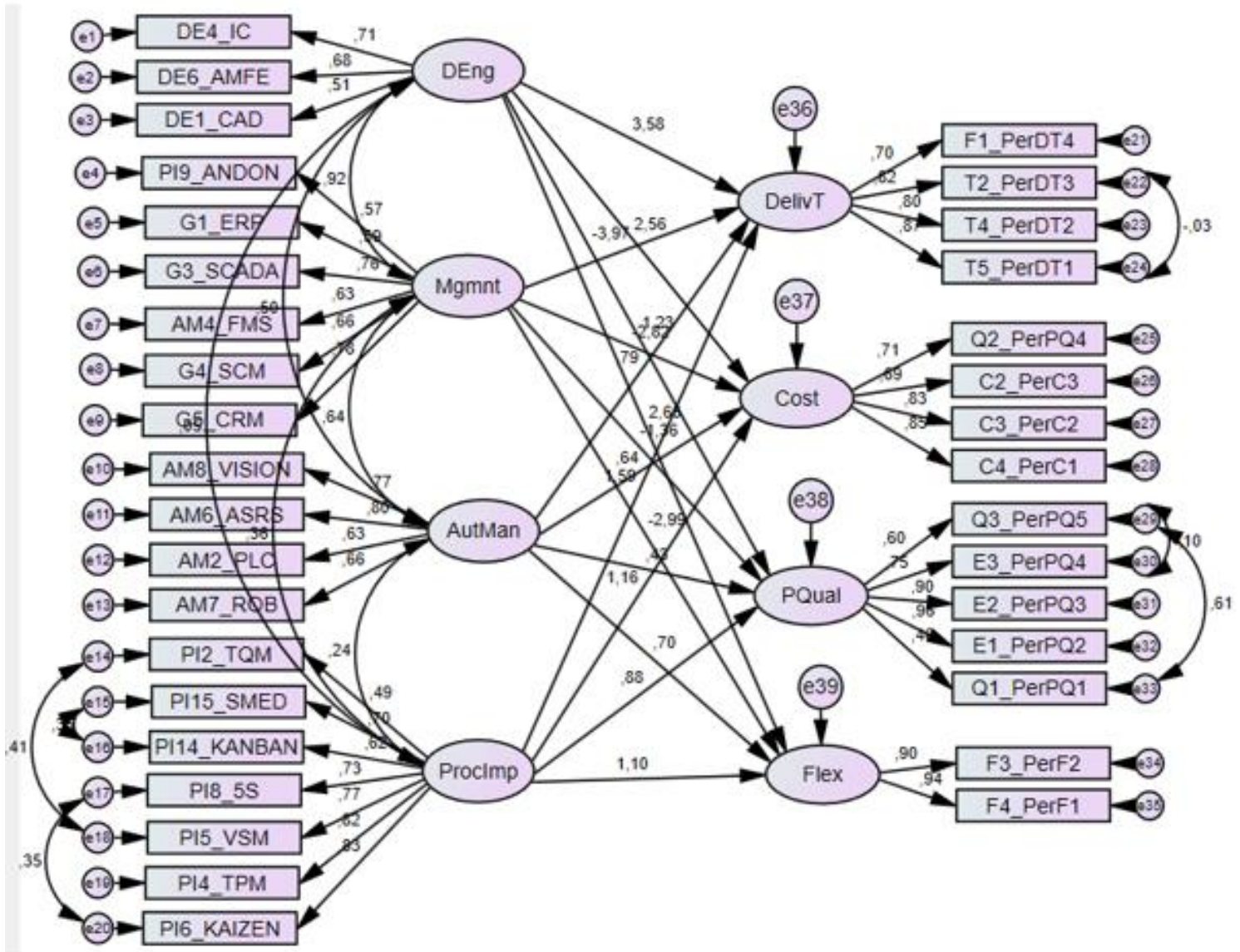

Figura 27. Resultado análisis SEM Herramientas AMT-Competitividad

Debido a la inhabilidad de usar el modelo completo debido al tamaño de la muestra disponible, se procedió a usar la técnica expuesta por Vickery et al. (2003) y Jabbour et al. (2012). Esta técnica toma el modelo completo (Figura 27) y lo secciona en submodelos estructurales con solo dos variables latentes, lo que reduce la complejidad y el número de variables a ser analizadas. Para hacer esto se tomaron las variables latentes 
de primer orden de los modelos de medición, es decir las capacidades competitivas y herramientas AMT, de forma individual siguiendo el modelo presentado en la Figura 17. En este modelo has herramientas AMT (Diseño e ingeniería, Administración, Fabricación automatizada, y Mejora de Procesos) se utilizaron como las variables exógenas. Las prioridades competitivas (Coste, Protección ambiental, Tiempo de entrega y Flexibilidad) se usaron como las variables endógenas. Usando los efectos entre las variables analizadas será posible probar las hipótesis planteadas.

La Figura 28 muestra los tres sub-modelos creados para analizar la relación existente entre el grupo de herramientas AMT de "Diseño e ingeniería" (DI) y las capacidades competitivas establecidas en $\boldsymbol{H}_{\mathbf{3} \boldsymbol{a}-\boldsymbol{c}}$ a través de un análisis de senderos que muestra los efectos existentes, el valor- $p$ de la regresión calculada (validez del efecto) y los índices de ajuste de cada modelo (validez del modelo).

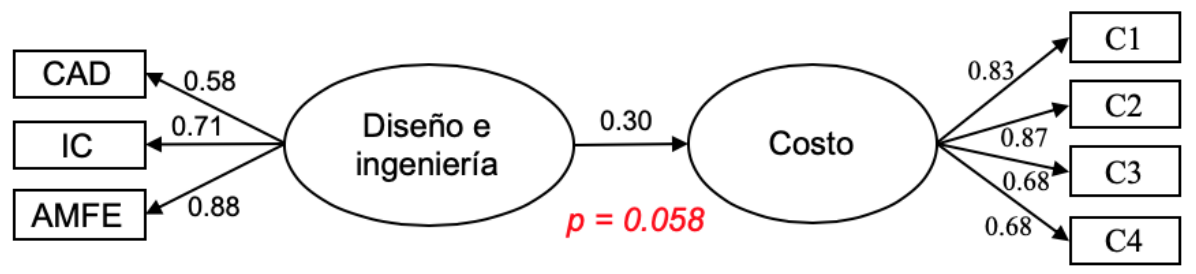

Índices de Ajuste:

$\chi 2=10.59$

d.f. $=13$

$\chi 2 / g . l .=0.82$

$\mathrm{CFI}=1.00$

RMSEA $=0.00$

SRMR $=0.05$

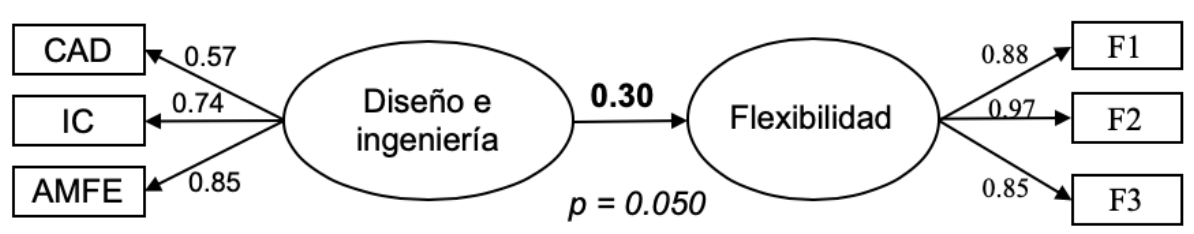

Índices de Ajuste:

$\chi 2=13.36$

d.f. $=8$

$\chi 2 / g . l .=1.67$

$\mathrm{CFI}=0.97$

RMSEA $=0.11$

SRMR $=0.08$

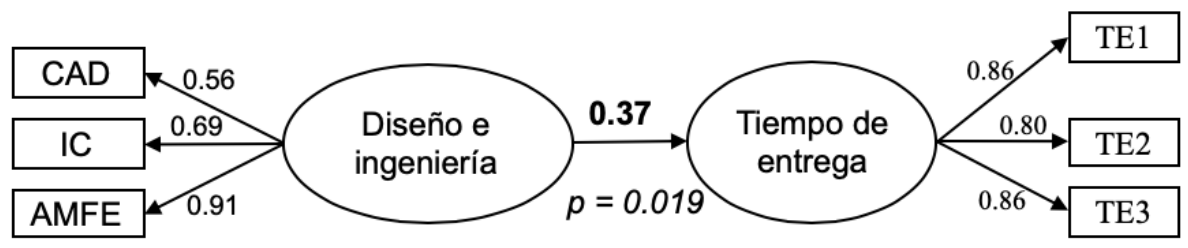

Índices de Ajuste:

$\chi 2=11.01$

d.f. $=8$

$\chi 2 / g . l .=1.38$

$\mathrm{CFI}=0.98$

RMSEA $=0.08$

SRMR $=0.07$

Figura 28. Resultado del análisis de senderos: Diseño e ingeniería

Los resultados de este análisis SEM permitieron probar las hipótesis $\boldsymbol{H}_{\mathbf{3} \boldsymbol{a}-\boldsymbol{c}}$ que relacionan las herramientas AMT de "Diseño e ingeniería" con ciertas prioridades competitivas. Como se puede observar en la Figura 28, los resultados fueron mezclados ya que solo las correlaciones con las capacidades competitivas de "Flexibilidad" (0.30) y "Tiempo de entrega" (0.37) son significativas, lo que confirma parcialmente $\boldsymbol{H}_{\mathbf{3} \boldsymbol{a}-\boldsymbol{c}}$. 
Esto significa que el uso de herramientas tales como CAD, ingeniería concurrente y AMFE puede mejorar la flexibilidad y el tiempo de entrega en las plantas maquiladoras. Es interesante destacar que la ingeniería concurrente fue la herramienta AMT de "Diseño e ingeniería" que según la encuesta era la menos usada por las empresas maquiladoras (Tabla 19). Esto significa que las fábricas que utilicen este método de diseño y desarrollo de productos tienen una gran oportunidad de mejorar su flexibilidad y tiempo de entrega, lo que puede ayudarles a diferenciarse de otros competidores en esta industria.

La Figura 29 muestra los cuatro sub-modelos creados para analizar la relación existente entre las herramientas AMT de "Administración" (A) y las capacidades competitivas establecidas en $\boldsymbol{H}_{\mathbf{4} \boldsymbol{a}-\boldsymbol{d}}$.

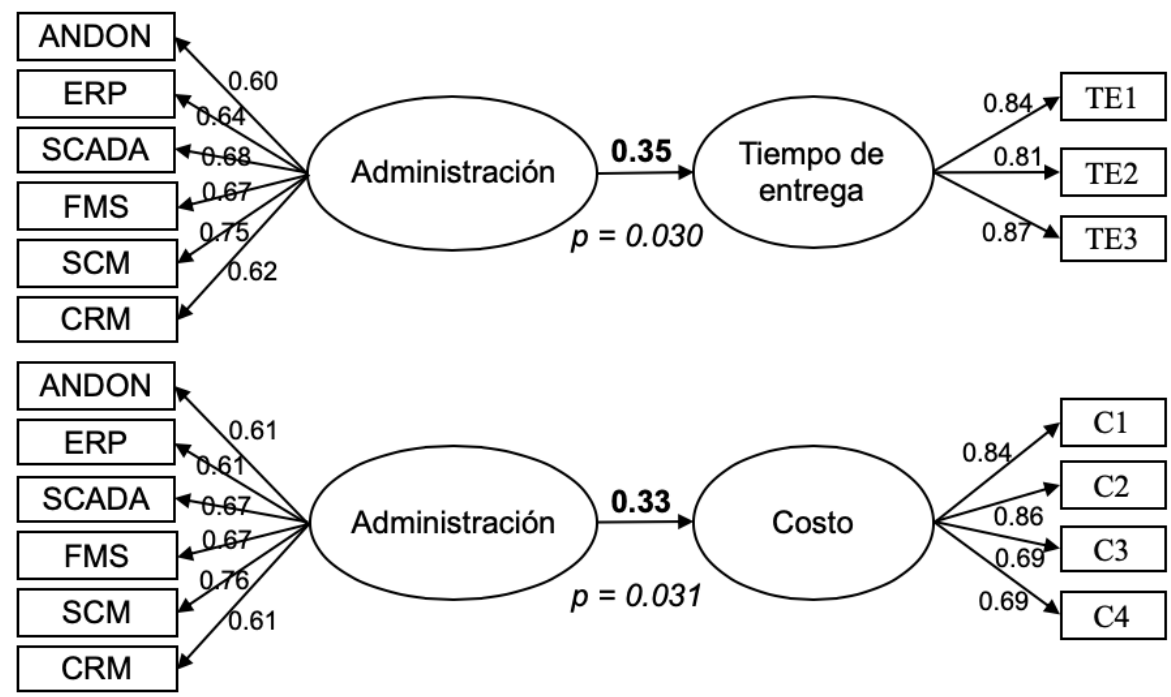

Índices de Ajuste:

$\chi 2=29.34$

d.f. $=26$

$\chi 2 / g . l .=1.13$

$\mathrm{CFI}=0.98$

RMSEA $=0.04$

SRMR $=0.07$

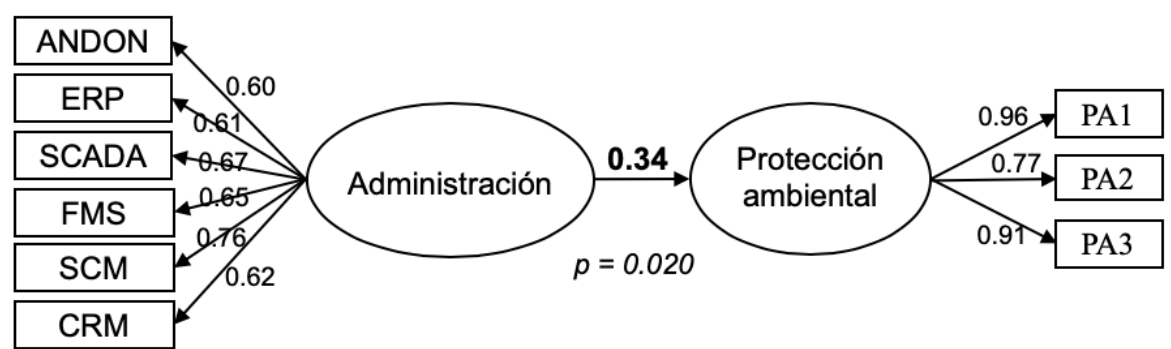

Índices de Ajuste:

Índices de Ajuste:

$\chi 2=36.66$

d.f. $=34$

$\chi 2 / g . l .=1.08$

$\mathrm{CFI}=0.98$

RMSEA $=0.04$

SRMR $=0.07$

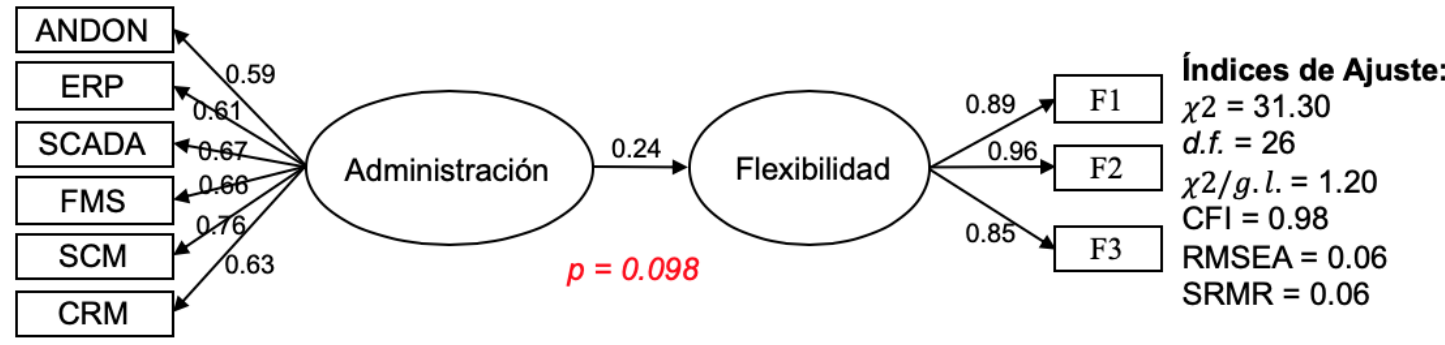

Figura 29. Resultado del análisis de senderos: Administración 
Como se muestra en la Figura 29, los resultados de este análisis SEM (efectos existentes, valor- $p$ e índices de ajuste del modelo) permitieron probar las hipótesis $\boldsymbol{H}_{\mathbf{4} \boldsymbol{a}-\boldsymbol{d}}$ y apoyarlas parcialmente ya que las herramientas de "Administración" tuvieron un efecto positivo significativo en el tiempo de entrega (0.35), coste $(0.33)$ y protección ambiental (0.34). Por lo tanto, el uso de herramientas de software tales como ERP, SCADA, CRM y SCM, así como elementos de control visual (ANDON) y los sistemas de manufactura flexible pueden ayudar a mejorar el tiempo de entrega y la protección ambiental y a disminuir el coste en las plantas maquiladoras.

Es interesante notar que la mayoría de estas herramientas están basadas en sistemas de gestión empresarial integrados de múltiples módulos que, generalmente, solo las grandes empresas multinacionales tienen capacidad de adquirir. Sin embargo, dado que hoy en día también existen soluciones independientes o de código abierto que se pueden utilizar a costes más bajos, los gerentes de las plantas maquiladoras más pequeñas aún pueden desarrollar sistemas de administración personalizados para sus necesidades específicas. La Figura 30 muestra los tres sub-modelos creados para analizar la relación entre las herramientas AMT de "Fabricación automatizada" (FA) y las capacidades competitivas establecidas en $\boldsymbol{H}_{\mathbf{5} \boldsymbol{a}-\boldsymbol{c}}$.

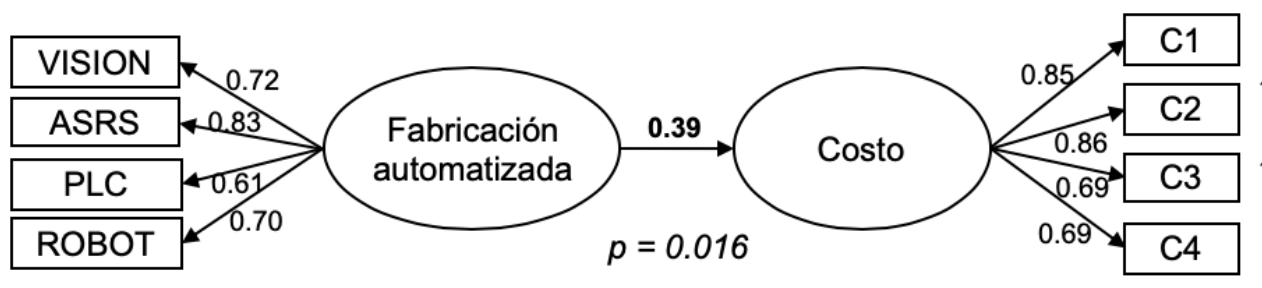

Índices de Ajuste: $\chi 2=18.26$ d.f. $=19$ $\chi 2 /$ d.f. $=0.96$ $\mathrm{CFI}=1.00$ RMSEA $=0.00$ SRMR $=0.06$

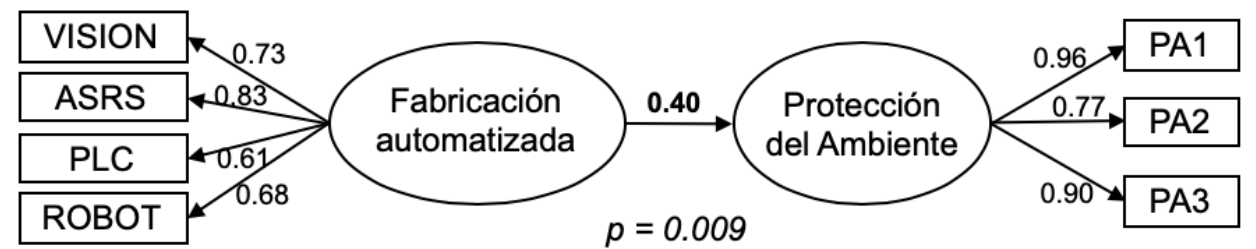

Índices de Ajuste:

$\chi 2=7.16$

d.f. $=13$

$\chi 2 / d . f .=0.55$

$\mathrm{CFI}=1.00$

RMSEA $=0.00$

$\mathrm{SRMR}=0.05$

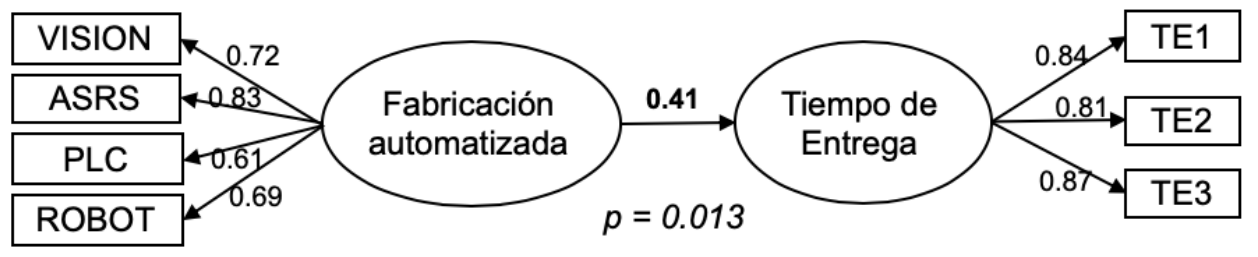

Índices de Ajuste:

$\chi 2=17.81$ d.f. $=13$

$\chi 2 /$ d.f. $=1.37$

$\mathrm{CFI}=0.97$

RMSEA $=0.08$

SRMR $=0.06$ 
Como se observa en la Figura 30, los resultados de este análisis SEM apoyan las hipótesis $\boldsymbol{H}_{\mathbf{5} \boldsymbol{a}-\boldsymbol{c}}$ ya que el grupo de herramientas de "Fabricación automatizada" muestra un efecto positivo significativo en coste $(0.39)$, protección ambiental $(0.40)$ y tiempo de entrega (0.41). Por lo tanto, se puede decir que el uso de herramientas tecnológicas tales como la visión, PLC, ASRS y robots puede aumentar el tiempo de entrega y la protección ambiental y también disminuir los costes.

Los resultados demuestran que, a pesar de que el nivel de uso de este tipo de herramientas es bien bajo en esta industria (Tabla 19 y Figura 26), aquellas plantas maquiladoras que usen algunas de estas "tecnologías duras" en sus operaciones tendrán un mayor rendimiento en su competitividad de fabricación que las que no las usen.

Estos datos apuntan a un área de oportunidad para la industria maquiladora textil. Aunque este tipo de herramientas tienen un elevado coste, el uso de soluciones de bajo coste basadas en plataformas integradas (embedded) puede ayudar a agregar la automatización para la mejora de competitividad a la industria maquiladora. Esta actuación requerirá cambios en la fuerza laboral actual de estas compañías ya que necesitarán emplear técnicos e ingenieros que puedan proponer proyectos de mejora continua utilizando tecnologías basadas en la automatización.

Finalmente, la Figura 31 muestra los cuatro sub-modelos creados para analizar la relación entre las herramientas AMT de "Mejora de procesos" (MP) y las capacidades competitivas establecidas en $\boldsymbol{H}_{\mathbf{6} \boldsymbol{a}-\boldsymbol{d}}$ a través de un análisis de senderos que muestra los efectos existentes, el valor- $p$ de la regresión calculada (validez del efecto) y los índices de ajuste de cada modelo (validez del modelo).

Los resultados del análisis SEM muestran que la hipótesis $\boldsymbol{H}_{\mathbf{6} \boldsymbol{a}-\boldsymbol{d}}$ es parcialmente correcta ya que el conjunto de herramientas AMT usadas se correlacionan positiva y significativamente con el Tiempo de entrega (0.53), el Coste (0.55) y la Protección ambiental (0.42).

Este hallazgo es coherente con la teoría, ya que las herramientas de mejora suelen mostrar un impacto positivo en el rendimiento del coste, la calidad, y la eficiencia de la producción cuando se utilizan de forma complementaria y como parte de una metodología (Cua, McKone, y Schroeder, 2001; Vinodh y Joy, 2012). 
Con estos datos puede concluirse que el uso de iniciativas como TQM, TPM, Kaizen, SMED, 5S, VSM y Kanban ayudan a mejorar los costes, la protección ambiental y el tiempo de entrega en las plantas maquiladoras.

Estos hallazgos empíricos deberían motivar a los gerentes de las empresas maquiladoras a invertir tiempo y recursos en el uso y la adopción de herramientas tales como eventos Kaizen, TPM, VSM y $5 S$ que tuvieron cargas factoriales superiores a 0.7 para mejorar la competitividad de sus plantas.

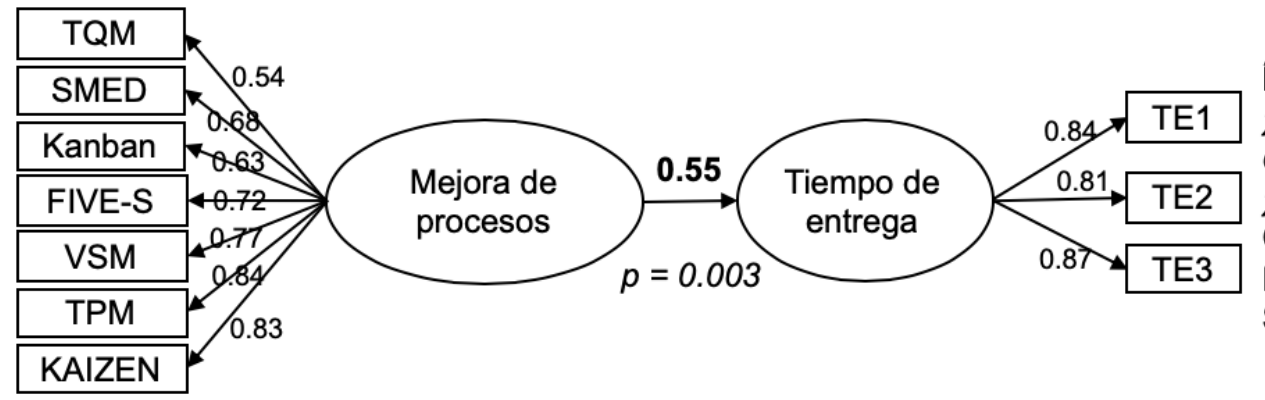
Índices de Ajuste: $\chi 2=49.76$ d.f. $=31$ $\chi 2 / d . f .=1.61$ $\mathrm{CFI}=0.94$ RMSEA $=0.10$ SRMR $=0.06$

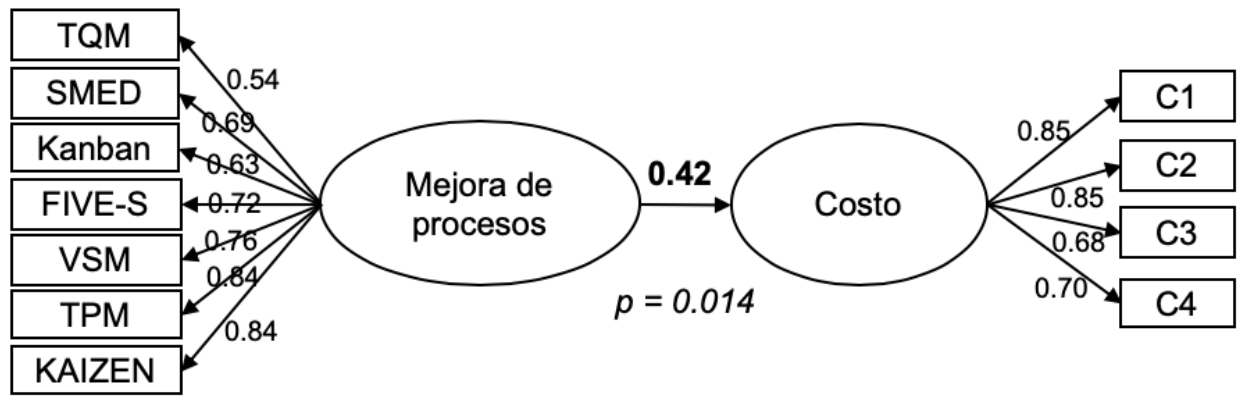

Índices de Ajuste: $\chi 2=61.69$ d.f. $=40$ $\chi 2 / d . f .=1.54$ $\mathrm{CFI}=0.93$

RMSEA $=0.09$

SRMR $=0.07$

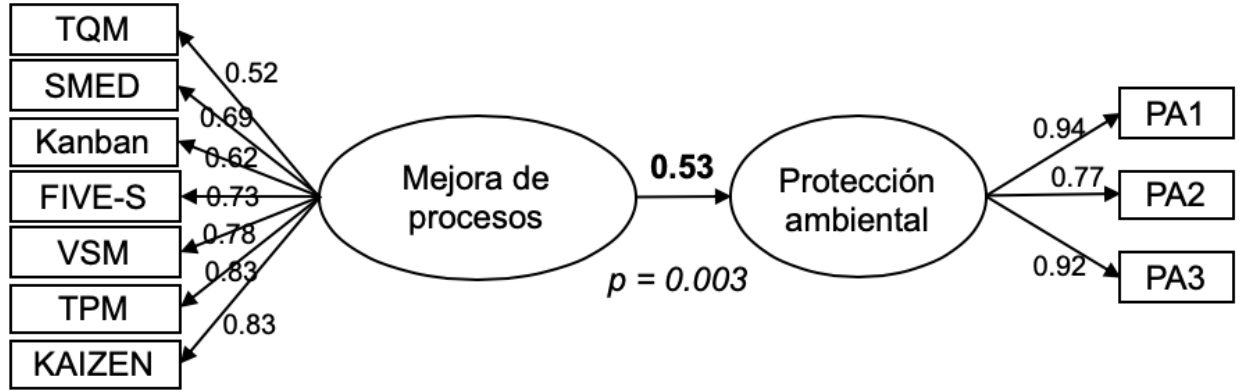

Índices de Ajuste:

$\chi 2=36.73$

d.f. $=31$

$\chi 2 / d . f .=1.19$

$\mathrm{CFI}=0.98$

RMSEA $=0.57$

SRMR $=0.07$

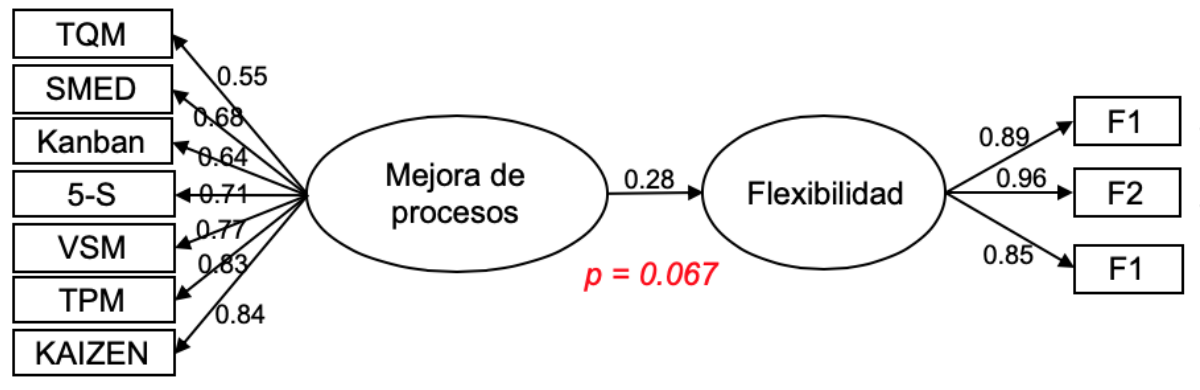

Índices de Ajuste:

$\chi 2=39.53$

d.f. $=31$

$\chi 2 / d . f .=1.27$

$\mathrm{CFI}=0.97$

RMSEA $=0.07$

SRMR $=0.07$

Figura 31. Resultado del análisis de senderos: Mejora de procesos 
A partir de todos los sub-modelos analizados y usando solo las líneas de regresión con efectos significativos, ha sido posible plantear el modelo final de regresión de las relaciones existentes entre las herramientas AMT y las capacidades competitivas de la industria de ensamblaje textil en Honduras (Figura 32) que constituye el resultado principal sobre el que se articulan las aportaciones de la investigación, cumpliendo los objetivos que se propusieron en la tesis doctoral.

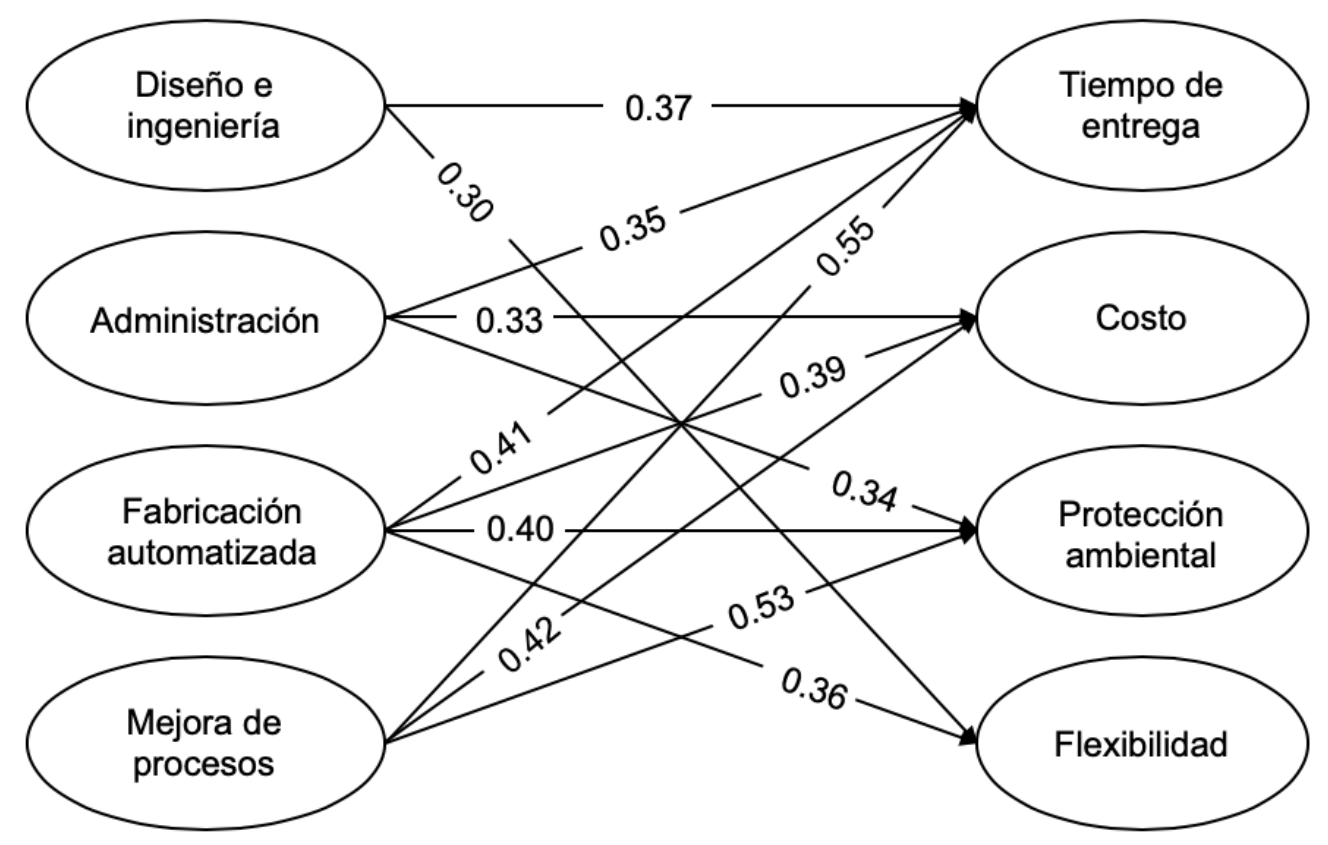

Figura 32. Modelo de regresión final 


\section{CONCLUSIONES}

\subsection{Introducción}

Uno de los mayores desafíos de las industrias actuales es encontrar maneras de aumentar su competitividad para mantenerse en el negocio. Los gerentes de planta deben tomar decisiones operativas que les ayuden a mejorar su desempeño y competitividad. Ser conscientes de donde enfocar sus esfuerzos les permitirá alinear su estrategia de fabricación para responder adecuadamente a las necesidades del mercado.

Este estudio de investigación presenta un método que permite identificar la influencia que el uso de las herramientas AMT tienen en la competitividad de fabricación de la industria maquiladora dedicadas a la producción de ropa en Centroamérica.

Para conseguir este objetivo, la tesis propone un método que utiliza un enfoque mixto que combina entrevistas cualitativas con encuestas cuantitativas y diferentes pruebas estadísticas para realizar los análisis necesarios que aseguren el acuerdo y la validez de la opinión de los expertos consultados y pueda calcular los efectos entre las variables estudiadas. Las diferentes técnicas para obtener y analizar los datos empíricos usados durante el análisis han sido desarrolladas con la premisa de poder ser usadas en muestras pequeñas, debido a las limitaciones y características de los países en desarrollo en donde se está realizando este caso de estudio.

\subsection{Conclusiones}

El análisis de los modelos obtenidos ha concluido que coste, flexibilidad, tiempo de entrega y protección ambiental fueron los factores de la competitividad de fabricación más importantes para la industria maquiladora de confección de ropa en Centroamérica. Este resultado es similar a los factores encontrados en otras industrias en naciones desarrolladas, con la única excepción de que hace falta el factor calidad. Esto no significa que la calidad no se perciba como un factor importante, sino que esta industria la considera una competencia central de esta industria, un factor ya asimilado en sus operaciones. Los cuatro grupos identificados y utilizados para agrupar las herramientas 
de fabricación avanzada: diseño e ingeniería, administración, fabricación automatizada y mejora de procesos, también son aplicables a otras industrias, aunque con una mayor cantidad de herramientas que las que tradicionalmente se asocian con la industria maquiladora de prendas de vestir en Centroamérica.

De los resultados del caso de estudio se puede concluir que el uso de herramientas AMT tiene un efecto positivo en la competitividad de fabricación de las plantas maquiladoras textiles en Honduras. Esto se determinó por causa de los resultados en las pruebas de hipótesis realizadas. Por ejemplo, se comprobó que las plantas con un desempeño más alto en el índice de competitividad de fabricación son aquellas que tienen un mayor uso de herramientas AMT.

Adicionalmente, se verificó que mejoras en coste, protección ambiental y tiempo de entrega están relacionadas con un alto uso de herramientas de fabricación automatizada. Similarmente se observó una relación positiva significativa entre el uso de herramientas de diseño e ingeniería y mejoras en flexibilidad y tiempo de entrega, también entre el uso de herramientas de administración y mejoras en el coste, tiempo de entrega y protección ambiental, así como en las herramientas de mejora de procesos y mejoras en el coste, tiempo de entrega y protección ambiental.

Aunque todos los factores de competitividad se ven afectados de forma positiva por el uso de las herramientas AMT, el factor tiempo de entrega es el más afectado en la muestra analizada ya que está relacionado positivamente con todos los grupos de herramientas AMT. Las herramientas AMT de mejora de proceso parecen ser las que más contribuyen a ese factor (efecto $=0.55$ ) y deberían ser adoptadas por las plantas que intentan mejorar su tiempo de entrega. Otro factor de competitividad muy afectado por las herramientas de mejora de proceso es la protección ambiental (efecto $=0.53$ ). Se demuestra que todos estos resultados son aplicables independiente del tamaño de la planta maquiladora.

Otra conclusión relevante es que, para la muestra analizada, el uso de herramientas de fabricación automatizada presenta un efecto positivo en los cuatro factores utilizados para explicar la competitividad de fabricación de la industria bajo estudio. Dado que las herramientas conocidas en la literatura como metodologías y tecnologías blandas son las más utilizadas por la mayoría de las maquiladoras de ropa, aquellas que se diferencien adoptando herramientas de automatización tendrán una gran ventaja sobre 
sus competidores. Las soluciones automatizadas destinadas a crear sistemas para la eliminación de errores, reducción de tiempo y desperdicio de material y el agregar agilidad en procedimientos repetitivos ayudarán a aumentar la competitividad de las plantas maquiladoras de ropa. La inclusión en su personal de ingenieros con experiencia en mecatrónica podría ser una gran adición a este tipo de industria que permitiría aprovechar esta oportunidad latente.

Todos estos resultados pueden ser de gran utilidad tanto para académicos como para profesionales que trabajan directamente en esto tipo de plantas. Para los académicos estos resultados agregan validación externa empírica a la teoría sobre las prioridades y capacidades competitivas de la industria maquiladora textil en economías emergentes y los efectos que el uso de tecnologías y metodologías de fabricación avanzada tienen en dichas capacidades. Para los profesionales, especialmente para aquellos en plantas maquiladoras de ropa o en contextos similares, estos resultados proponen un método de como medir y mejorar la competitividad de fabricación en sus plantas mediante el uso de herramientas AMT específicas. También se presentan evidencias de las herramientas especificas AMT que tienen un efecto positivo en las capacidades competitivas de esta industria y que los gestores e ingenieros de las empresas, pueden adoptar para mejorar el desempeño de las fábricas y responder mejor a las demandas del mercado.

Por último, se resalta que, tal como se indicó en el apartado de identificación del caso de estudio principal, y como ampliación de la investigación, se aplicó la metodología desarrollada a otro caso de estudio que validó la versatilidad de la misma. En este caso, se abordó el análisis de la influencia de las prácticas y herramientas de componente humano en el éxito de los procesos de implantación de metodologías de manufactura para la mejora de procesos, más concretamente, la fabricación delgada o lean manufacturing, debido a la importancia del modelo en la industria actual. El caso realizó una explotación avanzada de la información de 202 respuestas obtenidas durante una investigación realizada entre empresas españolas sobre los efectos de las prácticas de mejora basadas en factores humanos en el éxito de las implantaciones de Lean Manufacturing. Aplicando una adaptación de la metodología desarrollada en este estudio se obtuvo un modelo avanzado de las relaciones de influencia entre las herramientas Lean asociadas con el componente humano, tanto a nivel de dirección como a nivel de operarios, con el incremento de productividad y flexibilidad que caracteriza a las implantaciones Lean exitosas. Los resultados obtenidos permitieron 
plantear una hoja de ruta de recomendaciones de implantación de prácticas que favorezcan el éxito en los procesos de implementación Lean. No es objeto de este documento entrar en los detalles de esta investigación secundaria fruto de los resultados de la tesis. No obstante, en el anexo de publicaciones de impacto generadas durante la investigación se adjunta el articulo completo publicado en una revista de impacto JCR.

\subsection{Resumen de resultados}

El resumen de los resultados de la tesis en forma de contribuciones en el ámbito de aplicación de la tesis son los siguientes:

- Una propuesta de método que permite a gerentes de planta obtener un modelo de referencia que permite estimar la competitividad de fabricación de sus plantas y tener una idea de cómo su énfasis corporativo (capacidades competitivas) se compara con el énfasis de toda la industria en general y saber así a donde enfocar sus esfuerzos de mejora (Figura 24 y 25).

- Una propuesta de un método para identificar la influencia y los efectos que el uso de las herramientas AMT tienen en la competitividad de fabricación de las empresas maquiladoras dedicadas a la producción de ropa en Centroamérica (Figuras 14, 15 y 16). Aunque esta metodología utiliza técnicas para manejar muestras pequeñas, la metodología también podría usarse en otras industrias y en países desarrollados mediante el uso de encuestas con muestras más grandes, análisis estadístico paramétrico y un análisis SEM completo.

- Una categorización y taxonomía más amplia de las herramientas de manufactura avanzada con respecto al concepto tradicional AMT, que incluye no solo tecnologías de automatización, sino también aquellas metodologías de gestión que son clave en la mejora actual de la competitividad empresarial (Tabla 12). Esta taxonomía propuesta es aplicable a cualquier tipo de industria y economía.

- Modelos específicos de categorización y medición con los factores que explican las capacidades competitivas de fabricación y los conjuntos de herramientas AMT utilizadas en las maquiladoras en la industria de la fabricación de ropa en Centroamérica (Tablas 16 y 19).

- Un análisis empírico que ofrece evidencia para explicar los efectos que tiene el uso de las herramientas AMT en la competitividad de fabricación de las maquiladoras en la industria de la confección de ropa en Centroamérica (Figura 32). 


\subsection{Transferencia de resultados}

Los trabajos de investigación han generado transferencia de conocimiento en forma de publicaciones científicas. La producción científica completa ha sido la siguiente:

\section{$\underline{\text { Artículos en revistas internacionales JCR Q2 (*) }}$}

- A method for estimating the influence of advanced manufacturing tools on the manufacturing competitiveness of Maquiladoras in the apparel industry in Central America. Computers in Industry, Volume 87, May 2017, Pages 31-51.

- Lean manufacturing and operational performance: Interrelationships between human-related lean practices. Journal of Manufacturing Technology Management, Volume 31, Number 2, Pages 217-235.

(*) Estos artículos se incluyen como anexo del documento de tesis

\section{Artículos en revistas internacionales SJR Q2}

- Method for estimating manufacturing competitiveness: The case of the apparel maquiladora industry in Central America. Dyna 84 (200), 97-106.

\section{Ponencias en congresos internacionales}

- Methodology to Establish the Elements of a Reference Model Manufacturing Competitiveness in Maquiladora Plants. Proceedings of the Thirteenth Latin American and Caribbean Conference for Engineering and Technology. July 29 31, 2015, Santo Domingo - Dominican Republic. LACCEI 2015.

- Estimation of the Manufacturing Competitiveness of Honduran Apparel Assembly Factories. Fourteenth LACCEI International Multi-Conference for Engineering, Education and Technology, July 20-22, 2016, Costa Rica. LACCEI 2016.

- Rubric Expert: Development of a computer application to create evaluation tools. IEEE $37^{\text {th }}$ Central America and Panama Convention (CONCAPAN XXXVII), 1517 Nov 2017, Managua - Nicaragua. CONCAPAN 2017.

\section{$\underline{\text { Revistas de difusión tecnológica }}$}

- Diseño de un instrumento para identificar las prioridades competitivas del sector maquilador en San Pedro Sula. Innovare 4 (2), 38-55 
Además de los trabajos de investigación se pretende realizar acciones de difusión de los resultados a nivel empresarial de cara a fomentar acciones de mejora estratégica, tecnológica o formativa que garanticen el crecimiento y competitividad de una industria transcendental para la economía centroamericana.

\subsection{Líneas futuras de investigación}

La experiencia adquirida y resultados alcanzados a lo largo del trabajo doctoral permiten plantear nuevas líneas de investigación.

- Nuevo modelo del índice de competitividad de fabricación que incluya la comparación con métricas financieras y económicas.

- Uso de otras técnicas de ponderación y priorización tales como el proceso de jerarquía analítica (AHP) y la lógica difusa.

- Exploración en profundidad del factor "flexibilidad". A pesar de que una posible explicación para la aparente baja importancia que este factor tiene para esta industria es que su producción es relativamente estándar y ellos manejan cambios radicales en sus productos o en su mezcla en "plantas flexibles", el hecho que no tiene efectos significativos con más herramientas AMT aconseja una exploración adicional.

- Analizar los efectos de las herramientas AMT en nuevos modelos de fabricación de la industria maquiladora. Debido a que la industria de confección en Centroamérica se está moviendo del modelo de corte y confección (CMT) al modelo de fabricación de equipo original (OEM) (Fredericks y Gereffi, 2011) es razonable asumir que los factores que definen la competitividad de fabricación deben ser diferentes entre plantas especializadas en cada uno de estos modelos.

- Aplicar la metodología propuesta en diferentes tipos de empresas, industrias y áreas geográficas. En esta nueva línea de actuación se sugiere afrontar el estudio de los efectos de las tecnológicas habilitadoras de la Industria 4.0 de cara a obtener una visión de la situación de las estrategias actuales de digitalización de las empresas, sus nuevas necesidades 0 incluso recomendaciones de la hoja de ruta más adecuada para la implantación de la fábrica inteligente 


\section{BIBLIOGRAFÍA}

Albliwi, S. Antony, J. Abdul Halim Lim, S. y Van Der Wiele, T. (2014). Critical failure factors of lean six sigma: A systematic literature review. International Journal of Quality \& Reliability Management, 31(9), 1012-1030.

Alonso, J., Carrillo, J. y Contreras, O. (2002). Aprendizaje tecnológico en las maquiladoras del norte de Mexico. Revista Frontera Norte, 14(27), 43-82.

Álvarez Gil, M. J., Burgos Jiménez, J. D. y Céspedes Llorente, J. J. (2001). Un análisis exploratorio de las estrategias medioambientales y el contexto organizativo de los hoteles españoles. Cuadernos de Economía y Dirección de la Empresa, 8, 5-32.

Ambastha, A. y Momaya, K. (2003). Competitiveness of firms: Review of theory, frameworks and Models. Singapore Management Review, 26(1), 45-61.

Avella, L., Fernández, E. y Vásquez, C. J. (2001). Analysis of manufacturing strategy as an explanatory factor of competitiveness in the large Spanish industrial firm. International Journal of Production Economics, 72, 139-157.

Avella, L., Vazquez-Bustelo, D. y Fernandez, E. (2011). Cumulative manufacturing capabilities: An extended model and new empirial evidence. International Journal of Production Research, 49(3), 707-729.

Awwad, A.S., Al Khattab, A.A. y Anchor, J.R. (2013). Competitive priorities and competitive advantage in Jordanian manufacturing. Journal of Service Science and Management, $6(1), 69-79$.

Bagozzi, R.P. y Yi, Y. (1988). On the evaluation of structural equation models. Journal of the Academy of Marketing Science, 16(1), 74-94.

Barney, J. (1991). Firm Resources and Sustained Competitive Advantage. Journal of Management, 17(1), 99-120.

Barney, J., Wright, M. y Ketchen, D.J. (2001). The resource-based view of the firm: Ten years after 1991. Journal of Management, 27, 625-641.

$\mathrm{BCH}$ (2014). Bienes para la transformacion y actividades conexas 2014, expectativas 20142015, [Accesado 12 Noviembre 2017]. Disponible en http://bch.hn/download/maquila/informe bienest2014.pdf. 
Basu, C. (2018). The importance of Porter's diamond \& Porter's five forces in business. Small Business - Chron.com, [Online]. [Accesado 14 Septiembre 2019]. Disponible en: http://smallbusiness.chron.com/importance-poters-diamond-porters-five-forcesbusiness-33891.html.

Beaumont, N., Schroder, R. y Sohal, A. (2002). Do Foreign-Owned Firms Manage Advanced Manufacturing Technology Better. International Journal of Operations \& Production Management, 22(7), 759-771.

Bell, J. (2005). Doing your research project: $A$ guide for first-time researchers in education and social science, 4th ed., Buckingham: OUP.

Berenson, M., Levine, D. y Krehbiel, T. (2006). Basic Business Statistics: Concepts and applications, 10th. ed., Upper Saddle River, N.J.:Prentice-Hall.

Boyer, K. K., Ward, P. T. y Leong, G. K. (1996). Approaches to the factory of the future: an empirical taxonomy. Journal of Operations Management, 14, 297-313.

Boyer, K. K., Leong, G. K., Ward, P. T. y Krajewski, L. J. (1997). Unlocking the potential of advanced manufacturing technologies. Journal of Operations Management, 15(4), 331347.

Boyer, K. K., \& Lewis, M. W. (2002). Competitive priorities: investigating the need for trade-offs in operations strategy. Journal of Production and Operations Management, 11(1), 1-13.

Bozdogan, K. (2014). Towards An Integration Of The Lean Enterprise System, Total Quality Management, Six Sigma And Related Enterprise Process Improvement Methods. Disponible en: Massachussets Institute of Technology - Engineering Systems Division: https://esd.mit.edu/WPS/2010/esd-wp-2010-05.pdf.

Brouthers, L.E., McCray, J.P. y Wilkinson, T.J. (1999). Maquiladoras: Entrepreneurial experimentation to global competitiveness. Business Horizons, 42(2), 37-44.

Bülül, H., Ömürbek, N., Paksoy, T., \& Bektas, T. (2013). An empirical investigation of advanced manufacturing technology investment patterns: Evidence from a developing country. Journal of Engineering Technology Management, 30, 136-156.

Caballero, A.J. (2006). SEM vs PLS: Un enfoque basado en la práctica. IV Congreso de Metodología de Encuestas, Pamplona, 20, 21 y 22 de Septiembre de 2006.

Cai, S. y Yang, Z. (2014). On the relationship between business environment and competitive priorities: The role of performance frontiers. Internation Journal of Production Economics, 151, 131-145.

Carpinetti, L. C., Gerólamo, M. C. y Dorta, M. (2000). A conceptual framework for deployment of strategy-related continuous improvements. The TQM Magazine, 12(5), 340-349. 
Casas, M. (2002). Los modelos de ecuaciones estructurales y sus aplicaciones al índice Europeo de satisfacción del cliente. X jornadas Madrid 2002, Madrid: ASEPUMA, 1-11.

CEPAL (2005). El medio ambiente y la maquila en México: Un problema ineludible. Naciones Unidas, México, D.F.

Carbajal, A. (2019). Modelo Lean-Green en el proceso de producción dentro de la industria de confecciones textiles de lencería. Tesis. Universidad Peruana de Ciencias Aplicadas.

Casalet, M. (2018). La digitalización industrial: Un camino hacia la gobernanza colaborativa. Estudio de casos. Publicación de las Naciones Unidas.

Chan, K., Man, T. y Lau, T. (2002). The competitiveness of small and medium enterprises: A conceptualization with focus on entrepreneurial competencies. Journal of Business Venturing, 17, 123-142.

Chang, S.-C., Lin, R.-J., Chen, J.-H. y Huang, L.-H. (2005). Manufacturing flexibility and manufacturing proactiveness: Empirical evidence from the motherboard industry. Industrial Management \& Data Systems, 105(8), 1115-1132.

Cho, J. y Lee, J. (2013). Development of a new technology product evaluation model for assessing commercialization opportunities using Delphi method and fuzzy AHP approach. Expert Systems with Applications, 40(13), 5314-5330.

Cohen, J. (1988). Statistical Power Analysis for the Behavioral Science, $2^{\text {nd }}$ Ed., Lawrence Earlbaum Associates, Publishers, New York, 1988.

Conover, W.J. (2000). Practical Nonparametric Statistics, 3a. ed., Nueva York: Wiley, 2000.

Contreras, O., Carrillo, J., y Alonso, J. (2012). Local entrepeneurship within global value chains: A case study in the Mexican automotive industry. World Development, 40(5), 10131023.

Contreras, O. y Munguía, L. (2007). Evolución de las maquiladoras en México: Política industrial y aprendizaje tecnológico. Región y sociedad, 19, 71-87

Corbett, C. y Wassenhove, L. (1993). Trade-Offs? What Trade-Offs? Competence and Competitiveness in Manufacturing Strategy. California Management Review, 35(4), 107-122.

Cua, K. O., McKone, K. E. y Schroeder, R. G. (2001). Relationships between implementation of TQM, JIT, and TPM and manufacturing performance. Journal of Operations Management, 19(6), 675-694.

Da Silveira, G. y Slack, N. (2001). Exploring the trade-off concept. International Journal of Operations \& Production Management, 21(7), 949-964. 
da Silveira, G. (2014). An empirical analysis of manufacturing competitive factors and offshoring. International Journal of Production Economics, 150, 163-173.

Dangayach, G. S. y Deshmukh, S. G. (2001). Practice of manufacturing strategy: Evidence from select Indian automobile companies. International Journal of Production Research, 39(11), 2353-2393.

Davis, M. M., Aquilano, N. J. y Chase, R. B. (2001). Fundamentos de dirección de operaciones, 3ra edición. Madrid: McGraw-Hill.

de Mast, J., \& Lokkerbol, J. (2012). An analysis of the Six Sigma DMAIC method from the perspective of problem solving. International Journal of Production Economics, 139(2), 604-614.

Diaz, M. S., Machuca, J. D. y Alvarez-Gil, M. J. (2003). A view of developing patterns of investment in AMT through empirical taxonomies: new evidence. Journal of Operations Management, 21(5), 577-606.

Díaz-Garrido, E., Martín-Peña, M. L. y Sánchez-López, J. M. (2011). Competitive priorities in operations: Development of an indicator of strategic position. CIRP Journal of Manufacturing Science and Technology, 4, 118-125.

Diario Roatán (2018). En un 30\% las empresas Hondureñas utilizan la automatización [Online]. [Accesado 10 Febrero 2020]. Disponible en: https://diarioroatan.com/en-un-30-lasempresas-hondurenas-utilizan-la-automatizacion/hambrezona.

Dornier, P. P., Ernst, R., Fender, M. y Kouvelis, P. (1998). Global operations and logistics: Text and cases. New York: John Wiley \& Sons Inc.

Dou, W. y Philip, H. (1998). The competitiveness of EU insurance industries. The Services Industries Journal, 18(1), 39-54.

Eaton, M. (2010). Why change programs fail. Human Resource Management International Digest, 18(2), 37-42.

El Pais (2018). Socializarán efectos de la industria 4.0 en Honduras [Online]. [Accesado 10 Febrero 2020]. Disponible en: http://www.elpais.hn/2018/07/13/socializaran-efectos-laindustria-4-0-honduras/.

Esan, A. O., Khan, M. K., Qi, H. S. y Naylor, C. (2013). Integrated manufacturing strategy for development of CADCAM methodology in a SMME. Journal of Manufacturing Technology Management, 24(2), 257-273.

Escobar-Pérez, J. y Cuervo-Martínez, A. (2008). Valides de contenido y juicio de expertos: Una aproximación a su utilización. Avances en Medición, 6, 27-36. 
Fine, C. M. y Hax, A. C. (1985). Manufacturing Strategy: A methodology and an illustration. Interfaces, 15(6), 28-46.

Fiedman, T.L. (2006). The world is flat: A brief history of the twenty-first century. Farrar, Straus y Giroux.

Flanagan, R., Lu, W., Shen, L. y Jewell, C. (2007). Competitiveness in construction: A critical review of research. Construction Management and Economics, 25(9), 989-1000.

Fleiss, J. L. (1981). Statistical methods for rates and proportions. New York: Wiley \& Sons Inc.

Flynn, B.B., Sakakibara, S. y Schroeder, R. (1995). Relationship between JIT and TQM: Practices and performance. Academy of Management Journal, 38(5), 1325-1360.

Flynn, B., Schroeder, R. y Flynn, E. (1999). World class manufacturing: An investigation of Hayes and Wheelwright's foundation. Journal of Operation Management, 17, 249-269.

Fredericks, S. y Gereffi, G. (2011). Upgrading and restructuring in the global value chain: Why China and Asia are outperforming Mexico and Central America. International Journal of Technological Learning, Innovation and Development, 4(1-3), 67-95.

Fuller, F. T. (1985). Eliminating complexity from work: Improving productivity by enhancing quality. National Productivity Review, 4(4), 327-344.

García Alcaraz, J. L., Maldonado, A. A., Alvarado Iniesta, A., Cortes Robles, G. y Hernández, G. A. (2014). A systematic review/survey for JIT implementation: Mexican maquiladoras as case study. Computers in Industry, 65(4), 761-773.

Gaskin, J. (2016). Exploratory Factor Analysis. Gaskination's StatWiki [Online]. [Accesado 10 Mar 2019]. Disponible en: http://statwiki.kolobkreations.com.

Greasley, A. (2009). Operations Management, 2nd Edition. Chichester: John Wiley.

Größler, A. y Grübner, A. (2006). An empirical model of the relationship between manufacturing capabilities. International Journal of Operations \& Production Management, 26(5), 458485.

Grosse, R. y Fonseca, A. (2012). Learning through imports in the internationalization process. Journal of International Management, 18(4), 366-378.

Hadjimarcou, J., Brouthers, L. E., McNicol, J. P. y Michie, D. E. (2013). Maquiladoras in the 21st century: Six strategies for success. Business Horizons, 56(2), 207-217.

Hair, J., Black, W., Babin, B. y Anderson, R. (2010). Multivariate data analysis, 7th edition. Upper Saddle River, NJ: Prentice-Hall, Inc.

Hallgren, M. y Olhager, J. (2006). Quantification in manufacturing strategy: A methodology and illustration. International Journal of Production Economics, 104, 113-124. 
Hallgren, M. (2007). Manufacturing Strategy, Capabilities and Performance. PhD Thesis, Linköping: Linköping Studies in Science and Technology.

Hallgren, M. y Olghager, J. (2009). Flexibility configurations: Empirical analysis of volume and product mix flexibility. Omega, 37(4), 746-756

Hanson, D., Hitt, M. A., Ireland, R. D. y Hoskisson, R. E. (2012). Strategic Management: Competitiveness and Globalisation. South Melbourne: Cengage Learning Australia.

Heim, G. R. y Peng, D. X. (2010). The impact of information technology use on plant structure, practices, and performance: an exploratory study. Journal of Operations Management, 28(2), 144-162.

Hernández, J.C., Pérez, J.M., Pérez, H. y Vizán, A. (2005). La gestión de indicadores aplicada a la mejora de la productividad en fabricación. $7^{\circ}$ Congreso lberoaméricano de Ingeniería Mecánica, México D.F., 12 al 14 de Octubre de 2005.

Hernández, J. C. y Vizán, A. (2013). Lean manufacturing: Conceptos, técnicas e implantación. Madrid: Escuela de Organización Industrial.

Hill, T. (2000). Manufacturing strategy: Text and cases, $3^{\text {rd }}$ ed. Homework, IL: McGraw-Hill, Higher Education.

Howell, J.P., Romero, E.J., Dorfman, P.W., Paul, J. y Bautista, A. (2003). Effective leadership in the Mexican maquiladora: Challenging common expectations. Journal of International Management, 9, 51-73.

Hsu, C.-C. y Sandford, B.A. (2007). The Delphi technique: Making sense of consensus. Practical Assessment, Research \& Evaluation, 12(10), 1-8.

Hung, H.-L., Altschuld, J. W. y Lee, Y.-F. (2008). Methodological and conceptual issues confronting a cross-country Delphi study of educational program evaluation. Evaluation and Program Planning, 31(2), 191-198.

Interiano, J. R. (2004). Historia de la Maquiladora en Honduras [Online]. [Accesado 18 Julio 2014]. Disponible en: http://www.ahm-honduras.com/wpcontent/uploads/2011/08/historia-maquila-honduras.pdf.

Jabbour, C. J., da Silva, E. M., Paiva, E. L. y Almada Santos, F. C. (2012). Environmental management in Brazil: is it a completely competitive priority? Journal of Cleaner Production, 21(1), 11-22.

Johnson, R.A. y Wichern, D.W. (2002). Applied Multivariate Statistical Analysis. Prentice Hall, New Jersey.

Jonsson, P. (2000). An empirical taxonomy of advanced manufacturing technology. International Journal of Operations \& Production Management, 20(12), 1446 - 1474. 
Jun, M., Cai, S., Shin, H. (2006). TQM practice in maquiladora: Antecedents of employee satisfaction and loyalty. Journal of Operations Management, 24(6), 791-812.

Kathuria, R. (2000). Competitive priorities and managerial performance: a taxonomy of small manufacturers. Journal of Operations Management, 18, 627-641.

Khanchanapong, T., Prajogo, D., Sohal, A. S., Cooper, B. K., Yeung, A. C. y Cheng, T. (2014). The unique and complementary effects of manufacturing technologies and lean practices on manufacturing operational performance. International Journal of Production Economics, 153, 191-203.

Kline, R.B. (2015). Principles and practices of structural equation modeling, $4^{\text {th }}$ ed. The Gilford Press, New York.

Koc, T. y Bozdag, E. (2009). The impact of AMT practices on firm performance in manufacturing SMEs. Robotics and Computer-Integrated Manufacturing, 25(2), 303-313.

Kotha, S. y Swamidass, P. M. (2000). Strategy, advanced manufacturing technology and performance: empirical evidence from U.S. manufacturing firms. Journal of Operations Management, 18(3), 257-277.

Kroes, J. R. y Ghosh, S. (2010). Outsourcing congruence with competitive priorities: impact on supply chain and firm performance. Journal of Operation Management, 28(2), 124-143.

Lagacé, D. y Bourgault, M. (2003). Linking manufacturing improvement programs to the competitive priorities of Canadian SMEs. Technovation, 23(8), 705-715.

Lall, S. (2001). Competitiveness, technology and skills. Cheltenham, UK: Edward Elgar Publishing.

Landis, J.R. y Koch, C.G. (1977). The measurement of observer agreement for categorical data. Biometrics, 33, 159-174.

Lawrence, J. L. y Hottenstein, M. P. (1995). The relationship between JIT manufacturing and performance in Mexican plants affiliated with U.S. companies. Journal of Operations Management, 13, 3-18.

Lean Enterprise Institute (2017). Principles of Lean [Online]. [Accesado 14 Septiembre 2019]. Disponible en: https://www.lean.org/WhatsLean/Principles.cfm.

Leong, G. K., Snyder, D. L. y Ward, P. T. (1990). Research in the process and content of manufacturing strategy. Omega International Journal of Management Science, 18(2), 109-122.

Li, S., Ragu-Nathanb, B., Ragu-Nathanb, T.S. y Rao, S.S., 2006. The impact of supply chain management practices on competitive advantage and organizational performance. Omega-International Journal of Management Science 34(2), 107-124. 
Liargovas, P.G. y Skandalis, K.S. (2007). Factors affecting firm competitiveness: The case of Greek Industry. Disponible en: http://www.lse.ac.uk/Hellenic-

Observatory/Assets/Documents/HO-PhD-Symposia/The-3rd-HO-PhD-Symposium/15June/Session-2/Panel-3-Economy-IV-Competitiveness.pdf.

Liker, J.K. y Rother, M. (2011). Why Lean Program Fail. Lean Enterprise Institute, Madrid. Disponible en: www.lean.org/Search/Documents/352.pdf.

López, V., Marín, M. y Alcalá, M. (2012). Ergonomía y productividad: Variables que se relacionan con la competitividad de las plantas maquiladoras. Ingenieria Industrial: Actualidad y Nuevas Tendencias, 3(9), 17-32.

Ludwig, G. y Pemberton, J. (2011). A managerial perspective of dynamic capabilities in emerging markets: The case of the Russian steel industry. Journal for East European Management Studies, 16(3), 215-236.

Magretta, J. (2012). Understanding Michael Porter: The essential guide to competition and strategy. Boston, Massachusetts: Harvard Business Review Press.

Maldonado, G., Martínez, M. D., López, G. y García, R. (2012). Competitiveness in manufacturing SMEs: A perspective of Mexico. International Journal of Arts and Commerce, 4(4), 60-75.

Malhotra, N. K. y Dash, S. (2011). Marketing research: an applied orientation. New Delhi: Pearson Pub.

Man, T., Lau, Y. y Chan, K. (2002). The competitiveness of small and medium enterprises: A conceptualization with focus on entrepreneurial competencies. Journal of Business Venturing, 17(2), 123-142.

Maranto-Vargas, D. y Gómez-Tagle, R. (2007). Development of internal resources and capabilities as sources of differentiation of SME under increased global competition: A field study in Mexico. Technological Forecasting and Social Change, 4(1), 90-99.

Martín-Peña, M.L. y Díaz-Garrido, E. (2008). Posicionamiento estratégico de las empresas industriales en las prioridades competitivas de operaciones: Desarrollo y aplicación de un indicador de medida. Cuadernos de Economía y Dirección de Empresa, 39, 59-94.

Mefford, R.N. y Bruun, P. (1998). Transferring world class production to developing countries: A strategic model. International Journal of Production Economics, 56-57, 433-450.

Meijering, J.V., Kempen, J.K. y Tobi, H. (2013). Quantifying the development of agreement among experts in Delphi studies. Technological Forecasting and Social Change, 80(8), 1607-1614. 
Martinez, V. y Bititci, U. S. (2006). Aligning value propositions in supply chanis. International Journal of Value Chain Management, 1(1), 6-18.

Mendoza, J.E. (2010). The effect of the Chinese economy on Mexican maquiladora employment. The International Trade Journal, 24(1), 52-83.

Miller, J.G. y Roth, A. V. (1994). A taxonomy of manufacturing strategies. Management Science, 4O(3), 285-304.

Mohd-Hame, N.B., Kowang, T.O. y Fei, G.C. (2017). Categorization of lean research and development tools and techniques: A process-based approach. Indian Journal of Science and Technology, 10(3), 1-7.

Nambirajan, T. y Prabhu, M. (2011). Competitiveness of manufacturing industries in Union Territory of Puducherry (India): A critical analysis. Towards Managerial Excellece: Challenges and Choices, Tiruchirappalli, Mcmillian Publishers India.

Pearce, A., Pons, D. y Neitzert, T. (2018). Implementing lean - Outcomes from SME case studies. Operations Research Perspectives, 5, 94-104.

Niebel, T. (2018). ICT and economic growth - Comparing developing, emerging and developed countries. World Development, 104, 197-211.

Nunnally, J. y Bernstein, I. (1994). Psychometric Theory, 3rd ed. New York: McGraw-Hill.

Ocampo, J. y Pavón, A. (2012). Integrando la metodología DMAIC de Seis Sigma con la simulación de eventos discretos en FlexSim. 10th Latin American and Caribbean Conference for Engineering and Technology, Panama City: LACCEI, 1-10.

Okoli, C. y Pawlowski, S. D. (2004). The Delphi method as a research tool: an example, design considerations and applications. Information \& Management, 42, 15-29.

Padhi, S.P. (2015). An evaluation of Indian manufacturing exports performance. Foreign Trade Review, 50(1), 41-52.

Pampanelli, A.B (2014) A Lean \& Green Model for a production cell. Journal of Clean Produccion, 85, 19-30.

Panwar, A. Rakesh, J., Singh, A.P., Nepal, B. y Lyons, A.C. (2018). The impact of lean practices on operational performance - an empirical investigation of Indian process industries. Production Planning \& Control, 29(2), 158-169.

Patterson, M. G., West, M. A. y Wall, T. D. (2004). Integrated manufacturing, empowerment, and company performance. Journal of Organizational Behavior, 25(5), 641-665.

Peterson, R.A. (1994). A meta-analysis of Cronbach's coefficient alpha. Journal of Consumer Research, 21(2), 381-391. 
Petrillo, A., De Felice, F. y Zomparelli, F. (2019). Performance measurement for world-class manufacturing: A model for the Italian automotive industry. Total Quality Management \& Business Excellence, 30(7-8), 908-935.

Phusavat, K. y Kanchana, R. (2007). Competitive priorities of manufacturing firms in Thailand. Industrial Management \& Data Systems, 107(7), 979-996.

Pietrobelli, C. y Rabellotti, A. (2011). Global value chains meet innovation systems: Are there learning opportunities for developing countries? World Development, 39(7), 1261-1269.

Pinjala, S., Pintelon, L. y Vereecke, A. (2006). An empirical investigation on the relationship between business and maintenance strategies. International Journal of Production Economics, 104, 214-229.

Portella, A. (2018). Industria 4.0, una revolución que se retrasa en México [Online]. México Forbes, [Accesado 10 Febrero 2020]. Disponible en: https://www.forbes.com.mx/industria-4-0-una-revolucion-que-se-retrasa-en-mexico/.

Porter, M.E. (1980). Competitive strategy: Techniques for analyzing industries and competitors, New York: The Free Press.

Porter, M.E. (1998). The competitive advantage of nations. New York: Free Press, 1998.

Porter, M.E. (2008). The five competitive forces that shape strategy. Harvard Business Review, 86(1), 23-41.

Putranto, K, Stewart, D., Moore, G. y Diatmoko, R. (2003). Implementing a technology strategy in developing countries: the experience of the Indonesian rolling stock industry. Tecnological Forecasting \& Social Change, 70, 163-176.

Rahardjo, J. y Yahya, S. (2010). Advanced Manufacturing Technology Implementation Process in SME : Critical Success Factors. Jurnal Teknik Industri, 12(2), 101-108.

Ramírez González, A. (2015). Metodología de la investigación científica, Pontificia Universidad Javeriana, Colombia.

Rao, P.S. y Lampriere, T.L. (1992). A comparison of the total factor productivity and total cost performance U.S. and Canada industries. Working Paper, Economic Council of Canada.

Rencher, A.C. (2005). Methods for multivariate analysis, $2^{\text {nd }}$ ed. Wiley-Interscience.

Rostek, K. (2012). The reference model of competitiveness factor for SME medical sector. Economic Modelling, 29, 2039 - 2048.

Rudberg, M. y Olhager, J. (2003). Manufacturing networks and supply chains: An operations strategy perspective. OMEGA, 31(1), 29-39. 
Sarache, W. A., Castrillón, O. D. y Giraldo, J. A. (2011). Prioridades competitivas para la industria de la confección: estudio de caso. Cuadernos de administración, 24(43), 89110.

Sargent, J. y Matthew, L. (1997). Skill development and integrated manufacturing in Mexico. World Development, 25(10), 1669-1681.

Sargent, J. y Matthew, L. (2003). Boom and bust: Is it the end of Mexico's maquiladoras? Business Horizons, 46(2), 57-64.

Scott, G. (2000). Critical technology management issues of new product development in hightech companies. Journal of Product Innovation Management, 7(1), 57-77.

Seguino, S. y Grown, C. (2006). Gender equity and globalization: Microeconomic policy for developing countries. Journal of International Development, 18(8), 1081-1104.

Shah, R. y Goldstein, S. M. (2006). Use of structural equation modeling in operations management research: looking back and forward. Journal of Operations Management, 24(2), 148-169.

Shah, R., Chandrasekaran, A. y Linderman, K. (2008). In persuit of implementation patterns: The context of Lean and Six Sigma. International Journal of Production Research, 46(23), 6679-6699.

Sharma, S. (2006). Applied multivariate techniques. New York: Wiley, 1996.

Siegel, S. y Castellan, N. (1988). Non parametric statistics for the behavioral sciences. New York: McGraw-Hill.

Sim, J. y Wright, C.C. (2005). The Kappa statistic in reliability studies: Use, interpretation and sample size requirements. Physical Therapy, 85(3), 257-268.

Skinner, W. (1969). Manufacturing - Missing link in corporate strategy. Harvard Business Review, 5(1), 136-145.

Skulmoski, G.J., Hartman, F.T. y Krahn, J. (2007). The Delphi method for graduate research. Journal of Information Technology Education, 6(1) 1-21.

Small, M. H. y Yasin, M. M. (1997). Developing a framework for the effective planning and implementation of advanced manufacturing technology. International Journal of Operations \& Production Management, 17(5), 468-489.

Steensma, H.K., Tihanyi, L., Lyles, M.A. y Dhanaraj, C. (2005). The evolving value of foreign partnerships in transitioning economies. Academy of Management, 48(2), 213-235.

Sun, X.L., Tian, Y.Z. y Cui, G.G. (2007). The empirical study on the impact of advanced manufacturing technology on organizational structure and human resources 
management. Proceedings of the $14^{\text {th }}$ International Conference on Management Science \& Engineering, 1548-1553.

Swamidass, P. M. y Kotha, S. (1998). Explaining manufacturing technology use, firm size and performance using a multidimensional view of technology. Journal of Operations Management, 17(1), 23 - 37.

Swamidass, P. M. (2003). Modeling the adoption rates of manufacturing technology innovations by small US manufacturers: a longitudinal investigation. Research Policy, 32(3), 351366.

Swink, N., Narasimhan, R. y Kim, S. W. (2005). Manufacturing practices and strategy integration: Effects on cost efficiency, flexibility, and market-based performance. Decision Science, 36(3), 427-457.

Swink, M. y Nair, A. (2007). Capturing the competitive advantages of AMT: Designmanufacturing integration as a complementary asset. Journal of Operations Management, 25(3), 736-754.

Tan, K. C., Kannan, V. R. y Narasimhan, R. (2007). The impact of operations capability on firm performance. International Journal of Production Research, 45(21), 5135-5156.

Teece, D. y Pisano, G. (1994). The dynamic capabilities of firms: An introduction. Industrial and Corporate Change, 3(3), 537-556

Teece, D. J., Pisano, G. y Shuen, A. (1997). Dynamic capabilities and strategic management. Strategic Management Journal, 18, 509-533.

Tracey, M., Vonderembse, M. y Lim, J. (1999). Manufacturing technology and strategy formulation: keys to enhancing competitiveness and improving performance. Journal of Operation Management, 17(4), 411-428.

Ülengin, F., Önsel, Ş., Aktas, E., Kabak, Ö. y Özaydın, Ö. (2014). A decision support methodology to enhance the competitiveness of the Turkish automotive industry. European Journal of Operational Research, 234(3), 789-801.

Vargas-Hernández, J. y Nuñez-López, V. (2011). Impact of Central America Maquiladoras in Economic Growth and Employment. International Journal of Business and Social Science, 2(1), 255-263.

Vickery, S. K., Jayaram, J., Droge, C. y Calantone, R. (2003). The effects of an integrative supply chain strategy on customer service and financial performance: an analysis of direct versus indirect relationships. Journal of Operations Management, 21(5), 523-539.

Vivares-Vergara, J.A., Sarache-Castro, W.A. y Narango-Valencia, J.C. (2014). The content of manufacturing strategy: A case study in Colombian industries. Dyna, 81(183), 140-147. 
Vinodh, S., \& Joy, D. (2012). Structural Equation Modelling of lean manufacturing practices. International Journal of Production Research, 50(6), 1598-1607.

Wahab, A., Mukhtar, M. y Sulaiman, R. (2013). A conceptual model of lean manufacturing dimensions. Procedia Technology, 11, 1292-1298.

Ward, P. T., McCreery, J. K., Ritzman, L. P. y Sharma, D. (1998). Competitive priorities in operations management. Decision Science, 29(4), 1035-1046.

Ward, P. y Zhou, H. (2006). Impact of information technology integration and lean/just-in-time practices on lead-time performance. Decision Science, 37(2), 177-203.

Warrens, M.J. (2012). Equivalences of weighted kappas for multiple raters. Statistical Methodology, 9(3), 407-422.

Weisstein, E. W. (2019). Hypothesis testing from MathWorld - A Wolfram Web Resource [Online]. [Accesado 10 Febrero 2020]. Disponible en:

http://mathworld.wolfram.com/HypothesisTesting.html.

Wilson, P. (1991). The global assembly industry: Maquiladoras in international perspective. Journal of Borderlands Studies, 6(2), 73-104.

Yang, C.-L., Lin, S.-P., Chan, Y.-h. y Sheu, C. (2010). Mediated effect of environmental management on manufacturing competitiveness: An empirical study. International Journal of Production Economics, 123(1), 210-220.

Yang, M., Hong, P. y Modi, S. (2011). Impact of lean manufacturing and environmental management on business performance: An empirical study of manufacturing firms. International Journal of Productions Economics, 129, 251-261.

Yung-Ching, H. y Tsui-Hsu, T. (2006). The impact of dynamic capabilities with market orientation and resource-based approaches of NPD project performance. Journal of American Academy of Business, 8(1) 215-229.

Zaiontz, C. Real statistics using excel. [Online]. [Accesado 7 December 2014]. Disponible en: http://www.real-statistics.com/reliability/.

Zollo, M. y Winter, S. (2002). Deliberate learning and the evoluction of dynamic capabilties. Organization Science, 13(1), 339-351. 